\title{
PLANKTIC FORAMINIFERA-BASED SEA SURFACE TEMPERATURE ESTIMATES AND LATE QUATERNARY OCEANOGRAPHY OFF NEW ZEALAND'S WEST COAST
}

\author{
Andrew Peter Kolodziej
}

A thesis submitted in partial fulfillment for the degree of Masters of Science in Geology

School of Geography, Environment and Earth Sciences

Victoria University

2010 


\section{Abstract}

Planktic foraminiferal assemblages were used to investigate the paleoceanography of the Eastern Tasman Sea over the last 480 kyrs (Marine Isotope Stages 12-1). One hundred and sixty-two faunas (96 picked and identified as part of this project (MIS 12-6) added to 66 census counts from Dr. M. Crundwell (MIS 6-1)) have been assembled from Marion Dufresne piston core MD06-2986 ( $\sim 3^{\circ}$ S. off New Zealand's west coast, 1477 m water depth). Faunal changes through the last five glacial-interglacial cycles are used to track surface water mass movement. Glacial periods are dominated by the eutrophic species Globigerina bulloides, with significant contributions from the temperate species Globoconella inflata. Temperate species Neogloboquadrina incompta and Gc. inflata dominate interglacials, with the former dominating the warmer parts and the latter dominating the cooler parts of the interglacials. Modern Analogue Technique (MAT) and an Artificial Neural Network (ANN) were used to estimate past sea surface temperatures (SST) based on the foraminiferal census counts data (23 species, 446,000 specimens). SSTs show that MIS 12 was the longest, sustained cold period, while the coldest temperature was recorded in MIS $5 \mathrm{~d}\left(\sim 8^{\circ} \mathrm{C}\right)$. Interglacials MIS 11 and 5e are the two warmest stages of the record, with SSTs reaching $\sim 18.5^{\circ} \mathrm{C}$, about $\sim 2^{\circ} \mathrm{C}$ warmer than present day.

We find that contrary to either the western Tasman Sea or offshore eastern New Zealand, the eastern Tasman Sea has been fairly isolated from any major influx of subpolar or subtropical species carried in with surface water from either high or low latitude sources. Subtropical taxa abundance (Globigerinoides ruber, Neogloboquadrina dutertrei (D), Globigerinoides sacculifer, Globigerinella aequilateralis, Sphaeroidinellopsis dehiscens, Truncorotalia truncatulinoides (D), Beella digitata) is low (average $\sim 0.6 \%$ ) and only prominent during peak interglacials. Subantarctic taxa abundance (Neogloboquadrina pachyderma, Neogloboquadrina dutertrei $(\mathrm{S})$ ) is low (average $~ 5.1 \%$ ), but significant, particularly in glacial periods. Comparison of faunal and $\mathrm{SST}_{\mathrm{ANN}}$ data along with ratios of $N q$. pachyderma:Nq. incompta (previously referred to as coiling ratios of $N q$. pachyderma) and absolute abundance of planktic productivity (a productivity proxy) suggest that the STF migrated northwards towards the site in all glacial periods, and may have moved over the site in MIS 12 and possibly MIS 5d. 
A latitudinal $\mathrm{SST}_{\mathrm{ANN} 25}$ comparison between offshore eastern and western New Zealand reveals that MD06-2986 $\left(\sim 43^{\circ} \mathrm{S}\right)$ is most similar $\left(\sim 0.5^{\circ} \mathrm{C}\right)$ to ODP Site $1125\left(\sim 42^{\circ} \mathrm{S}\right)$. On the contrary, ODP Site $1119\left(44^{\circ} \mathrm{S}\right)$ is $\sim 5^{\circ} \mathrm{C}$ cooler than MD06-2986. This comparison highlights the significant changes in surface water masses off eastern New Zealand that exist in such a short span of latitude because of the influence of a complex submarine topography. 


\section{Acknowledgements}

There are many people I would like to thank; people whose contributions helped me get through this thesis, either academically, financially, or for the sake of mental stability.

I would like to thank Bruce Hayward for designing and funding the project, and for feedback and edits on all my chapters. I was looking for a project similar to this one, and it has kept me thinking throughout, advancing my knowledge of geology, climatology, and oceanography. I also want to thank Martin Crundwell for his taxonomic expertise, compiling lab data and allowing me to use his census data from MIS 6-1 from this hole. His invaluable knowledge of foraminifera and oceanography, as well as patience in teaching me to identify foraminifera, kept this thesis work advancing at a fast rate. I would also like to thank George Scott for his hard work in generating the sea surface temperature models for this study. I feel extremely privileged and honoured to have worked with someone who has done so much for New Zealand biostratigraphy. Without his knowledge and expertise, this thesis would not have been possible. I also thank Dr. Silke Steph allowing me to use isotope data for my age model.

I would like to thank my VUW support, both Michael Hannah and Lionel Carter. They have provided me with excellent feedback on many decisions regarding this thesis. I appreciate, in particular, LC's enthusiasm of oceanography and paleoclimatology, as it was a motivating factor which helped me through my two years as a Masters student. I also very much appreciate the time he spent with me on this project, in both personal meetings, as well as feedback of my chapters and ideas. I cannot thank him enough.

My family certainly needs to be thanked. Their love and support is especially appreciated, given the fact that I may have been too busy to communicate with them at times. I sincerely hope they still think of me as part of the family. Finally, I would like to thank all my friends here in New Zealand who have made the past four years truly memorable. I want to especially thank Zara Rawlinson for love and support that helped keep this thesis moving towards its end. I would also like to thank Alec LaGrow and Chris Egden for being great friends who have both helped me along the way over the past two years. Overall, living in New Zealand has been the most eye opening, educational experience that one could ask for. 


\section{TABLE OF CONTENTS}

TITLE

ABSTRACT iii

ACKNOWLEDGEMENTS v v

TABLE OF CONTENTS vii

LIST OF FIGURES - xi

LIST OF TABLES X xiii

LIST OF ABBREVIATIONS xiv

1.0 INTRODUCTION

1.1 REGIONAL SETTING 3

1.2 WATER MASSES

$\underline{1.3}$ FRONTS 9

1.4 MAJOR GLOBAL CURRENTS 12

1.5 REGIONAL CURRENTS - EASTERN NEW ZEALAND 12

1.6 REGIONAL CURRENTS - WESTERN NEW ZEALAND 13

1.7 CLIMATE VARIABILITY OF NEW ZEALAND 14

$\begin{array}{lll}1.8 & \text { SUMMARY } & 18\end{array}$

2.0 NEW ZEALAND PALEOCEANOGRAPHY

2.1 FORAMINIFERA

$\underline{2.2}$ PROXIES 26

$\underline{2.3}$ TASMAN SEA PALEOCEANOGRAPHY 30 
$\underline{2.4}$ OFFSHORE EASTERN NEW ZEALAND PALEOCEANOGRAPHY 36

$\underline{2.5}$ SUMMARY $\quad 40$

3.0 METHODS

3.1 FORAMINFER PREPARATION 43

3.2 MODERN ANALOGUE TECHNIQUE

$\underline{3.3}$ ARTIFICIAL NEURAL NETWORK 46

4.0 $\underline{\text { RESULTS }} \quad 49$

$\underline{4.1}$ FAUNAL COMPOSITION

$\begin{array}{lll}\text { 4.2 } & \text { SSTs } & 57\end{array}$

4.3 OXYGEN ISOTOPE AGE MODEL

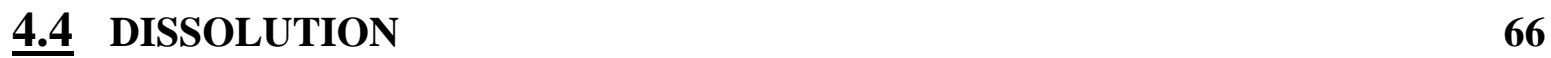

$\begin{array}{lll}4.5 & \text { PRODUCTIVITY } & 67\end{array}$

4.6 SUMMARY

5.0 DISCUSSION

$\begin{array}{lll}5.1 & \text { FAUNAL COMPOSITION } & 71\end{array}$

5.2 FEATURES OF THE SST RECORD

$\underline{5.3}$ MIGRATION OF THE STF, WEST OF NEW ZEALAND 96

$\begin{array}{ll}5.4 & 102\end{array}$

5.5 COMPARISON TO OFFSHORE EASTERN NEW ZEALAND 104

6.0 CONCLUSIONS 119

$\begin{array}{ll}\text { 6.1 PROJECT ACHIEVEMENTS } & 119\end{array}$ 
6.3 FUTURE WORK

APPENDIX A) CENSUS COUNTS OF MD06-2986

On CD

APPENDIX B) SST DATA OF MD06-2986

On CD

APPENDIX C) DATA FOR EAST/WEST NEW ZEALAND COMPARISON On CD 


\section{List of Figures}

Figure 1.1 - Map of New Zealand microcontinent 4

Figure 1.2 - Summary of New Zealand currents and water masses $\quad 6$

Figure 1.3 - Summary of subsurface water masses $\quad 8$

Figure 1.4 - Southern Hemisphere westerly wind direction $\quad 15$

Figure 1.5 - Present-day seasonal SSTs of New Zealand 16

Figure 1.6 - ENSO variability around New Zealand 17

Figure 2.1 - Neogloboquadrina incompta 23

Figure 2.2 - Neogloboquadrina pachyderma 23

Figure 2.3 - Globigerina bulloides $\quad 23$

Figure 2.4 - Globoconella inflata $\quad 24$

Figure 2.5 - Truncorotalia truncatulinoides $\quad 24$

Figure 2.6 - Turborotolita quinqueloba 25

Figure 2.7 - Globigerina falconensis $\quad 25$

$\begin{array}{ll}\text { Figure 2.8 - Globigerinita glutinata } & 25\end{array}$

Figure 2.9 - Globigerinoides ruber $\quad 26$

Figure 2.10 - Orbulina universa 26

Figure 2.11 - Martinez, (1994) Nq. pachyderma coiling ratios 31

Figure 2.12 - Nees et al. (1996) Paleo-productivity estimates from Tasman Sea 32

Figure 2.13 - Barrows et al. (2007) Last Glacial Maximum Australasian SST estimates 34

Figure 2.14 - Sikes et al. (2009) STF locations MIS 5, 3, 2 and 1

Figure 2.15 - Weaver et al. (1998) Paleo-SST gradients offshore eastern New Zealand 37

Figure 2.16 - Crundwell et al. (2008) Summary of paleo-circulation at ODP Site $1123 \quad 39$

Figure 2.17 - Crundwell et al. (2008) Glacial-deglacial faunal changes 40 
Figure 3.1 - Distribution of Southern Hemisphere coretop database SH1204

Figure 4.1 - Biogeographic location of temperate taxa 50

Figure 4.2 - Biogeographic location of subtropical taxa 50

Figure 4.3 - Biogeographic location of eutrophic taxa

Figure 4.4 - Biogeographic location of subantarctic taxa 51

Figure 4.5 - Biogeographic location of subtropical/temperate taxa 52

Figure 4.6 - MD06-2986 total faunal composition 52

Figure 4.7 - MD06-2986 temperate taxa record 53

Figure 4.8 - MD06-2986 eutrophic taxa record 54

Figure 4.9 - MD06-2986 subantarctic taxa record 55

Figure 4.10 - MD06-2986 subtropical taxa and subtropical/temperate record 56

Figure 4.11 - MD06-2986 MAT SSTs $\quad 58$

Figure 4.12 - MD06-2986 ANN SSTs 60

Figure 4.13 - MD06-2986 SSTs and planktic $\delta 180$ record $\quad 64$

Figure 4.14 - MD06-2986 SSTs and benthic $\delta 180$ record 65

Figure 4.15 - MD06-2986 dissolution record 66

Figure 4.16 - MD06-2986 productivity record $\quad 68$

Figure 5.1 - MD06-2986 total faunal composition 71

Figure 5.2 - MD06-2986 SST ANN 25 record $\quad 72$

$\begin{array}{ll}\text { Figure 5.3 - MD06-2986 productivity record } & 73\end{array}$

Figure 5.4 - Biogeographic location of Truncorotalia crassula 76

Figure 5.5 - MD06-2986 $\mathrm{SST}_{\mathrm{ANN} 25}$ and benthic $\delta 18 \mathrm{O}$ record 77

Figure 5.6 - MD06-2986 temperate taxa and $\mathrm{SST}_{\mathrm{ANN} 25}$

Figure 5.7 - MD06-2986 Nq. incompta and Gc. inflata 80

Figure 5.8 - Tasman Sea core location map $\quad 83$

xii 
Figure 5.9 - Barrows et al. (2007) Pelejero et al. (2006) SSTs and MD06-2986 SST ANN 2584

Figure 5.10 - Pelejero et al. (2006) alkenone SSTs from western Tasman Sea 86

Figure 5.11 - MD06-2986 subantarctic taxa grouped according to Martinez, (1994) 89

Figure 5.12 - Martinez, (1994) coiling ratio and abundance of subantarctic taxa 89

Figure 5.13 - MD06-2986 subtropical taxa grouped according to Martinez, (1994) 91

Figure 5.14 - MD06-2986 MIS 11 and Holocene SSTs 93

Figure 5.15 - MD06-2986 MIS 11 and Holocene faunal data 95

Figure 5.16 - MD06-2986 ratio of Nq. pachyderma to Nq. incompta 98

Figure 5.17 - Subantarctic taxa biogeographic data with MD06-2986 glacial abundances 99

Figure 5.18 - MD06-2986 ratio of Nq. pachyderma to Nq. incompta and productivity 100

Figure 5.19 - MD06-2986 dissolution and productivity 102

Figure 5.20 - Faunal data MD06-2986 vs ODP Site 1123

Figure 5.21 - Faunal data MD06-2986 vs ODP Site 1125

Figure 5.22 - Faunal data MD06-2986 vs ODP Site 1119

Figure 5.23 - Faunal data MD06-2986 vs DSDP Site 594

\section{List of Tables}

Table 3.1 - List of foraminiferal species identified in MD06-2986 47

Table 3.2 - ANN 35/ANN 25 species ranks and weighting 48

Table 5.1 - Maximum abundance of Nq. pachyderma for E36-23 and MD06-2986 90

Table 5.2 - SST comparison between MD06-2986 and ODP Site 1123

Table 5.3 - SST comparison between MD06-2986 and ODP Site 1125

Table 5.4 - SST comparison between MD06-2986 and ODP Site 1119

Table 5.5 - SST comparison between MD06-2986 and DSDP Site $594 \quad 114$

Xiii 


\section{List of Abbreviations}

ACC - Antarctic Circumpolar Current

ANN - Artificial Neural Network

AAIW - Antarctic Intermediate Water

BP - Before Present

CDW - Circumpolar Deep Water

D - Dextral

DC - D'Urville Current

DSDP - Deep Sea Drilling Project

DWBC - Deep Western Boundary Current

EAUC - East Auckland Current

ECC - East Cape Current

ENSO - El Nino Southern Oscillation

FI - Fragmentation Index

G - IG-glacial-interglacial

HNLC - High Nitrate Low Chlorophyll

kyr - thousand years

ka - kiloannum (one thousand years)

km - Kilometer

LCDW - Lower Circumpolar Deep Water

LGM - Last Glacial Maximum

m - Meter

MAT - Modern Analogue Technique

MIS - Marine Isotope Stage

MPT - Mid-Pleistocene Climate Transition

Myr - Million Years

NADW - North Atlantic Deep Water

ODP - Ocean Drilling Program

p/i - Nq. pachyderma/Nq. incompta ratio 
S - Sinistral

SAF - Subantarctic Front

SAM - Southern Annual Mode

SAMW - Subantarctic Mode Water

SAT - Subantarctic taxa

SAW - Subantarctic Water

SC - Southland Current

SST - sea surface temperature

STF - Subtropical Front

STR - South Tasman Rise

STW - Subtropical Water

Sv - Sverdrup

TF - Tasman Front

UCDW - Upper Circumpolar Deep Water

WC - Westland Current 



\subsection{Introduction}

\subsubsection{Overview}

This project is part of the MATACORE project, a collaboration of New Zealand, German, French and US scientists. Its broad aim is to define and constrain tectonic and climatic influences on landscape evolution and sedimentary budget, offshore New Zealand. There are three main MATACORE research themes: paleoclimate, sediment budgets and submarine landslides (Proust et al., 2006). This study is directed to the paleoclimate portion of MATACORE which aims to determine New Zealand's response to past rapid climate change. This new knowledge will shed light on how the Earth's climate behaves and will allow for a more informed preparation for projected climate change.

For an island nation like New Zealand, a key component to understanding climate change is to evaluate past records of oceanographic conditions, such as surface water mass variability, oceanic frontal movements and changes in circulation. The RV Marion Dufrense (2006) recovered a series of giant piston cores on the Challenger Plateau, west of the central New Zealand (Fig. 1.1). These cores are being used to decipher surface, intermediate and deep water mass change for the past one million years.

\subsubsection{Thesis Objectives}

This thesis's main objective is to investigate the paleoceanographic conditions in the Tasman Sea, offshore western New Zealand, over the past $~ 500,000$ years (500 kyr). This is important because Tasman Sea paleoceanography is poorly known, yet it is the location of a major water mass boundary, the Subtropical Front (STF), which separates warm subtropical and cool subantarctic surface waters. Offshore eastern New Zealand, the STF is influenced by the bathymetry of the eastern continental shelf (Nelson et al., 1993), and on Chatham Rise by east flowing currents located north and south of the rise (Carter et al., 1998). Such currents dynamically lock the STF to the Rise. In contrast, the Tasman seafloor is more open with fewer bathymetric features and very little inflow of major ocean currents. Therefore, it stands to reason that during glacial and interglacial periods, the STF 
in the Tasman Sea was free to migrate north and south of its present-day position, similar to STF migrational patterns in the Indian Ocean (Howard and Prell, 1992) and in the western Tasman Sea (Sikes et al., 2009). Any migration over glacial-interglacial (G-IG) cycles has the potential to affect local climate in light of high atmospheric moisture contents associated with the STF (Sturman and Tapper, 2006). In that frame of reference, this thesis attempts to:

- Detect STF movement in the eastern Tasman Sea through time by tracking changes in surface water masses by way of sea surface temperature and microfossil assemblage change.

- Compare and contrast the oceanographic changes through G-IG cycles between offshore western New Zealand (this study), where ocean circulation is comparatively weak and offshore eastern New Zealand, where oceanography is largely determined by the competing inflows of the Southwest Pacific Subtropical Gyre (Stanton et al., 1997; Chiswell and Roemmich, 1998; Crundwell et al., 2008) and the Antarctic Circumpolar Current (Orsi et al., 1995; Moore et al., 1999; Meinen et al., 2003; Budillon and Rintoul, 2003).

This study reconstructs sea surface temperatures (SSTs) for the past 500 kyr using planktic foraminiferal assemblages. The transfer functions Modern Analogue Technique (MAT) (Hutson, 1980; Prell, 1985) and an Artificial Neural Network (ANN) (Malmgren and Nordlund, 1997; Malmgren et al., 2001) are used to estimate SST by comparing the fossil planktic assemblages with those of a present day Southern Hemisphere database (Crundwell et al., 2008). Other paleoclimate proxies e.g. for ocean productivity and water mass characteristics are also used to provide a more comprehensive picture of past conditions and Tasman Sea circulation.

This first chapter provides an overall summary of the important oceanographic features and climatic components of New Zealand. 


\subsubsection{Core site}

Core MD06-2986 forms the basis for this study. The $32 \mathrm{~m}$ long, giant piston core was recovered from the southernmost margin of the Challenger Plateau at $43^{\circ} 26,91^{\prime} \mathrm{S}, 167^{\circ} 54$, 00' E, at a water depth of $1,477 \mathrm{~m}$ (Proust et al. 2006). The core has flat-lying, parallelbedded, undisturbed strata, with a maximum age based on oxygen isotopes of $\sim 479 \mathrm{kyr}$. This is a complete record back to Marine Isotope Stage (MIS) 13 (Dr. Silke Steph, Alfred Wegener Institute for Polar and Marine Research, unpub.).

\subsection{Regional Setting}

\subsubsection{New Zealand Microcontinent and Bathymetry}

The New Zealand continent is located in the Southwest Pacific Ocean, $19^{\circ} \mathrm{S}-56^{\circ} \mathrm{S}$ and $155^{\circ}$ E-170 ${ }^{\circ} \mathrm{W}$ (Fig. 1.1). It is bordered by the Tasman Sea to the west and the Southern Ocean to the south and Pacific Ocean to the north and east. The continent is a remnant of Gondwanaland that is now disrupted by the boundary between the convergent Pacific and the Australian Plates. Most of the continent is largely submerged, and as such, the position of oceanic fronts, currents and water masses are strongly influenced by it (e.g. Hayward et al., 2008).

Offshore New Zealand is ideal for paleoceanographic studies. Its location on an active plate margin is coupled with high erosion rates that reflect the weak source rocks, variable climate, high tectonic uplift rates and anthropogenic activities. This results in an unusually high input of sediment to the ocean, $\left(0.21 \times 10^{9} \mathrm{t} / \mathrm{yr}\right.$ from New Zealand compared to $20 \mathrm{x}$ $10^{9} \mathrm{t} / \mathrm{yr}$ globally (Milliman and Syvitski, 1992; Hicks and Shankar, 2003)). High sedimentation rates are necessary for detailed paleoceanographic studies, by providing thick sequences suitable for high resolution sampling of the proxy record of terrestrial and oceanic environmental change. 


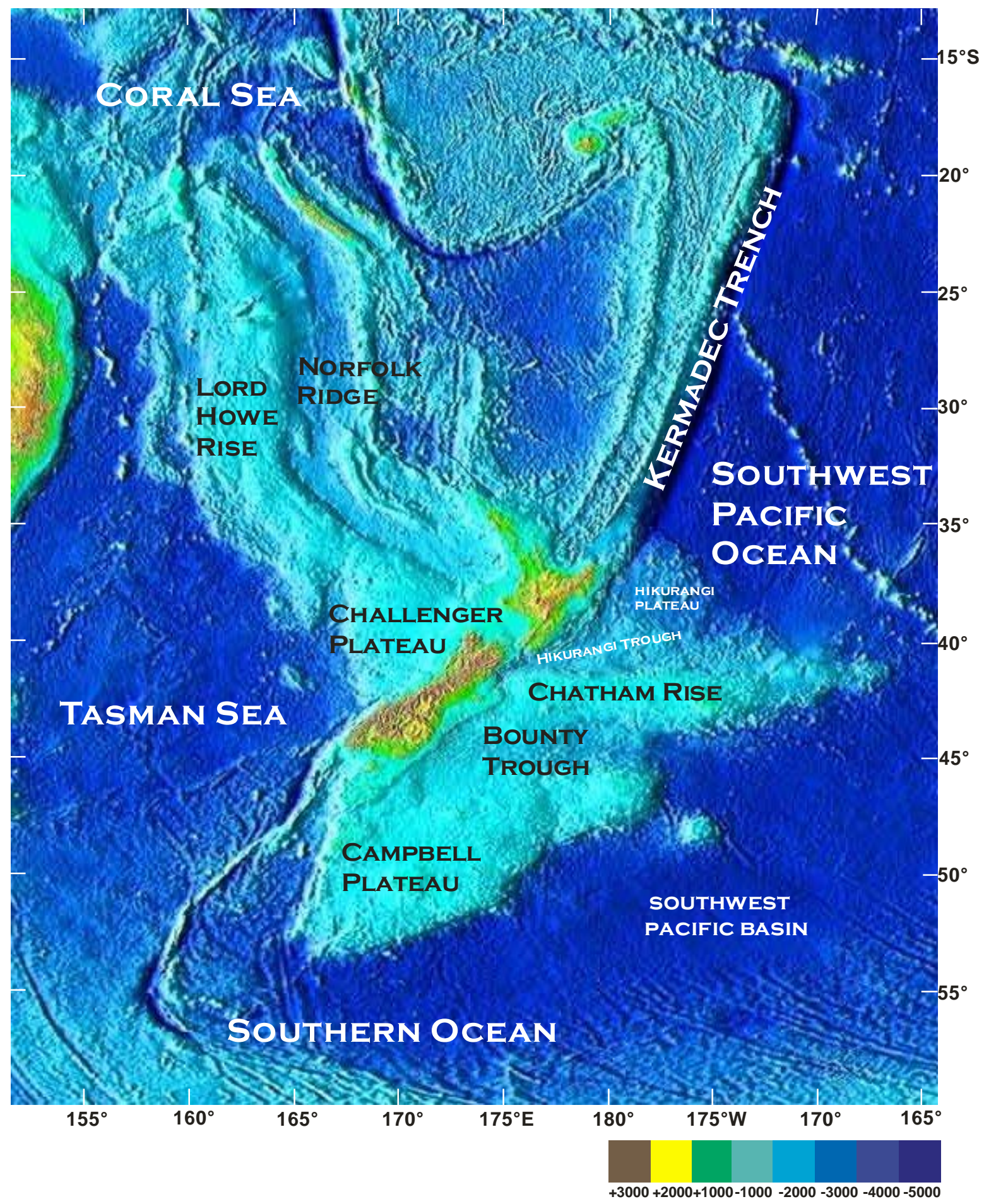

Fig. 1.1 - New Zealand Microcontinent (from NOAA public domain, June 2006)

In the Tasman Sea, the Lord Howe Rise is a prominent feature trending northwest from $\sim 35^{\circ} \mathrm{S}$ to $\sim 23^{\circ} \mathrm{S}$ (Fig. 1.1). It covers an estimated $1.5 \times 10^{6} \mathrm{~km}^{2}$ and reaches depths between 1,500 and 2,500 $\mathrm{m}$. This underwater landmass is considered the northern boundary of the Tasman Sea. Also of note is the Norfolk Ridge which lies to the east of the Lord 
Howe Rise, at $\sim 33^{\circ} \mathrm{S}$ to $\sim 32^{\circ} \mathrm{S}$ and reaches depths of $2,000 \mathrm{~m}$. The Challenger Plateau protrudes from the western margin of New Zealand, extending northwest from $\sim 44^{\circ} \mathrm{S}$ to $\sim 37^{\circ} \mathrm{S}$ and connects with the Lord Howe Rise. In contrast to the prominent topographic relief to the northwest, south-western New Zealand is adjacent to the open abyssal plain of the Tasman Sea, reaching depths to $>4,500 \mathrm{~m}$ (Fig. 1.1).

The bathymetry of the east coast is much more complex. The Campbell Plateau extends $1,100 \mathrm{~km}$ southwards of the South Island from $\sim 48^{\circ} \mathrm{S}$ to $\sim 55^{\circ} \mathrm{S}$ and reaches depths between 500-1,000 m. It is bounded to the south by the Southwest Pacific Basin, which reaches depths to 4,000-5,000 $\mathrm{m}$. This gives the plateau $\sim 3,000 \mathrm{~m}$ of topographic relief, which is a powerful control on the Antarctic Circumpolar Current (ACC) and the Deep Western Boundary Current (DWBC). North of the Plateau is the Bounty Trough, a 1,000 km-long, failed rift between $\sim 47^{\circ} \mathrm{S}$ to $\sim 44^{\circ} \mathrm{S}$. North of the Bounty Trough is the Chatham Rise, a $1,300 \mathrm{~km}$ elongate plateau that extends east, between latitudes $\sim 44^{\circ} \mathrm{S}$ to $\sim 42^{\circ} \mathrm{S}$. North of the Chatham Rise is the Hikurangi Trough, which drops to water depths of 3,000-3,750 m. East of the trough is the Hikurangi Plateau, at 3,250-3,750 m (Fig. 1.1).

\subsection{Water Masses}

Five distinct water masses surround New Zealand. At the surface are Subtropical Water (STW) and Subantarctic Water (SAW), which are underlain by Antarctic Intermediate water mass (AAIW), Subantarctic Mode Water (SAMW) found only in southern New Zealand waters, and Circumpolar Deep Water (CDW). 


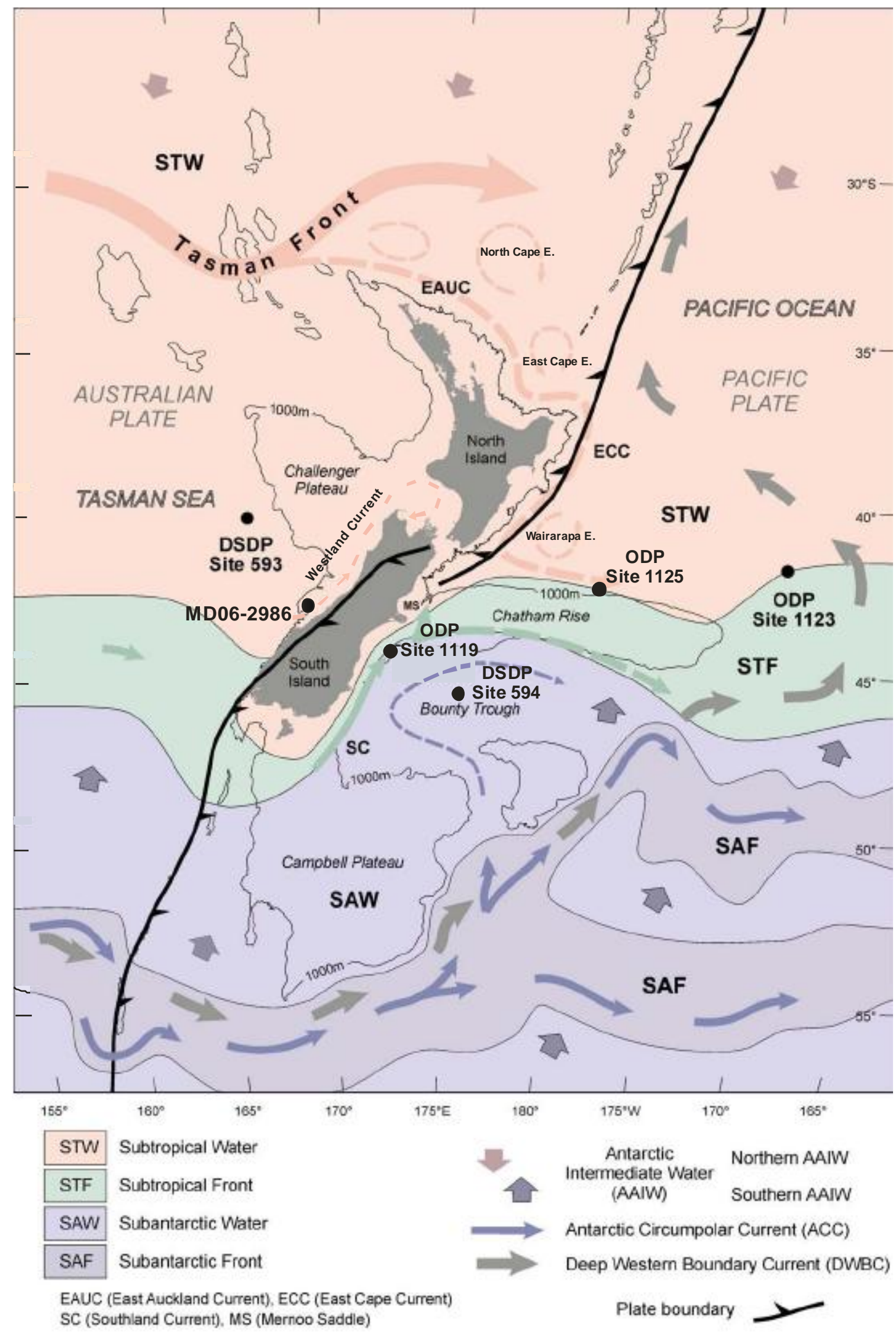

Fig. 1.2 - New Zealand bathymetry chart (1000 $\mathrm{m}$ contour) with present day circulation, fronts and water masses (summer location), including DSDP, ODP and this study's MD core locations. STWSubtropical Water; SAW-Subantarctic Water; STF-Subtropical Front; SAF-Subantarctic Front (after 


\subsubsection{Surface Water Masses}

\subsubsection{Subtropical Water}

STW is found north of the STF which, off western New Zealand today, is centered on $~ 45$ $46^{\circ} \mathrm{S}$ and $\sim 43-45^{\circ} \mathrm{S}$ in the east (Fig. 1.2). Summer SSTs range from $15^{\circ} \mathrm{C}$ at the southern boundary to $25^{\circ} \mathrm{C}$ to the north (e.g. Uddstrom and Oien 1999). STW has salinities $>35.1 \%$, and reaches depths to $\sim 500-600 \mathrm{~m}$. Characteristically, STW is macro-nutrient poor (nitrates, phosphates) and micro-nutrient rich (iron, zinc) (Murphy et al., 2001).

Off western New Zealand, STW is carried into the Tasman Basin via a combination of eddies shed from the East Australian Current in the north (Ridgway and Dunn, 2003) and the west-wind drift or wind forcing through Bass Strait (located between Australia and Tasmania) in the south (Tomczak, 1981; Villanoy and Tomczak, 1991). STW transport east of New Zealand is dominated by the Tasman Front which forms the southern arm of the Southwest Pacific Subtropical gyre. The East Auckland Current (EAUC), a boundary current that is steered by the eastern margin of New Zealand, separates from the Tasman Front (TF) near North Cape and flows to East Cape and becomes the East Cape Current (ECC). This flow continues south, and then turns eastwards along the northern flank of Chatham Rise (Roemmich and Sutton, 1998). Occasionally some STW passes south of the STF via Mernoo Saddle (Greig and Gilmour, 1992) and by eddy exchange across the Chatham Rise (Williams, 2004).

\subsubsection{Subantarctic Surface Water}

SAW is colder $\left(8-14^{\circ} \mathrm{C}\right.$ mean SST) and less saline (34.2-34.8\%) than STW. It occurs at depths down to 500-600 m, and is macro-nutrient rich and micro-nutrient poor (Heath 1985). The latitudinal extent of the SAW varies, as it is a circumpolar feature whose southern limit is the Subantarctic Front, i.e., the northern boundary of the ACC. The northern limit of SAW is the STF (Fig. 1.2). Off New Zealand, SAW can be found as far north as $45^{\circ} \mathrm{S}$ and as far south as $55^{\circ} \mathrm{S}$, in part reflecting the strong deflection of Subantarctic Front (SAF) by Campbell Plateau (see section 1.3 Fronts). 


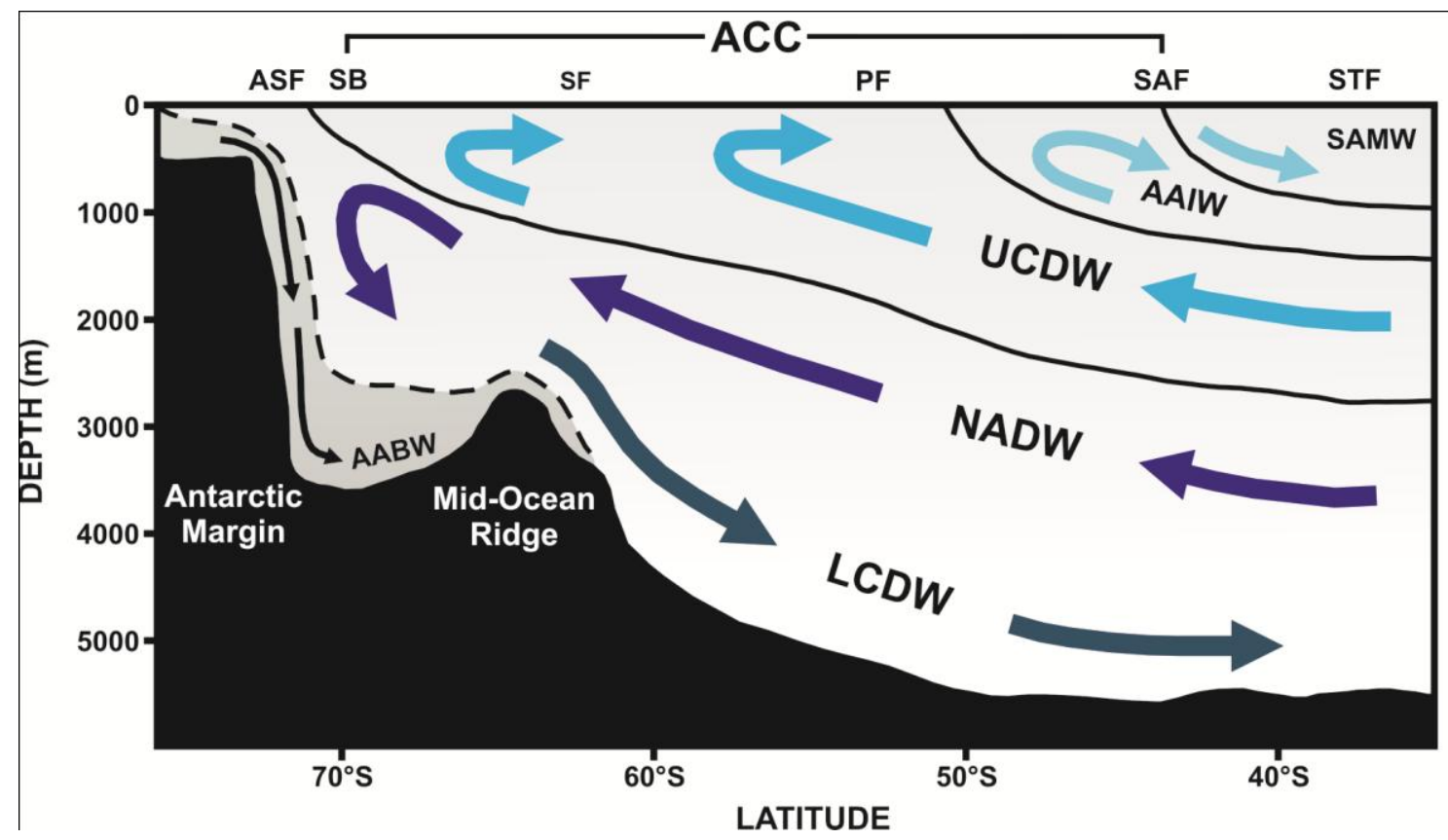

Fig. 1.3 - Subsurface water masses from $75^{\circ} \mathrm{S}$ to $35^{\circ} \mathrm{S}$. Note the surface water mass boundaries that comprise the Antarctic Circumpolar Current. SAMW-Subantarctic Mode Water, AAIW-Antarctic Intermediate Water, UCDW-Upper Circumpolar Deep Water, NADW-North Atlantic Deep Water, LCDW-Lower Circumpolar Deep Water, AABW-Antarctic Bottom Water, STF-Subtropical Front, SAF-Subantarctic Front, PF-Polar Front, SF-Southern Front, SB-Southern Boundary of ACC, ASFAntarctic Slope Front, from Carter et al. (2009)

\subsubsection{Intermediate Water Masses}

\subsubsection{Antarctic Intermediate Water and Subantarctic Mode Water}

SAMW, thought to be a component of AAIW, is an isothermal sub-surface water mass found north of the SAF at depths of 300-700 m (Fig. 1.3). The SAMW is a circumpolar feature with temperatures of $8-9^{\circ} \mathrm{C}$ in the New Zealand region, decreasing to $7^{\circ} \mathrm{C}$ east of the Campbell Plateau (McCartney, 1977).

AAIW lies directly below surface water masses and SAMW (Figure 1.3). It is characterised by a temperature/salinity/depth profile of $3-7^{\circ} \mathrm{C}, 34.3-34.5 \%$, and $600-1450 \mathrm{~m}$, respectively (Piola and Georgi, 1982). AAIW enters the New Zealand region from both the north and the south. The southern component of AAIW is formed from lower salinity surface waters at the Polar Front and sinks to deeper depths at the Antarctic Convergence. In the north, AAIW enters the region via the Coral and Tasman Seas from the Southwest Pacific Ocean. 
Northern-sourced AAIW is characterised by a higher-salinity minimum compared to its southern counterpart (Gordon, 1975).

\subsubsection{Deep Water Masses}

\subsubsection{Circumpolar Deep Water}

CDW is found below the AAIW and is generally separated into two components; Upper CDW (UCDW) and Lower CDW (LCDW) (Fig. 1.3). UCDW is generally found between 1450-2900 m water depths off eastern New Zealand and is mainly distinguished by lowoxygen content and low dissolved-silica content. Temperatures of the UCDW are generally between $1-2^{\circ} \mathrm{C}$ (Gordon 1975).

LCDW is found at depths $\geq 2900$ to the abyssal floor. It has temperatures between $0-2^{\circ} \mathrm{C}$ and a salinity maximum of 34.72-34.72\%o. LCDW is, in part, derived from the North Atlantic, as North Atlantic Deep Water (NADW). LCDW travels from the Southern Ocean into the Southwest Pacific Ocean via the Deep Western Boundary Current (DWBC) and the ACC (Carter and McCave, 1994, 1997). From the southern margin of New Zealand, the LCDW is transported northwards into the Pacific Ocean along the eastern margin of the New Zealand continent via the DWBC (Gordon, 1975).

\subsection{Fronts}

There are three major oceanic fronts in the region. From north to south they include the Tasman Front (TF) the Subtropical Front (STF), and the Subantarctic Front (SAF) (Figs. $1.2,1.3)$

\subsubsection{Tasman Front}

The TF is located in the northern Tasman Sea between $32^{\circ} \mathrm{S}$ and $33^{\circ} \mathrm{S}$ and is the connecting flow of subtropical water from the East Australian Current to the east coast of New Zealand (Fig. 1.2) (Warren, 1970; Andrews et al., 1980; Heath, 1980; Ridgeway and 
Dunn, 2003). Variations in the intensity and flow direction of the Tasman Front arise from mid-Tasman bathymetric features such as the Lord Howe Rise and the Norfolk Ridge (Denham and Crook, 1976). The Australasian Region is the only location in the world where a major western boundary current detaches from a landmass, flows across an ocean and reattaches to another landmass (Ridgway and Dunn, 2003).

\subsubsection{Subtropical Front}

The STF is described in more detail due to its significance for this study. The STF in the western Tasman Sea appears to be influenced by zonal westerly winds. It is an eastwardflowing front, continuing globally except through Drake Passage, where it is interrupted by the southern tip of South America (Orsi et al., 1995). The STF is less constrained in the mid and eastern Tasman Sea near New Zealand. In the New Zealand region, the STF follows the $15^{\circ} \mathrm{C}$ surface isotherm in the summer and the $10^{\circ} \mathrm{C}$ surface isotherm in the winter. The STF follows the $34.9 \%$ isohaline, and is found down to depths of $250 \mathrm{~m}$ (Heath 1985; Stanton and Ridgway 1988).

The STF extends eastward along $43-45^{\circ} \mathrm{S}$ from Tasmania to $160^{\circ} \mathrm{E}$, where it is forced south to $\sim 45-46^{\circ} \mathrm{S}$ around the South Island of New Zealand. Around the South Island, the STF travels northeastward and locally is known as the Southland Front, which is associated with Southland Current (SC), and flows along the upper continental slope of New Zealand up to the Chatham Rise. There, part of the Southland Front (and SC) flows through Mernoo Saddle, whereas the main flow is diverted eastward along the southern side of Chatham Rise at $\sim 44^{\circ} \mathrm{S}$. East of the Chatham Rise, where the STF is less constrained by the northern and southern inflows, the STF projects southwards as a tongue-like feature (Fig. 1.2) (Heath, 1981).

The presence of a shallow, secondary front north of the main STF in the Tasman Sea has been documented with several different interpretations. Jeffrey (1986) found two distinct fronts based on salinity records; a northern front on the $35.1 \%$ isohaline and a southern front on the $34.9 \%$ isohaline. Jeffrey (1986) could not offer an explanation for the existence of two fronts. Stanton and Ridgeway (1988) confirmed the presence of a second, northern front in the southern Tasman Sea. They had difficulty naming the northern front as 
a water mass boundary as it was located in STW. Instead, they interpreted the southern front as the main STF known today, and the northern front as remnants of warm-core eddies from the East Australian Current.

Hamilton (2006) reanalyzed 30 years of temperature and salinity data in the Tasman Sea, including those of Jeffrey (1986) and Stanton and Ridgeway (1988), and reinterpreted their results. First, Hamilton corroborated the interpretation of a secondary northern front. Hamilton confirmed Stanton and Ridgeway's interpretation of the warm-core eddies from the EAC; however, he did point out that the northern front of Stanton and Ridgeway (1988) was not the same as observed by Jeffrey (1986). Instead, Hamilton concluded that the northern front of Jeffrey (1986) was the northern limit of surface SAW, driven by the westerly winds to override the denser STW. The southern front marks the boundary of subsurface STW with subsurface SAW, making the southern front the main STF (i.e., water mass boundary). This double frontal structure for the Tasman Sea STF is also observed east of Chatham Rise (Jeffrey, 1986), in the South Pacific (Belkin, 1988) and in the Atlantic and Indian Oceans (Belkin, 1993; Belkin and Gordon, 1996).

\subsubsection{Subantarctic Front}

The SAF separates SAW and Circumpolar Surface Water (Fig. 1.2). The SAF is a zonal jet within the ACC, and transports 90 Sverdrups $(\mathrm{Sv})\left(1 \mathrm{~Sv}=1 \times 10^{6} \mathrm{~m}^{3} / \mathrm{sec}^{-1}\right)$ in the New Zealand region (Morris et al., 2001). The SAF is a complicated flow that often splits into northern and southern branches in the Southern Ocean, particularly south of New Zealand (Budillon and Rintoul 2003). Globally, the SAF flows eastward with the Antarctic Circumpolar Current along $\sim 50^{\circ} \mathrm{S}$, except around New Zealand, where it is bathymetrically constrained around the southern margin of the Campbell Plateau, to $\sim 55^{\circ} \mathrm{S}$. The SAF then splits into northern and southern branches. The northern branch flows northeast to the Bounty Trough, and then resumes its journey eastward. The southern branch of the SAF flows over the abyssal plain of the Southern Ocean. Budillion and Rintoul (2003) show that the two branches of the SAF can be separated geographically by as much as $900 \mathrm{~km}$, and intense eddies and meanders can displace isotherms by as much as five degrees of latitude. 


\subsection{Major Global Currents}

\subsubsection{Antarctic Circumpolar Current}

The ACC is an unbroken, major deep-reaching system of currents which transports heat, salt, gases and nutrients between the major ocean basins (Fig. 1.3). The ACC is driven primarily by the strong, zonal westerly winds. Located in the Southern Ocean between $\sim 45^{\circ}$ $\mathrm{S}-70^{\circ} \mathrm{S}$, there are four main fronts from north to south of the ACC zone: the SAF, the Polar Front, the Southern Front and the Southern Boundary Front (Carter et al., 2009). Surface temperatures of waters carried by the ACC range from $3^{\circ}-7^{\circ} \mathrm{C}$, and salinity ranges from 34.9-34.2\%, with a volume transport of $\sim 130 \mathrm{~Sv}$ (Budillon and Rintoul 2003).

\subsubsection{Deep Western Boundary Current}

The DWBC is a 4,500 km long current with a total volume transport of $\sim 20 \mathrm{~Sv}$ off central New Zealand, and as such, it has the largest deep-water transport of the global thermohaline circulation (Warren 1981). The DWBC brings deep water from Antarctica to eastern New Zealand where it travels along the outer margins of the continent at depths between 2000 $5000 \mathrm{~m}$ (Fig. 1.3). Initially, the DWBC flows with the ACC, along the flanks of the Campbell Plateau, where the ACC turns east and the DWBC continues northwards around Chatham Rise, into Kermadec Trench and onwards to the central Pacific Ocean (Carter and McCave, 1994).

\subsection{Regional Currents-Eastern New Zealand}

\subsubsection{East Auckland Current}

The EAUC is a western boundary current that flows east past the tip of the North Island down to East Cape (Fig. 1.2). It is a local extension of the flow associated with the TF. It varies in speed and position throughout its southward flow. Current speeds measured between North Cape and $35^{\circ} \mathrm{S}$ registered between $30 \mathrm{~cm} / \mathrm{sec}$ to $130 \mathrm{~cm} / \mathrm{sec}$, with a maximum volume transport of $20 \mathrm{~Sv}$ (Heath, 1980; Harris 1985; Stanton et al., 1997). The EAUC is found down to depths of $\sim 2000 \mathrm{~m}$ around the North Cape area (Harris, 1985). 
Locally the current helps drive two semi-permanent anticyclonic eddies: the North Cape Eddy at $\sim 34^{\circ} \mathrm{S}$ and the East Cape Eddy, at $36^{\circ} \mathrm{S}$ (Fig. 1.2).

\subsubsection{East Cape Current}

ECC is the southern extension of the EAUC (Fig. 1.2). It flows south around East Cape with a volume transport of $2-4 \mathrm{~Sv}$ down to $42^{\circ} \mathrm{S}$. Some recirculation occurs to form the Wairarapa Eddy (Fig 1.2). The rest of the ECC turns eastwards along the northern side of Chatham Rise (Fig. 1.2) (Denham et al., 1984; Chiswell and Roemmich, 1998).

\subsubsection{Southland Current}

The SC flows north along the shelf and slope off eastern South Island (Fig. 1.2). It originates on the Campbell Plateau and flows northward with the STF (Fig. 1.2). The SC mainly advects SAW with small contributions of STW (Sutton 2003). The SC continues northwards to $43^{\circ} \mathrm{S}$ to Mernoo Saddle, a $580 \mathrm{~m}$ deep gap between Banks Peninsula and Chatham Rise. Here, part of the flow passes over the saddle with the main flow steered east along southern Chatham Rise (Heath, 1972). The SC transports 3.4-12.9 Sv, with larger transport volumes found in the northern end of the current. Heath (1972) and Sutton (2003) suggest this could indicate a strengthening flow upstream.

\subsection{Regional Currents - Western New Zealand}

\subsubsection{Westland Current and D'Urville Current}

In contrast to eastern New Zealand, where oceanography is strongly affected by large, interacting flows of STW and SAW, western New Zealand is devoid of such strong circulation. Instead, Tasman Sea oceanography is primarily determined by wind-driven, ephemeral currents. In the southern Tasman Sea, the wind-driven flow of STW diverts at Jackson Head in both northeastern and southwestern directions (Heath 1973). The southern diversion at Jackson Head joins up with the STF off Fiordland and continues east. Current meter readings and geostrophic measurements suggest this flow becomes stronger south of Jackson Head (e.g. Heath, 1973, 1985; Stanton, 1976). The northern diversion at Jackson's 
Head is the Westland Current (WC), a highly variable, wind driven flow in which STW flows primarily northeast along the west coast of the South Island to Cook Strait. Heath $(1978,1973)$ and Stanton (1976) show that the WC is influenced more by atmospheric pressures and tides rather than geostrophic conditions.

The D'Urville Current (DC) is an offshoot of the WC and is directed towards Cook Strait. It is a weak current which primarily flows in an anti-clockwise direction around Tasman Bay (Heath 1976, 1978).

\subsection{Climate Variability of New Zealand}

\subsubsection{Winds}

The New Zealand region is dominated by the mid-latitude westerly winds which are the northern margin of the west wind drift (Fig. 1.4). The mean core of the mid-latitude winds is centred $\sim 30^{\circ} \mathrm{S}$ in the winter and $\sim 45^{\circ} \mathrm{S}$ in the summer (Shulmeister et al., 2004). The westerly winds are responsible for weather variation on different scales. Short period Rossby waves which have more peaks and troughs produce more meridional flow and hence, more perturbed weather patterns. Long period Rossby wave structures produce a more zonal flow. For a more complete explanation of Southern Hemisphere atmospheric circulation, see Sturman and Tapper, (2006). 


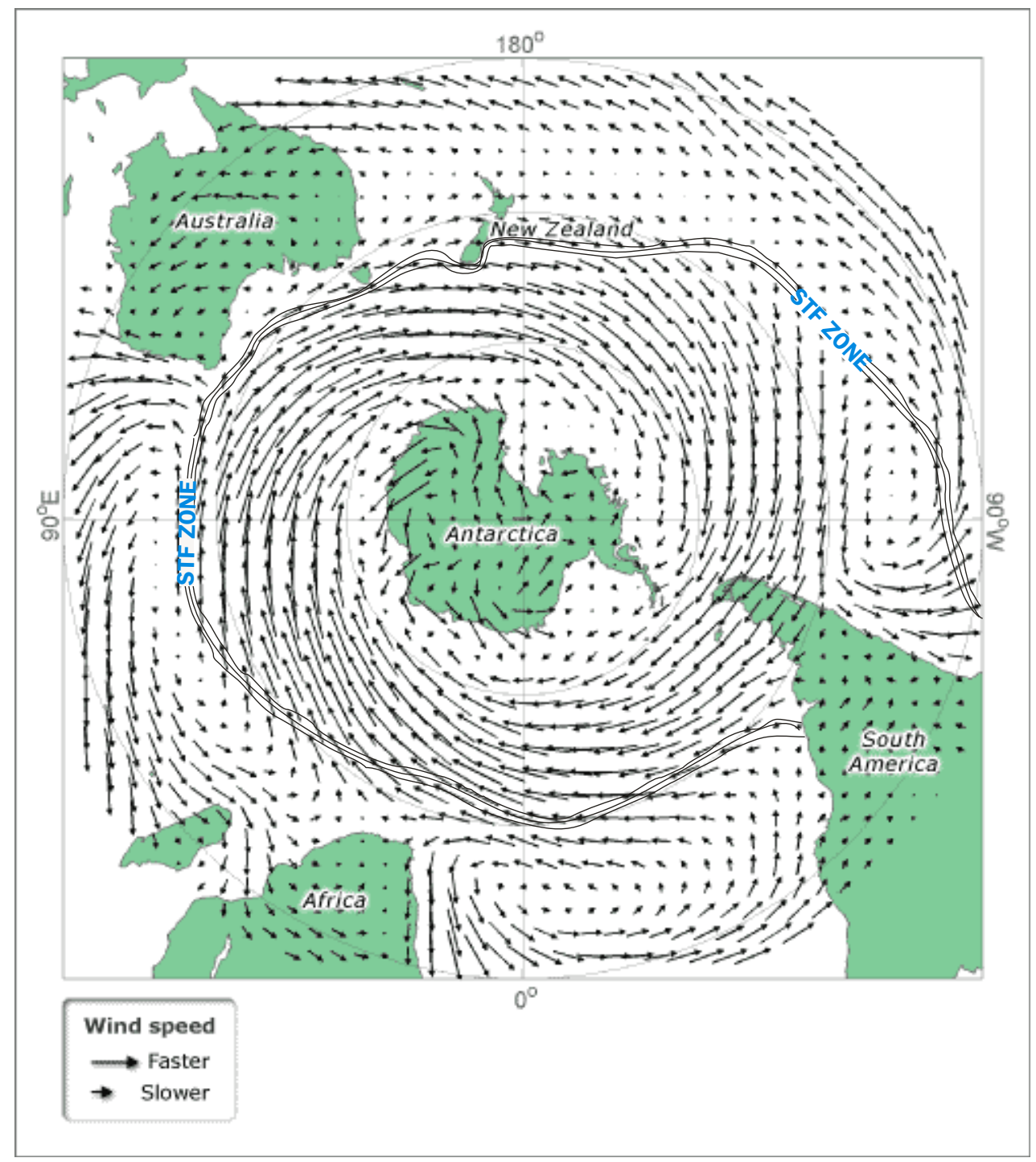

Fig. 1.4 - Southern Hemisphere westerly winds. Circumpolar band is approximate location of STF zone (after Orsi et al., 1995) (Copyright image from NIWA)

Atmospheric circulation and the westerly wind climate have important implications for New Zealand's weather patterns in relation to paleoclimate studies. The STF is the northern boundary of the westerly wind zone, and its latitudinal location is closely associated with the position of the westerly winds. Presumably, an increased thermal gradient between the equator and the poles during glacial periods would increase wind strength and cause an equator-ward shift in the location of the westerlies affecting the location of storm tracks (Shulmeister et al., 2004). A STF position north of its present location in the Tasman Sea indicates that mainland New Zealand will be within the westerly wind belt, changing moisture availability and precipitation to New Zealand. Currently there exists some debate about the behavior of the glacial westerlies. Several climate models suggest the westerly 
winds weakened during glacial periods, (Toggweiler et al., 2006; Rojas et al. 2009) or were not stronger than in the Holocene (Hesse and McTainsh, 1999), while others suggest LGM winds were stronger than present (Shulmeister et al., 2004; Menviel et al., 2008).

\subsubsection{Present Day Sea Surface Temperatures and Variability}

SSTs vary greatly in the New Zealand region (Fig. 1.5). SSTs between the STF and the TF are $15-22^{\circ} \mathrm{C}$ in summer and $11-18^{\circ} \mathrm{C}$ in winter. Temperatures south of the STF are $11-15^{\circ}$ $\mathrm{C}$ in summer and $8-11^{\circ} \mathrm{C}$ in winter (Uddstrom and Oien, 1999). Isothermal gradients differ off eastern New Zealand compared to western New Zealand. Isothermal gradients are a measurement of how SST changes over geographical distance; generally given by ${ }^{\circ} \mathrm{C} / 100$ $\mathrm{km}$. Offshore eastern New Zealand, the temperature gradients are lower than the Tasman Sea, about $\sim 0.5^{\circ} \mathrm{C} / 100 \mathrm{~km}$. The isothermal gradients are higher in the Tasman Sea, with a gradient of $\sim 0.75^{\circ} \mathrm{C} / 100 \mathrm{~km}$ between $34-45^{\circ} \mathrm{S}$. The thermal gradient in the Tasman Sea, in particular in the western Tasman Sea, is the highest in the region, as a consequence of warm South Pacific Subtropical Gyre waters advected into the northern Tasman Sea, and Ekman transport of SAW in the southern Tasman Sea (Uddstrom and Oien, 1999).

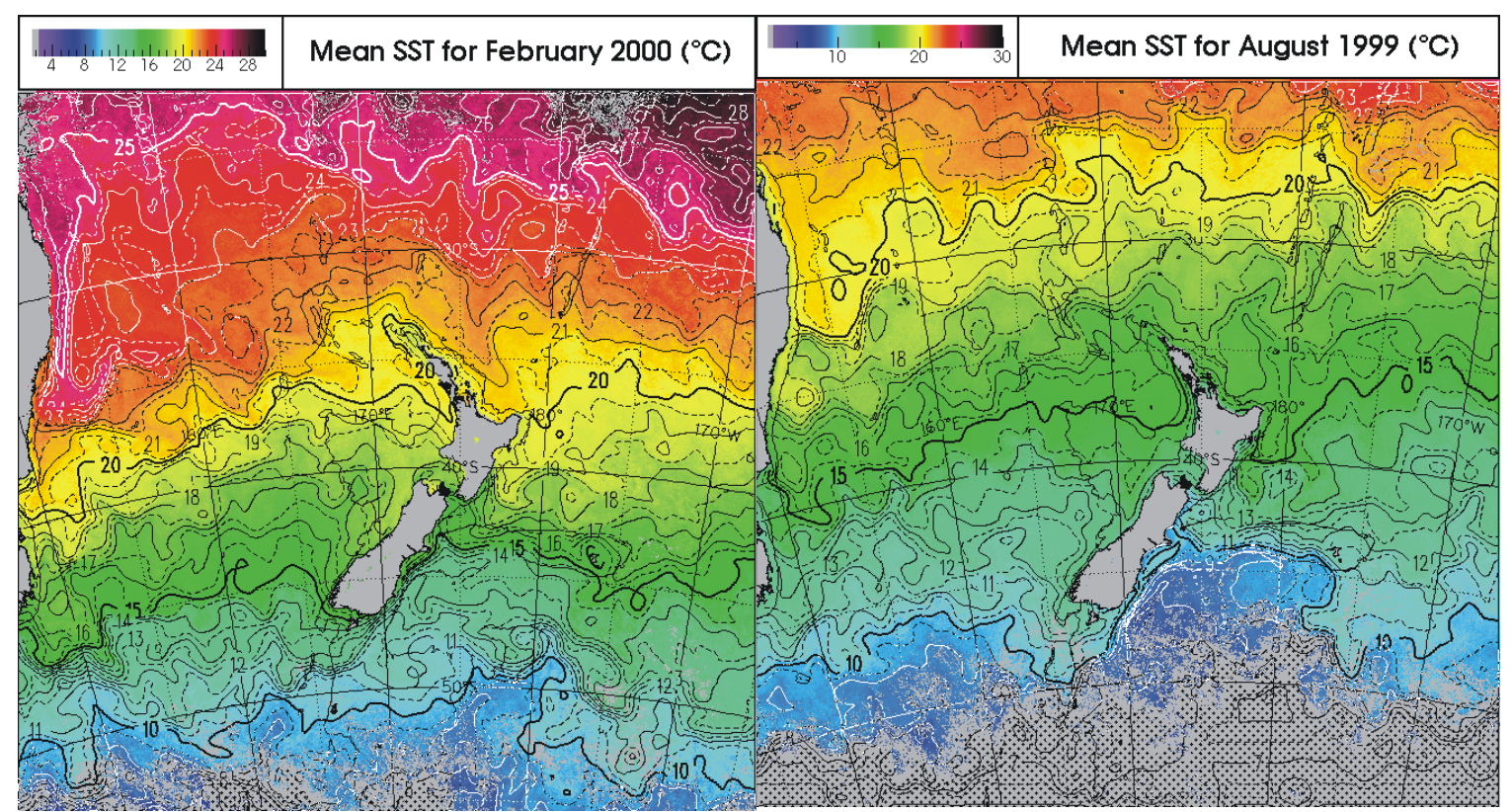

Summer SST

Winter SST

Fig. 1.5 - Summer and Winter SST in New Zealand Waters (Image courtesy of NIWA) 


\subsubsection{El Niño-Southern Oscillation (ENSO) and Southern Annular Mode (SAM)}

ENSO is the perturbation of the ocean-atmospheric cycle in the tropical Pacific Ocean. There is a positive and a negative phase of ENSO. Normally, easterly winds in the equatorial Pacific transport warm surface waters to the western Pacific Ocean, while nutrient rich water upwells off the coast of South America (Stewart, 2008). During the negative phase of the Southern Oscillation Index (El Niño), a change in wind direction occurs, and warm waters are transported east. This changes climate worldwide, as moisture and heat are transported to different parts of the world (Stewart, 2008). The affect of ENSO is significant to New Zealand, and in certain years, dominates the oceanography and climate (Fig. 1.6). During El Niño events, westerly winds are stronger throughout the year, and the west coast receives more rainfall than the east coast. During La Niña events, or the positive phase of the Southern Oscillation Index, winds tend to come from the northeast, bringing excess moisture to northeast North Island and drier conditions to the South Island (Salinger et al., 1995; Mullan, 1995).

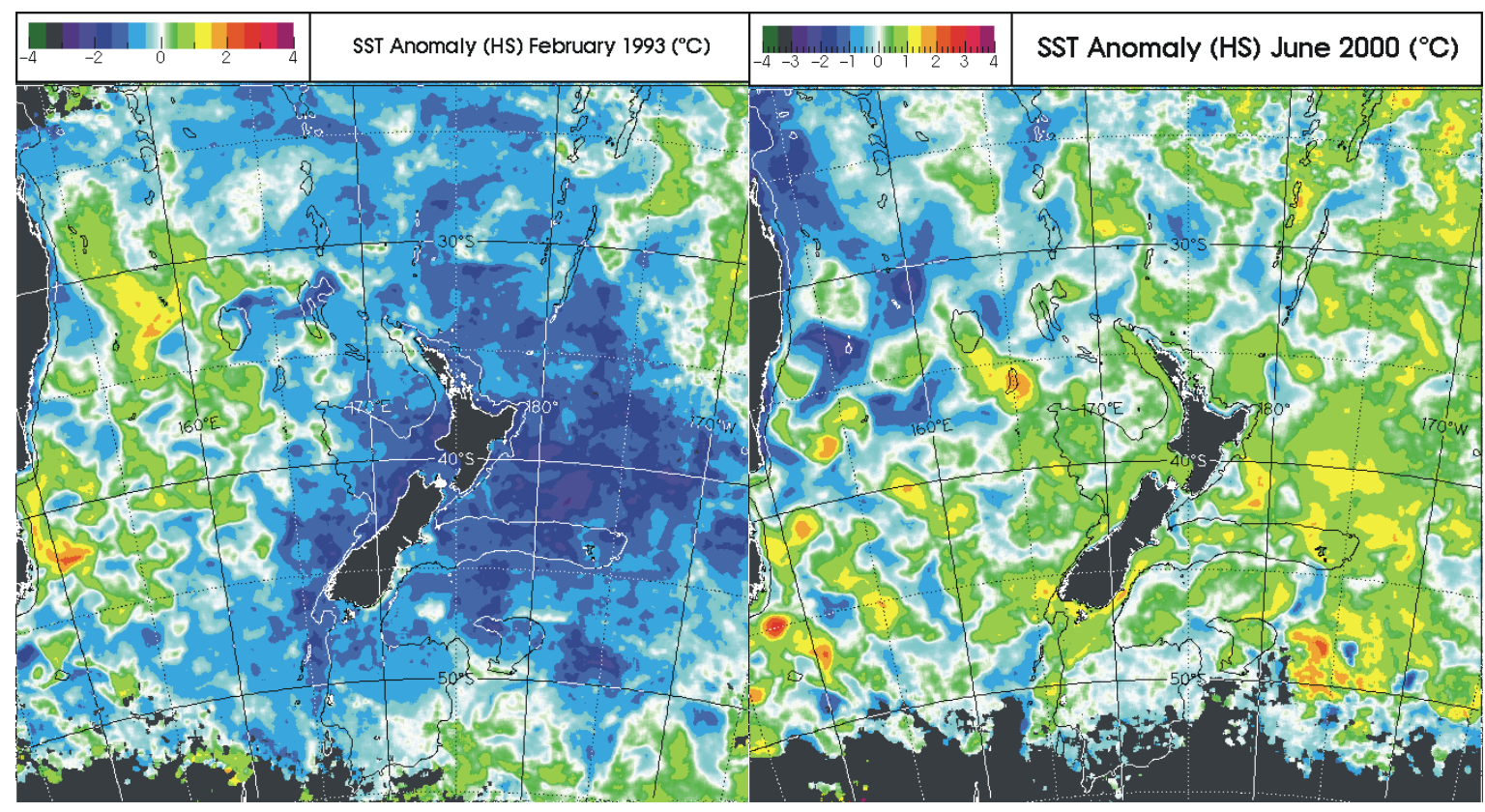

El Niño Conditions

La Niña Conditions

Fig. 1.6 - ENSO variability in New Zealand for summer (El Niño) and winter (La Niña) (Image courtesy of NIWA)

SAM is a ring of climate variability around Antarctica which extends up into the middle latitudes and is associated with two phases of alternating patterns of wind and storm activity 
between the two regions (Kidson, 1988). In a positive SAM, calmer conditions such as reduced wind and storm activity are found in middle latitudes, and increased westerlies over the Southern Ocean. The opposite occurs in a negative SAM, with unsettled weather in the mid-latitudes, and reduced westerlies in the Southern Ocean. The SAM is not well understood, as its variability is short, between one and three weeks, and oscillations between the phases appear to be random. Since its discovery in the 1970's, the SAM appears to be trending in a more positive phase. This has resulted in a reduction of total rainfall on the west coast of New Zealand (Gillett et al., 2006).

\subsection{Summary}

The oceanography of New Zealand is unique, as the landmass and associated drowned continent span several water masses and influences major global currents such as the DWBC and ACC. The oceanography is characterised by having contrasting hydrographic regimes off the east and west coast. Offshore eastern New Zealand, competing inflows of subtropical water from the north and subantarctic water from the south produce highly variable SSTs over a small geographic region. The complex bathymetry of the eastern continental shelf controls and influences the movement of fronts and water masses.

Off western New Zealand, the hydrographic regime is more wind driven, with fewer bathymetric features to affect circulation. In contrast to the east coast, there is no prominent inflow of either STW or SAW. The structure of the STF in the Tasman Sea is not fully understood; however there appears to be a main STF, marking the water mass boundary, and a minor, wind-driven front to the north.

New Zealand's climate is influenced by several factors. Summer and winter SSTs are variable around New Zealand, changing by as much as $5^{\circ} \mathrm{C}$ between the seasons. The midlatitude westerlies have a direct influence on New Zealand's climate. The structure of these westerlies dictates calm or stormy weather. Finally, climatic oscillations such as ENSO and SAM affect the ocean climate system, bringing about changes in SSTs, circulation and weather patterns. 
This project aims to resolve questions about Tasman Sea paleoceanography by using planktic foraminiferal assemblages to determine past SST and oceanic frontal movement. By comparing Tasman Sea paleoceanographic data from this study with paleoceanographic data from offshore eastern New Zealand, a broad picture of New Zealand's past ocean climate will be revealed. This is particularly important for predicting and understanding future responses to rapid climate change. 


\subsection{NZ Paleoceanography}

\subsubsection{Overview}

New Zealand's past oceanography is far better known offshore eastern New Zealand compared to offshore western New Zealand. Many researchers have worked on the deep sea cores from off the east coast (Fenner et al., 1992; Nelson et al., 1993; Kowalski and Meyers, 1997; Wells and Okada, 1997; Nelson et al., 2000; Hall et al., 2001; Sikes et al., 2002; Sikes et al., 2005, Schaefer et al., 2005; Wilson et al., 2005; Pahnke and Sachs, 2006; Crundwell et al., 2008). This work has produced several SST records up to 1.2 million years before present (myr BP), and has revealed details of glacial and interglacial frontal migrations (of the STF and the SAF), and paleo-circulation of deep and surface currents. In this chapter, paleoclimate proxies and their applications are reviewed, followed by a discussion of research completed offshore from eastern and western New Zealand.

\subsection{Foraminifera}

Foraminifera are unicellular protozoa that live either in the upper photic zone of the ocean or on the sea floor. Foraminiferal shells are mostly made of calcium carbonate $\left(\mathrm{CaCO}_{3}\right)$, and the walls of the shell are arranged as a series of chambers. These shells are often preserved after burial. Foraminifera can be highly abundant and diverse in marine sediment. The combination of their preservation and abundance in ocean sediments makes them useful for detailed proxy studies of past oceanography and climate change. Foraminifera have also been used as biostratigraphic and chronostratigraphic tools in geological studies and in the petroleum industry for nearly a century (Armstrong and Brasier, 2005). In paleoceanography, foraminifera are valuable because different species prefer to inhabit different water conditions, and their widespread distribution makes it possible to use species as indicators of certain oceanographic conditions. By identifying and counting foraminifera in a sediment sample from a core, it is possible to interpret the ocean conditions at the time of burial (Armstrong and Brasier, 2005; Bé, 1977). It is also possible to identify temporal change in paleoceanography by examining series of samples from different levels in a core. 
There are two main types of foraminifera: benthic and planktic. Benthic forms live on the seafloor, either infaunally (under the surface of the sediment), or epifaunally, (on the surface of the sediment). The composition of benthic foraminiferal faunas is dependent on many factors, including the quality, quantity and seasonality of food supply, bottom oxygen concentration, the carbonate corrosiveness of bottom waters, and bottom current strength (e.g. Hayward et al., 2002, 2007). Benthic foraminifera mostly feed on organic material that falls to the seafloor from the upper layers of the ocean (Haslett, 2002). The composition of benthic foraminiferal faunas in Neogene deep-sea cores can be used as a proxy for phytoplankton productivity and seasonality, the oxygenation levels of bottomwaters, carbonate dissolution, movement of ocean fronts, changes in the depth stratification and strength of water masses, and even paleo-water depth (Wefer et al., 1999; Hayward et al., 2004a, b, 2005).

Planktic foraminifera, which are the primary focus of this thesis, live in the surface waters of the ocean, are widely distributed and live at all latitudes. Most species live in the surface mixed-layer of the ocean (the upper $100 \mathrm{~m}$ of the water column), though some living Globorotaliids are found down to $2000 \mathrm{~m}$ (Hemeblen et al., 1989). This makes planktic foraminifera ideally suited as sea-surface temperature and water mass proxies. The walls of planktic foraminiferal tests tend to be thinner than the walls of the benthic forms, creating more buoyancy and enabling planktics to float (Bé, 1977; Armstong and Brasier, 2005).

This thesis uses planktic foraminiferal assemblages to reconstruct mean annual SSTs at site MD06-2986 in the Tasman Sea.

\subsubsection{Planktic foraminifera - key characteristics}

The following section details the unique morphological features that are useful for identifying individual planktic species, and the oceanic environments where they are most frequently found. While there are 28 or more extant species of planktic foraminifera, the ten most abundant species from the present study are discussed below. 
Neogloboquadrina incompta - (Cifelli, 1961) (Fig. 2.1)

Fig. 2.1

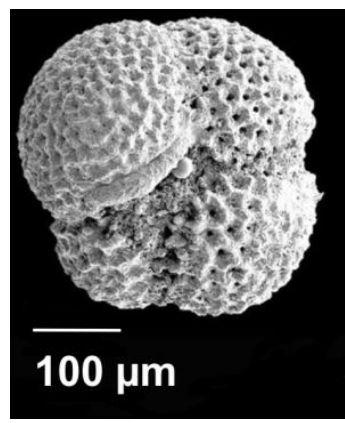

Distinguishing characteristics: Four chambers in the outer whorl, dextrally coiled, non-spinose, cancellate surface-ultrastructure and a aperture with a well developed lip. It was previously identified as dextrally-coiled forms of Neogloboquadrina pachyderma, but recent work (Darling et al., 2004; Darling et al., 2006) has shown that the sinistrally-and dextrally-coiled forms of $N q$. pachyderma are

genetically distinct.

Distribution: Nq. incompta is typically found in temperate waters, but can also be found in subtropical and subantarctic waters, in depths of 50-150 m.

Neogloboquadrina pachyderma - (Ehrenberg, 1861) (Fig. 2.2)

Fig. 2.2

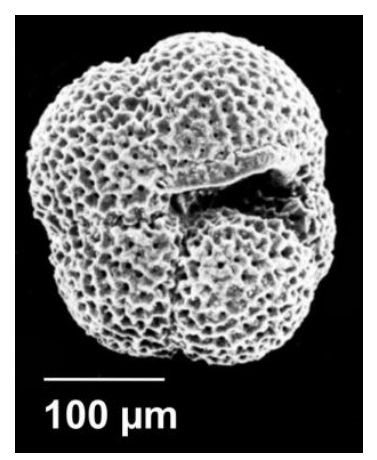

Distinguishing characteristics: Four and a half chambers in the outer whorl, sinistrally-coiled, non-spinose, cancellate surfaceultrastructure and a low-arched interiomarginal, umbilicaextraumbilical aperture with a well developed lip.

Distribution: The abundance of $N q$. pachyderma increases markedly towards high latitudes and it becomes dominant in polar regions, in depths of 50-150 m. It is primarily a polar and sub-polar cold water indicator.

Globigerina bulloides - (d'Orbigny, 1826) (Fig. 2.3)

Fig. 2.3

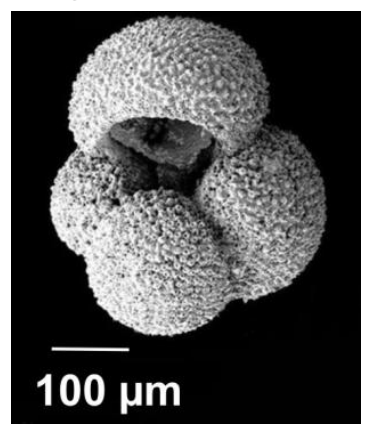

Distinguishing characteristics: Globular appearance, non-cancellate spinose surface ultrastructure, and a large, open, centrally located aperture.

Distribution: Globigerina bulloides thrives in high nutrient waters and is not necessarily limited to water of specific temperatures. In the New Zealand region, the highest abundances of $G g$. bulloides are generally found near 
the TF and the STF, in areas of water mass mixing and high productivity and nutrient content (Boersma et al., 1998). Gg. bulloides is found at depths of 0-100 m.

Globoconella inflata - (d'Orbigny, 1839) (Fig. 2.4)

Fig. 2.4

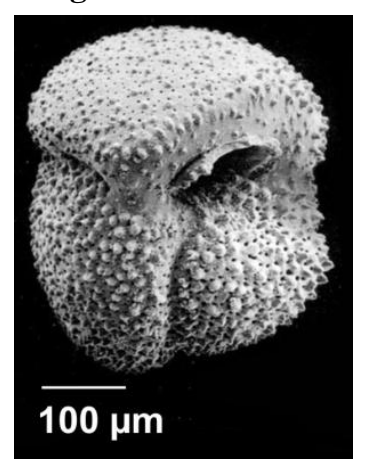

Distinguishing characteristics: Three to four chambers in the outer whorl, non-spinose, trochospiral with a flattend spiral side. Has a low-arched, off-center aperture. Predominantly sinistrally-coiled. Globoconella inflata is also known as Globorotalia inflata.

Distribution: Gc. inflata is most abundant in cool subtropical (temperate) waters, though it is also common in subtropical and subantarctic waters, and found at depths between 100-400 m.

Truncorotalia truncatulinoides - (d'Orbigny, 1839) (Fig. 2.5)

Fig. 2.5

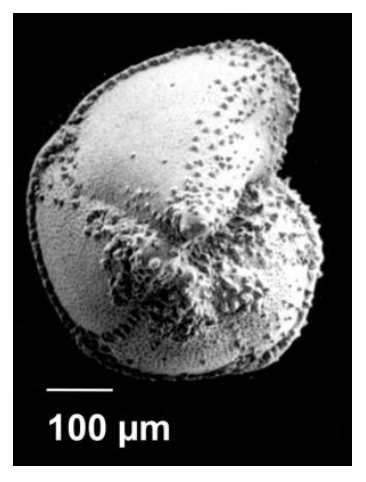

Distinguishing characteristics: Trochospirally coiled, strongly ventoconical axial profile, with a distinctly flattened spiral side. Five chambers in the outer whorl. Asymmetric final chamber, and low, slit-like aperture.

Distribution: Truncorotalia truncatulinoides is most common in temperate waters and is also found in subtropical and subantarctic waters. Dextrally-coiled populations are found mostly in subtropical waters, at depths of 50-2000 m. Tr. truncatulinoides is also known as Globorotalia truncatulinoides. 
Turborotalita quinqueloba - (Natland, 1938) (Fig 2.6)

Fig. 2.6

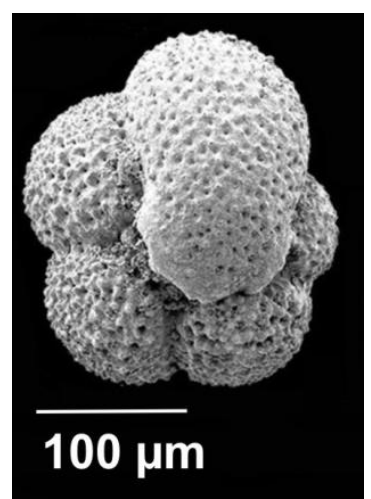

Distinguishing characteristics: Low trochospirally-coiled, and five chambers in the outer whorl. The final chamber is distinctly spinose, especially near the peripheral outline. The final chamber often has a flap-like umbilical extension and an elongate slit-like aperture.

Distribution: Turborotalita quinqueloba is most abundant in stratified waters with lower temperature gradients, but generally thrives in waters with high nutrients, including areas of upwelling and water mass mixing (Boersma et al., 1998). They are found in depths between 0-100 m. Tb. quinqueloba is also known as Globigerina quinqueloba.

Globigerina falconensis - (Blow, 1959) (Fig. 2.7)

Fig. 2.7

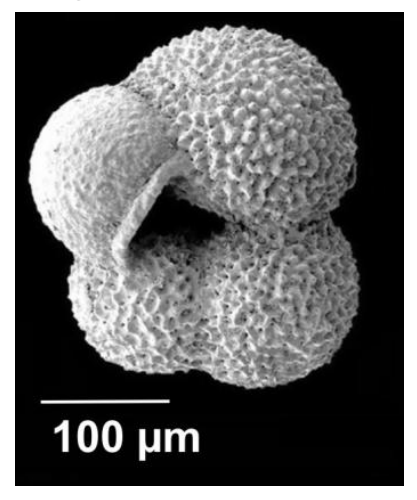

Distinguishing characteristics: globular appearance, four chambers in outer whorl, spinose surface ultrastructure, and a low aperture with a well defined lip.

Distribution: In the New Zealand region, Globigerina falconensis is most abundant in cool subtropical (temperate) waters (Crundwell et al., (2008).

Globigerinita glutinata - (Egger, 1893) (Fig. 2.8)

Fig. 2.8

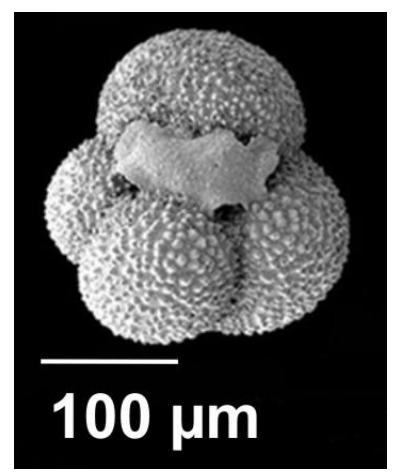

Distinguishing characteristics: globular appearance, four chambers in the outer whorl, fine spinose, microperforate ultra-structure. Primary umbilical aperture a low arch with a thin lip, often covered by a bull with small supplementary apertures that resemble tubules.

Distribution: Globigerinita glutinata is a widely distributed cosmopolitan species, similar to Gg. Bulloides, and is most 
commonly found in nutrient-rich waters, rather than temperature specific waters (Boersma et al., 1998). They are found at a depth of 50-200 m.

Globigerinoides ruber - (d'Orbigny, 1839) (Fig. 2.9)

Fig. 2.9

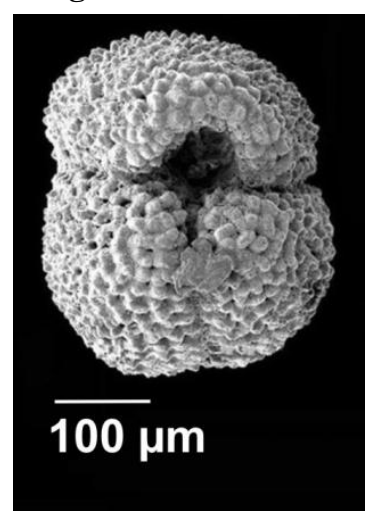

Distinguishing characteristics: Compactly coiled, three chambers in outer whorl, centrally located umbilical aperture, and smaller supplementary apertures at the junctions of sutures on the spiral side.

Distribution: Globigerinoides ruber is a shallow mixed layer species and is most abundant in tropical and subtropical waters at depths of 0-50 m.

Orbulina universa - (d'Orbigny, 1839) (Fig. 2.10)

Fig. 2.10

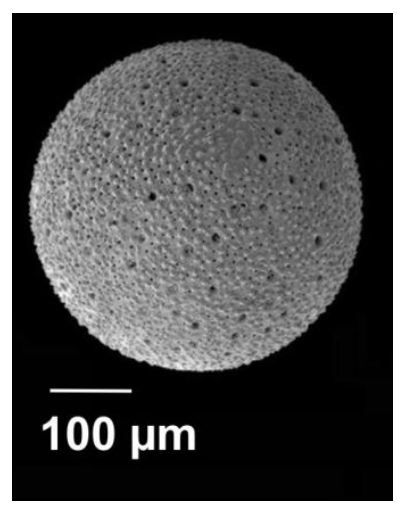

Distinguishing characteristics: spherical, with many small apertures distributed evenly over the surface of the test. Small juvenile specimens are often sub-spherical and have small apertures concentrated along sutures.

Distribution: Orbulina universa is a widely distributed cosmopolitan species that is most commonly found in tropical and subtropical waters, though is not particularly abundant. They are found at depths of 50-300 m.

\subsection{Proxies}

Since it is not possible to measure past oceanic and atmospheric conditions directly, oceanographers use proxies for these conditions that have been captured in the shells of marine organisms preserved in oceanic sediment. Climate proxies are indicators of local records that are interpreted, using physical, biophysical and geochemical principles, to represent some combination of climate-related variations back in time (IPCC WG1 report, 2007). 


\subsubsection{Water mass identification}

Present-day water masses can be identified using direct measurements of temperature, salinity, oxygen, dissolved gases, chemistry and biological content. Finding proxies that represent these variables allows one to reconstruct the temporal and areal distribution of past water masses. There are several methods for interpreting paleo-water masses, but the most commonly used proxies are the stable isotopes; $\delta^{18} \mathrm{O}$, which measures a combination of global ice volume, water temperature, and salinity, and $\delta^{13} \mathrm{C}$, which has a negative correlation to oxygen content, and is primarily a measure of nutrient flux, and atmospheric ventilation (Wefer et al., 1999). Microfossil assemblages, that are the primary focus of this study, are also used as important and indirect measures of SST.

There are several SST proxies, and these include $\mathrm{Mg} / \mathrm{Ca}$ ratios, alkenone paleothermometry, transfer functions, Modern Analogue Technique and Artificial Neural Networks (e.g., Wefer et al., 1999, Malmgren and Nordlund, 1997). When estimating past SST, it is important to use several different methods, as there are limitations with each method. Comparison between the various techniques provides the best, overall understanding of past SST records.

Alkenone palaeothermometry uses the unsaturation index of long chain $\mathrm{C}_{37}$ alkenones mainly in the calcareous nannofossil species Emiliania huxleyi (Volkman et al., 1980; Brassell et al., 1986). The ratio of di-unsaturated to tri-unsaturated compounds has been shown to change linearly with water temperature (Prahl and Wakeham, 1987; Muller et al., 1998; Prahl et al., 2000), and by using a regional calibration, provides an accurate measure of surface temperature.

$\mathrm{The} \mathrm{Mg} / \mathrm{Ca}$ proxy for SST uses the ratio of magnesium to calcium in the tests of planktic foraminifera. The magnesium content in seawater is incorporated into the calcium carbonate tests by a process that is thermodynamically controlled (Clarke and Wheeler, 1922). By using a regional calibration based on $\mathrm{Mg} / \mathrm{Ca}$ in modern foraminifera, a direct SST record can be produced from this ratio. 
Transfer functions (Imbrie and Kipp, 1971) and the Modern Analogue Technique (MAT, see methods) (Ortiz and Mix, 1997) are mathematical or statistical representations of input and output data of a system. These techniques compare the down-core fossil foraminiferal assemblages with a regional database of present-day coretop assemblages, for which there is an associated present-day SST, and computationally finds the five most similar faunas to give an estimate of SST for each fossil assemblage.

Artificial Neural Networks (ANN, see methods) (Malmgren and Nordlund, 1997; Malmgren et al., 2001) is a complicated series of algorithms that can learn the similarities between input and target data. For paleo-SST models, ANN will learn the similarities between present day faunas and SSTs, then apply those similarities to fossil faunas to get a paleoSST record. Chen et al., (2005) showed that MAT and ANN provide more robust paleoSST estimates in the Pacific Ocean than the Imbrie-Kipp Model (Imbrie and Kipp, 1971) transfer functions.

\subsubsection{Frontal movement and surface circulation}

Patterns of surface oceanic circulation, including the movement of oceanic fronts, can be tracked through a number of ways. Presently, satellite data show the STF in the New Zealand region of the Southwest Pacific migrates by as much as $2^{\circ}$ latitude during summer and winter, in places where it is not constrained by bathymetry (Uddstrom and Oien, 1999). Frontal movements in the Southern Hemisphere have been tracked through time in a number of studies (Howard and Prell 1992; Weaver et al., 1998; Sikes et al., 2009; Bard and Rickaby, 2009). These studies primarily rely on the use of zooplankton assemblage data and temperature data.

The preferred method of estimating the paleo-position of oceanic fronts is to have a latitudinal transect of cores whose geographical locations intersect the present day position of the front. By comparing SST proxies from the different sites, and the composition of planktic foraminiferal assemblages, it is possible to identify abrupt changes in the latitudinal transect that correlate with the positions of major oceanic fronts (Howard and Prell 1992; Weaver et al., 1998; Sikes et al., 2009). This method does not assume that the temperature gradient of the front, nor the SSTs on either side of the front, have remained constant 
through time (Wells and Okada 1997; Ikehara et al., 1997; Passlow et al., 1997; Wells and Connell, 1997).

A single core can be used to determine the past positions of the STF relative to that particular site. Kennett (1968) and Malmgren and Kennett (1972) show that a 50\% ratio of $N q$. pachyderma relative to the temperate species $N q$. incompta occurs at $48^{\circ} \mathrm{S}$. The ratio of Nq. pachyderma/Nq. incompta can therefore be used as a guide for approximating the location of the STF. Martinez (1994) assumed a constant relationship between the $N q$. pachyderma/Nq. incompta ratio and latitude and took a $40 \%$ ratio as an approximation for the STF in the Tasman Sea (Fig. 2.11). It is important to note that the original work of Martinez (1994) described this technique as the Nq. pachyderma coiling ratio since he was measuring the ratio of coiling directions (sinistral or dextral) for the species $N q$. pachyderma. Today, the sinistral (S) form is the polar/subpolar species $N q$. pachyderma described here, and the dextral form is now known as the temperate species $\mathrm{Nq}$. incompta (see earlier discussion). Despite the changes in taxonomy sparked by the work of Darling et al. (2006), the use of this species ratio, as a front indicator, remains valid. The use of this application in this study is referred to as the $N q$. pachyderma/Nq. incompta ( $p / i$ ) ratio.

Since this study examines samples from one site only (MD06-2986) in the south-east Tasman Sea, it is only possible to determine relative movements of the STF through time. However, the use of SSTs, the planktic foraminiferal assemblage data and the $N q$. pachyderma/Nq. incompta ratio should provide useful insights into paleoceanic-surface circulation in this region.

\subsubsection{Productivity}

Productivity proxies are important because they provide an understanding of the characteristics of the water masses and the climatic factors that influenced them, such as oceanic circulation and wind patterns, water mass mixing, biogeography and the carbon cycle. Productivity can be measured by changes in the amount of organic matter, opaline silica, or biogenic carbonate content in sediments; and chemical tracers, such as barium, and microfossil assemblages such as diatom or foraminiferal microfossils (see review, Wefer et al., 1999). 
Productivity reconstruction based on planktic foraminiferal assemblages can be derived from the number of specimens per square centimeter per one thousand years, also known as planktic foraminifera flux. This provides a reasonable understanding as to how favorable the water conditions were for planktic foraminiferal production. Since certain species are dependent on certain water conditions, such as temperature, light or nutrient availability, their abundance in an assemblage can also give clues to the water mass conditions at the time of deposition. For example, species of Gg. bulloides, Tb. quinqueloba and Gt. glutinata are useful productivity indicators (Prell and Curry, 1980; Vincent and Berger 1981; Boersma et al., 1998).

\subsection{Tasman Sea Paleoceanography}

Compared to offshore eastern New Zealand, very little paleoceanographic research has been undertaken for the Tasman Sea, especially at sites close to New Zealand. Few SST records exist, and even fewer records show multiple glacial-interglacial cycles.

Prior to this study, the only high-resolution SST records in the Tasman Sea extended 450 ka(western Tasman Sea), and $380 \mathrm{ka}$ (eastern Tasman Sea), and both records were based on alkenone paleothermometry (Pelejero et al., 2006). Others record, using a combination of alkenones and faunal assemblages only extend back to a maximum of $150 \mathrm{ka}$ (Barrows et al., 2000; Barrows et al., 2007; Sikes et al., 2009). 


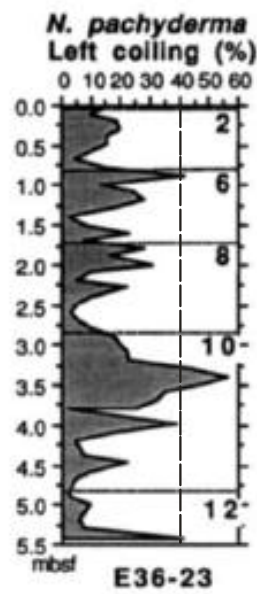

Fig. 2.11 - Neogloboquadrina pachyderma coiling ratios from E36$23\left(43^{\circ} 53 \mathrm{~S}, 150^{\circ} 03 \mathrm{E}, 2561 \mathrm{~m}\right)$ and DSDP $593\left(40^{\circ} 30 \mathrm{~S}, 167^{\circ} 40 \mathrm{E}, 1068\right.$ m). A $40 \%$ ratio is used as a proxy for the location of the STF. Note that for core E36-23 the STF migrates north to $\sim 3^{\circ} \mathrm{S}$ to reach the site in MIS 6, 10 and 12 but did not reach DSDP 593 at $\sim \mathbf{4 0}{ }^{\circ} \mathrm{S}$. Modified from Martinez, 1994

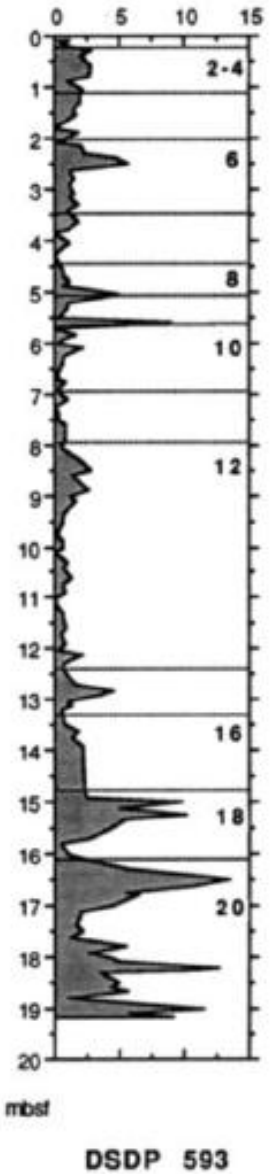

\subsubsection{Sea surface temperatures and frontal movement}

Martinez (1994) examined planktic foraminifera from a meridional transect of cores in the Tasman Sea to determine late Quaternary paleoceanography. The transect of cores spanned the region between Vanuatu $\left(15^{\circ} \mathrm{S}\right)$ and a location east of Tasmania $\left(44^{\circ} \mathrm{S}\right)$ and the records extend as far back as MIS $20(\sim 850 \mathrm{ka})$, though most records only extend back to MIS 10 ( $370 \mathrm{ka})$. This transect allowed Martinez (1994) to reconstruct the past hydrographic conditions, including frontal movements based on the planktic foraminiferal faunal distribution. Martinez (1994) concluded that the Tasman Front had migrated north from $30^{\circ}$ $\mathrm{S}$ to $26^{\circ} \mathrm{S}$ during the last glacial maximum $(\sim 19 \mathrm{ka})$. This could indicate that there was a reduction in the equatorial Warm Pool, or a northward expansion of temperate water masses. Martinez used a 40\% N. pachyderma coiling ratio (sinistral/dextral) to estimate the 
position of the STF from a single core east of Tasmania (Fig. 2.11). He found that the STF had migrated north of $43^{\circ} \mathrm{S}$ during MIS 12, 10 and 6. Martinez (1994) also plotted the $p / i$ ratio at DSDP Site $593\left(40^{\circ} \mathrm{S}\right)$, located on the Challenger Plateau $\sim 330 \mathrm{~km}$ northwest of site MD06-2986. He found that the $p / i$ ratios were low $(<15 \%)$ and concluded that the STF remained south of this latitude.

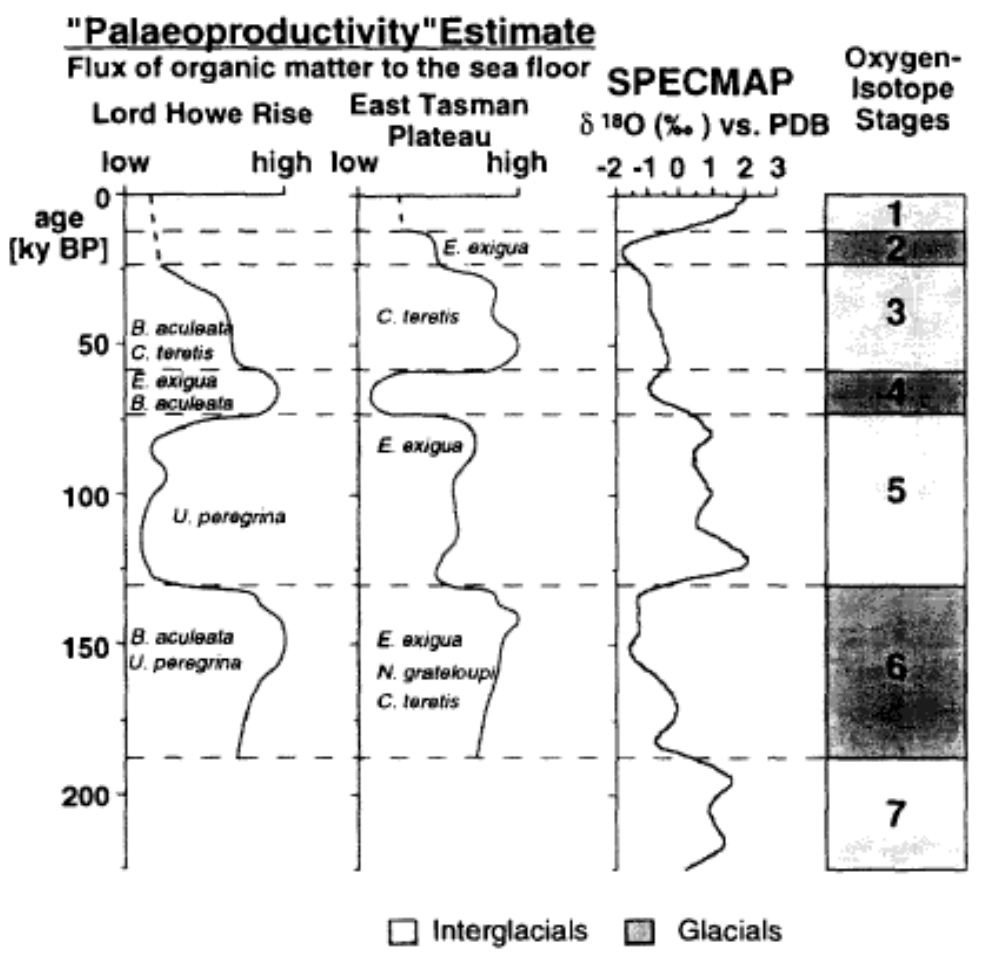

Fig. 2.12 - Productivity estimates from Lord Howe Rise (Tasman Front) and East Tasman Plateau (Subtropical Front). Abundances of the listed benthic foraminiferal species indentify periods of high productivity (from Nees, 1997).

Nees (1997) investigated the hydrography of the Tasman Sea using benthic foraminiferal assemblages from Marine Isotope Stage (MIS) 6-1. He examined four cores in areas of significant productivity and overturning near the TF (cores SO 36-61 and Z 2108) and the STF (cores E36-23 and FR 1/94-GC 3) (Fig. 2.12). The composition of benthic foraminiferal assemblages was used as indicators of surface productivity, as benthic organisms mainly feed on the flux of organic matter that sinks to the seafloor. An increase in the abundance of the species Epistominella exigua indicates high levels of surface productivity, (Hermelin and Shimmield, 1995), and increases in Bulimina aculeata and Uvigerina peregrina suggest low bottom-water oxygen levels, another indicator of high 
organic matter input, usually a result of high surface productivity (Pedersen et al., 1988; Jorrisen et al., 1992). The TF cores showed high productivity during glacial period MIS 6, whereas in the southern cores, high productivity occurs during interglacial MIS 5. Nees suggested a northward shift of both the TF and STF during MIS 6, and a southward shift of the TF during MIS 5e. Nees also suggested that the STF migrated northwards, not southwards, during MIS 5e. This is somewhat unusual since a decrease in polar and tropical temperatures would imply a southwards movement in the front (e.g. Howard and Prell, 1992; Sikes et al., 2009). Nees, however, attributed the northward movement of the STF to high levels of productivity, and a decrease in the strength of East Australian Current's warm eddy field, due to contributions of cooler water from Bass Strait.

Barrows et al. (2000) compared six different analogue technique methods to ascertain the reliability of the different methods to measure faunal-based SSTs. In this work they compared the results from three different Transfer Functions, as well as MAT estimates derived from three different global and southern hemisphere databases. In particular, they tested a new database (AUSMAT-F2) that included more than 1,000 southern hemisphere coretop faunas. They also derived SST estimates for a number of cores that spanned latitudes ranging from the tropical Pacific to the Southern Ocean, and compared results with other studies. MAT estimates of SST using the AUSMAT-F2 database were shown to be the most reliable, as statistical data such as squared correlation and the Root Mean Squared Error of Prediction achieved the highest quality for maximum and minimum temperatures $\left(r^{2}=0.99\right.$ and 0.98, RMSEP=0.9 and 1.0). The AUSMAT-F2 database also proved useful in applying MAT to a wide range of oceanic environments. This work provides reliable faunal-based MAT SSTs and as such, is useful to compare with the MD06-2986 SSTs.

Barrows and Juggins (2005) reconstructed SSTs from 165 shallow sediment cores across the Southwest Pacific Ocean and Indian Ocean and, using MAT, reconstructed temperature isotherms back to the Last Glacial Maximum (LGM). Compared to modern day isotherms, their results show a northward shift in the isotherms. In western Tasman Sea, eddies shed from the East Australian Current brought warm water down the east coast of Australia to Tasmania, reducing the effect of LGM cooling. With no shallow warm-water inflow off western New Zealand, isotherms shifted northward by as much as $8^{\circ}$ of latitude (Fig. 2.13). These results may have important implications for movement of the STF in the eastern 
Tasman Sea. The results suggest that the SAW, as indicated by the temperatures, migrated into the Tasman Sea region during the LGM.

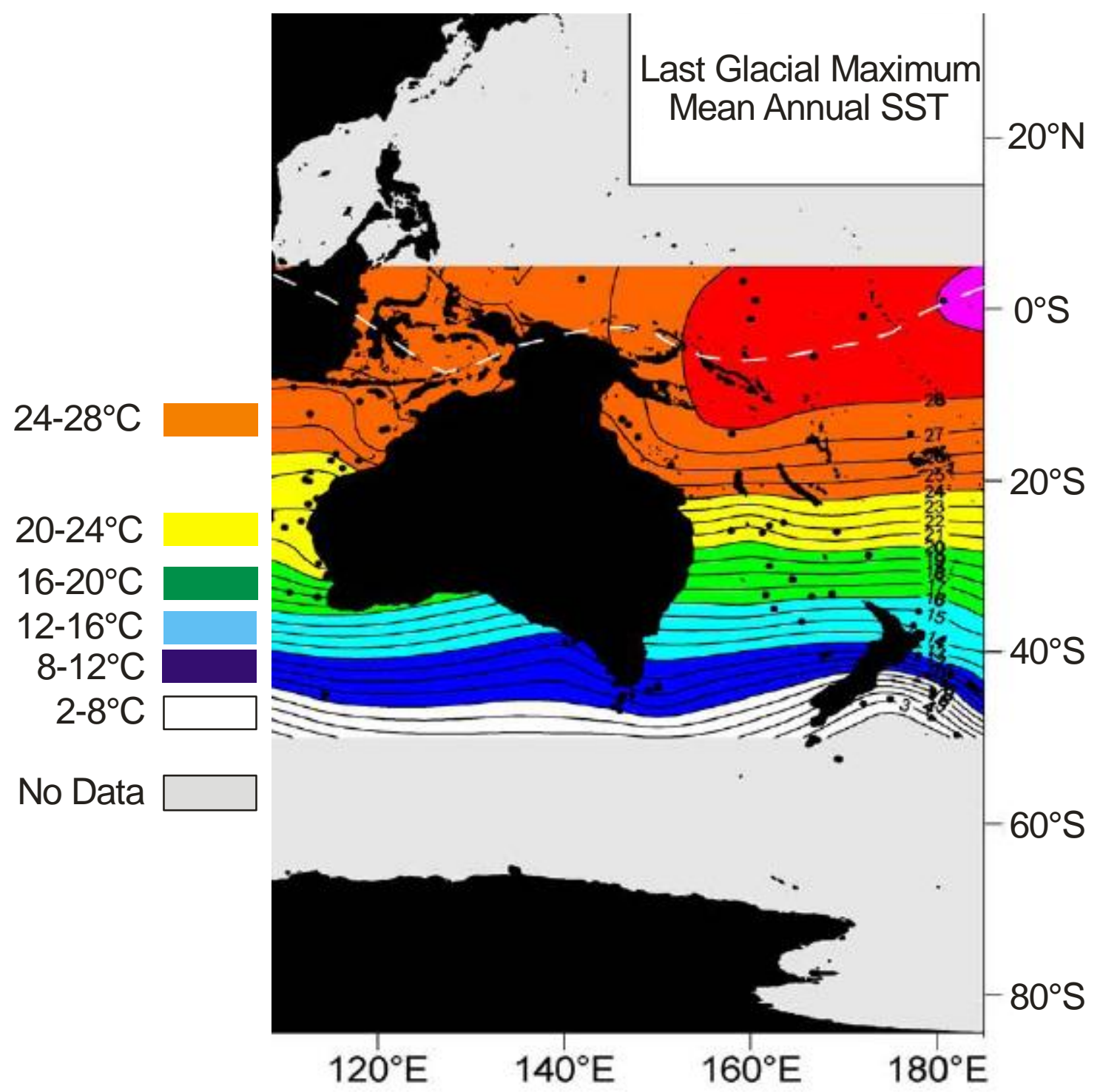

Fig. 2.13 - LGM SST isotherms in Tasman Sea during the LGM. Note colour scale on the side. Modified after Barrows and Juggins, 2005

Barrows et al. (2007) compared high resolution SST and pollen records from 4 sediment cores in the Australian-New Zealand region, with records extending back 150 kyr. During their study they compiled SST records based on alkenones, faunal assemblages and $\mathrm{Mg} / \mathrm{Ca}$, and compared these records with pollen and glacier records from New Zealand, and the insolation curve at $65^{\circ} \mathrm{N}$. They found that first order temperature perturbations coincide with changes in northern hemisphere insolation. In New Zealand, the covariance of SST 
and terrestrial records indicate a strong climatic link between SST and terrestrial temperature.

Pelejero et al. (2006) compiled alkenone-based SSTs from south of Tasmania, and west of the South Island of New Zealand. The Tasmanian record extends back to $460 \mathrm{ka}$, and the New Zealand record extends back to $290 \mathrm{ka}$. In their study, they reported high amplitude $\left(>7^{\circ} \mathrm{C}\right)$ SST changes during glacial-interglacial transitions west of New Zealand, and lower amplitude SST changes south of Tasmania (4.3-6.9 $\mathrm{C}$ ). They also noted that south of Tasmania, peak glacial SSTs decrease towards present-day, whereas west of New Zealand, peak glacial SSTs increase. They also suggest that the higher SST amplitudes, west of New Zealand, are due to the area being more susceptible to fluctuations of the Western Pacific Warm Pool. They also suggest changing intensities, or meridional migrations of the Tasman Front, whereas south of Tasmania was influenced more by thermal changes in the Southern Ocean.

A study by Sikes et al. (2009) constrained STF movement in the western Tasman Sea, in records extending back to MIS 5 ( $120 \mathrm{ka}$ ) (Fig. 2.14). They used a latitudinal transect of

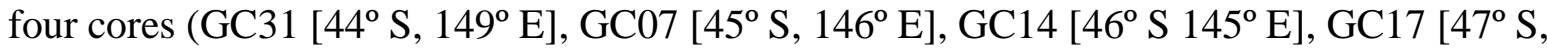
$\left.145^{\circ} \mathrm{E}\right]$ ) from the South Tasman Rise (STR) and East Tasman Plateau and estimated frontal movements based on alkenone and faunal assemblage derived SSTs. However, SSTs were only obtained back to MIS 5 in two of the cores. Alkenone derived SSTs were $\sim 2^{\circ} \mathrm{C}$ warmer than present during MIS 5e at sites GC07 and GC14 and indicated that the STF had moved south of $\sim 47^{\circ} \mathrm{S}$, and possibly as far south as the early Holocene summer location of the STF $\left(\sim 48^{\circ} \mathrm{S}\right)$. During MIS 3, the STF was positioned at $\sim 46^{\circ} \mathrm{S}$. During the LGM, SSTs were $4^{\circ} \mathrm{C}$ colder than present-day temperatures and the STF appears to have been pinned against the south coast of Tasmania. They also suggest that there was no evidence that bathymetry controlled frontal movement over the South Tasman Rise (STR). 

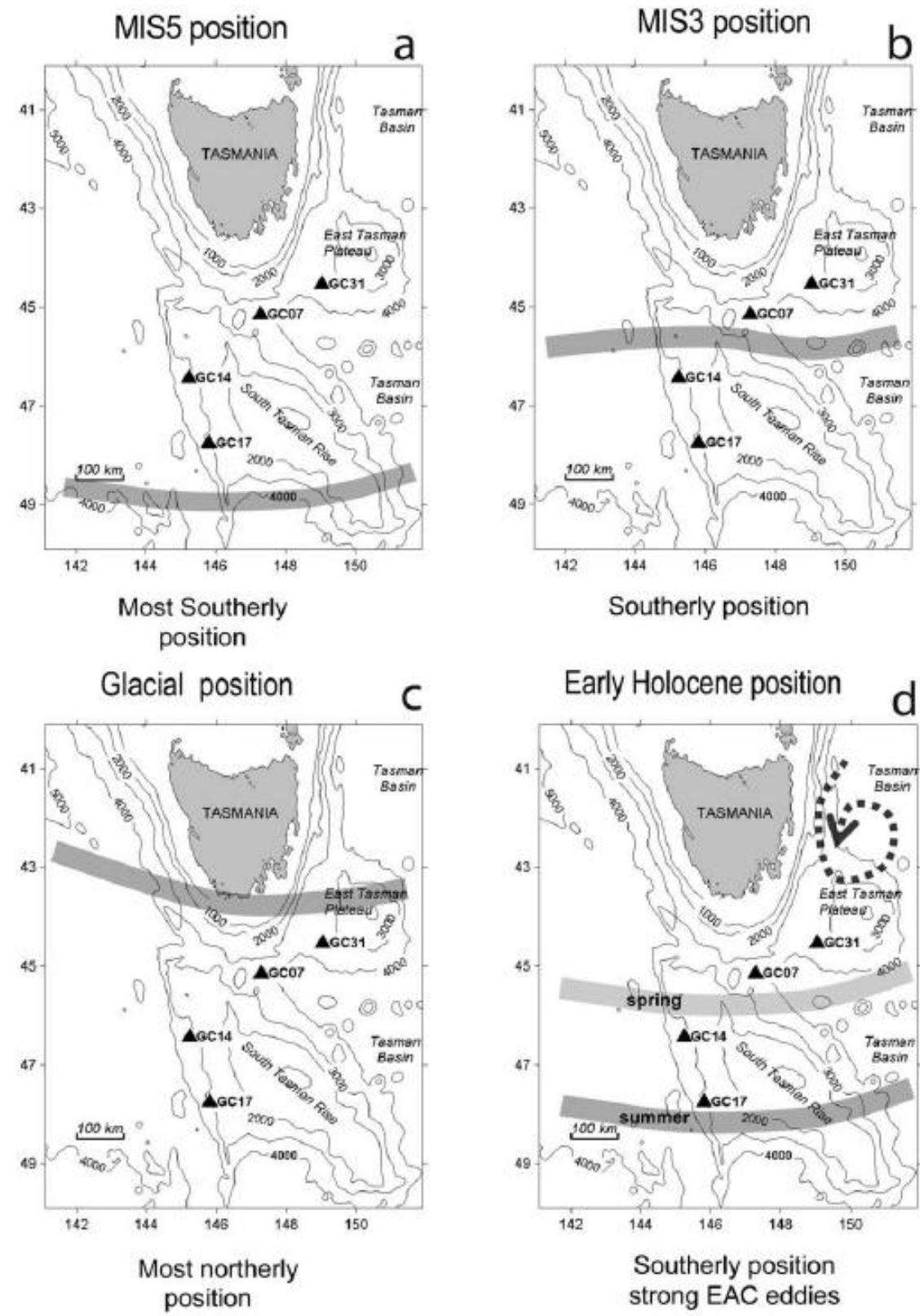

Fig. 2.14 - Reconstructions of STF locations extending back to MIS 5 (from Sikes et al., 2009).

\subsection{Offshore Eastern New Zealand Paleoceanography}

In contrast to offshore western New Zealand, offshore eastern New Zealand oceanography is dominated by the major current systems of the Subtropical Gyre from the north, and the polar ACC from the south. There exists a plethora of published research on the paleoceanography off eastern New Zealand, as there was much scientific interest in 
resolving the complex hydrodynamics through time (Fenner et al., 1992; Nelson et al., 1993; Kowalski and Meyers, 1997; Wells and Okada, 1997; Nelson et al., 2000; Hall et al., 2001; Sikes et al., 2002; Sikes et al., 2005, Schaefer et al., 2005; Wilson et al., 2005;

Pahnke and Sachs, 2006). The following sections review only the most relevant and current knowledge of eastern New Zealand paleoceanography, and in particular, those based around microfossil proxy evidence.

\subsubsection{Sea Surface Temperatures, Frontal Movement and Surface Circulation}

Weaver et al. (1998) investigated the paleoceanographic conditions through the LGM, east of New Zealand, using planktic foraminiferal assemblages. The cores used in their study came from subtropical and subantarctic waters, near the STF, on the Chatham Rise. Their data revealed that planktic faunal assemblages south of the STF were dominated by subantarctic taxa during glacial periods. Their SST records indicate subantarctic waters cooled by as much as $8^{\circ} \mathrm{C}$ during the LGM, and subtropical waters cooled by $4-6^{\circ} \mathrm{C}$. This data suggests that the thermal gradient across the STF increased to $\sim 3^{\circ} \mathrm{C}$ per $1^{\circ}$ of latitude during the LGM (Fig. 2.15). The SSTs also suggest interglacial stage MIS 5e was warmer than present day, and that MIS 4 was as cold as MIS 2. The SSTs also show a Holocene climatic optimum between 10,000-7,500 ka.

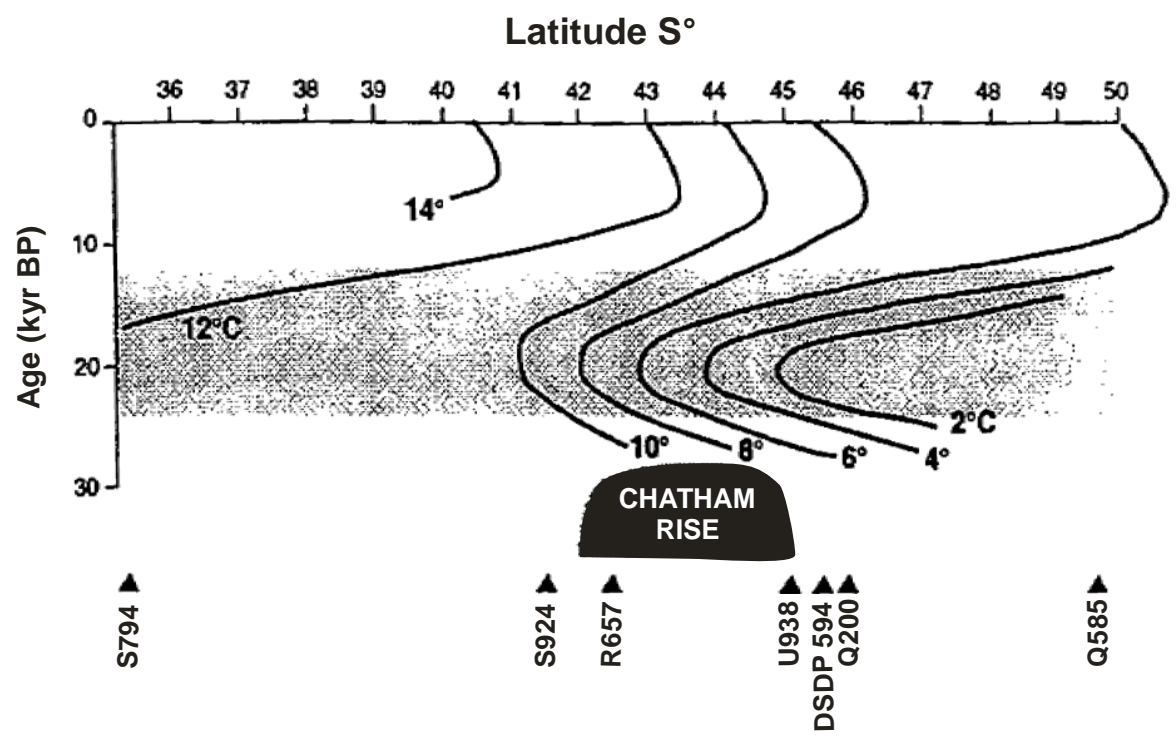

Fig. 2.15 - SST gradients back to the LGM. Notice the tight thermal gradients are maintained over Chatham Rise from the LGM through to the Holocene. Modified after Weaver et al. (1998). 
Hayward et al. (2008) summarised a comprehensive study of planktic foraminiferal assemblages and SSTs dating back to 1.2 Ma (Schaefer et al., 2005; Wilson et al., 2005; Crundwell et al., 2008). In this study, data were compared from four East Coast cores, ODP Sites $1123\left(42^{\circ} \mathrm{S}, 178^{\circ} \mathrm{E}\right), 1125\left(41^{\circ} \mathrm{S}, 171^{\circ} \mathrm{E}\right)$, (north of the STF) and ODP Site $1119\left(44^{\circ}\right.$ $\mathrm{S}, 172^{\circ} \mathrm{E}$ ) and DSDP Site $594\left(45^{\circ} \mathrm{S}, 174^{\circ} \mathrm{E}\right)$ (south of the STF) in an attempt to understand the effects of the eastern New Zealand bathymetry had on ocean circulation, SSTs and water mass movements through the middle to late Quaternary. They concluded that the eastern bathymetry influences local ocean and climate records, and are atypical of the Pacific Ocean. They also concluded that the STF and the SAF were dynamically positioned along the Chatham Rise and the eastern margin of the Campbell Plateau, respectively, and that neither front migrated significantly during glacial and interglacial cycles. They also suggest that the bathymetry had a local affect on SSTs by way of water jetting through submarine saddles and creating gyres and offshoots of both warm waters and cold waters. The authors also conclude that the STW contributions to the Southland Front may be a relatively modern feature and suggest that STW has only flowed around the bottom of the South Island on a few occasions since MIS 11, and not prior to MIS 11. This indicates that the present-day oceanography around the South Island may be atypical in terms of the last 1.2 myr.

Crundwell et al. (2008) used planktic faunal assemblages and ANN estimates of SSTs to investigate changes in marine climate during the last 1.2 Myr, at ODP Site 1123, east of Chatham Rise, at the northern limit of the modern STF. Based on SSTs and faunal composition, they recognized four distinct climate periods (Fig. 2.16). Their results show a change in the dynamics of competing subantarctic and subtropical inflow at the site, during the mid-Pleistocene Climate Transition (MPT) corresponding to change from $41 \mathrm{kyr}$ cycles to $100 \mathrm{kyr}$ cycles. The pre-MPT period at this site is characterised by increasing subantarctic inflow, decreasing subtropical inflow, and invigorated deep Pacific circulation. The early MPT period is characterised by a decrease in subantarctic inflow, an increase in subtropical inflow and reduced deep Pacific circulation. The late MPT period is marked by sub-equal subantarctic and subtropical inflows, and sluggish deep Pacific circulation. The subsequent post-MPT period is characterised by $100 \mathrm{kyr}$ glacial-interglacial cycles, increasing subantarctic and decreasing subtropical inflows, and more invigorated deep Pacific circulation. 


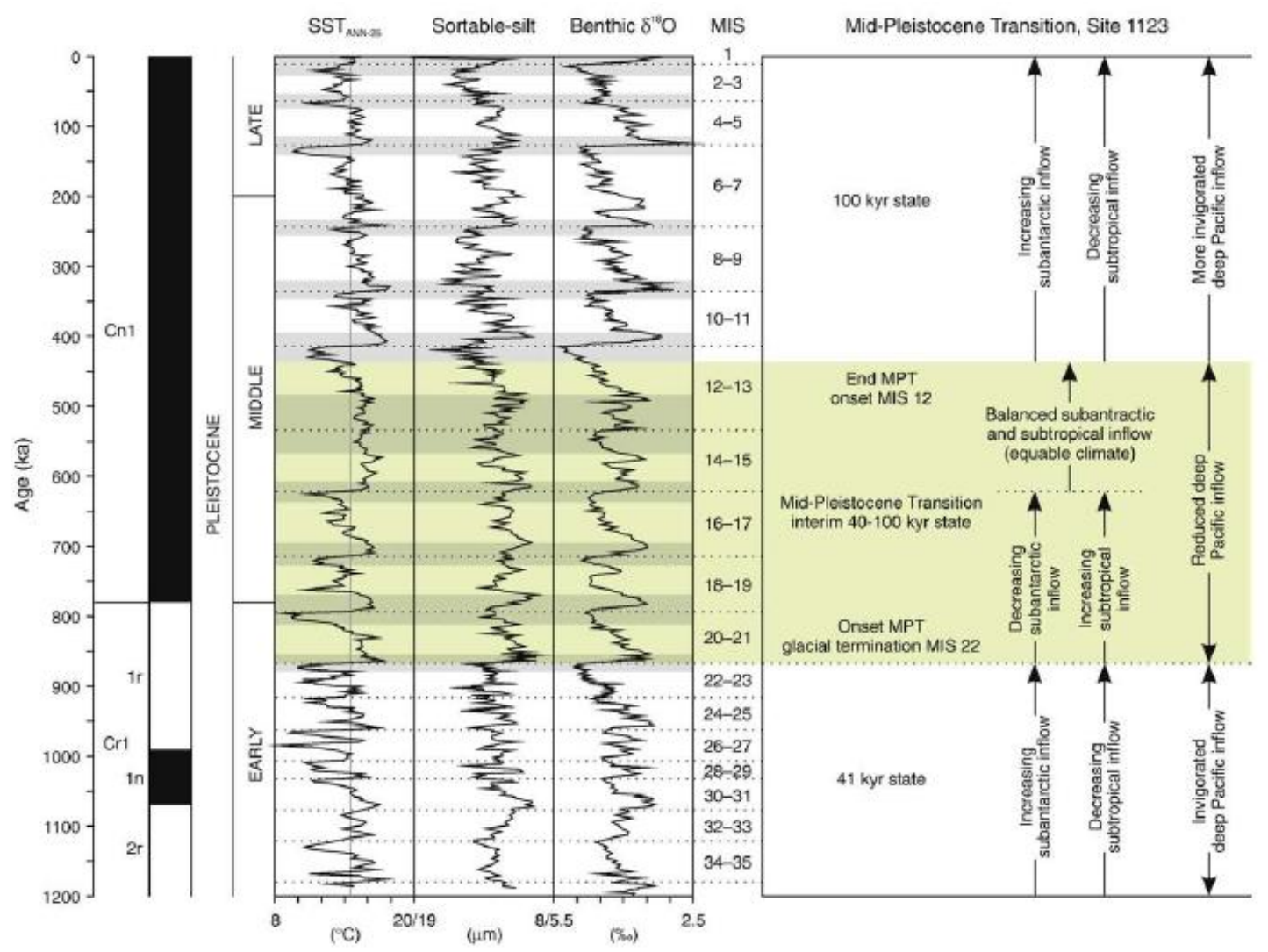

Fig. 2.16 - Summary of surface circulation at ODP Site 1123 for the past 1.2 Myr, with the MPT highlighted. Sortable-silt and benthic $\delta^{18} \mathrm{O}$ data from Hall et al. 2001. Diagram from Crundwell et al. (2008)

Relative changes in the abundances of climate-related taxonomic groups were used in this study to record different water temperature signals during glacial-deglacial transitions (Fig. 2.17). Glacial-deglacial cycles show systematic changes in peak abundances of subantarctic, eutrophic, subtropical and temperate faunal groups (Fig. 2.17). These faunal transitions occur over relatively short periods of time ( $20 \mathrm{kyr})$, and they point to very short periods of cold glacial climate, followed by a peak in productivity (i.e. nutrient mixing) and subsequent very short periods of deglacial climate. The intervening interglacial periods that lasted $\sim 80 \mathrm{kyr}$ are for the most part, characterized by high abundances of temperate species. 


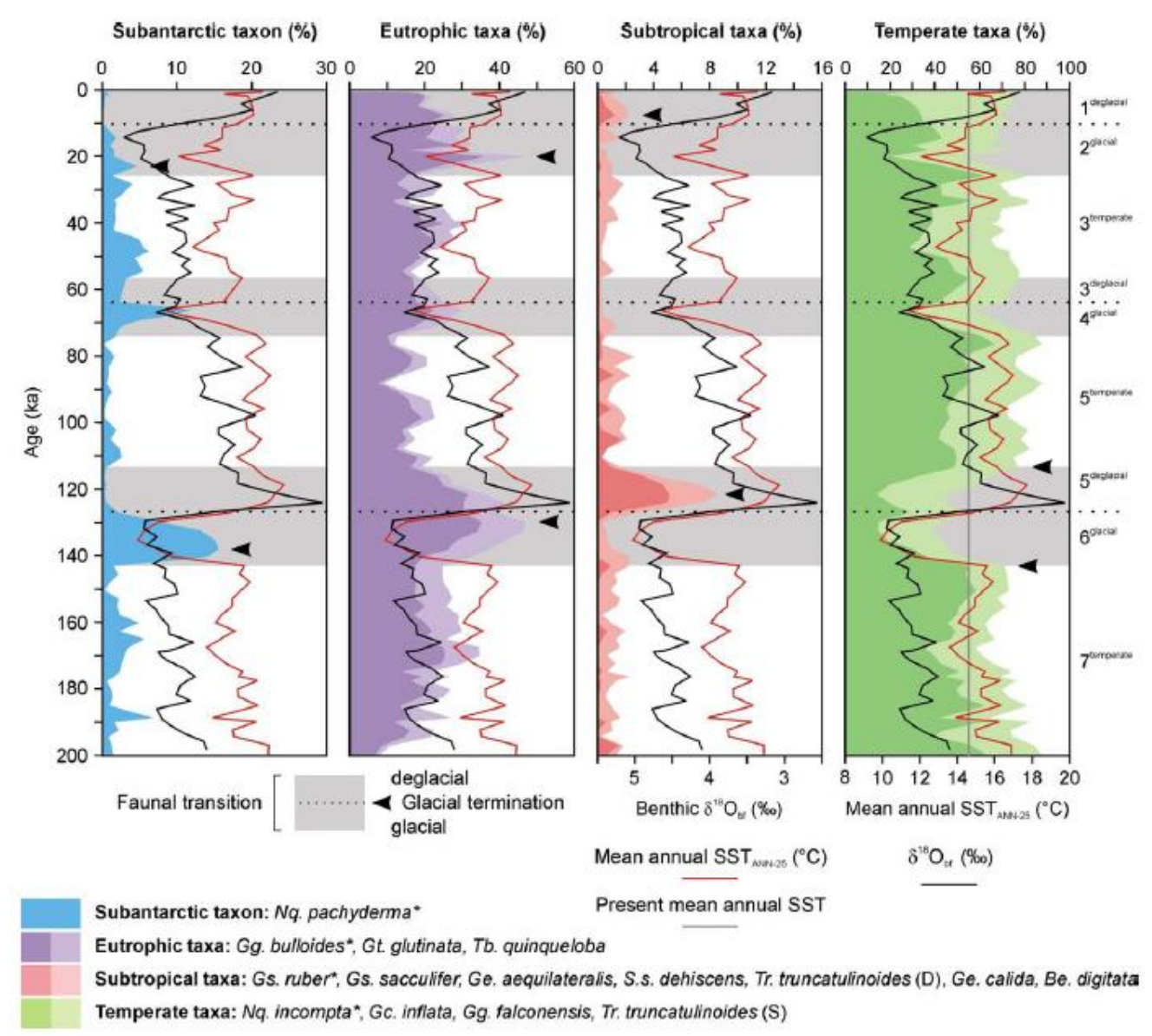

Fig. 2.17 - Faunal change pattern in ODP 1123 during glacial-deglacial transition over $\sim 20$ kyr. Subantarctic taxa indicates glacial maximum. Eutrophic taxa indicates upwelling and early deglacial phase. Subtropical taxa indicate peak warm water inflow and coincide with peak temperatures. Temperate taxa indicate sustained cool-subtropical water state. Diagram from Crundwell et al. (2008)

\subsection{Summary}

Eastern New Zealand has SST records dating back to $~ 1$ myr on both sides of the STF, revealing the surface conditions of STW and SAW during glacial and interglacial periods. These records also show changes to the competing inflows of subtropical water, from the Southwest Pacific Subtropical Gyre, and Subantarctic water from the ACC.

Few paleoceanographic studies have been undertaken off the western side of New Zealand and only a few SST records have been compiled. These records show that during MIS 5e and the early Holocene (early MIS 1), temperatures were warmer than today. Studies also show that the TF migrated northwards of its current position during glacial periods, and that 
off eastern Tasmania, the STF also migrated north during glacial periods. The extent of STF migrations in the mid and eastern Tasman Sea is not known, but it is speculated that it migrated north of its present-day position. 


\subsection{Methodology}

\subsection{Foraminifer Preparation}

\subsubsection{Washing}

88 samples from MD06-2986, dating from 479 ka to $131 \mathrm{ka}$ (MIS 12-6), were processed, sieved and counted by the author. Sample spacing was every $20-25 \mathrm{~cm}$ through the core for an average resolution of $\sim 3.9 \mathrm{kyr}$ per sample. An additional 8 infill samples were counted to increase resolution around certain time periods, to identify any possible higher abundances of species.

The samples were weighed and dried in the oven at $40^{\circ} \mathrm{C}$ overnight. Samples were reweighed and soaked with warm water and a drop of Sunlight dish detergent for one or two days. This helps to disaggregate the sample and makes washing easier. The samples were then washed using a combination of warm and cold water over a $63 \mu \mathrm{m}$ sieve to remove all sediment finer than $63 \mu \mathrm{m}$. Samples were dried for a final time and were weighed (Appendix A).

To prevent contamination, the sink was rinsed before and after washing each sample. Sieves were rinsed and inspected before and after each sample. Methylene blue dye was poured on the sieve mesh to colour any foraminifers stuck in the mesh. If any blue foraminifer turned up in a sample, then it was immediately obvious that it was a contaminant.

\subsubsection{Sieving}

The washed and dried samples were then dry-sieved over three different grain-size fractions: $>150 \mu \mathrm{m}, 63-150 \mu \mathrm{m}$ and $<63 \mu \mathrm{m}$. Each sample was shaken through the sieves by hand for 2-4 minutes each. Each fraction was collected from the sieve, weighed, and stored separately in clean, small jars as a bulk sample.

To prevent contamination, benches were cleaned between each sample. Sieves were cleaned with compressed air to ensure any remnant grains were removed before the next 
sample was sieved. The brush used for recovering samples from storage jars and sieves was also cleaned with compressed air.

\subsubsection{Splitting}

The $>150 \mu \mathrm{m}$ fraction of each sample was systematically split in half using a microsplitter until a target sample weight of between 0.5-1 mg was reached. A microsplitter randomly splits a sample into two parts of roughly equal weight. One part was returned to the bulk sample jar, the other part was put through the splitter again, and the procedure repeated. When the splits became small $(<4 \mathrm{mg})$, all parts were kept in their own separate jar, to ensure that the specimen target for a sample was met without having to resplit the entire sample again.

Each sample was split individually, meaning that no other sample could come in contact while being split. To prevent contamination, the microsplitter, brush, and split jars were cleaned with compressed air before a sample was split. As with other procedures, the laboratory bench was wiped down before and after sample splitting.

\subsubsection{Picking and Identification}

Final samples were emptied onto a picking tray. Using the microscope, foraminifers were picked and grouped on the tray by species. All whole or nearly whole specimens were then counted. A minimum of 200 specimens per sample was the goal for the total assemblage count. Then under 40x magnification (high power), the foraminifers were checked to find any initial mis-identification mistakes. If any specimens were incorrectly identified, they were subsequently moved into their proper group. Specimens were then moved from the picking tray to a labeled microfaunal slide and put in the appropriate boxes. M. Crundwell's (GNS Science) Pleistocene faunal slide map was used for this project.

After all species of planktic and benthic foraminifers were tallied and moved to the microfaunal slide, fragments were also counted and moved to the faunal slide as well. The fragments were counted to be used as a proxy for test dissolution (e.g Le and Shackleton, 1992). When determining if a specimen is a fragment or if it is considered whole, a 
standard criterion was followed. For this project we used the standard of $\sim 50 \%$ of the test intact plus the proloculus. With the proloculus included, it is difficult for one broken specimen to be counted twice, since each test only has one proloculus.

39 samples were counted by Dr. Martin Crundwell, for the period from $130 \mathrm{ka}$ to present day (MIS 5-1). His sample spacing was every $\sim 30 \mathrm{~cm}$ for an average resolution of $\sim 3.3 \mathrm{kyr}$ per sample. An additional 27 infill samples were counted to increase the resolution of the data. The same method of picking and counting faunas were employed by Dr. Crundwell. However, he picked a minimum of 300 planktics per sample compared to the minimum of 200 used by the author (see Table 3.1 for list of species identified from MD06-2986). Census data were then tabulated on a worksheet (Appendix A), and species were grouped according to a biogeographical classification (e.g. Crundwell et al. 2008).

\subsection{Modern Analogue Technique}

MAT compares the similarity between down-core (fossil) assemblage to a core-top (present day) microfaunal assemblage database (e.g. the SH1204 coretop database from Crundwell et al. 2008 (Fig. 3.1) by using geometric distances (squared chord distance). The squared chord distance is a measure of the number of specimens of a species in a fossil assemblage compared to the number of the same species in a present day assemblage. This formula is represented by:

$$
D_{i j}=\Sigma_{\mathrm{k}=1}^{\mathrm{k}}\left(\sqrt{\mathrm{X}_{\mathrm{ik}}}-\sqrt{\mathrm{X}_{\mathrm{jk}}}\right)^{2}
$$

where $D_{i j}$ is the squared chord distance between two multivariate samples $i$ and $j, k=$ number of species in a sample, and $\mathrm{x}_{\mathrm{ik}}$ and $\mathrm{x}_{\mathrm{jk}}$ is the proportion of species $\mathrm{k}$ in samples $\mathrm{i}$ and $\mathrm{j}$. This equation is run for every species of a sample against the core-top assemblage database. The shortest geometric distance, and hence, smallest squared chord distance represents the best match between fossil and present-day faunas. The measured SSTs from the five most similar present-day faunas (modern analogues) are averaged to give an estimation of SST for each fossil fauna. For an in-depth explanation, see Hutson, (1980) and Prell, (1985). 


\subsection{Artificial Neural Network}

ANN is a non-linear statistical data modeling tool. ANN mimics human learning by using a complicated system of algorithms in which the network learns similarities between input data and target data. ANN operates by building a model that reflects the relationship between the input and target data, (in this case, present-day coretops and associated SSTs as typically derived from ship-borne or satellite observations). This is known as the training mode, or model building mode. In this model building mode, the neural network adaptively adjusts weights on input data (census counts) in a way that minimizes errors in their use as estimators of the target data (SSTs) (see Table 3.2). In paleoceanographic studies, this model, which is effectively a transfer function, can be applied to microfossil faunas with compositions that are similar to the modern faunas to give an estimate for paleo-SST. The neural network used in this study is the same as that used by Crundwell et al. (2008). The ranks and weighting of species has not changed (Table 3.2), nor have the distribution and number of coretops from the SH1204 database. For a full explanation of ANN, see Malmgren and Nordlund, (1997) and Malmgren et al. (2001). 
Table 3.1

\section{Species identified in MD06-2986}

Neogloboquadrina incompta (Cifelli, 1961)

Neogloboquadrina dutertrei (D) (d'Orbigny, 1839)

Globoconella inflata (d'Orbigny, 1839)

Globigerina bulloides (d'Orbigny, 1826)

Neogloboquadrina pachyderma (Ehrenberg, 1861)

Neogloboquadrina dutertrei s.1. S (d'Orbigny, 1839)

Globigerinita glutinata (Egger, 1893)

Truncorotalia truncatulinoides (S) (d'Orbigny, 1839)

Truncorotalia cavernula S (Bé, 1967)

Truncorotalia crassula (Cushman and Stewart, 1930)

Turborotalita quinqueloba (Natland, 1938)

Globigerinoides ruber (d'Orbigny, 1939)

Orbulina universa (d'Orbigny, 1839)

Orbulina bilobata (d'Orbigny, 1839)

Globigerina falconensis (Blow, 1959)

Globigerinella aequilateralis (Brady, 1879

Truncorotalia truncatulinoides (D) (d'Orbigny, 1939)

Hirsutella scitula (Brady, 1882)

Globigerinella obesa (Bolli, 1957)

Table 3.1 - Species (and

Beella digitata (Brady, 1879)

Hirsutella hirsuta (d'Orbigny, 1839)

authors) identified in this study from MD06-2986

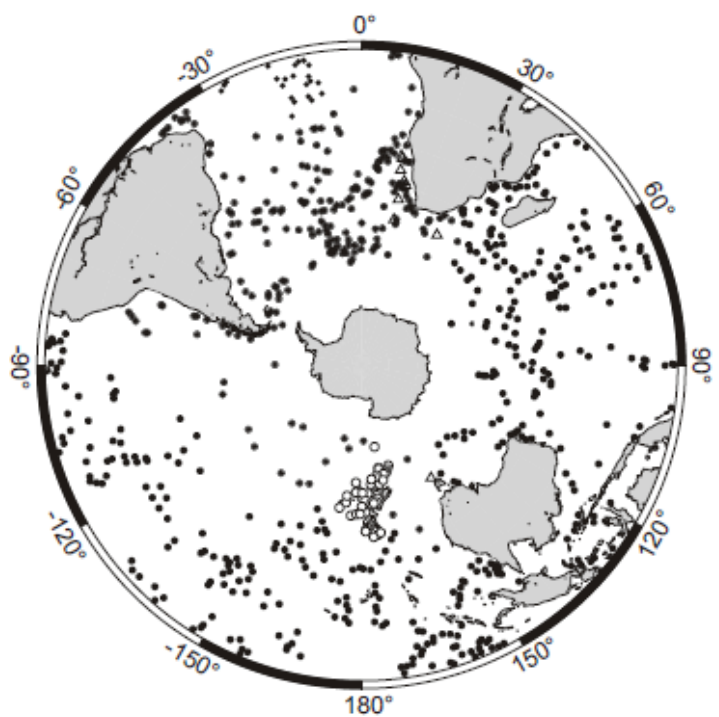

Fig 3.1 - Distribution of Southern Hemisphere coretops from the $\mathrm{SH} 1204$ database. From Crundwell et al. (2008) 
Table 3.2

\begin{tabular}{|c|c|c|c|c|c|c|c|}
\hline ANN-35 taxa & Rank & Weighting & Abundance (\%) & ANN-25 taxa & Rank & Weighting & Abundance (\%) \\
\hline Neogloboquadrina pachyderma & 1 & 1.000 & 5.36 & $\begin{array}{l}\text { Neogloboquadrina } \\
\text { pachyderma }\end{array}$ & 1 & 1.000 & 7.46 \\
\hline Globigerinoides ruber & 2 & 0.344 & 0.39 & Pulleniatina obliquiloculata & 2 & 0.897 & - \\
\hline Pulleniatina obliquiloculata & 3 & 0.304 & - & Globigerina falconensis & 3 & 0.740 & 0.77 \\
\hline Truncorotalia truncatulinoides $(S)^{*}$ & 4 & 0.251 & 6.52 & Globigerinoides ruber & 4 & 0.714 & 1.32 \\
\hline Globigerina falconensis & 5 & 0.191 & 0.55 & Neogloboquadrina incompta & 5 & 0.585 & 35.03 \\
\hline Menardella menardii* & 6 & 0.187 & - & Beella digitata & 6 & 0.395 & 0.07 \\
\hline Globigerinella aequilateralis & 7 & 0.177 & 0.30 & Shaeroidinella dehiscens & 7 & 0.312 & - \\
\hline Globoconella inflata* & 8 & 0.137 & 20.15 & Globorotaloides hexagona & 8 & 0.302 & - \\
\hline Neogloboquadrina dutertrei & 9 & 0.134 & 1.02 & Neogloboquadrina dutertrei & 9 & 0.269 & 1.42 \\
\hline Truncorotalia truncatulinoides $(D)^{*}$ & 10 & 0.124 & 0.21 & Globigerinella aequilateralis & 10 & 0.265 & 0.42 \\
\hline Zeaglobigerina rubescens & 11 & 0.101 & 0.08 & Globigerina bulloides & 11 & 0.257 & 37.85 \\
\hline Globigerina bulloides & 12 & 0.091 & 27.19 & Globoquadrina conglomerata & 12 & 0.204 & - \\
\hline Globoquadrina conglomerata & 13 & 0.069 & - & Turborotalita quinqueloba & 13 & 0.160 & 9.64 \\
\hline Orbulina universa & 14 & 0.069 & 0.58 & Zeaglobigerina rubescens & 14 & 0.152 & 0.11 \\
\hline Globigerinita glutinata & 15 & 0.060 & 4.23 & Orbulina universa & 15 & 0.146 & 0.80 \\
\hline Globorotaloides hexagona & 16 & 0.059 & - & Globigerinoides tenellus & 16 & 0.141 & \\
\hline Turborotalita humilis & 17 & 0.052 & - & Globigerinita glutinata & 17 & 0.134 & 5.88 \\
\hline Globigerinoides conglobatus & 18 & 0.046 & - & Globigerinoides conglobatus & 18 & 0.059 & \\
\hline Hirsutella hirsuta* & 19 & 0.044 & 0.13 & Globigerinella adamsi & 19 & 0.047 & \\
\hline Shaeroidinella dehiscens & 20 & 0.042 & - & Candeina nititda & 20 & 0.040 & \\
\hline Globigerinella adamsi & 21 & 0.037 & - & Globigerinita iota & 21 & 0.039 & \\
\hline Globigerinoides sacculifer & 22 & 0.037 & - & Globigerinoides sacculifer & 22 & 0.024 & \\
\hline Candeina nititda & 23 & 0.029 & - & Globigerinita uvula & 23 & 0.015 & \\
\hline Truncorotalia crassiformis ${ }^{*}$ & 24 & 0.028 & 0.01 & Turborotalita humilis & 24 & 0.005 & \\
\hline Hirsutella theyeri* & 25 & 0.027 & - & Globigerinella calida & 25 & 0.003 & \\
\hline Turborotalita quinqueloba & 26 & 0.020 & 6.92 & & & & \\
\hline Globigerinita uvula & 27 & 0.018 & - & & & & \\
\hline Globigerinita iota & 28 & 0.016 & - & & & & \\
\hline Neogloboquadrina incompta & 29 & 0.016 & 25.16 & & & & \\
\hline Globigerinoides tenellus & 30 & 0.014 & - & & & & \\
\hline Globigerinella calida & 31 & 0.013 & - & & & & \\
\hline Beella digitata & 32 & 0.010 & 0.05 & & & & \\
\hline Tenuitella anfracta & 33 & 0.007 & - & & & & \\
\hline Hirsutella scitula* & 34 & 0.003 & 0.66 & & & & \\
\hline Truncorotalia crassula* & 35 & 0.002 & 0.28 & & & & \\
\hline
\end{tabular}

Table 3.2 - Ranks and weighting of planktic foraminifera for ANN 35 and ANN 25 models, based on the SH1204 coretop database (modified after Crundwell et al., 2008) 


\subsection{Results}

\subsubsection{Overview}

This chapter documents the planktic faunal composition of MD06-2986, followed by the SST results derived using the Modern Analogue Technique (MAT) and an Artificial Neural Network (ANN), a comparison of MD06-2986 SSTs and oxygen isotopes to determine age correlation, and finally the dissolution and productivity proxies.

It is important to mention that assemblage work for this study was performed by two workers. The author contributed all assemblages from the beginning of MIS 12 (479 ka) to the end of MIS 6 (131 ka). Dr. Martin Crundwell (MC) contributed all assemblages from the beginning of MIS 5 (130 ka) to the top of the core (present day).

\subsection{Faunal Composition}

\subsubsection{Taxonomic groupings}

Taxonomic groupings used in this study are based on the SH1204 coretop assemblage database (Fig. 3.1) which has been used to identify groups of species based primarily on geographical location and temperature data in the southern hemisphere (e.g. Crundwell et al., 2008). Most common are species found in water north and south of the Tasman Front, north and south of the Subtropical Front, and cool subtropical waters in between (Figs. 4.14.5). The five main taxonomic groups are:

Temperate taxa: This group is also known as the cool subtropical water taxa and is most commonly found in waters between the TF and the STF (Fig 4.1). The temperate taxonomic group is dominated by Neogloboquadrina incompta and Globoconella inflata, and includes Globigerina falconensis and Truncorotalia truncatulinoides. 


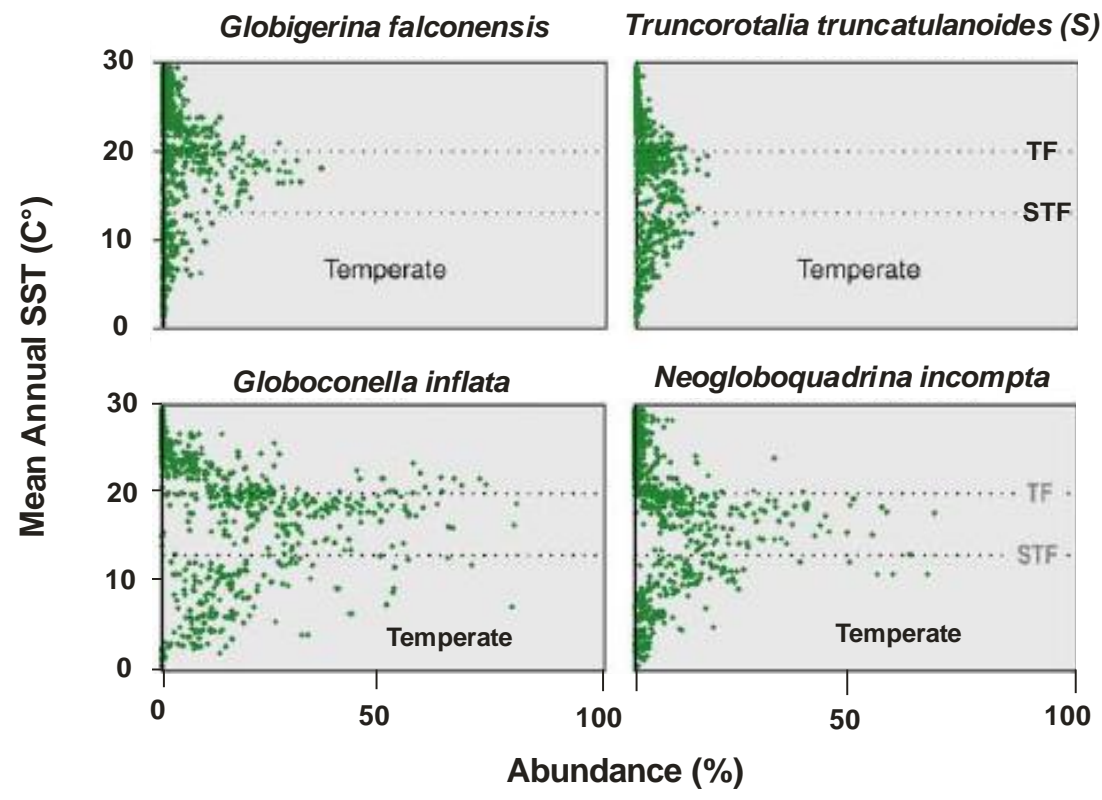

Fig 4.1 - Biogeographical locations of temperate species based on the SH1204 coretop database. Peak abundances indicate location and temperature conditions in the Southwest Pacific Ocean where species flourish. Dashed lines indicate location of Tasman Front (TF) and Subtropical Front (STF). Modified after Crundwell et al. (2008)

Subtropical taxa: This group refers to species most frequently located north of the TF (Fig 4.2). It is recognized by a high abundance of Globigerinoides ruber, and Neogloboquadrina dutertrei (D), with additional contributions of Globigerinoides sacculifer, Globigerinella aequilateralis, Sphaeroidinellopsis dehiscens, Truncorotalia truncatulinoides dextral coiling form (D), and Beella digitata.

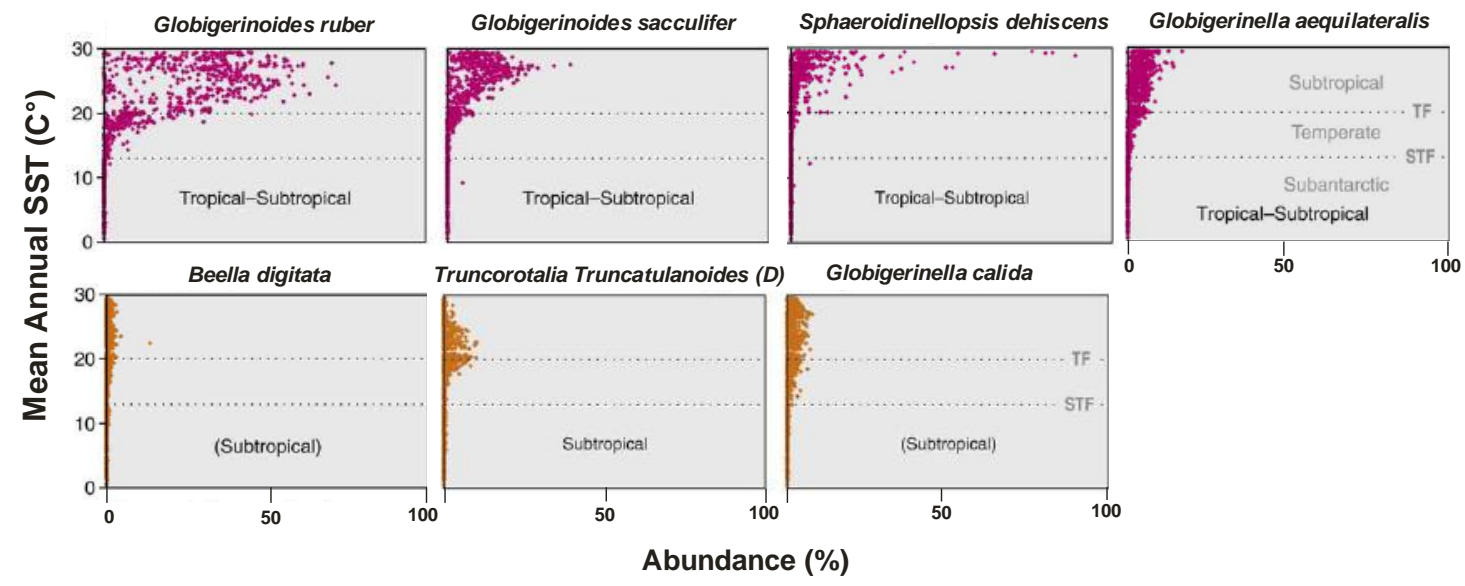

Fig 4.2 - Biogeographical locations of tropical and subtropical species based on the SH1204 coretop database. Peak abundances indicate location and temperature conditions in the Southwest Pacific Ocean where species flourish. Dashed lines indicate location of Tasman Front (TF) and Subtropical Front (STF). Modified after Crundwell et al. (2008) 
Eutrophic taxa: Taxa are assigned to this group on the basis of their preference for nutrient availability, rather than being temperature dependent (Boersma et al., 1998). Therefore a high abundance indicates high productivity and available nutrients, and is not necessarily an indicator of specific water temperature or location (Fig 4.3). Eutrophic taxa include Globigerina bulloides, Globigerinita glutinata and Turborotolita quinqueloba. All three species can be present in other taxonomic groups.
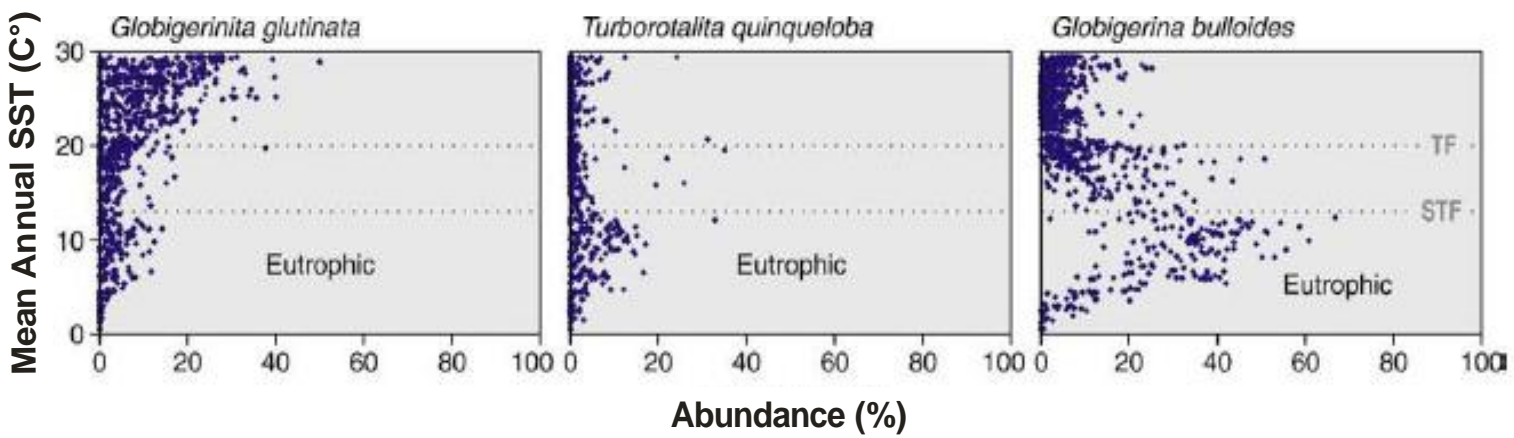

Fig. 4.3 - Biogeographical locations of eutrophic species based on the SH1204 coretop database. Peak abundances indicate location and temperature conditions in the Southwest Pacific Ocean where species flourish. Dashed lines indicate location of Tasman Front (TF) and Subtropical Front (STF). Modified after Crundwell et al. (2008)

Subantarctic taxa: This taxonomic group has a high abundance of Neogloboquadrina pachyderma, Neogloboquadrina dutertrei (S) and small contributions of Neogloboquadrina. incompta, and eutrophic species Gg. bulloides, Tb. quinqueloba and Globigerinita glutinata. This taxonomic group is typically found south of the STF and is a cold water indicator (Fig 4.4).

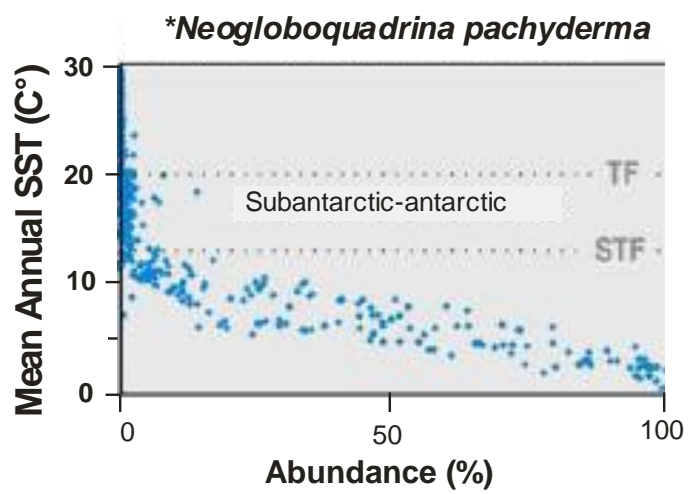

Fig. 4.4 - Biogeographical locations of Neogloboquadrina pachyderma based on the SH1204 coretop database. Biogeographical data for Neogloboquadrina dutertrei (S) is not available. Peak abundances indicate location and temperature conditions in the Southwest Pacific Ocean where species flourish. Dashed lines indicate location of Tasman Front (TF) and Subtropical Front (STF). Modified after Crundwell et al. (2008) 
near the TF (Fig. 4.5). This group contains Orbulina universa, Hirsutella hirsuta, Hirsutella scitula, Truncorotalia crassiformis, Truncorotalia crassula and Neogloboquadrina dutertrei (D).

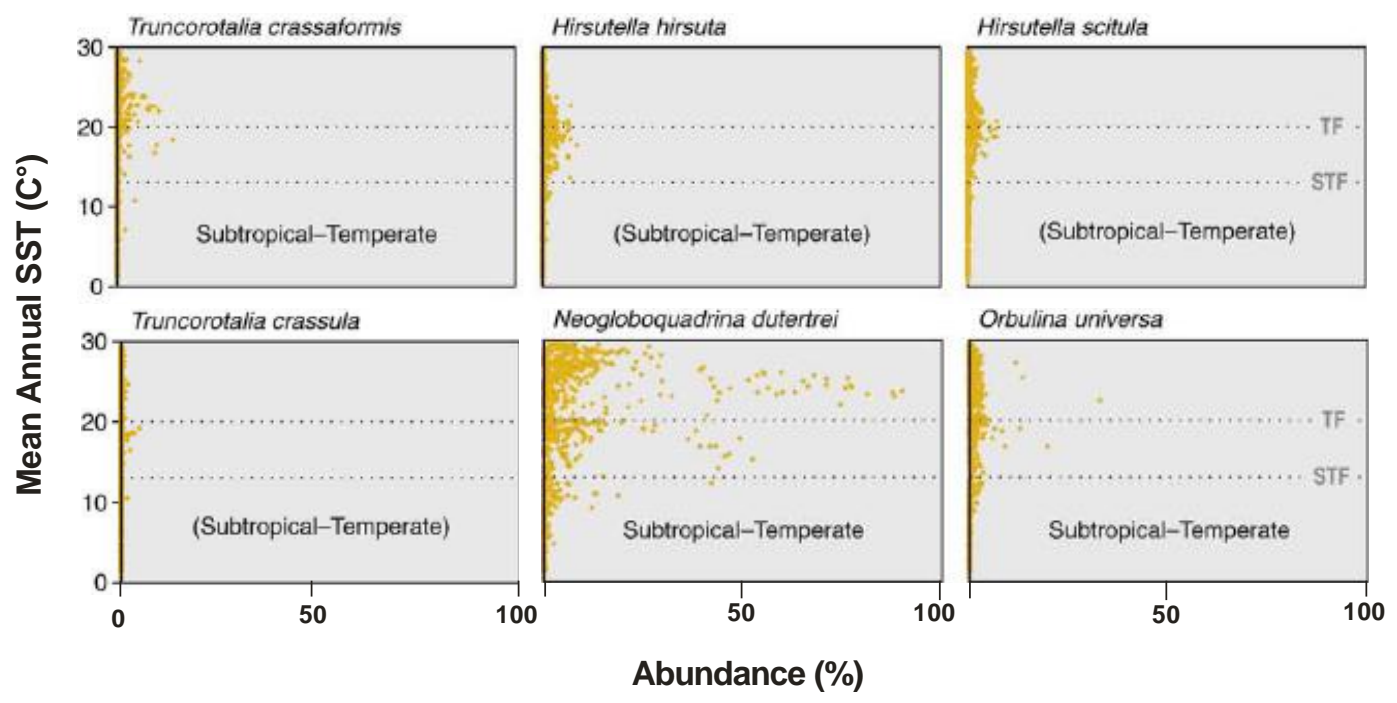

Fig 4.5 - Biogeographical locations of subtropical/temperate species based on the SH1204 coretop database. Peak abundances indicate location and temperature conditions in the Southwest Pacific Ocean where species flourish. Dashed lines indicate location of Tasman Front (TF) and Subtropical Front (STF). Modified after Crundwell et al. (2008)

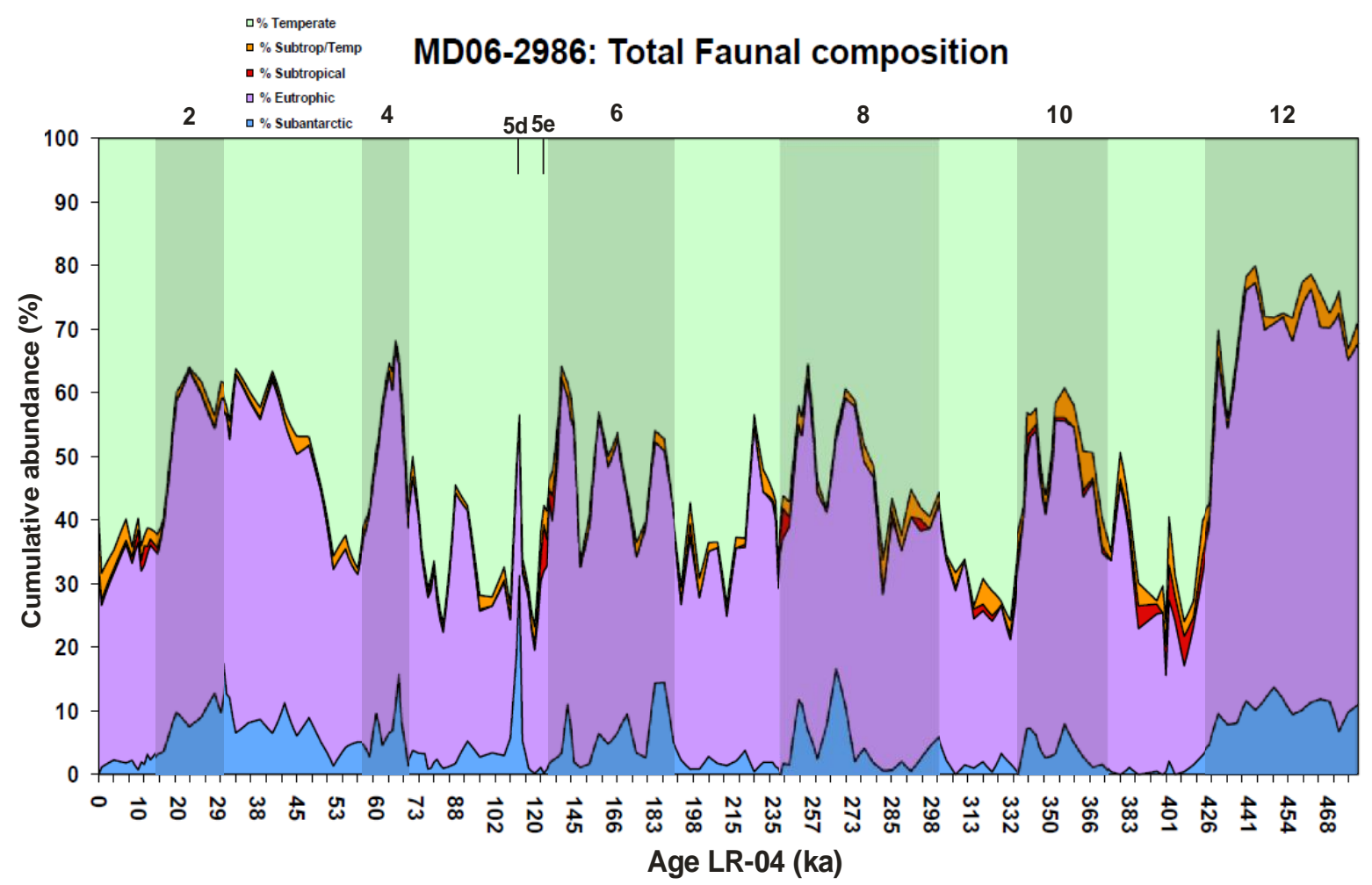

Fig. 4.6 - Total cumulative faunal composition of MD06-2986. Shaded areas indicate glacial periods with appropriate Marine Isotope Stage number above. Blue-subantarctic taxa. Purple-eutrophic taxa. Redsubtropical taxa. Orange-subtropical-temperate taxa. Green-temperate taxa. Note timescale is based on MD062986 age model timings, however, chart type restricted freedom for formatting $\mathrm{X}$-axis. 


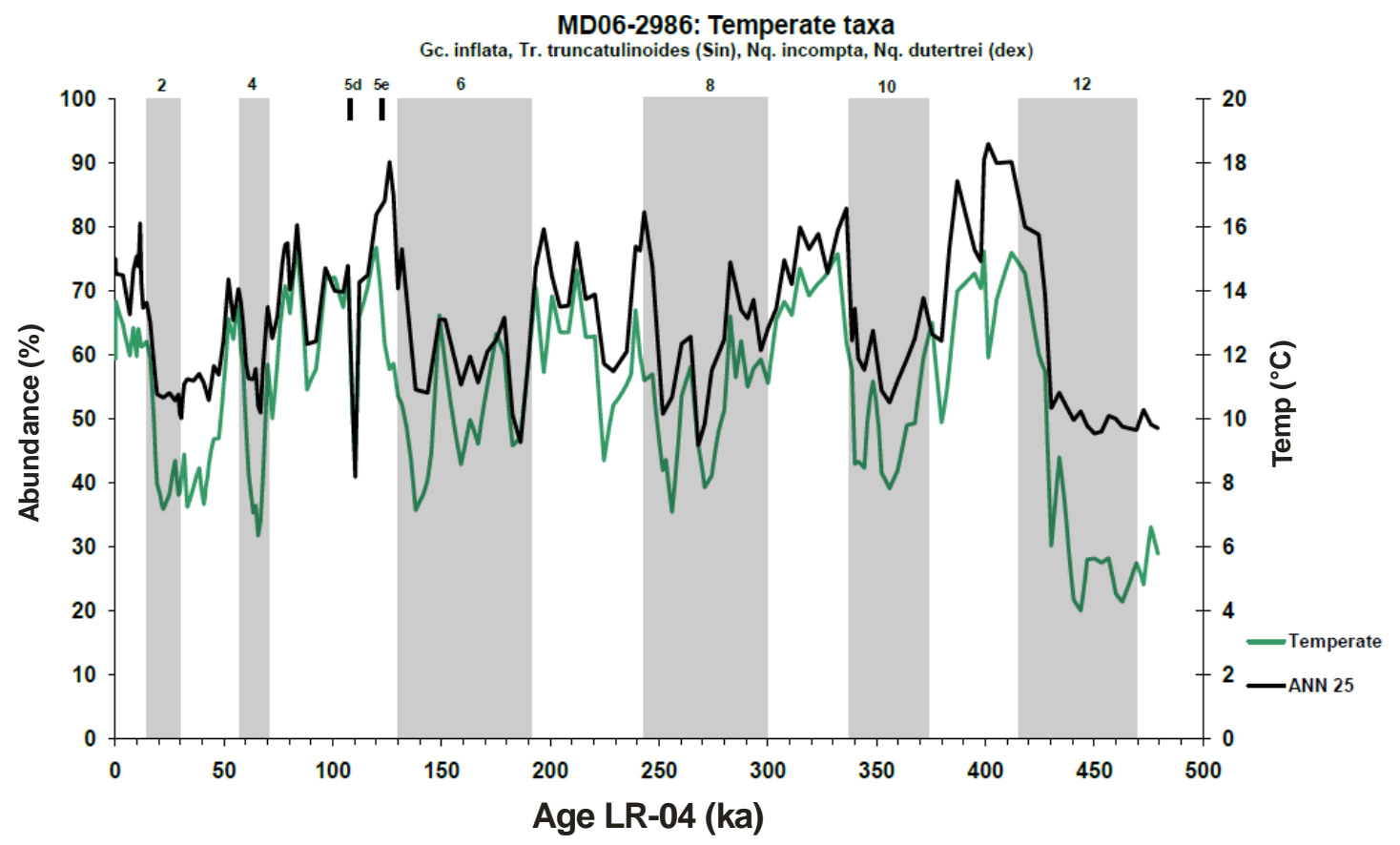

Fig. 4.7 - Temperate taxa and ANN 25 from MD06-2986

The total faunal assemblage composition of MD06-2986 allows inferences of water mass type and changes to be tracked through time, in this case from MIS 12-1 (Fig. 4.6). Faunal data show excellent G-IG cyclicity.

In MIS 12, the temperate taxa of the assemblages comprise only $25-30 \%$ (Fig. 4.7). This percentage then increases sharply towards the 12/11 glacial-interglacial transition. After MIS 12, the record is mostly dominated by the temperate taxa, which reach abundances of $\sim 35-75 \%$ per sample (average $\sim 53 \%$ ). The overall trend of the temperate taxa shows high abundance in the beginning of some interglacials, with a gradual decrease to the end of glacials, followed by a sudden rise at the beginning of the next interglacial. This cycle occurs between 80-120 kyr. In glacial stages, the abundance of temperate taxa are relatively high ( $\sim 55-65 \%)$ during the early part of the stage, then decrease towards the end of the glacial. This is evident in all glacial stages, with the exception of MIS 12, where the eutrophic taxa dominate throughout and in MIS 6 and 2, where abundances average $\sim 40$ $45 \%$. Temperate taxa dominate all interglacial stages, with abundances of $65-75 \%$. Highest abundances $(\sim 75 \%)$ occur at the start of MIS 11, 9 and 5e, followed by a gradual reduction $(\sim 65 \%)$ at the end of the interglacial. MIS 7 and 1 have an opposite trend, when high abundance is attained at the middle or end of the interglacial. The abundance of the 
temperate taxa varies between 55-75\% throughout MIS 5, with an exceptionally low abundance of $\sim 45 \%$ in MIS $5 \mathrm{~d}$.

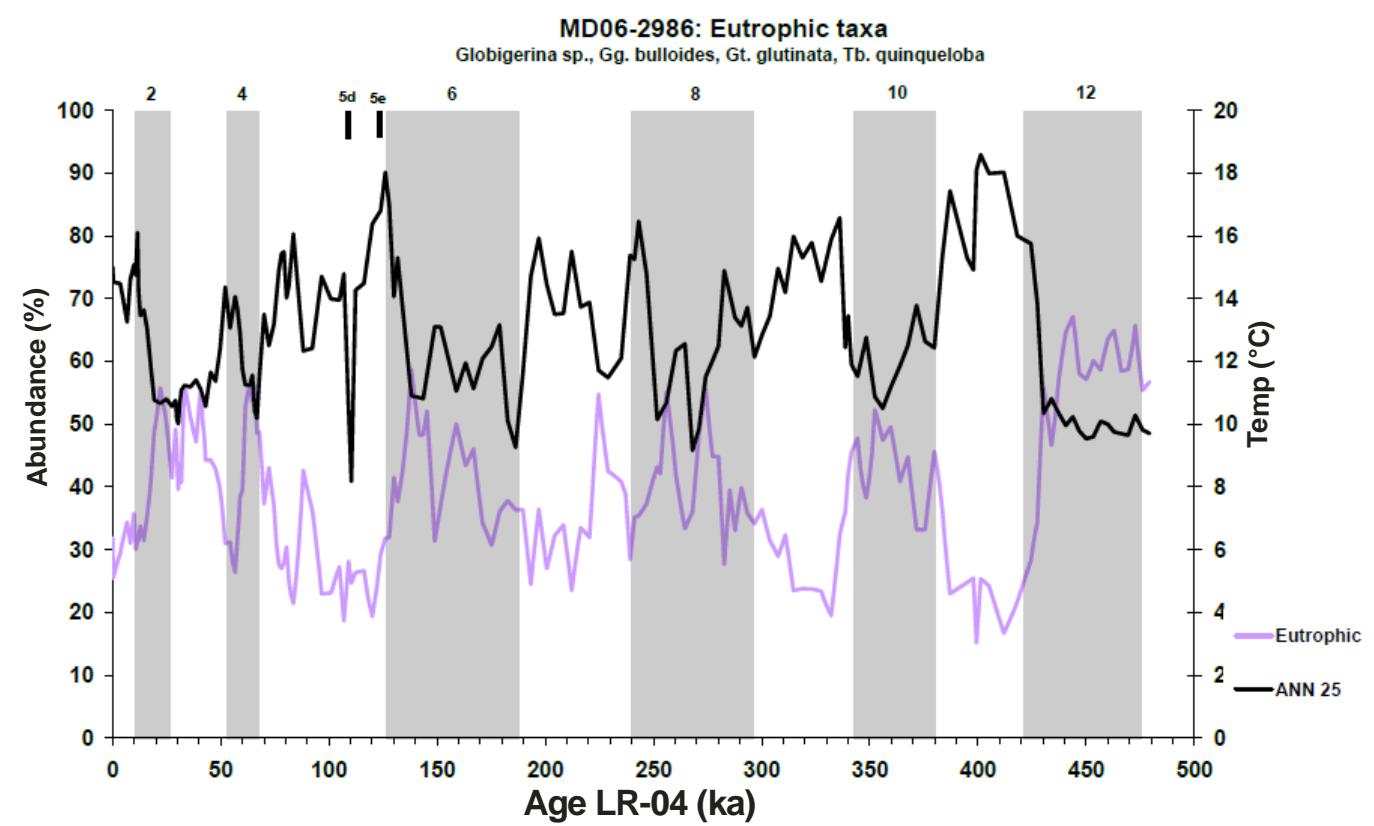

Fig. 4.8 - Eutrophic taxa and ANN 25 from MD06-2986

The eutrophic taxonomic group is the second most dominant of the record, averaging 39\% abundance throughout. The eutrophic taxa appear to have an opposite pattern to their temperate counterparts (Fig. 4.8). The overall trend of the eutrophic taxa is a low abundance ( $25-30 \%)$ in the beginning of an interglacial, with gradually increasing abundances to peak glacial conditions, followed by a rapid decrease back to interglacial conditions. The highest abundances of eutrophic taxa are in glacial periods $(\sim 50 \%)$ and their lowest abundances in interglacials (20-35\%). There is a notable exception to this in MIS 7. Abundances of $65 \%$ are recorded here, and this seems peculiar given that abundances return to peak glacial abundances of MIS 8. MIS 12 is dominated by the eutrophic taxa with abundances of $\sim 55-65 \%$ throughout most of the stage. 


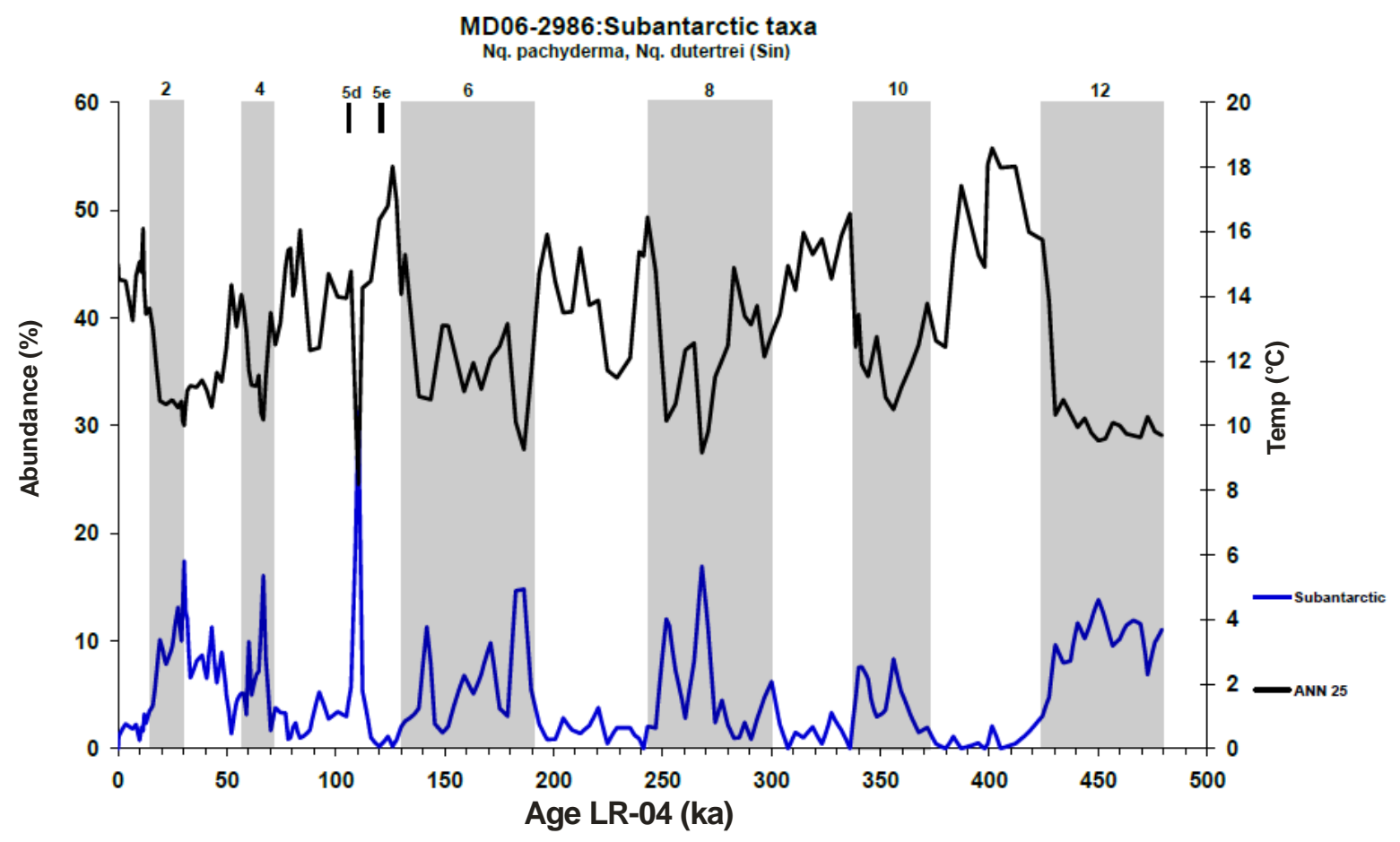

Fig. 4.9 - Subantarctic taxa and ANN 25 from MD06-2986

The subantarctic taxa have minimal abundance throughout the record (average $\sim 5.1 \%$ ), particularly in interglacial periods (Fig. 4.9). MIS 12 contains the longest sustained abundance, comprising 8-13\% of the assemblages. MIS 8, 6, 4 and 2 have small spikes between $10-17 \%$. The abundance of subantarctic species in MIS 10 is $<10 \%$, indicating little cold water influence during that stage. The subantarctic taxa are insignificant in interglacials $11,9,7$, and 1, comprising less than $\sim 3 \%$. An anomalous subantarctic abundance occurs in MIS 5d at 110ka with a 33\% abundance. This is surprising since it is the highest subantarctic abundance of the record and it occurs during an interglacial. It is also important to note that the morphotypes of the $N q$. pachyderma in this sample are not typical of the compact-coiled Nq. pachyderma, and are more lobate (Martin Crundwell, pers. comms.). Darling et al. (2006) showed that Nq. pachyderma can be subdivided into 5 different molecular types based on RNA gene sequences. This raises the possibility that different types of $N q$. pachyderma may prefer to live strictly in either high-latitude polar regions, or mid-latitude subpolar regions, and therefore, may have an effect on analogue SST estimations. Regardless, the unusually high abundance of $N q$. pachyderma in MIS 5d may indicate an unusual climatic event in the New Zealand region during this period, or could indicate anomalous surface circulation, and will be discussed in greater detail in chapter 5. Another anomalous subantarctic taxa abundance peak occurs at the MIS 3-2 
transition, with an abundance of $\sim 17.4 \%$. This abundance is higher than any glacial period for the record, and may indicate that MIS 3 was not a particularly warm interglacial period, and could be classified more as an interstadial, rather than a true interglacial. A third anomalous feature is the unusual timing of peak subantarctic abundance in MIS 6 . The highest abundance $(\sim 15 \%)$ occurs in the beginning of the stage at $186 \mathrm{ka}$. Subsequent peaks are $9.8 \%$ and $11.3 \%$.
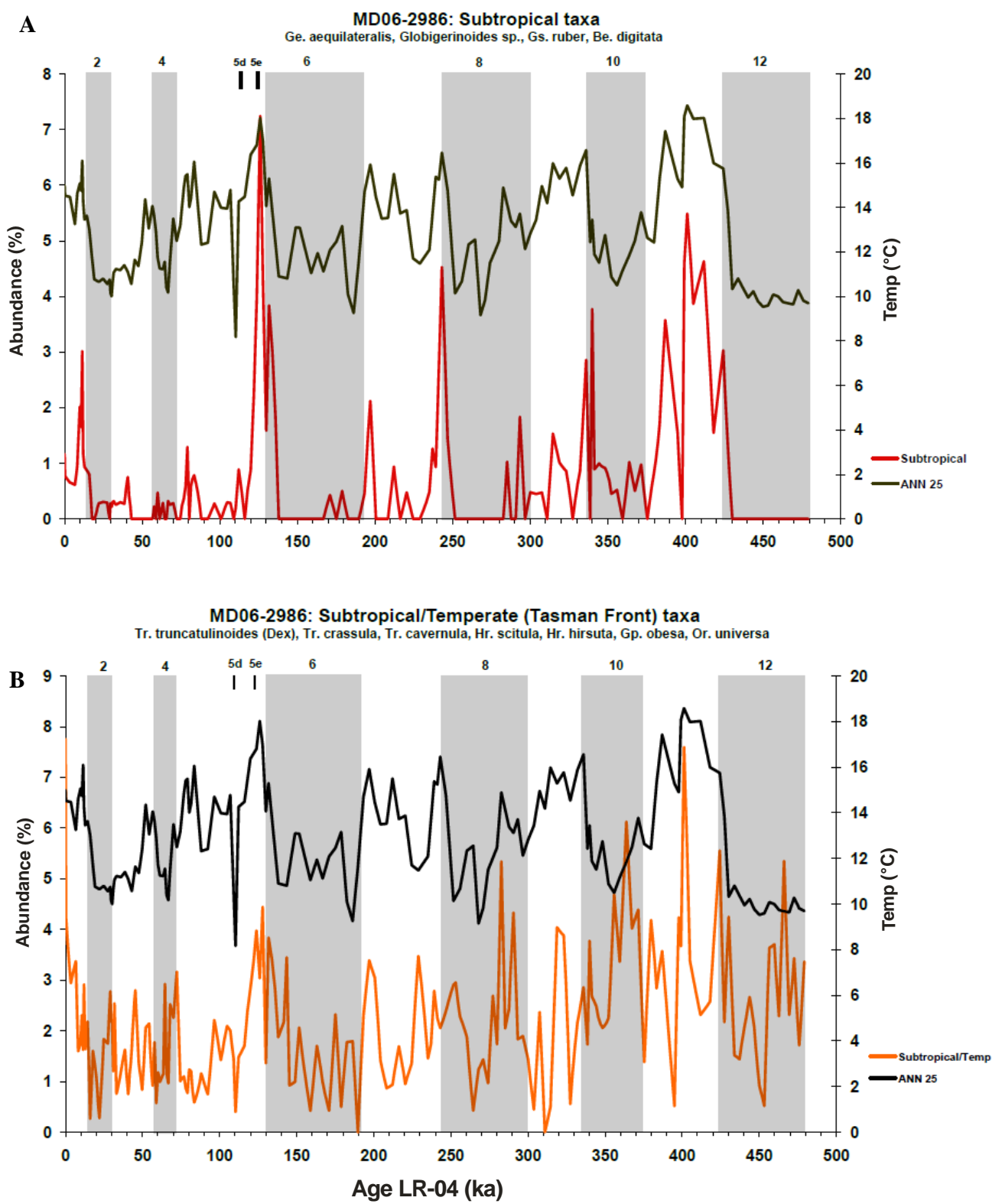

Fig. 4.10A - Subtropical taxa and ANN 25 from MD06-2986. Fig. 4.10B-Subtropical/Temperate taxa and ANN 25 from MD06-2986.

Subtropical and subtropical/temperate taxa represent only a minor part of the assemblages

(Figs. 4.10A, B). Highest abundances for subtropical and subtropical/temperate taxa are 
7.2\% (MIS 5e) and 7.8\% (MIS 1), respectively, and average 0.6-2.1\%. This indicates that very little warm subtropical water reaches the southern Challenger Plateau. The highest abundance of subtropical taxa occurs during "super-interglacials" MIS 11 and 5e, giving biological evidence that these were indeed unusually warm periods. There is no subtropical signal in MIS 12, further giving evidence that MIS 12 is unusually cold. Interestingly however, small but significant abundances ( $-5-6 \%)$ of subtropical/temperate taxa occur in MIS 12, MIS 10 and MIS 8 . The significance of all faunal data will be discussed in greater detail in the next chapter.

\subsection{SSTs}

Nomenclature needs to be addressed here to prevent confusion for the SST sections.

"Method" will be used when describing and comparing different sets of SST records, such as $\operatorname{SST}_{\mathrm{ANN}}$ with $\mathrm{SST}_{\mathrm{MAT}}$, i.e., "The two methods are in good agreement with each other." "Model" will be used to describe a specific 25 or 35 (or both) SST method, i.e., “...both MAT models show..."

SST results of each method will be presented individually, with a description of overall features of the record. Two databases of 891 southern hemisphere core tops were used to estimate SSTs. The SH1204-35 database includes 35 taxa; the SH1204-25 model excludes the 10 Globorotaliid taxa, which have many adult specimens living around the thermocline (e.g. Crundwell et al. 2008). Ideally for SST estimates, only those species living closer to surface waters should be included. 

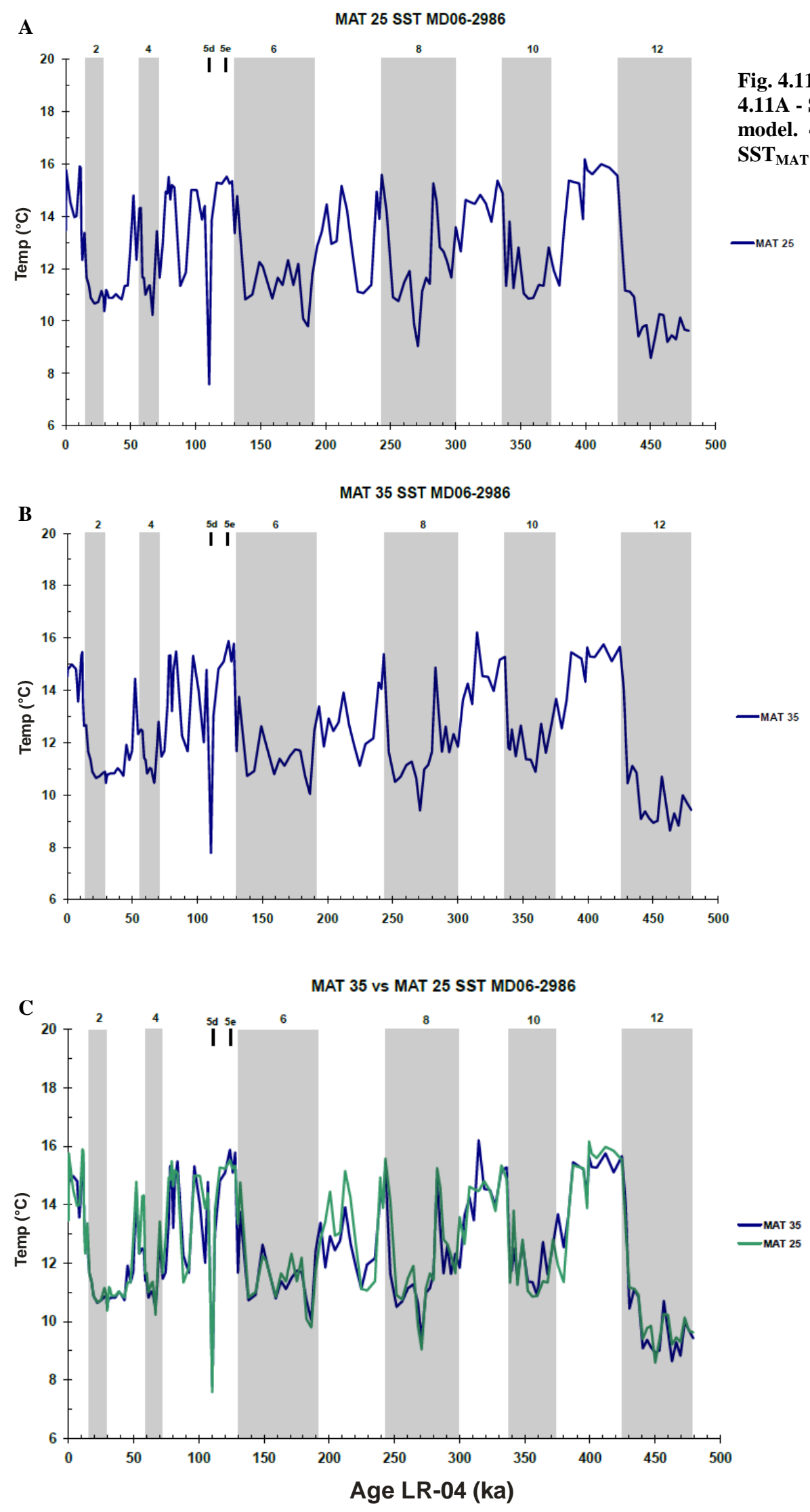
$\mathrm{SST}_{\mathrm{MAT}}$ estimates show excellent glacial-interglacial (G-IG) cyclicity throughout the record. The highest temperature in both models is $16.2^{\circ} \mathrm{C}$; however it is recorded at different times. SST $_{\text {MAT } 25}$ (Fig. 4.11A) records the highest temperature at $399 \mathrm{ka}$ in MIS 11, and $\mathrm{SST}_{\text {MAT } 35}$ (Fig. 4.11B) records it at $312 \mathrm{ka}$ in MIS 9. The lowest temperature for $\mathrm{SST}_{\text {MAT25 }}$ is $7.6^{\circ} \mathrm{C}$, and the lowest temperature for $\mathrm{SST}_{\text {MAT35 }}$ is $7.8^{\circ} \mathrm{C}$ in MIS 5d at $110 \mathrm{ka}$; however this is viewed with caution because of the limited number of control points. A comparison between the models shows that both SST estimates are in good agreement with each other, barring a few exceptions (Fig. 4.11C). SST MAT 35 estimates that SST in the MIS 11-10 transition is $\sim 2^{\circ} \mathrm{C}$ higher than $\mathrm{SST}_{\text {MAT } 25}$, and $1.5^{\circ} \mathrm{C}$ higher at $363 \mathrm{ka}$ in MIS 10. In MIS 9, $\mathrm{SST}_{\text {MAT } 35}$ estimates SST $\sim 1.7^{\circ} \mathrm{C}$ higher at $314 \mathrm{ka}$. Conversely, $\mathrm{SST}_{\text {MAT } 25}$ estimates SST $1.2^{\circ} \mathrm{C}$ and $1.5^{\circ} \mathrm{C}$ higher in MIS 7 at $212 \mathrm{ka}$ and $200 \mathrm{ka}$, respectively.

Comparison of both models (Fig. 4.11C) shows that MIS 12 is the most prolonged cold period of the record, with sustained SSTs of $\sim 9^{\circ} \mathrm{C}$ for most of the interval. After MIS 12, the maximum cooling of any glacial period does not dip far below $11^{\circ} \mathrm{C}$, except for sharp drops during glacial periods 8, 6, and 5d. Peak interglacial temperatures are, on average 15$16^{\circ} \mathrm{C}$ for both models. The longest sustained interglacial is MIS 11, with minimal SST variation of $15.5-16.1^{\circ} \mathrm{C}$ for $\mathrm{SST}_{\mathrm{MAT} 25}$, and for $\mathrm{SST}_{\text {MAT35 }}$ is $15.1-15.6^{\circ} \mathrm{C}$ from $423 \mathrm{ka}$ to $399 \mathrm{ka}$. Other interglacials display short-term temperature spikes followed by extended cooling, or in the case of MIS 5, high temperature variability, with short-term temperature fluctuations between $\sim 3-7^{\circ} \mathrm{C}$. With the exception of MIS 12 and three temperature dips in MIS 8, 6 and 5d, SSTs amplitude remains between $\sim 11-16^{\circ} \mathrm{C}$.

The "super-interglacials" of MIS 11 and 5e record the highest temperatures for $\mathrm{SST}_{\text {MAT 25, }}$

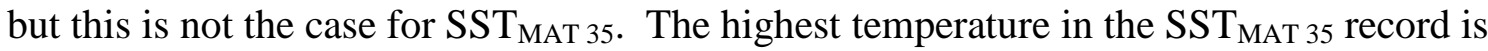
found in MIS 9 when SSTs are estimated to be $16.2^{\circ} \mathrm{C}$. $\mathrm{SST}_{\text {MAT } 25}$ estimates SST between 15.6-16.1 ${ }^{\circ} \mathrm{C}$ in MIS 11 and $15.5^{\circ} \mathrm{C}$ for MIS 5e. SST $_{\text {MAT } 35}$ estimates SST between 15.1$15.8^{\circ} \mathrm{C}$ in MIS 11 and $15.9^{\circ} \mathrm{C}$ for MIS 5e. 


\subsubsection{Artificial Neural Network (ANN)}
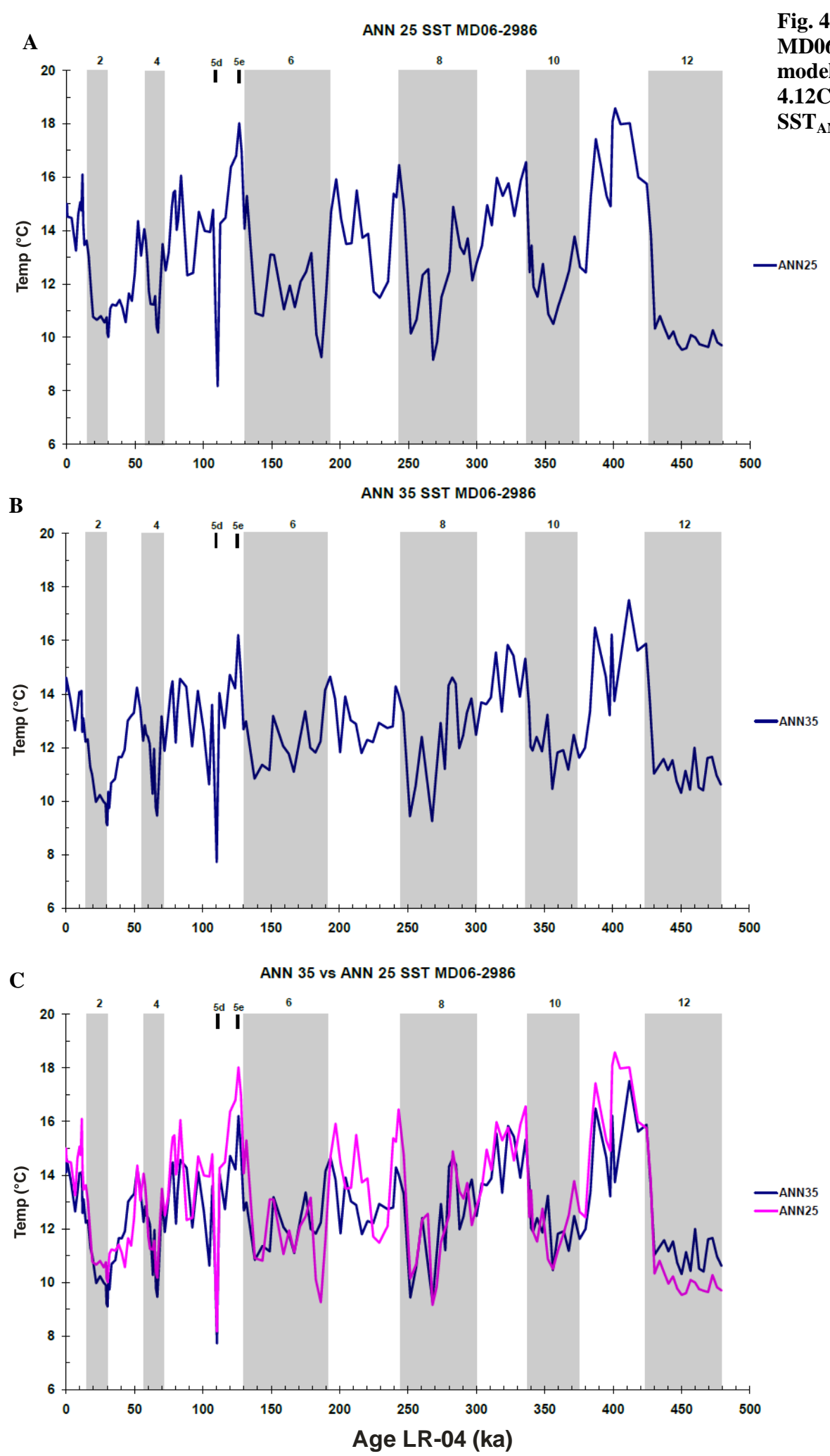

$\mathrm{SST}_{\text {ANN }}$ show excellent G-IG cyclicity throughout the record. The peak $\mathrm{SST}_{\mathrm{ANN}} 25$ temperature is $18.6^{\circ} \mathrm{C}$, and the peak $\mathrm{SST}_{\mathrm{ANN}} 35$ is $17.5^{\circ} \mathrm{C}$, and both are recorded at $401 \mathrm{ka}$ 
and $412 \mathrm{ka}$, respectively, in MIS 11 (Fig. 4.12A, B). These SSTs are higher than SST MAT temperatures of this study, and similar to those of Pelejero et al. (2006). The lowest temperature for $\mathrm{SST}_{\mathrm{ANN} 25}$ is $8.2^{\circ} \mathrm{C}$ and $7.7^{\circ} \mathrm{C}$ for $\mathrm{SST}_{\mathrm{ANN} 35}$. Both occur at $110 \mathrm{ka}$ in MIS 5d. $\operatorname{SST}_{\mathrm{ANN} 25}$ (Fig. 4.12A) estimates an MIS 7 warmer than $\operatorname{SST}_{\mathrm{ANN} 35}$ (Fig. 4.12B), with three separate temperature peaks of at least $15.5^{\circ} \mathrm{C}$, whereas peak temperatures for $\mathrm{SST}_{\mathrm{ANN}}$ 35 are no higher than $14.7^{\circ} \mathrm{C}$. Both models agree fairly well with each other, with MIS 7 and early MIS 6 as the exceptions (Fig. 4.12C).

MIS 12 is the least variable glacial, with temperatures for $\mathrm{SST}_{\mathrm{ANN} 25}$ remaining between 9.5$10.8^{\circ} \mathrm{C}$ and $10.3-12.0^{\circ} \mathrm{C}$ for $\mathrm{SST}_{\mathrm{ANN} 35}$. In contrast to $\mathrm{SST}_{\mathrm{MAT}}$, MIS 12 is not the coldest glacial period. MIS 8, 4 and 2 and 5d all have lower temperature minima. MIS 12 is however, characterized by having the least amount of SST variability, and shows very little warming through much of the interval, whereas other glacial periods have SST changes on the order of $\sim 2^{\circ} \mathrm{C}$. One exception to this is in MIS 8 , where a temperature change of $\sim 3^{\circ} \mathrm{C}$ is recorded.

The models estimate SST of "super-interglacials" MIS 11 and 5e to be the highest temperatures of the record; however, the models record these temperatures differently. Though the pattern of temperature is similar, that is, peak temperatures early in the interval followed by a gradual cooling, $\mathrm{SST}_{\mathrm{ANN}} 25$ is greater than $18^{\circ} \mathrm{C}$ for $12 \mathrm{kyr}$ of MIS 11 , and at $18^{\circ} \mathrm{C}$ at MIS 5e. SST $_{\text {ANN } 35}$ estimates in MIS 11 are not sustained, with a peak temperature of $17^{\circ} \mathrm{C}$ at $412 \mathrm{ka}$, then dropping to less than $\sim 14^{\circ} \mathrm{C}$. Temperatures do not exceed $16.5^{\circ} \mathrm{C}$ for the rest of the interval. $\operatorname{SST}_{\mathrm{ANN} 35}$ estimates peak in MIS 5e to $16.2^{\circ} \mathrm{C}$, about $2^{\circ} \mathrm{C}$ less than $\operatorname{SST}_{\mathrm{ANN}} 25$.

\subsubsection{Comparing and Contrasting SST methods}

Both methods show excellent G-IG cyclicity (Figs. 4.11C, 4.12C). SST MAT $_{\text {and }}$ SST $\mathrm{ANN}_{\mathrm{A}}$ indicate MIS 12 was a sustained, cold glacial period with very little SST variation. Both methods show a strong temperature drop in MIS 5d. Both methods also show SSTs dropping to minimum levels at the conclusion of MIS 3.

There are a few notable differences between the methods. $\mathrm{SST}_{\mathrm{ANN}}$ is generally more variable than $\mathrm{SST}_{\mathrm{MAT}}$, with higher temperature amplitude between glacial and interglacial 
periods. SST $_{\mathrm{ANN}}$ estimates above-normal temperatures at "super-interglacials" MIS 11 and 5e (Fig. 4.12C), where as SST $_{\text {MAT }}$ estimates MIS 11 and 5e to be no warmer than present (Fig. 4.11C). $\mathrm{SST}_{\mathrm{ANN}}$ estimates SST of the "super-interglacials" higher than $\mathrm{SST}_{\mathrm{MAT}}$, about $\sim 18.5^{\circ} \mathrm{C}$ versus $\sim 16^{\circ} \mathrm{C}$. $\mathrm{SST}_{\mathrm{ANN}}$ glacial periods have colder temperatures, $\sim 10-12^{\circ} \mathrm{C}$ versus $\sim 11^{\circ} \mathrm{C}$. Contrary to the other methods, $\mathrm{SST}_{\mathrm{ANN} 35}$ temperatures for MIS 12 appear to be typical for glacials of the record.

Of the two methods, $\mathrm{SST}_{\mathrm{ANN}}$ appears to be more robust, given that ANN produces results with a lower Root Mean Square Error compared to MAT (see Appendix B). While SST MAT $_{\text {T }}$ is useful to compare with $\mathrm{SST}_{\mathrm{ANN}}$ to confirm large scale temperature changes, we prefer to use $\mathrm{SST}_{\mathrm{ANN}}$ in comparison to other results (e.g. Malmgren and Nordlund 1997; Malmgren et al., 2001; Crundwell et al., 2008). We also prefer to use $\mathrm{SST}_{\mathrm{ANN} 25}$ over $\mathrm{SST}_{\mathrm{ANN}} 35$ simply for the exclusion of the deep-dwelling globorotaliid species, which can affect SST estimates by underestimating SSTs (e.g. Crundwell et al., 2008). For full SST results, see Appendix B.

\subsection{Oxygen Isotope Age Model}

Records of $\delta^{18} \mathrm{O}$ stable isotopes are used as a standard to compare and determine the age of paleoclimate records, providing an accurate age for the SSTs recorded here. The $\delta^{18} \mathrm{O}$ stable isotope is the measure of deviation of the ratio between the ${ }^{16} \mathrm{O}$ and ${ }^{18} \mathrm{O}$ content in seawater (Emiliani, 1954; Hays et al., 1976). When oxygen isotopes fractionate, ${ }^{16} \mathrm{O}$ is preferentially taken up into the atmosphere. During glacial periods, ${ }^{16} \mathrm{O}$ is precipitated as rain or snowfall and is locked into continental glaciers, seawater becomes enriched with ${ }^{18} \mathrm{O}$, and the deviation of the ratio is high. During interglacials, continental glaciers melt, ${ }^{16} \mathrm{O}$ returns to the oceans, and the deviation of the ratio lowers. The $\delta^{18} \mathrm{O}$ is used primarily as a proxy for ice volume and temperature. Foraminifera, both benthic and planktic, are used to obtain this measurement. As the calcite test of the foraminifera grows, the test of the foraminifera records the ratio of ${ }^{16} \mathrm{O}$ and ${ }^{18} \mathrm{O}$. Benthic foraminifera record deep-water signals, and planktic foraminifera record surface signals.

The ${ }^{16} \mathrm{O} /{ }^{18} \mathrm{O}$ ratio contained in the foraminiferal calcite shell changes through time. Since the waxing and waning of ice sheets affect global oceanography through aspects such as sea 
level and ${ }^{16} \mathrm{O}$ content, a broad model of climate change through time can be derived. By analysing the $\delta^{18} \mathrm{O}$ ratio of foraminifera from a sediment core, one can get a climatic history and timing of major events. In paleoceanographic studies, a $\delta^{18} \mathrm{O}$ record is the most common way to accurately date sediment cores of a long time series. Multiple $\delta^{18} \mathrm{O}$ records increase the confidence in the timing of these events, and a better constrained time series is produced with which to compare other paleoclimate proxies. Without these $\delta^{18} \mathrm{O}$ records, dating SST records and other paleoclimate proxies would be difficult.

To determine accurate ages for the SSTs of MD06-2986, $\delta^{18} \mathrm{O}$ data were compiled by Dr. Silke Steph (Alfred Wegener Institute for Polar and Marine Research). Samples were taken every $4 \mathrm{~cm}$ through the core, and $\delta^{18} \mathrm{O}$ measurements were performed on two species, Cibicides wuellestorfi (benthic) and Truncorotalia truncatulinoides (planktic). $\delta^{18} \mathrm{O}$ values were then compared to the LR04 benthic stack (Lisiecki and Raymo, 2005) to determine ages of the samples in MD06-2986.

Since $\delta^{18} \mathrm{O}$ is a measure of ice volume and temperature, SST values should not directly coincide with $\delta^{18} \mathrm{O}$ data. Also, since SST change leads ice volume change, then changes in SST should occur before changes in $\delta^{18} \mathrm{O}$. This is particularly true for benthic $\delta^{18} \mathrm{O}$, where surface temperature change would occur $<1000$ years before bottom temperature change. Therefore, the planktic $\delta^{18} \mathrm{O}$ data pattern should match with SSTs better than benthic $\delta^{18} \mathrm{O}$. 

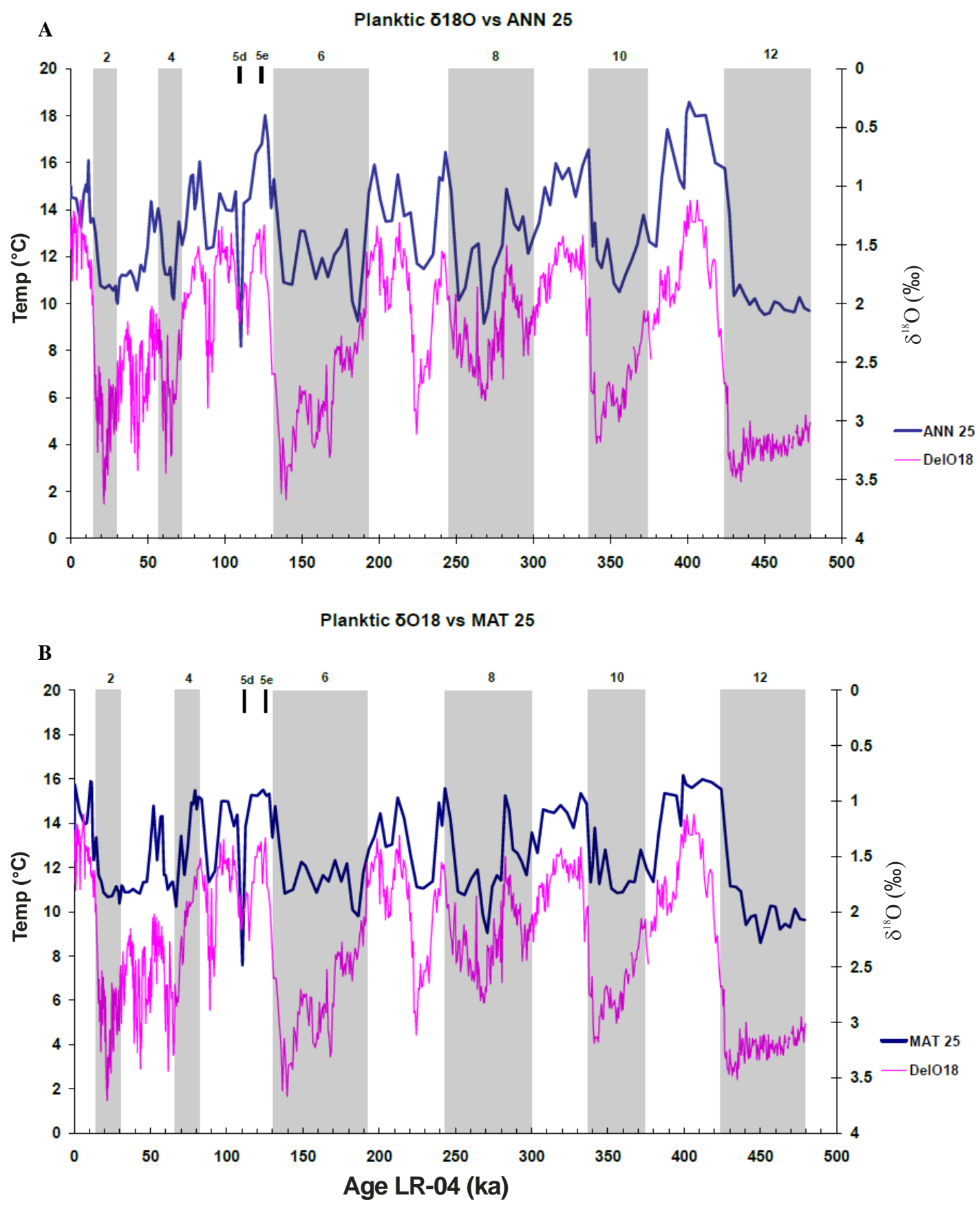

Fig 4.13 - Planktic $\delta^{18} O$ and SST from MD06-2986. 4.13A-ANN 25 model and Planktic $\delta^{18}$. 4.13B-MAT 25 model and Planktic $\delta^{18} O$.

SST records of MD06-2986 using MAT and ANN correlate well with the $\delta^{18} \mathrm{O}$ data (Figs. 4.13A, B). There is excellent correlation between planktic $\delta^{18} \mathrm{O}$ and $\mathrm{SST}_{\mathrm{ANN}} 25$ and $\mathrm{SST}_{\mathrm{MAT}}$ 25. Interglacial variation matches up well, and in general, the glacial variation matches fairly well, with the exception of MIS 6. 


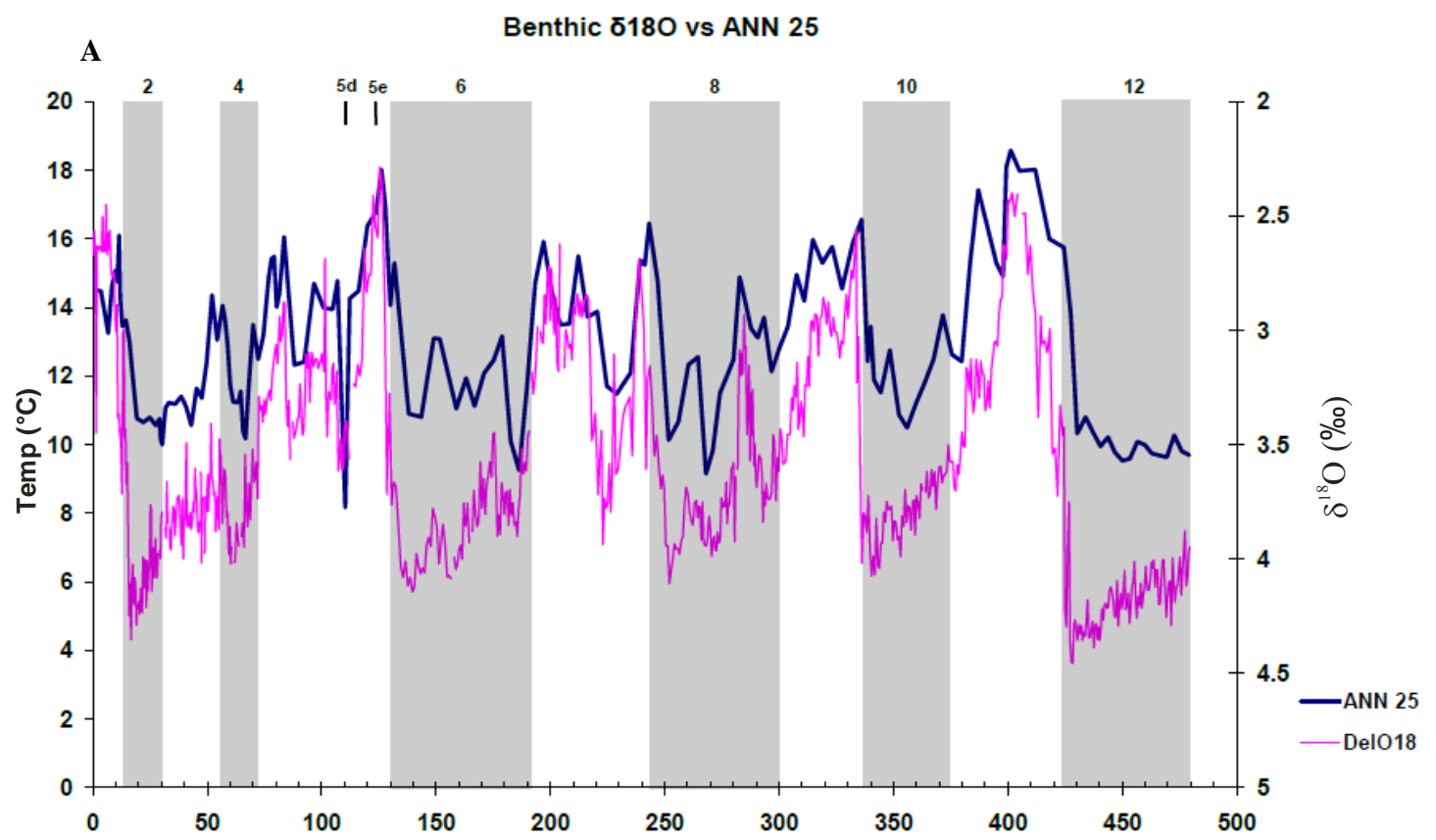

B Benthic $\delta 180$ vs MAT 25

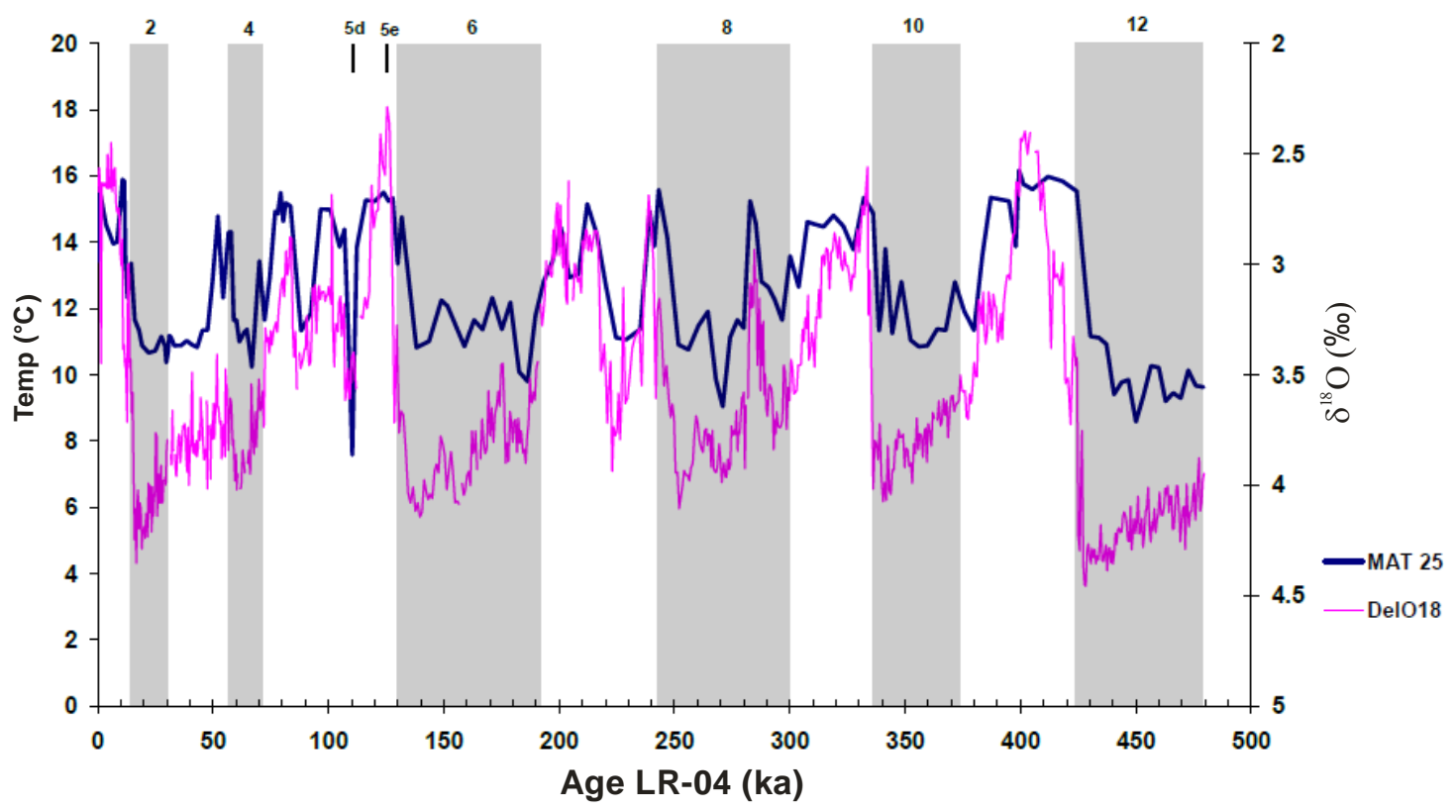

Fig 4.14 - Benthic $\delta^{18} O$ and SST from MD06-2986. 4.14A-ANN 25 model and Benthic $\delta^{18}$ O. 4.14B-MAT 25 model and Benthic $\delta^{18} \mathrm{O}$.

Benthic $\delta^{18} \mathrm{O}$ values correlate well with $\mathrm{SST}_{\mathrm{MAT} 25}$ and $\mathrm{SST}_{\mathrm{ANN} 25}$ (Figs. 4.14A, B). Similar to the comparisons with planktic $\delta^{18} \mathrm{O}$, benthic $\delta^{18} \mathrm{O}$ glacial and interglacial peaks match well with $\mathrm{SST}_{\mathrm{MAT}} 25$ and $\mathrm{SST}_{\mathrm{ANN}} 25$. While amplitudes of $\delta^{18} \mathrm{O}$ and SST are not necessarily supposed to match, it is interesting that the amplitude of $\mathrm{SST}_{\text {MAT } 25}$ does not reflect the same pattern of amplitude with benthic $\delta^{18} \mathrm{O}$ in MIS 11 and 5e. SST and 5e are comparable to other interglacials, whereas benthic $\delta^{18} \mathrm{O}$ values are higher than 
average for those intervals. This would again be indication that $\mathrm{SST}_{\mathrm{ANN}} 25$ is a better choice of method to use, rather than $\mathrm{SST}_{\text {MAT } 25}$.

\subsection{Dissolution}

The foraminiferal fragmentation index (FI) is a commonly used proxy for dissolution (Thunnell, 1976; Peterson and Prell, 1985; Le and Shackleton, 1992; Weaver et al., 1998). The FI used here is that of Le and Shackleton (1992) who assumed that during dissolution, foraminiferal tests fragment into eight pieces larger than the $150 \mu \mathrm{m}$ sieve size. This gives a proportion of the forams that have fragmented relative to the whole sample population.

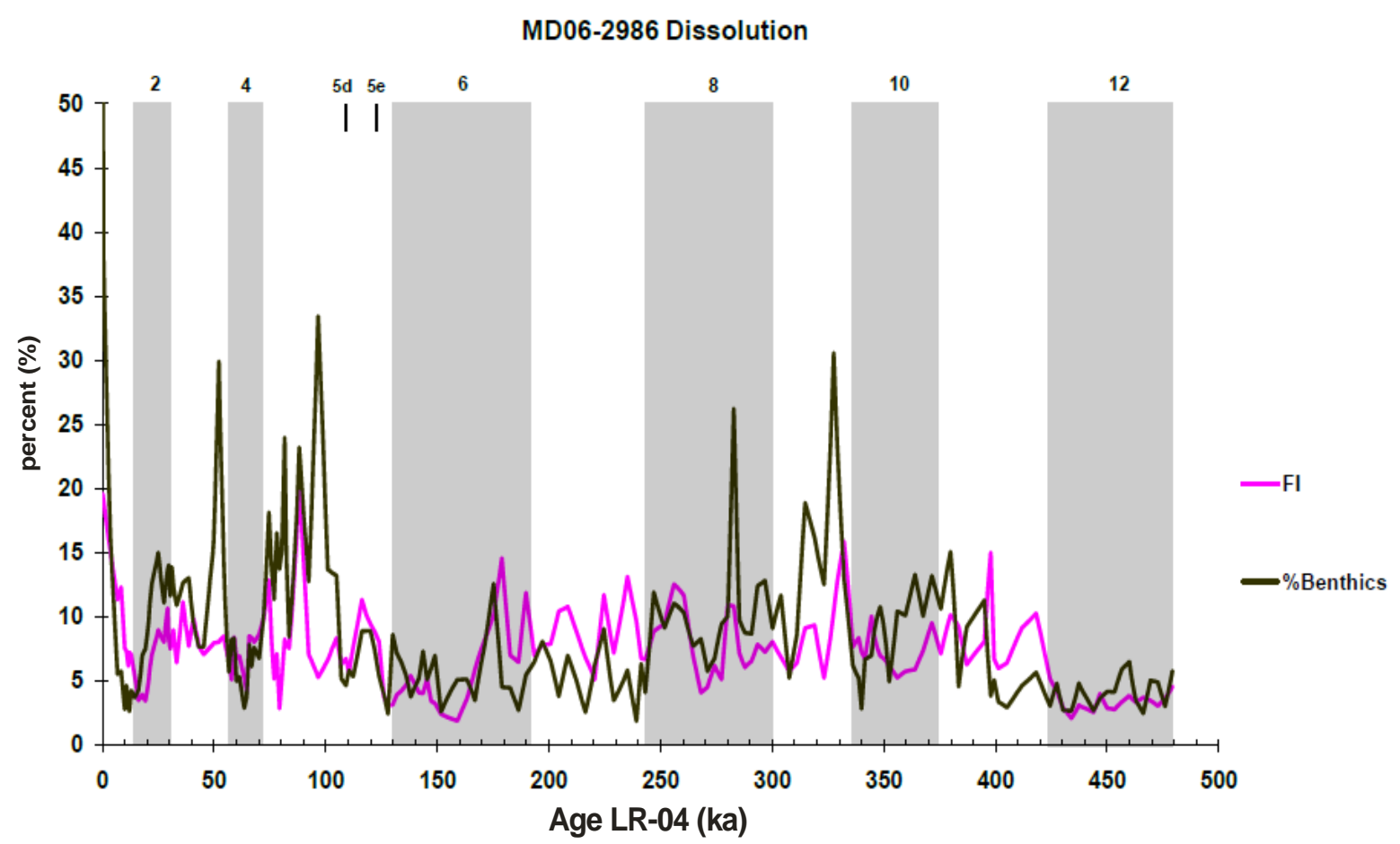

Fig. 4.15 - Fragmentation Index and \%Benthics for MD06-2986 as a measure of dissolution. The low numbers indicate dissolution does not affect assemblages.

Another dissolution proxy is the percentage of benthic foraminifera in a sample. Thunnel (1976) provides statistical evidence of the robustness of this proxy. Benthic foraminiferal test walls are thicker than planktic test walls, and are more resistant to dissolution.

Therefore, a spike in benthic abundance may be an indicator of higher dissolution. Here, $\%$ benthic is the percentage of benthics relative to total planktics in a sample. 
The dissolution of foraminiferal tests of MD06-2986 is low throughout the record (Fig. 4.15). The average fragmentation is between 6-9\%. In MIS 8, 7 and early 6, FI fluctuates between $6-12 \%$. There are four instances when fragmentation is higher than $15 \%$. These are found in MIS 11, 7, 5 and 1. The highest fragmentation is $20.5 \%$ in MIS 5 at $88 \mathrm{ka}$. Fragmentation spikes could indicate higher dissolution, or it could indicate a mishandling of those samples during preparation (appendix A). It should be mentioned that low dissolution occurs in concert with the MIS 5d subantarctic spike, indicating that dissolution is not artificially affecting the assemblage.

The FI is unusually low for MIS 12, 6 and the latter part of 2, with an FI of 3-5\%. Other glacials, such as MIS 2, 8 and 10 have lower FI than the interglacials. This is unusual because as Hall et al. (2001) show, the DWBC intensifies during glacial periods, which raises the lysocline, and the dissolution of foraminifera increases. Our results show an opposite trend, where dissolution increased during interglacials and reduced during glacials. The dissolution records of Weaver et al. (1998) do indeed reveal higher dissolution during glacial periods. However, the FI pattern of core R657, located on the northern margin of Chatham Rise, is similar to MD06-2986. R657 was cored at a depth of $\sim 1400 \mathrm{~m}$, similar to that of MD06-2986.

Benthic foraminiferal percentages (\% benthics) do not appear to follow any G-IG pattern, though the proxy does show that, following a large rapid increase in abundance, a slow reduction of the abundance occurs. This is most evident in MIS 10, 9 and 5. The largest $\%$ benthics spikes occur mostly in interglacials 9 and 5 and interstadial 3, with one spike occurring in MIS 8. These abundances are between 23-33\%. Most major FI spikes are in agreement with the $\%$ benthic spikes, though are not necessarily of the same magnitude. There is good agreement between the two proxies in MIS 12 and MIS 6, further providing evidence that dissolution was not a factor at the site during the cold intervals.

\subsection{Productivity}

The productivity proxy used here is given by the flux of planktics per centimeter squared per one thousand years (planktics $/ \mathrm{cm}^{2} / \mathrm{kyr}$ ) and is derived by finding the number of planktics in one gram of sediment, then multiplying that number by the sedimentation rate 
of the core. This assumes that a gram of washed sediment equals one cubic centimeter. A simple formula normalizes the weight of the number of planktics picked per sample to one gram. This gives an estimation of the total number of planktics $(>150 \mu \mathrm{m})$ found in one gram of washed sediment. When this formula is applied to the core samples, an estimation of the foraminiferal productivity through time can be made. The formula is:

\section{Pn*(1/pw)}

where Pn is the number of total planktics picked from a sample, and pw is the weight of the picked sample. This number is then multiplied by the sedimentation rate, which is found by dividing the core length $(\mathrm{cm})$ by the core age $(\mathrm{kyr})$ to give an average sedimentation rate for the length of the core.

\section{MD06-2986 Productivity}

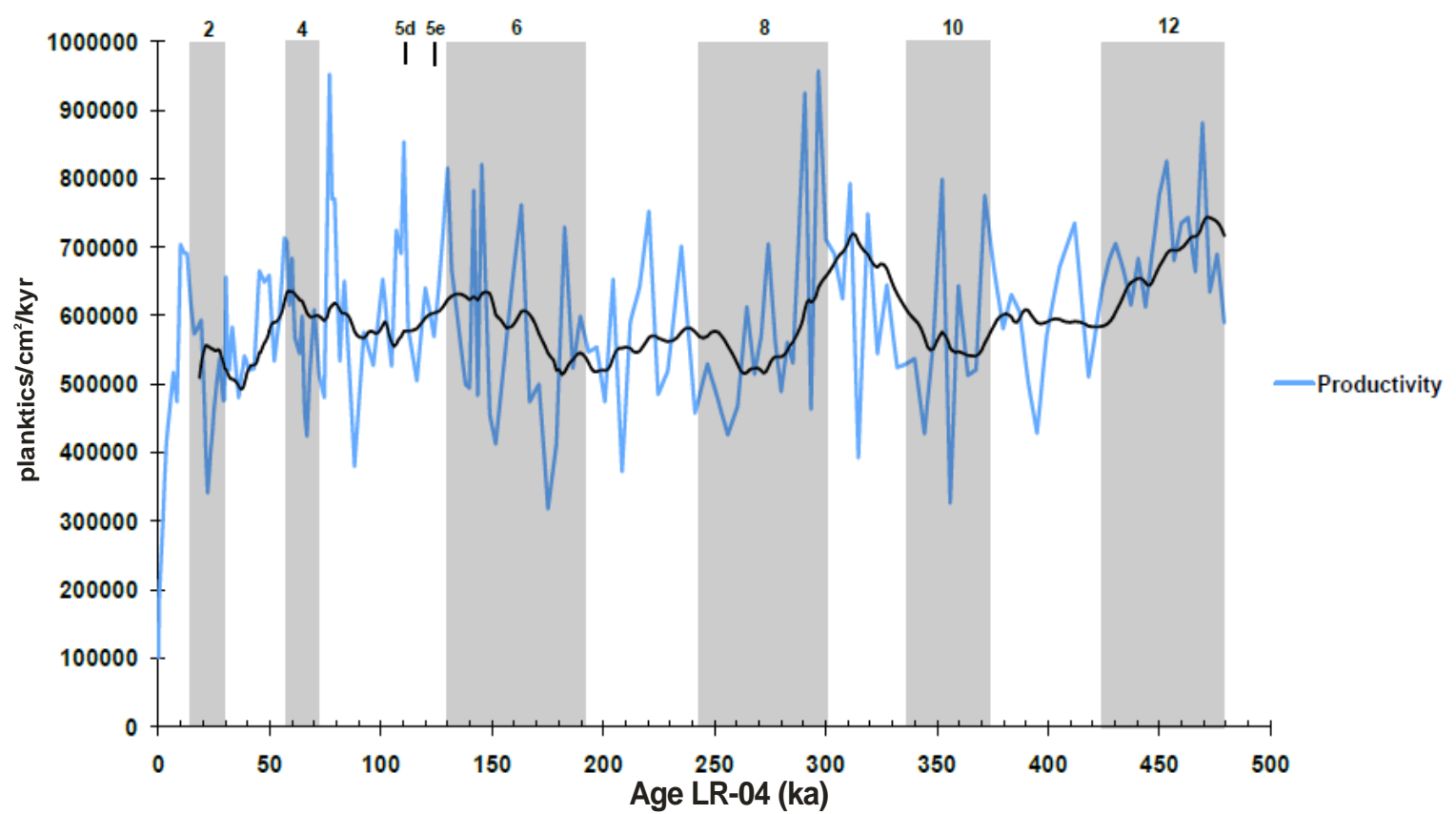

Fig. 4.16 - Productivity record from MD06-2986, expressed as number of planktics per centimeter sq. per one thousand years. Trendline is a 25-point moving average.

Productivity for MD06-2986 (Fig. 4.16) averages between 500,000-700,000 pl./cm²/kyr.

Based on the moving average, productivity highs occur in MIS 12 and $9(\sim 700,000$ $\left.\mathrm{pl} . / \mathrm{cm}^{2} / \mathrm{kyr}\right)$, and lows occur in MIS 10, 8,6 and $3\left(\sim 320,000 \mathrm{pl} . / \mathrm{cm}^{2} / \mathrm{kyr}\right)$. There do not appear to be any clear trends in productivity specific to glacial and interglacial periods; however, low productivity appears to be focused in glacials, yet the timing of these productivity lows varies. For instance, in MIS 12, productivity estimates are on average, 
the highest of the record, yet by the end of the stage, the productivity values are more towards the lower end of productivity values. MIS 6 shows an opposite trend, where productivity estimates are low $\left(\sim 520,000 \mathrm{pl} . / \mathrm{cm}^{2} / \mathrm{kyr}\right)$ at the start of the period, and increased to the higher end of the average productivity values. Given the lack of G-IG trend and varied timings of high and low productivity with respect to the glacials suggest that the transitions are most likely to have an increase in productivity.

Carter and Manighetti (2006) examined productivity proxies in four cores offshore eastern New Zealand. Two cores north of the STF had distinctly different productivity signals (higher carbonate Mass Accumulation Rates in interglacials) compared to the two cores south of the STF (higher carbonate Mass Accumulation Rates in glacials). The productivity record of MD06-2986 is more similar to the eastern cores north of the STF, yet still shows some similarities to the productivity records from the cores to the south of the STF. This may indicate that unlike offshore eastern New Zealand, where the oceanography has been dominated by the competing inflows of warm STW from the north and cool SAW from the south, resulting in pronounced temperature and productivity fluctuations (Kowalski and Meyers, 1997; Carter and Manighetti, 2006; Crundwell et al., 2008; Hayward et al., 2008), offshore western New Zealand may be a more stable oceanographic system, with less pronounced inflows from either a high or low latitude source.

\subsection{Summary}

There are several key points from this chapter in regards to the data. Total faunal composition data shows that after MIS 12, the temperate taxonomic group dominates. This is confirmed by most SST data, which estimates MIS 12 colder than any other glacial period. The subantarctic taxonomic group is not particularly abundant in glacial periods; however, there are two anomalously large spikes in early MIS 6 and 5d.

SST methods are in reasonably good agreement with each other. All glacials exhibited an early to mid interval of maximum cooling, a pattern different to the typical saw-tooth pattern of glacial cooling in Middle Pleistocene climate records. Both SST methods record

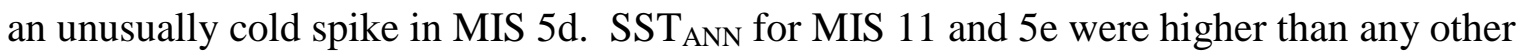
interval, indicating these periods were indeed much warmer than present. In contrast, 
SST $_{\text {MAT }}$ estimates that MIS 11 and 5e were not any higher than other interglacials, despite faunal composition and $\delta^{18} \mathrm{O}$ values suggesting that these intervals were warmer. This suggests the $\mathrm{SST}_{\mathrm{ANN}}$ method is more reliable than $\mathrm{SST}_{\mathrm{MAT}}$.

The dissolution pattern shows higher dissolution for interglacials and lower dissolution for glacials, and was unusually low for the cold glacial periods of MIS 12 and $6(\sim 3 \%)$. This pattern is opposite to that shown by offshore eastern New Zealand cores (Weaver et al., 1998).

Productivity averages between $\sim 500,000-700,000 \mathrm{pl} . / \mathrm{cm}^{2} / \mathrm{kyr}$, and does not appear to follow any G-IG pattern. The productivity pattern can be described as an "in-between" signal compared to cores from offshore eastern New Zealand. The comparison of productivity signals from both sides of New Zealand may highlight the different oceanographic systems between east and west New Zealand. The eastern side has been dominated by competing inflows of northern and southern sourced waters, and the western side may have been a more stable system. 


\subsection{Discussion}

\subsubsection{Overview}

This chapter discusses and reviews the results of MD06-2986 to provide a record of oceanographic change for the eastern Tasman Sea for the past $\sim 500 \mathrm{kyr}$. Faunal composition was used to document surface water movements, with emphasis on glacialdeglacial transitions. The faunal-based SST estimates from MD06-2986 are compared to records of alkenone-based SSTs and other faunal-based SST estimates from the Tasman Sea with emphasis on temperature patterns and differences between the eastern and western Tasman Sea. An evaluation is made of the migration of the STF by comparing several proxies of frontal movement. The dissolution record in MD06-2986 is discussed. Finally, SSTs and faunal data are compared with four cores from offshore eastern New Zealand to evaluate past changes in the oceanographic regimes that affect both sides of the New Zealand land mass.

\subsection{Faunal Composition}

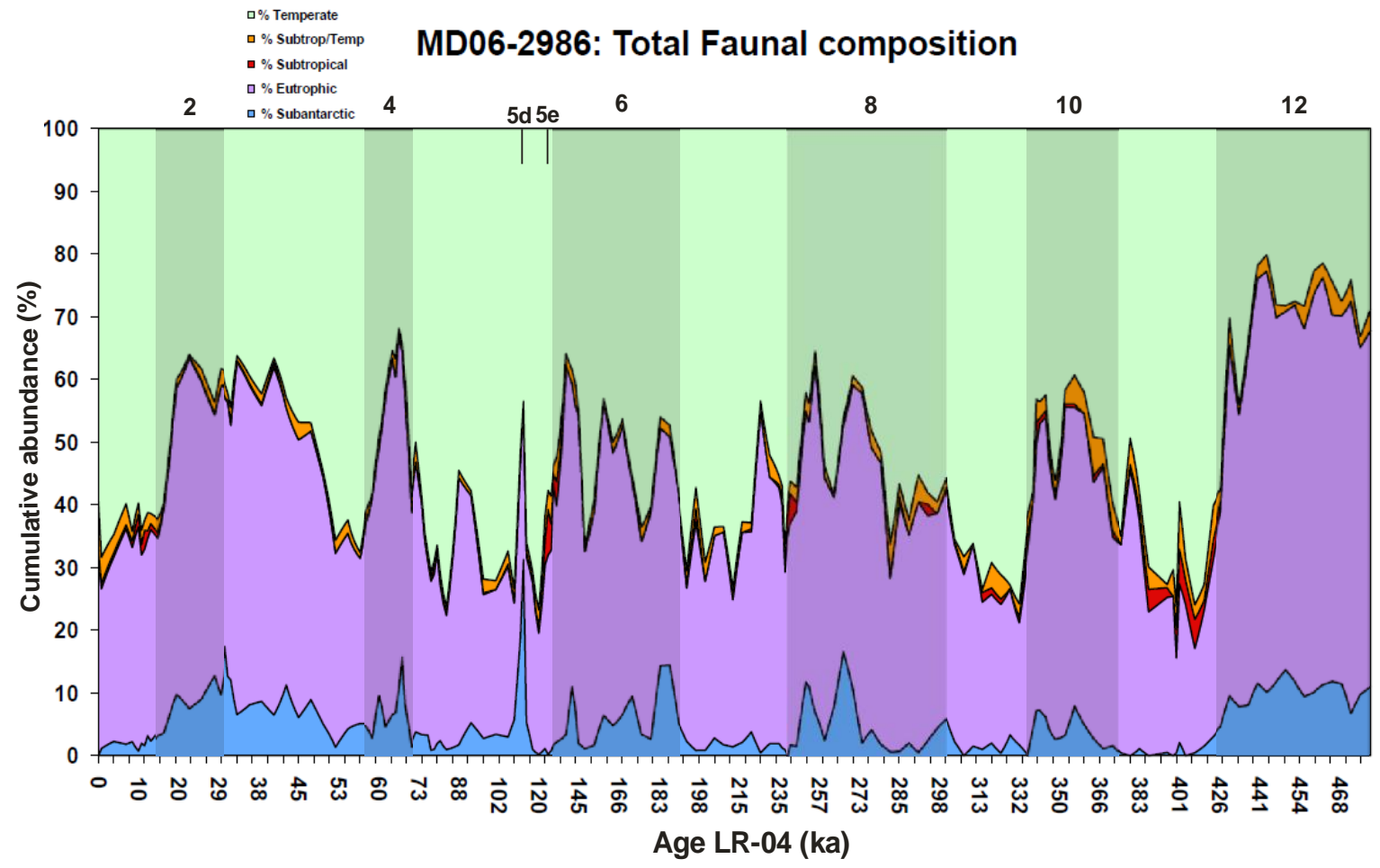

Fig. 5.1 - Total cumulative faunal composition of MD06-2986. Shaded areas indicate glacial periods with appropriate Marine Isotope Stage number above. Blue-subantarctic taxa. Purple-eutrophic taxa. Redsubtropical taxa. Orange-subtropical-temperate taxa. Green-temperate taxa. Note timescale is based on MD06-2986 age model timings, however, chart type restricted freedom for formatting $\mathrm{X}$-axis. 
Census counts from MD06-2986 reveal new insights into past oceanographic changes in the Tasman Sea (Fig. 5.1). The total faunal composition suggests several key features: MIS 12 appeared to have been much colder than any other glacial of the record; temperate taxa dominated after MIS 12; there were two anomalous cold periods in early MIS 6 and 5d, and a repeated succession of faunal changes through glacial-deglacial periods.

\subsubsection{MIS 12}

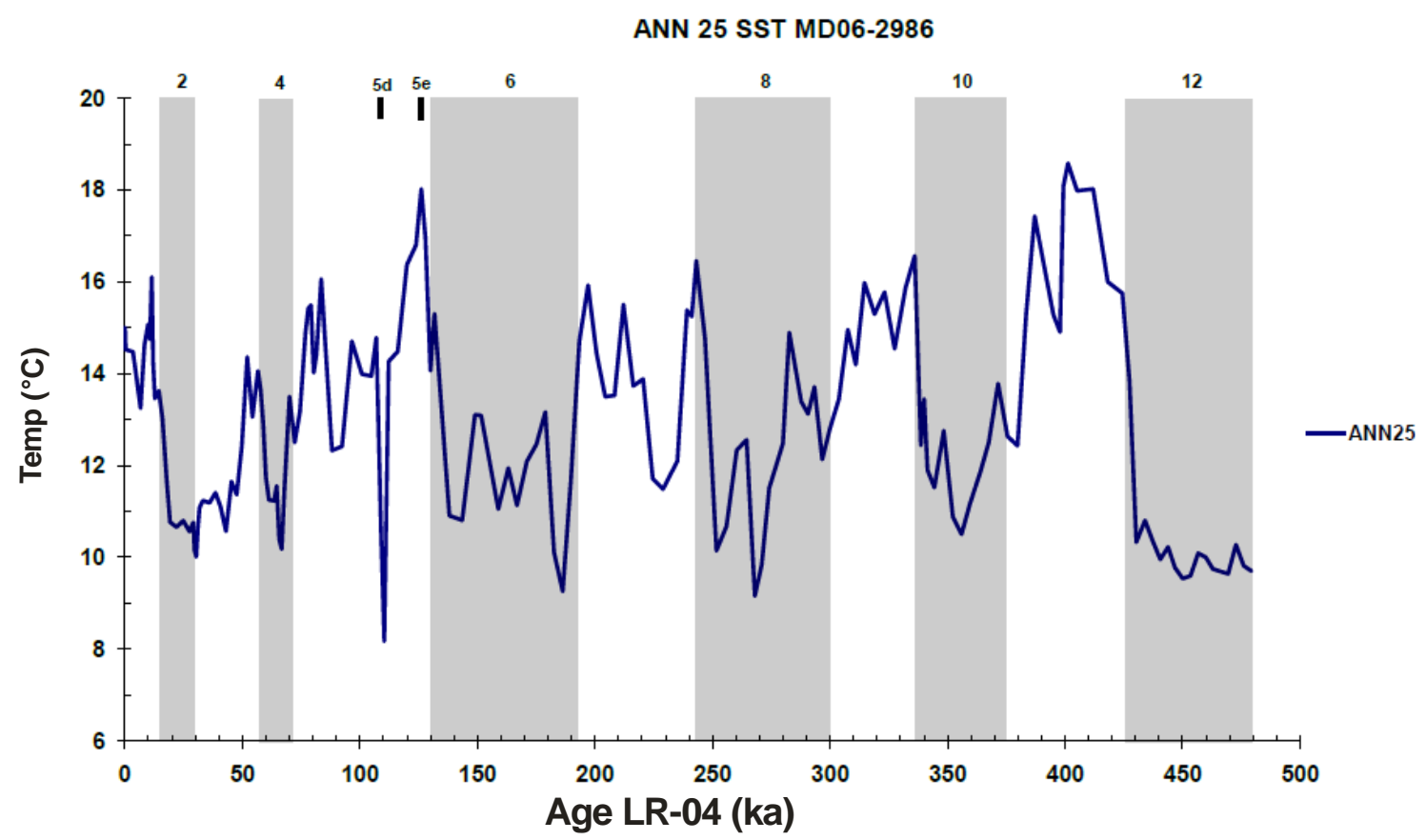

Fig. 5.2 - $\mathrm{SST}_{\mathrm{ANN} 25}$ from MD06-2986.

Through most of MIS 12, the subantarctic and eutrophic taxa occurred in relatively high abundances (65-75\%), whereas the temperate taxonomic group was low in abundance (2025\%) (Fig. 5.1). It appears that MIS 12 was the most prolonged cold and productive period in the record, though $\mathrm{SST}_{\mathrm{ANN}} 25$ minimum was lower for a brief time in MIS 8, 6 and 5d (Fig. 5.2).

The most important feature of the subantarctic taxa in MIS 12 is the sustained abundance of the group through the interval, whereas in other glacial periods, the subantarctic taxa have several short-lived pulses (Fig. 5.1). This indicates persistent cold temperatures, and a SAW that was further north than the present position of $\sim 45-50^{\circ} \mathrm{S}$. Certainly the $\delta^{18} \mathrm{O}$ and 
$\mathrm{SST}_{\mathrm{ANN} 25}$ records from the core support the pronounced cooling, but they are the only available records for the eastern Tasman Sea that date back to MIS 12, and hence, the cooling cannot be regionally confirmed. However, other records from the Southern Hemisphere also reveal that MIS 12 was unusually cold (e.g. Howard and Prell, 1992). The data of Hall et al. (2001) from ODP 1123, east of New Zealand, indicates that MIS 12 had the most enriched $\delta^{18} \mathrm{O}$ values of the past 1.2 myr. The $\mathrm{SST}_{\mathrm{ANN} 25}$ record of ODP Site 1123 of Crundwell et al. (2008) indicates that MIS 12 was colder than all glacial periods of the past $\sim 600 \mathrm{kyr}$, except for MIS 6. $\mathrm{SST}_{\mathrm{ANN}} 25$ from Hayward et al. (2008) shows MIS 12 to have been one of the most sustained, cold glacials of the last $\sim 1.0$ myr at DSDP 594. In contrast, $\mathrm{SST}_{\mathrm{ANN}} 25$ data from ODP Site 1125 suggests that MIS 2, 4 and 6 were warmer than MIS 12 over the past 600 kyr (Hayward et al., 2008).

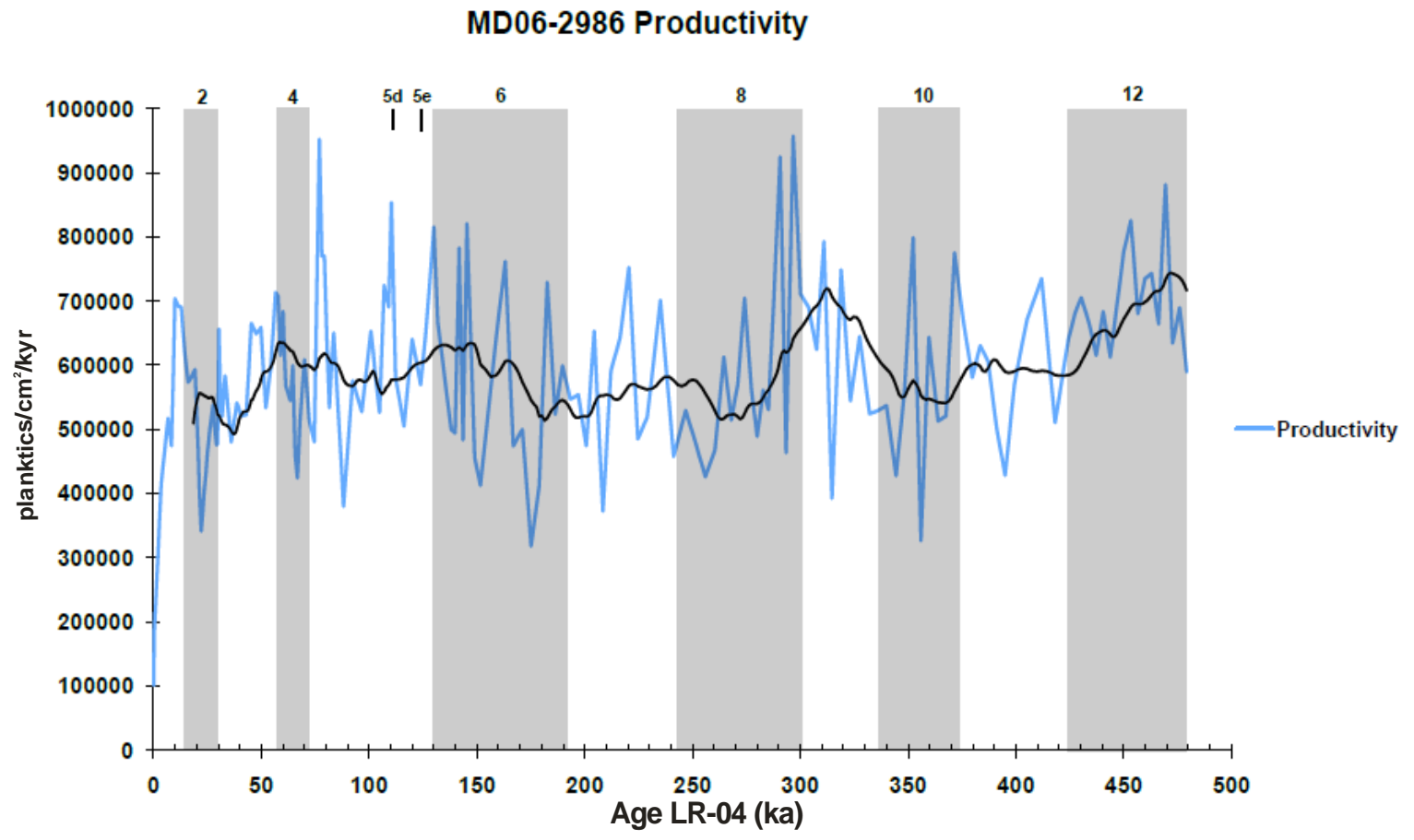

Fig. 5.3 - Productivity chart from MD06-2986, measured in number of planktic foraminifera per $\mathrm{cm}^{2} / \mathrm{kyr}$. Trendline is a 25-point moving average. Grey bars indicate glacial periods, with appropriate Marine Isotope Stage number.

Similar to the subantarctic taxa, eutrophic taxa had a high, sustained abundance through the MIS 12 interval as well $(\sim 55-65 \%)$. Since the relative abundance of eutrophic taxa are an indicator of productivity (e.g. Crundwell et al., 2008), MIS 12 appears to have been the most fertile stage of the record, as suggested by the absolute abundance of planktic foraminifera productivity proxy (Fig. 5.3). High productivity could indicate an increase in 
the supply of a limiting macro or micro-nutrient which in turn may be a consequence of an influx of aeolian dust, a mixing of water masses (i.e. STF) (Yoder et al., 1994) or increased upwelling of nutrient-rich water.

It is unclear whether or not iron fertilisatio from increased dust deposition in the Tasman Sea would lead to algal blooms. The Tasman Sea, including core site MD06-2986, is not presently categorised as a high nitrate, low chlorophyll (HNLC) area (i.e. an area where productivity is limited by a lack of iron), so an increase of iron-rich dust may not stimulate the algal blooms necessary to increase planktic productivity. Recent investigations into phytoplanktic productivity in the Tasman Sea show that, while the iron levels are low, phytoplankton production does not appear to be limited by these low levels (M. Ellwood pers. comm. 2011). However, Boyd et al. (2004) show that SAW south of New Zealand is an HNLC area and it may be possible that a northward migrating STF would lead SAW into the Tasman Sea, thereby creating conditions necessary for algal blooms induced by Fe-rich dust.

Australia is a large source of dust, and it has been documented that increases in aeolian sedimentation in the Tasman Sea occurred during glacial periods (Thiede, 1979; Hesse, 1994). Increased aridity and low vegetation on the Australian continent during cold glacials (Markgraf et al., 1992), coupled with an increased equator-polar thermal gradient and subsequent increase in westerly trade wind intensity (Thiede, 1979; Moreno et al., 1999; Shulmeister et al., 2004) could have led to increased deposition of aeolian sediments in the Tasman Sea. Hesse (1994) investigated this influx of aeolian sediment in the Tasman Sea and found that the southern Tasman Sea received the highest percentage of aeolian dust ( $\sim 60-80 \%$ dust content in cores, though there are several assumptions with these values). The core of the glacial dust plume is centred between $\sim 36^{\circ} \mathrm{S}-45^{\circ} \mathrm{S}$, and the dust influx had a reduced east-west gradient (core E26.1 located on Challenger Plateau recorded dust levels only between 6-8\%). The high percentage of aeolian dust in the southern-central Tasman Sea indicates that dust "blooms" could be a possible mechanism for high productivity values of MD06-2986 if the surface watersat the core site were otherwise iron-limited. Hesse (1994) also reported that there was a distinct increase in the total aeolian dust transport to the Tasman Sea after $350 \mathrm{ka}$ (MIS 10) and concluded that this was a consequence of the drying of the Australian continent. Since the significant increase in dust 
in the Tasman Sea occurs after MIS 10, it is difficult to see how this mechanism could account for increased Fe-fertilisation during MIS 12. However, if the STF migrated northward during stage 12 and site MD06-2986 became a HNLC area from SAW-sourced waters, a large amount of iron-rich dust would not be necessary to stimulate algal blooms, and therefore plankton productivity for MIS 12.

It is difficult to distinguish between increased productivity from upwelling and increased productivity associated with oceanic fronts. Presently, upwelling offshore western New Zealand is mainly confined to the western Cook Strait, and the latitudinal extent of upwelling varies, since it appears to be related to the wind strength that drives the Westland Current (Bowman, 1983). Any increase in productivity from upwelling here will spread north to Taranaki Bight, rather than southward to Challenger Plateau, due to the prevailing westerlies (Shirtcliffe et al., 1990). Upwelling as a response to surface winds is also associated with submarine canyon heads (Sobarzo et al. 2001), such as Hokitika and Cook canyons (Bradford et al., 1983; Chang, 1995). During the LGM, upwelling increased east of New Zealand (Weaver et al., 1998; Carter et al., 2000), and Dudley and Nelson (1989) suggest upwelling occurred on the Challenger Plateau during glacial periods of the late Quaternary. So, while an upwelling system is present on the West Coast today, it varies periodically on the Challenger Plateau and does not appear to be a sustained system (Stanton, 1971). The increased intensity of westerly winds during glacial periods (Shulmeister et al. 2004) would presumably increase the strength of the WC, thereby increasing upwelling offshore western New Zealand.

Another indication that upwelling may be responsible for the high productivity in MIS 12 is the presence of the species Truncorotalia (Globorotalia) crassula. As with other truncorotaliids, $T r$. crassula is classified as a deep-dwelling (>100 m) subtropical/temperate species (Hemeblen et al., 1989). The literature on the ecology and habitats of Tr. crassula is sparse; however, it has been hypothesised as having a close morphological relationship to Tr. crassaformis (Scott et al., 1990), and hence, could have similar ecological relationships. Tr. crassaformis has been classified as a species that prefers upwelling regions (Berger and Herguera, 1992). If ecological similarities exist between the two species, then perhaps $T r$. crassula can be viewed as an indicator of upwelling. Indeed this is the case for several Truncorotaliids (Berger and Herguera, 1992; Stanley, 1990) 


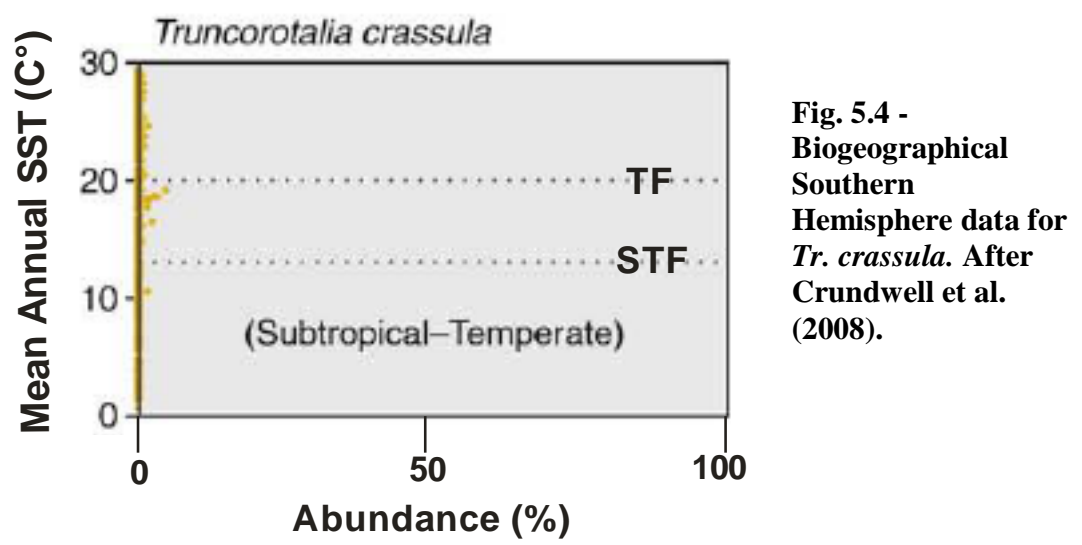

Tr. crassula has been found both east and west of New Zealand; however, it is rare $(<0.5 \%)$ in New Zealand waters at the present day. Biogeographic data from core tops show $T r$. crassula is most abundant around the Tasman Front (Fig 5.4). However, the present-day distribution of $T r$. crassula is atypical of Quaternary data (M. Crundwell, pers. comm.) At ODP Site 1123, Crundwell et al. (2008) report that the numbers of Tr. crassula became insignificant after $380 \mathrm{ka}$. Tr. crassula numbers at MD06-2986 were only abundant ( 2-5\% of assemblages) in MIS 12 and 10 and were rare elsewhere in the record. Given the relationship between deep-dwelling Truncorotaliids and upwelling, the appearance of $T r$. crassula in MIS 12 and 10 may indicate that productivity during these intervals is upwelling-induced.

Productivity can also increase due to nutrient mixing at water mass boundaries (Yoder et al. 1994). Murphy et al. (2001) assessed present day productivity in the New Zealand region and found that surface productivity was highest in the STF region throughout the year, both east and west of New Zealand. This suggests that a mixing of water masses is important for present-day West Coast productivity, given that upwelling on the Challenger Plateau is known to be sporadic. If the STF migrated to near site MD06-2986, it is possible that this could cause the productivity signal to increase. Furthermore, a northward migrating STF may also introduce HNLC waters, stimulating algal blooms from Australian-sourced dust. Given that productivity was higher in MIS 12 than in MIS 10, the productivity signal in MIS 12 could be from a combination of all three mechanisms: upwelling offshore western New Zealand due to higher winds, a mixing of water masses from a northward migrating 
STF, and an influx of HNLC waters, also from a northward migrating STF. The implications of STF movement at MD06-2986 will be discussed in greater detail later.

\subsubsection{Faunal composition anomalies - Is the cold event of MIS 5d real?}

Two anomalous cold periods occur in early MIS 6 and MIS 5d. There was an unusually large abundance of subantarctic taxa at the onset of MIS 6, which corresponds to an SST minimum for the interval (Figs. 5.1, 5.5). When compared to both temperature and benthic $\delta^{18} \mathrm{O}$, it does appear to be anomalous (Fig 5.5). It is unclear why such a large abundance should have occurred at the beginning of the MIS 6 glacial, rather than later. This contrasts with the eastern Tasman Sea SST record of Pelejero et al. (2006), who report gradual cooling to SST minima at the end of MIS 6.

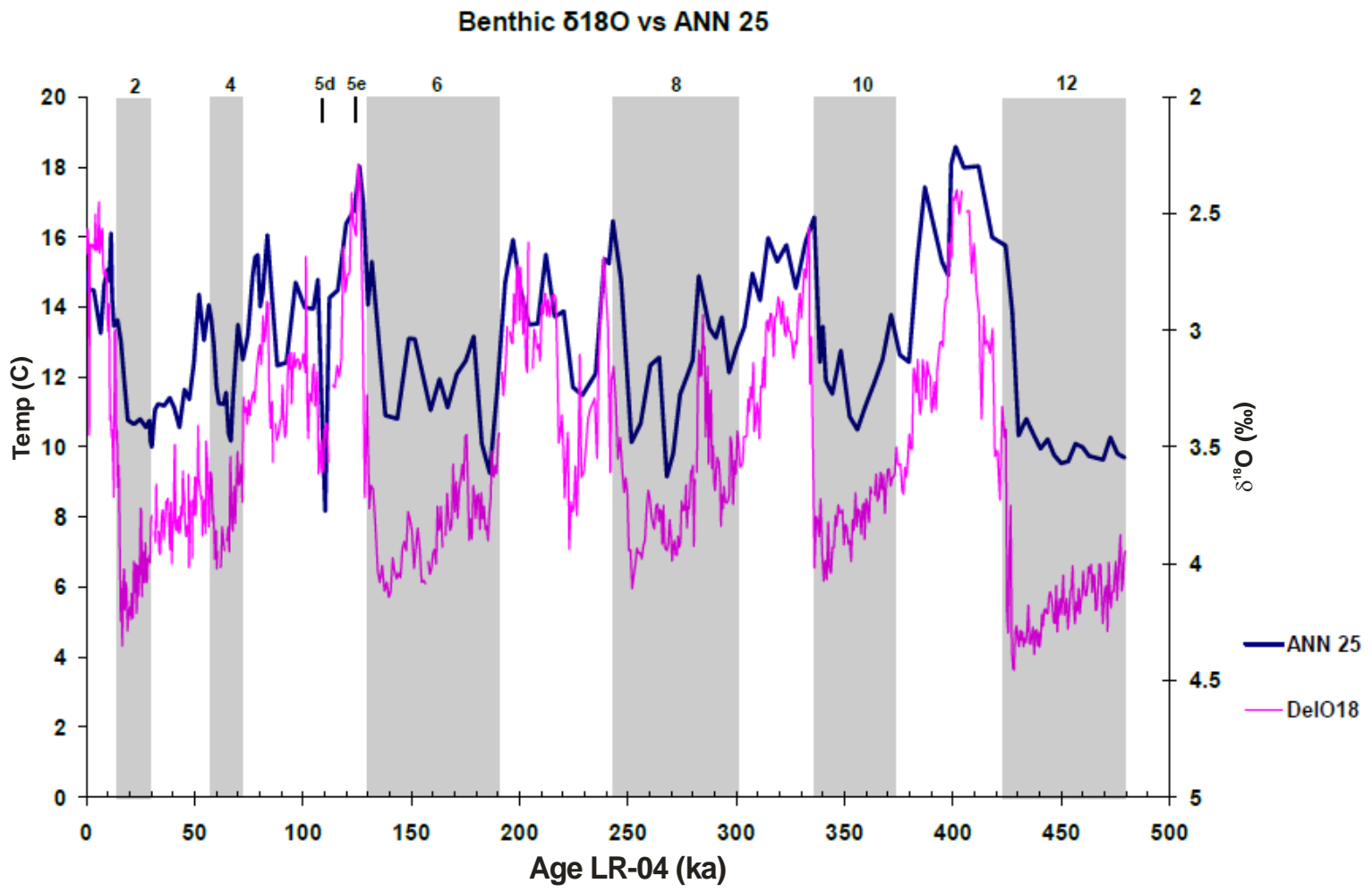

Fig. 5.5 - ANN 25 (this study) and benthic $\delta^{18}$ O data for MD06-2986 (Steph, unpublished data).

The highest abundance of subantarctic taxa is recorded in MIS 5d, corresponding to a $\mathrm{SST}_{\mathrm{ANN25}}$ minimum of $\sim 8^{\circ} \mathrm{C}$. However, given that the subantarctic taxa are so heavily weighted in ANN SST estimates, it is unlikely that SST was actually this low. In that regard, while the SST minimum of the record at MIS 5d is understandable, an important 
question to ask is why such a large spike in subantarctic taxa occurs here, especially given that other published records suggest that temperatures were not particularly low (e.g. Barrows et al., 2007, Pelejero et al., 2006). There are three samples assigned to MIS 5d, at $112 \mathrm{ka}, 110 \mathrm{ka}$ and $109 \mathrm{ka}$. The subantarctic abundance for these three dates is $\sim 5 \%, \sim 31 \%$ and $\sim 19 \%$, respectively. Given that the abundance at $109 \mathrm{ka}$ is the second highest of the record, it is certainly possible that an unusual cold event occurred at MIS 5d. Perhaps though, the subantarctic abundance at 110 ka may still be artificial in some way, given it is unusually high for the record. It is unlikely to be a counting or identifying error, since only samples from MIS 12-6 were used for the thesis work. There is a slight chance that this sample may have been swapped with one from another interval, though this is unlikely as well, since all samples were labeled with their core depth, core section and core section depth. Therefore, by eliminating the obvious questions about the lab handling of sample, it appears that the event in MIS 5d is real. Furthermore, offshore pollen records from the Challenger Plateau show an anomalously high increase in shrubs and grasses, which are reliable palynological indicators of cold climate (McGlone, 1995), in this period (M. Ryan, MSc thesis, unpub.) While it is unlikely that SSTs were as low as $\sim 8^{\circ} \mathrm{C}$, it is very likely that a significant cold event did occur in the eastern Tasman Sea at this time. Given the northward migration of the STF in cold periods (Howard and Prell, 1992, Sikes et al. 2009), it is possible that the local STF migrated towards MD06-2986 for a time in stadial 5d to either impinge on the site or shed eddies northward as has been recorded off eastern Chatham Rise (Chiswell, 2001). 


\subsubsection{Temperate taxa post-MIS 12}

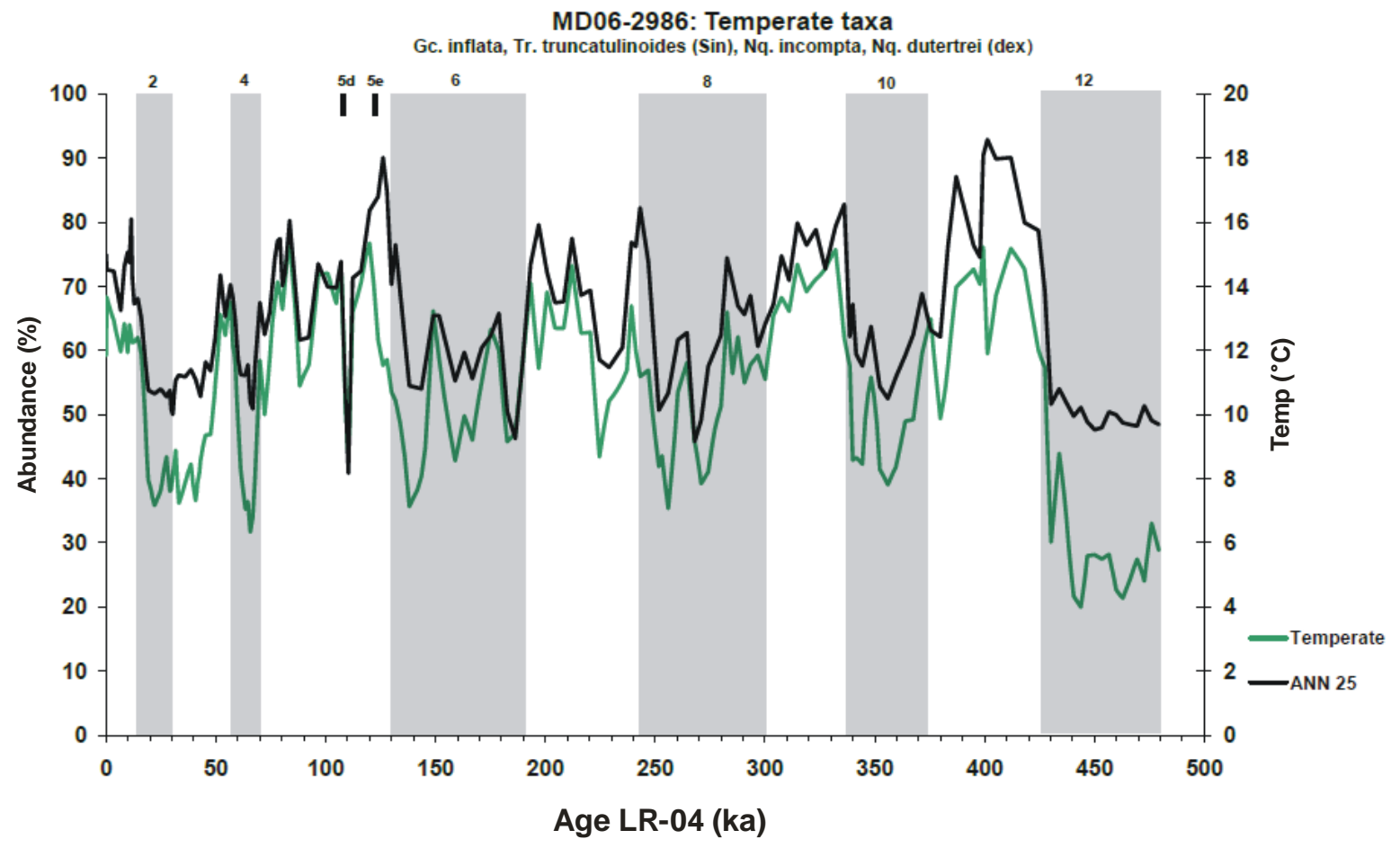

Fig. 5.6 - Temperate taxa and ANN 25 from MD06-2986

The abundance of temperate taxa was markedly low for most of MIS 12 ( 20-30\%); but given the strength of this glacial period, this is unsurprising. However, after MIS 12, temperate taxa dominate the assemblages, reaching $\sim 75 \%$ in interglacials and $\sim 35-40 \%$ in glacials (average $\sim 53 \%$ ) (Fig. 5.6). The temperate taxa display pronounced cyclicity of 80$120 \mathrm{kyr}$ cycles during G-IG transitions through the record. Although dominant in the eastern Tasman Sea, temperate taxa abundances are not as high as in ODP 1123, where abundances reach $\sim 95 \%$ (average 71\%) (Crundwell et al., 2008). 


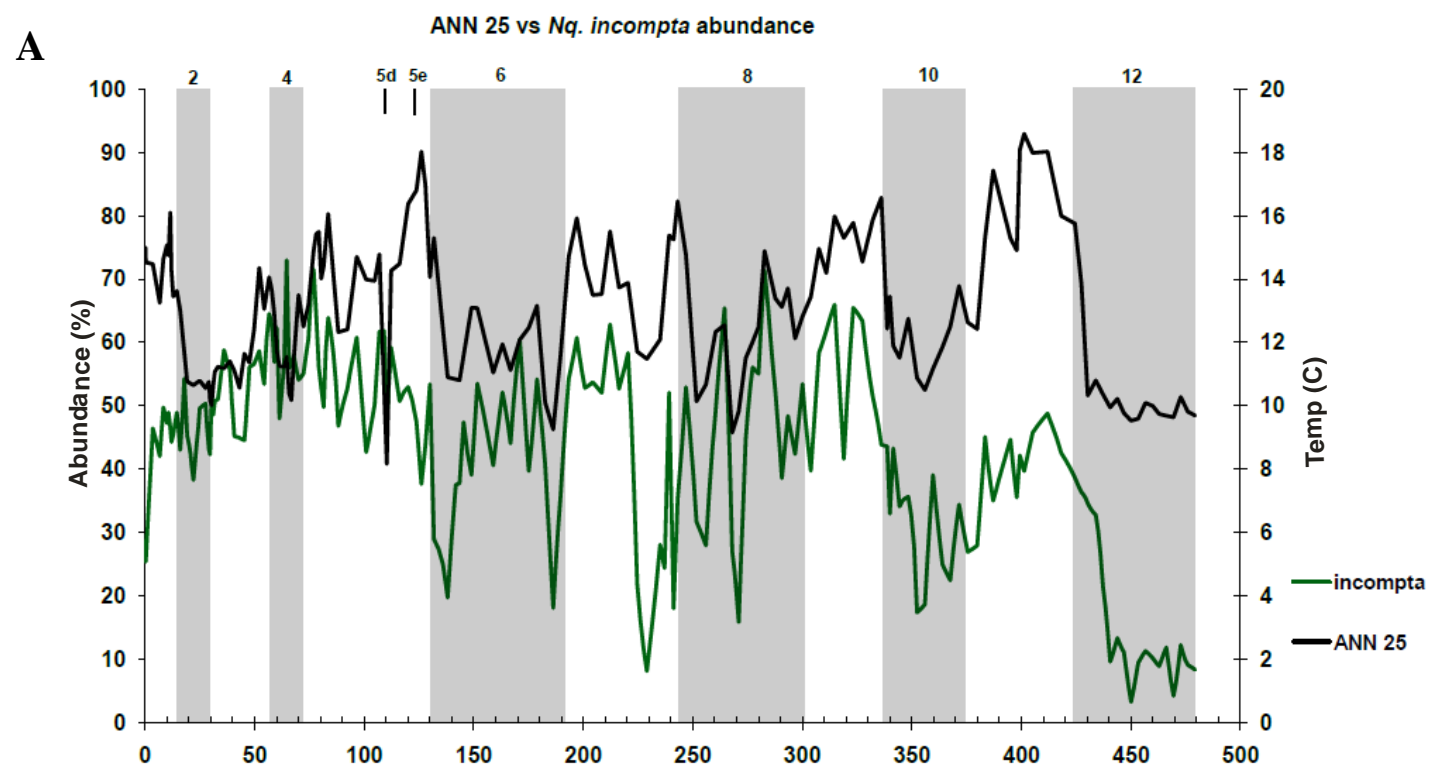

B

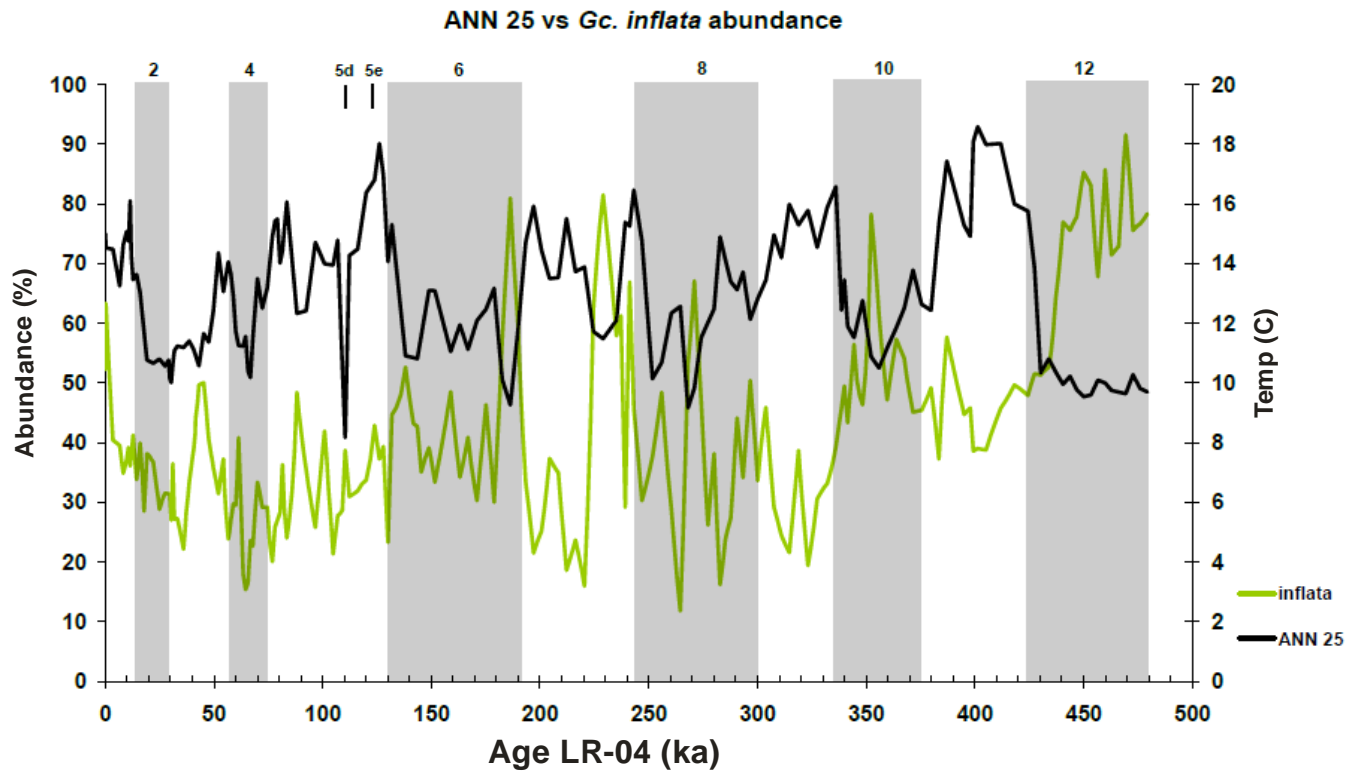

Fig. 5.7A - Abundance of Nq.incompta (relative to the temperate taxa) and ANN 25 for MD06-2986. Fig 5.7B - Abundance of Gc. inflata (relative to the temperate taxa) and ANN 25 for MD06-2986. Note the inverse relationship with abundance of $N q$. incompta higher during warmer periods and Gc. inflata thriving in cooler conditions until MIS 5, when the onnosite relationshin occurs.

The two main temperate species, Neogloboquadrina incompta and Globoconella inflata, account for $>90 \%$ of the record of temperate species. When these species' abundance relative to the temperate taxa is individually plotted against $\mathrm{SST}_{\mathrm{ANN} 25}$, several interesting trends become apparent (Figs. 5.7A, B). First, there is a negative correlation between the species, similar to that reported by Crundwell et al. (2008) for ODP 1123. Nq. incompta thrived in the warmer parts of the interglacials while Gc. inflata thrived in the cooler parts of the interglacials. It appears that $N q$. incompta preferred warmer water. Secondly, the 
record can be divided into four distinct time periods; MIS 12, MIS 11-10, MIS 9-6, MIS 51, based on the abundances of Gc. inflata and Nq. incompta. Thirdly, there is a response from both species to the anomalous cooling of early MIS 6. However, there is no clear response in MIS 5d.

Four distinct patterns through the record highlight the ecological differences between the two species.

- MIS 12 is characterised by low abundance of the temperate taxa ( 20-30\%), 80\% of which is Gc. inflata. This interval was markedly different from all other intervals as the abundances of Gc. inflata and Nq. incompta were the highest and lowest of the entire record, respectively.

- The abundance of Gc. inflata and Nq. incompta during MIS 11 and MIS 10 appeared to be a transition period for these species between MIS 12 and MIS 9-6. The abundance of $N q$. incompta in MIS 11 was lower than subsequent interglacials, despite MIS 11 being characterised as a warm, sustained "super-interglacial." Its abundance throughout MIS 10 was overall lower than in subsequent glacials (though some intervals briefly attained a lower abundance, i.e. minima in MIS 8 and 7.) Abundances of Gc. inflata in MIS 11were higher than in subsequent interglacials, and MIS 10 abundances of Gc. inflata were higher than in subsequent glacials. The abundances of these two species, along with the lack of variation generally throughout these intervals, set MIS 11 and 10 apart from other periods.

- MIS 9-6 is characterised by an overall decrease of Gc. inflata to $\sim 35 \%$, and a slight decrease of $N q$. incompta, though both vary significantly within the period. Cool intervals throughout this period were marked by a rapid increase in Gc. inflata, and a subsequent decrease in $N q$. incompta.

- MIS 5-1 was distinctly different to the other stages because, although the negative correlation between the two species still applied, the temperature relationship between the two species was reversed: $N q$. incompta increased during cold periods, and Gc. inflata increased during warm periods. For instance, Gc. inflata's lowest 
abundance in this interval $(\sim 15 \%)$ coincided with SST minimum during MIS 4 . It did not have a response to the cooling event of MIS 5d, and it increased in abundance from MIS 2 to present day ( $65 \%)$. Nq. incompta, meanwhile, increased in abundance to the SST minimum in MIS $4(\sim 70 \%)$, and decreased in abundance $(\sim 25 \%)$ to present day with little variation. It appears that Gc. inflata preferred warmer waters and Nq. incompta preferred cooler waters during MIS 5-1. While it is true that assemblages from MIS 5-1 were identified and counted by a different worker (Martin Crundwell), the samples from MIS 12-6 were also verified by MC to make sure identifications were correct, so it appears that this likely is not a factor.

There are two unique features of the temperate taxa record. One feature is that G-IG transitions in the early part of the record coincided with increases of $N q$. incompta abundance by $\sim 45-50 \%$, though this did not occur during the MIS 6-5 and MIS 2-1 transitions. Another unique feature of the temperate taxa, particularly for the early part of the record, was that interglacials were defined by a higher, sustained abundance of $N q$. incompta, with less variation. The $\sim 50 \%$ increase occurred in the MIS 12-11, and 10-9 transitions, but did not occur at MIS 8-7. Instead, it occurred in MIS 7a at 229-224 ka. The sustained, less varied abundance of Nq. incompta also occurred in MIS 7a. MIS 7 is an unusual interglacial in that global $\delta^{18} \mathrm{O}$ records indicate an extended cold period abruptly after the MIS 8-7 transition (7c), with ice volume and temperature values decreasing to near glacial values in 7b, and returning to interglacial values in 7a (Lisiecki and Raymo, 2005; Martinson et al. 1987). It is unclear why $N q$. incompta did not respond to the MIS 8-7 transition (Termination III), yet did respond to MIS 7b/7a transition. Most likely, the onset of the cold event of MIS $7 \mathrm{~b}$ prevented $\mathrm{Nq}$. incompta from reaching its normal interglacial abundance until MIS 7a.

\subsection{Features of the SST record}

Comparison of the $\mathrm{SST}_{\mathrm{ANN}} 25$ record with other regional SST data is difficult, as MD062986 is the oldest dated record available in the Tasman Sea. The alkenone SST record of Pelejero et al. (2006) dates back to $350 \mathrm{ka}$ (SO136-GC3), and $450 \mathrm{ka}$ (FR1/94-GC3) and 
the $\mathrm{SST}_{\mathrm{MAT}}$ record of Barrows et al. (2007) extends back to $150 \mathrm{ka}$ (SO136-GC3) (Fig. 5.8). This section will begin by first comparing $\operatorname{SST}_{\mathrm{ANN}} 25$ with the $\sim 150 \mathrm{kyr}$ record of Barrows et al. (2007), followed by the $\sim 350 \mathrm{kyr}$ long Pelejero et al. (2006) dataset. Finally, a comparison will be made between the eastern and western Tasman Sea for the past $\sim 450$ kyr (Pelejero et al., 2006).

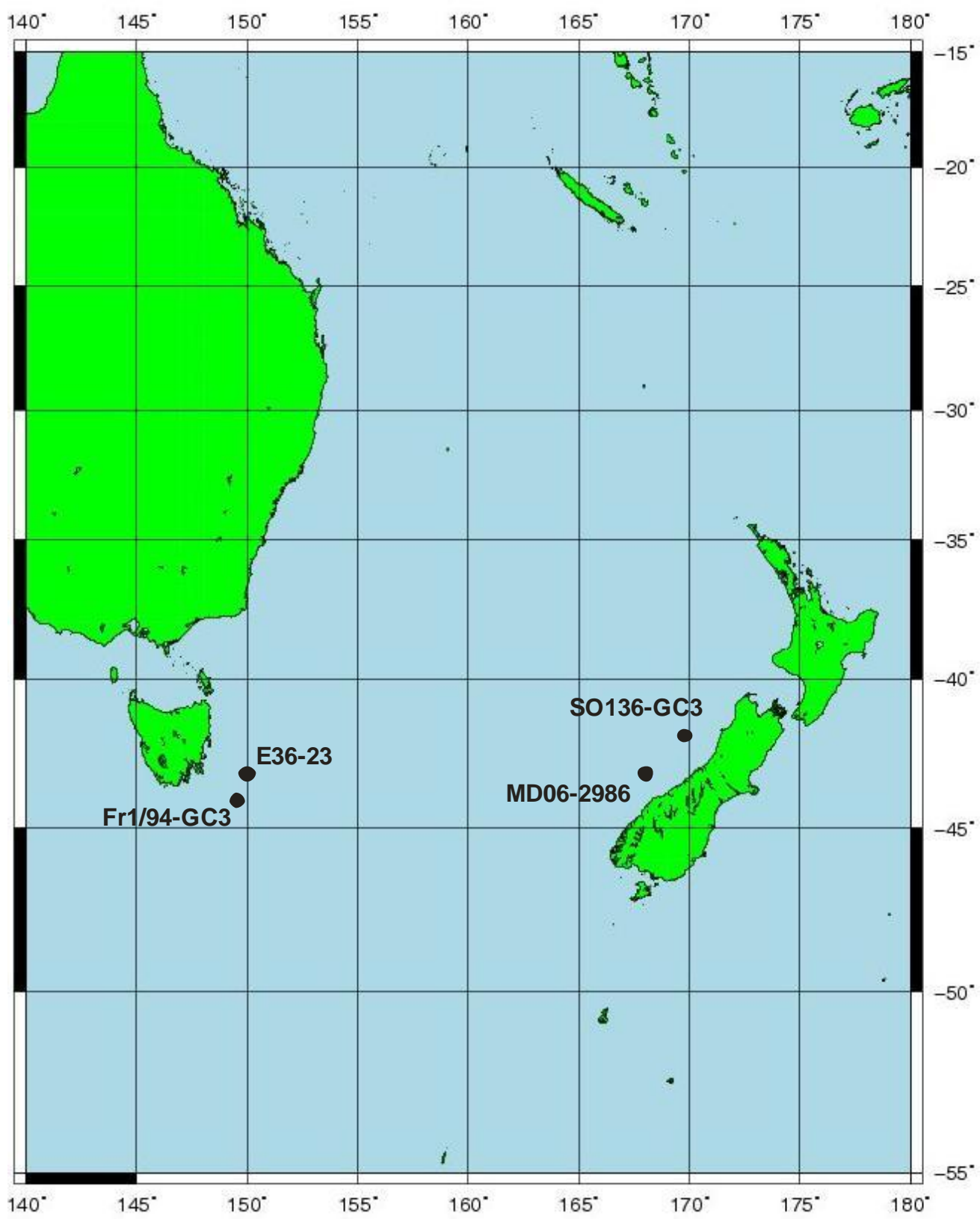

Fig 5.8 - Location of Tasman Sea Cores from Barrows et al. (2007), Pelejero et al. (2006) (SO136-GC3 and Fr1/94-GC3) and Martinez, (1994) (E36-23) 


\subsubsection{Eastern Tasman Sea Comparisons}

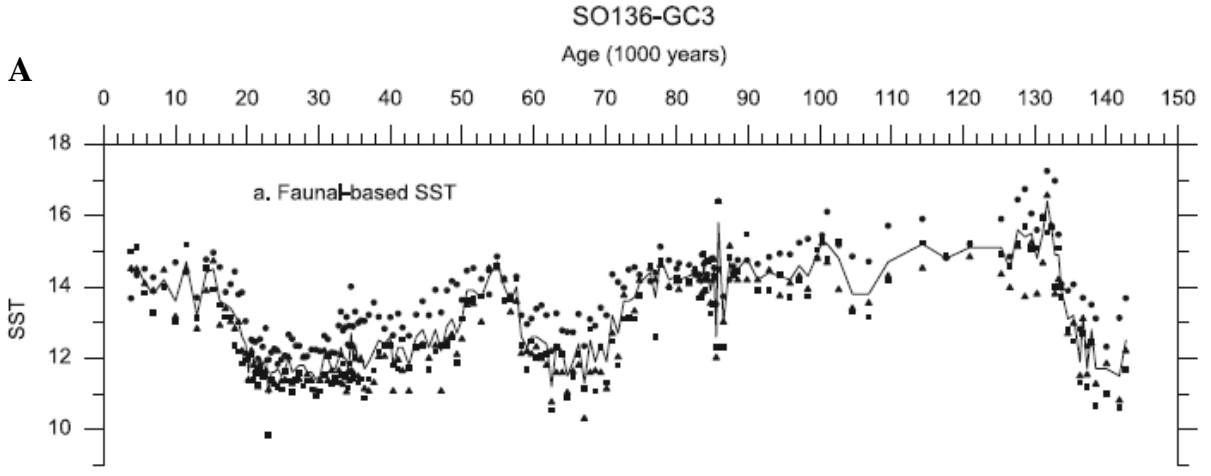

B

kyr BP

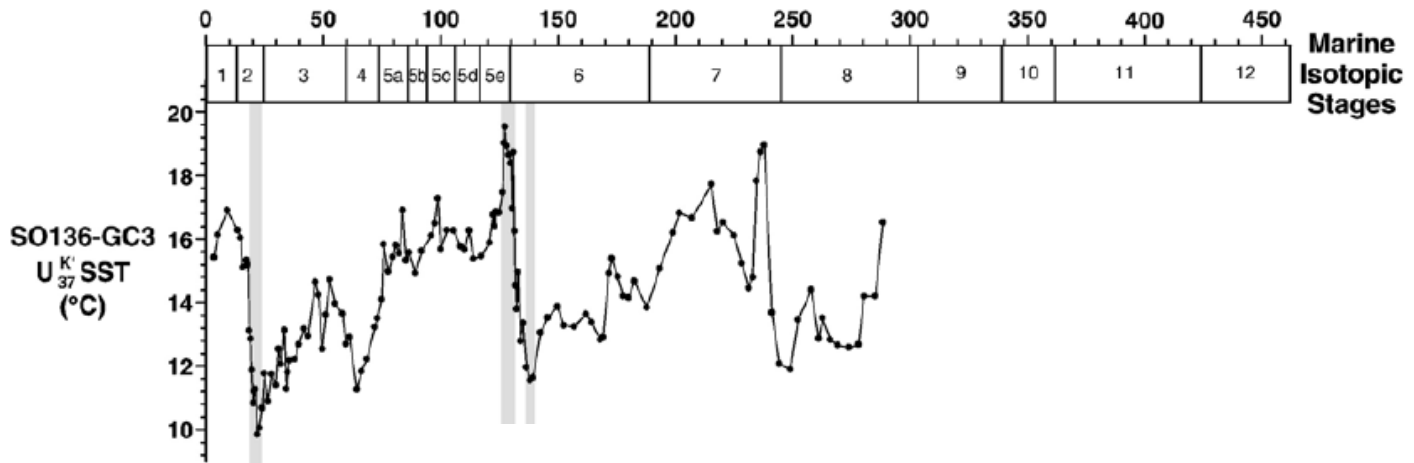

C

ANN 25 SST MD06-2986

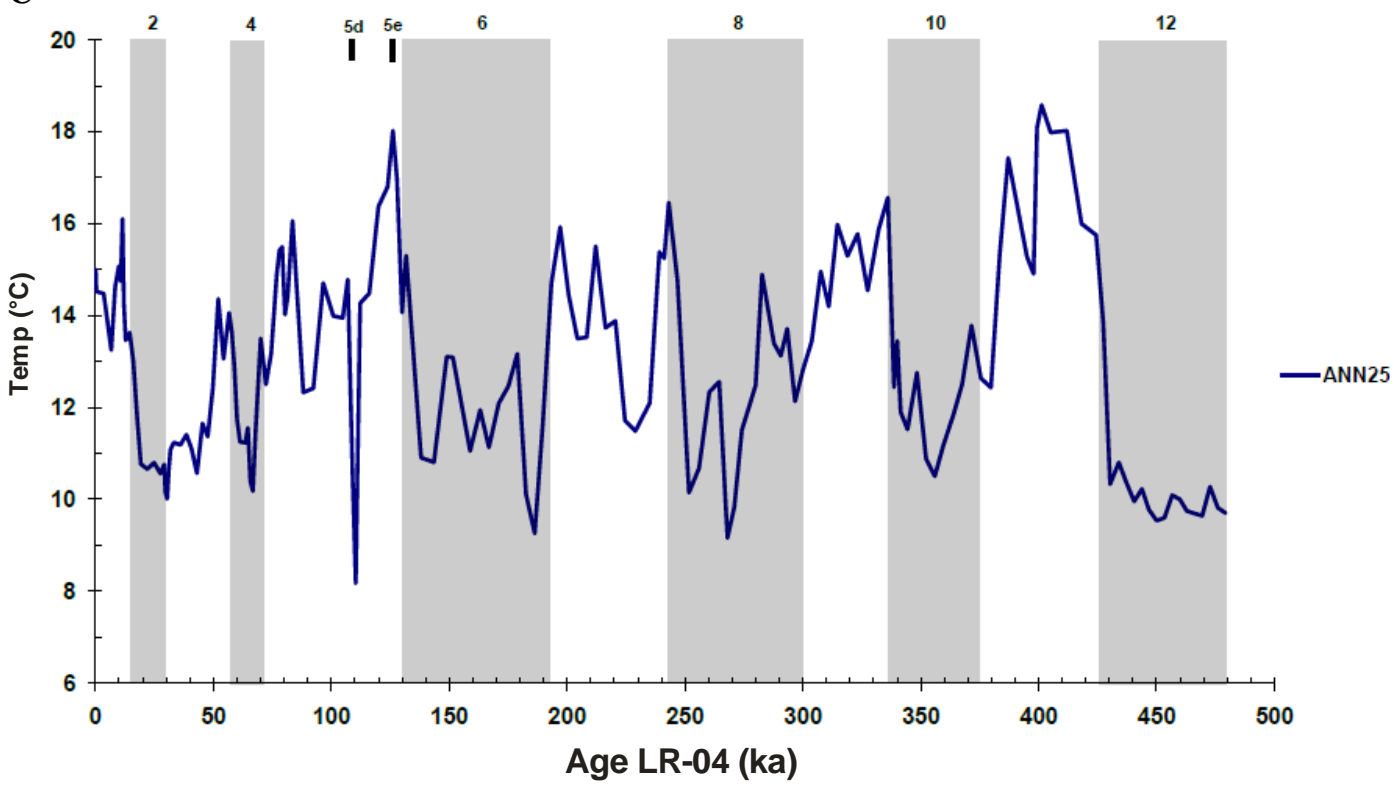

Fig. 5.9A - Faunal SSTs from eastern Tasman Sea over the last $\sim 150 \mathrm{kyr}$. SSTs are $\sim 1^{\circ} \mathrm{C}$ cooler during MIS 5e and $\sim 5^{\circ} \mathrm{C}$ warmer during MIS 5d. From Barrows et al. (2007). Fig. 5.9B - Alkenone SSTs from the same location over the last $\sim 300$ kyr. From Pelejero et al. (2006). Fig. 5.9C - SST ${ }_{\text {ANN } 25}$ from MD062986. Despite some small differences, both SST records compare well with MD06-2986. Different age models were used for the three records, so the time scale does not line up exactly. 
The faunal-based SST records of the Challenger Plateau (Barrows et al. 2007 and MD062986) are fairly similar. SST $_{\mathrm{ANN}} 25$ estimates plot within the errors of Barrows et al. (2007) SST (Fig 5.9A, C). However, three differences exist: the $\operatorname{SST}_{\mathrm{ANN} 25}$ temperature estimates for MIS 5e are $\sim 2^{\circ} \mathrm{C}$ higher than Barrows et al. (2007); SSTs are $1^{\circ} \mathrm{C}$ higher in the early Holocene; and $\mathrm{SST}_{\mathrm{ANN}} 25$ records a sharp temperature drop for MIS 5d. The timing of events also differs slightly, though this is probably due to the difference of the age models. Overall, the two SST records are in good agreement with each other, thus providing an independent test to the robustness of MD06-2986 $\mathrm{SST}_{\mathrm{ANN}} 25$ data.

Similarly, the $\mathrm{SST}_{\mathrm{ANN}} 25$ and alkenone SSTs from Pelejero et al. (2006) for site SO136-GC3 are comparable, but with a few differences (Figs. 5.9B, C). Maximum and minimum temperatures of the interglacials and glacials agree well, although alkenone SST estimations are generally higher than faunal-based SSTs (e.g. Barrows et al., 2007; Sikes et al., 2009). Pelejero et al. (2006) compared the SST amplitude change between glacials and interglacials from Terminations III-I $\left(7.1^{\circ} \mathrm{C}, 7.9^{\circ} \mathrm{C}, 7.1^{\circ} \mathrm{C}\right.$, respectively), which are comparable to MD06-2986 (7.3 $\left.\mathrm{C}, 7.4^{\circ} \mathrm{C}, 6.5^{\circ} \mathrm{C}\right)$. Pelejero et al. (2006) suggested that offshore western New Zealand was more susceptible to lower latitude SST changes associated with the Western Pacific Warm Pool and the TF, resulting in this large G-IG temperature change. Despite some minor differences between $\mathrm{SST}_{\mathrm{ANN}} 25$ and SST estimates of Pelejero et al. (2006), which may be mostly due to the different analytical methods used, SST estimates for the eastern Tasman Sea appear to be robust and discussion can now be focused on comparing SSTs between eastern and western Tasman Sea.

\subsubsection{SST comparison for eastern and western Tasman Sea}

For the first time, a SST comparison can be made from MIS 12 to present day between the eastern and western Tasman Sea. This comparison expands the current published paleotemperature record for the Tasman Sea by two full G-IG cycles. 
$\mathbf{A}$ kyr BP

\begin{tabular}{|c|c|c|c|c|c|c|c|c|c|c|c|}
\hline 0 & 5 & & 100 & 150 & 200 & 250 & 300 & & 350 & 400 & 450 \\
\hline \begin{tabular}{l|l}
1 & 2
\end{tabular} & 3 & 4 & $d 5 c$ & 6 & 7 & & 8 & 9 & 10 & 11 & 12 \\
\hline
\end{tabular}
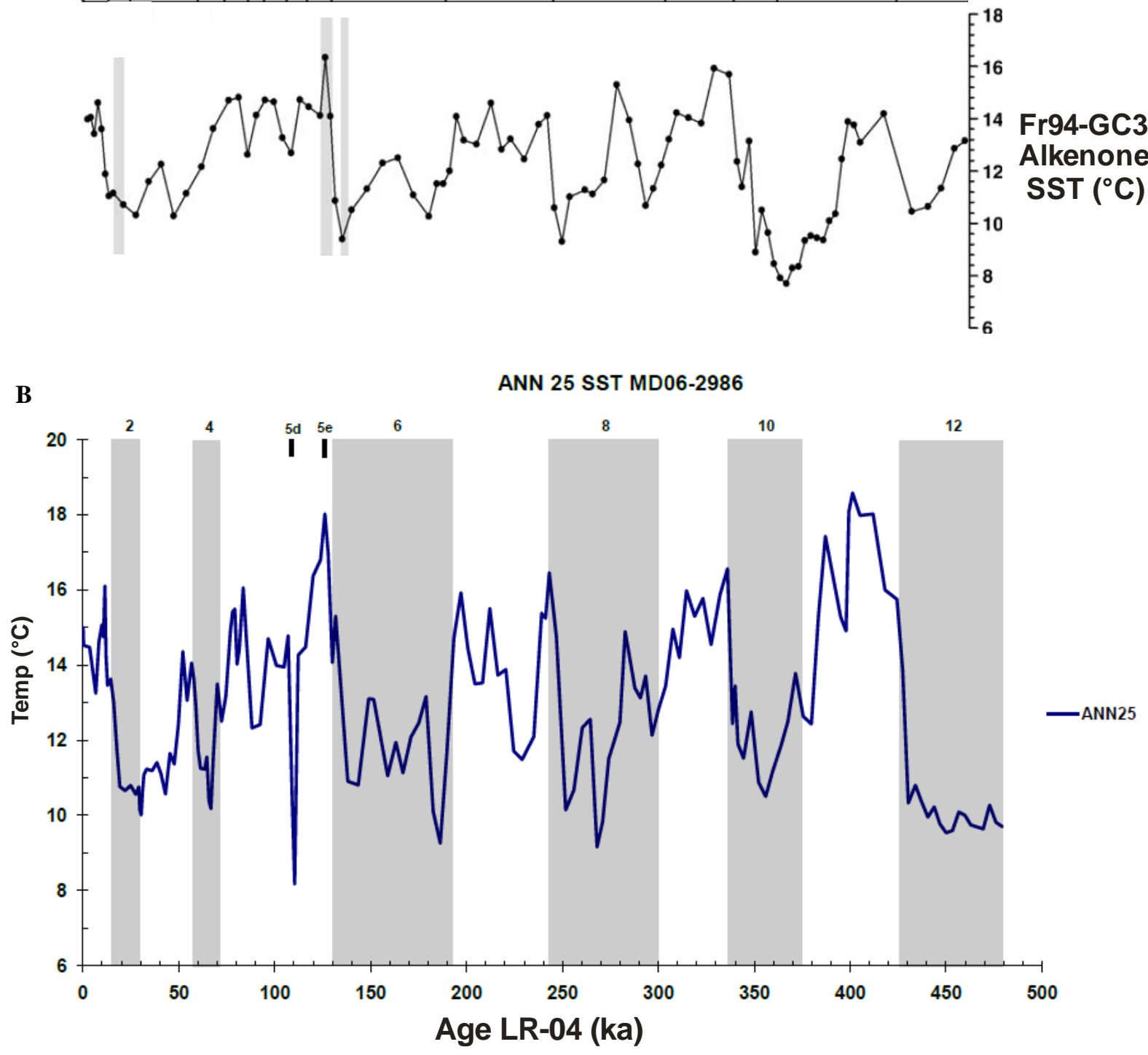

Fig. 5.10A - Alkenone SSTs from core Fr94-GC3, western Tasman Sea. From Pelejero et al. (2006). 5.10B - $\mathrm{SST}_{\mathrm{ANN} 25}$ from MD06-2986. Different age models were used for the two records, so the time scale does not line up exactly.

Core FR1/94-GC3 is located on the STR, just east of Tasmania, $\sim 44^{\circ} \mathrm{S}$ (Fig. 5.8). The 450 kyr alkenone SST record of Pelejero et al. (2006) shows low amplitude SST fluctuations between glacials and interglacials $\left(\sim 4-7^{\circ} \mathrm{C}\right)$, increasingly warmer SST minima for glacial periods, a warmer-than-expected MIS 12, a colder-than-usual MIS 11, and a cold MIS 10 (Fig. 5.10A). Pelejero et al. (2006) concluded that the low peak interglacial temperatures $\left(<16^{\circ} \mathrm{C}\right)$ indicated that the STR was susceptible to high latitude SST changes. 
Comparison of SST $\mathrm{ANN}_{25}$ records of MD06-2986 (eastern Tasman Sea) and alkenone SSTs of Pelejero et al. (2006) (western Tasman Sea) reveals several differences (Figs. 5.10A, B). MIS 12 in the western Tasman Sea was relatively warm $\left(\sim 10.5-13.5^{\circ} \mathrm{C}\right)$ compared to the eastern Tasman Sea $\left(\sim 9.5-10.8^{\circ} \mathrm{C}\right)$. MIS 11 was cooler in the west $\left(\sim 14^{\circ} \mathrm{C}\right)$ compared to the east $\left(\sim 18^{\circ} \mathrm{C}\right)$. MIS 10 was significantly colder in the west, with SST minima of $\sim 8^{\circ} \mathrm{C}$, compared to an SST minimum of $\sim 10.5^{\circ} \mathrm{C}$ in the east. Peak temperatures in the western Tasman Sea were $\sim 16^{\circ} \mathrm{C}$ in MIS 9 and 5e, compared to $\sim 18^{\circ} \mathrm{C}$ in the western Tasman Sea in MIS 11 and 5e.

The G-IG amplitude of SST change between eastern and western Tasman Sea derived here is not particularly different from the results of Pelejero et al. (2006). Pelejero et al. (2006) suggest that the eastern Tasman Sea is more susceptible to expansions of the Western Pacific Warm Pool. This is known to occur but it is rare (Sutton et al., 2005). Indeed, subtropical taxa at MD06-2986 averaged only 0.6\% throughout the entire record (Fig. 5.1). The highest abundance of subtropical taxa was recorded in MIS 5e ( 7\%), and this total is still less than any interglacial spike in ODP Site 1123 off eastern New Zealand, a region that does receive direct inflow of STW (Stanton et al., 1997; Chiswell and Roemmich, 1998). Therefore, it seems unlikely that the G-IG SST amplitude change offshore western New Zealand was modulated by subtropical water inflow, as suggested by Pelejero et al. (2006).

The unusually low interglacial temperatures of the western Tasman Sea appear to be counter to the modern oceanography. The location of the FR1/94-GC3 has been shown to periodically receive direct flows of subtropical water from the East Australian Current, usually via a shedding of eddies (Ridgeway and Dunn, 2003). More recently, it has been proposed that STW from the Southwest Pacific Gyre flows down past Tasmania and turns westward into the Indian Ocean to form a Southern Hemisphere "supergyre" (Ridgway and Dunn, 2007). Hill et al. (2008) show the EAC arm of the subtropical gyre extending down to Tasmania as a result of wind forcing. With FR1/94-GC3 in the path of direct STW flow, it would be more likely that the western Tasman Sea, rather than the eastern Tasman Sea, would be more affected by enhancement of the Western Pacific Warm Pool. Sikes et al. (2009) produced alkenone SSTs for the South Tasman Rise. Core RS147-GC14 (Fig. 2.14), located $\sim 45^{\circ} \mathrm{S}$, recorded an MIS 5e of $\sim 22^{\circ} \mathrm{C}$. In contrast to Sikes et al. (2009), $\mathrm{Mg} / \mathrm{Ca}$ ratios (Nürnberg and Groeneveld, 2006) from the STR at $\sim 43{ }^{\circ} \mathrm{S}$ record SST values similar 
to those of Pelejero et al. (2006). Nürnberg and Groeneveld suggest these are more representative of spring SSTs (similar to mean annual SST), whereas Sikes et al. (2009) suggest their temperatures are summer SSTs.

It is possible that the alkenone SSTs of Pelejero et al. (2006) were underestimated for interglacials. If this is the case, then we would argue for the opposite oceanographic interpretations of Pelejero et al. (2006) for the Tasman Sea, which is that the western Tasman Sea was more susceptible to inflow of both STW and SAW, whereas the eastern Tasman Sea was more isolated from any major incursions of STW or SAW. In order to assess this, faunal composition plus SST data must be compared. While there is no faunal data for FR1/94-GC3, there is faunal data available from core E36-23 (Martinez, 1994), located at $\sim 43^{\circ} \mathrm{S}$ east of Tasmania. The abundance of the subantarctic taxa from this core is high ( 40-80\%) compared to MD06-2986 (0-31\%). Supporting the conclusions of Ridgway and Dunn (2003), Ridgway and Dunn (2007) and Hill et al. (2008), the abundance of the subtropical taxa is at least $5 \%$ for the entire record and sometimes reached $10-15 \%$ in glacials and interglacials. This is higher than the abundance of subtropical species from MD06-2986 ( 0-7\%) and ODP Site 1123 ( 0-14\%) The significantly higher abundance of subantarctic and subtropical taxa compared to MD06-2986 is likely due to how Martinez (1994) grouped his species. For instance, he included the right coiling form of $N q$. pachyderma ( $N q$. incompta) in the subantarctic taxa, whereas we have included that form with the temperate taxa. Likewise, Gt. glutinata is grouped with the subtropical taxa in the E36-23 data, whereas we group it with the eutrophic taxa. This presents a problem for direct comparison of faunal data between eastern and western Tasman Sea.

For the subantarctic taxa, we decided to group Nq. incompta in with the subantarctic taxa and Gt. glutinata in with the subtropical taxa as a way to compare with Martinez (1994). When $N q$. incompta is added to the subantarctic taxa, the abundance of this taxonomic group does increase overall ( 8.6-67.8\%) (Fig 5.11). This is still far less than the $\sim 40-80 \%$ subantarctic 


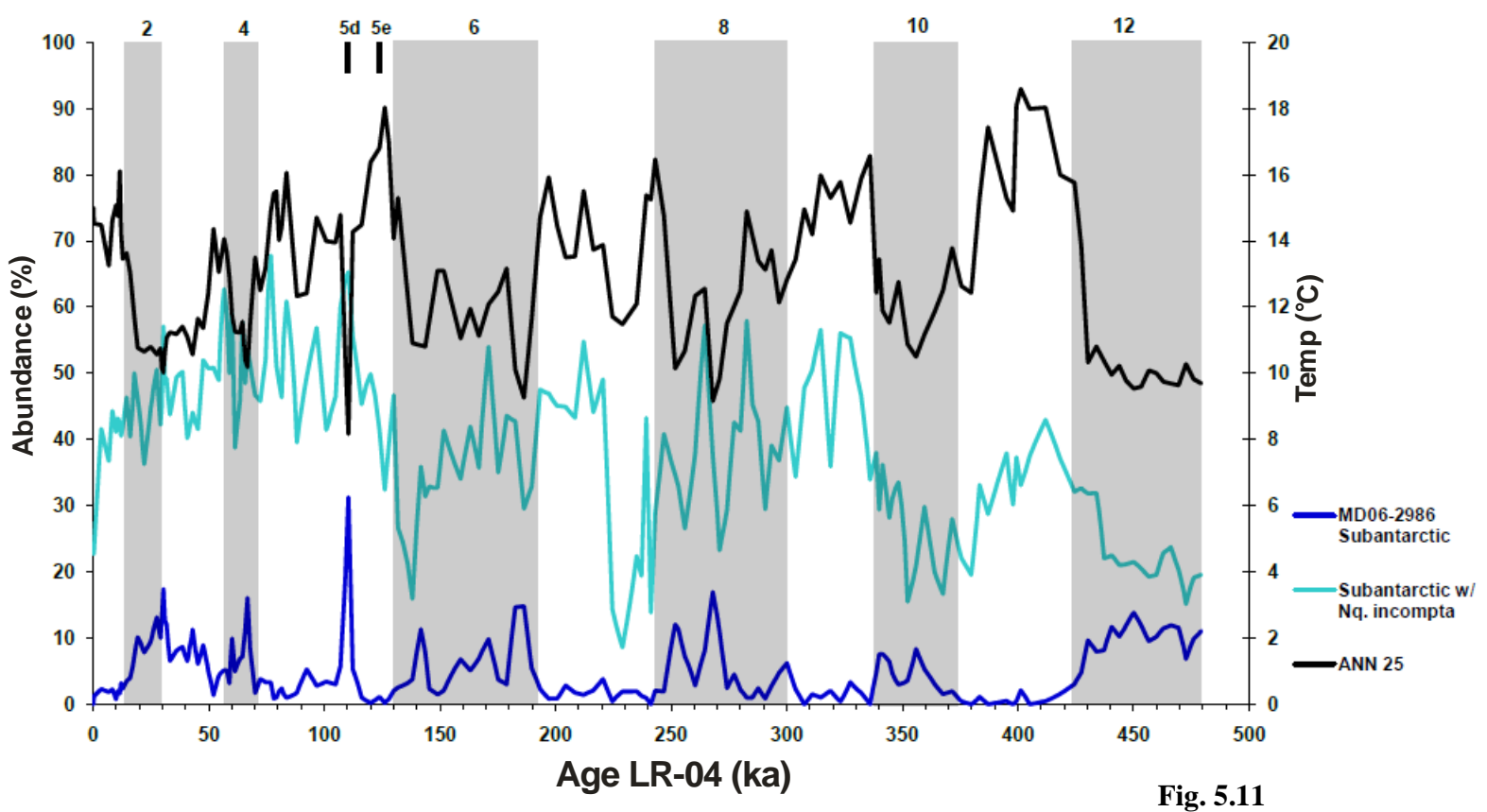

\section{N. pachyderma}

Left coliling $(\%)$

0102030405060

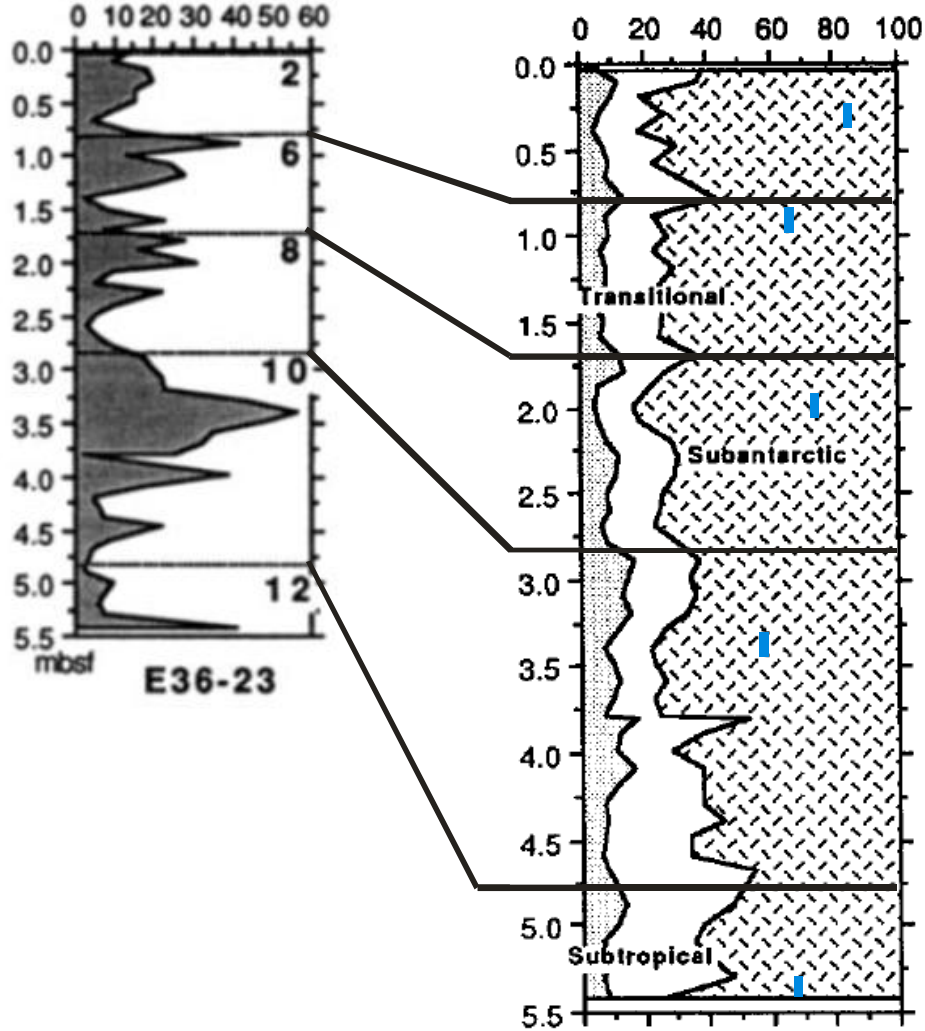

Fig. 5.11

Fig. 5.11 - (Above) Subantarctic taxa from MD06-2986 (dark blue) plotted against subantarctic taxa using the grouping of Martinez (1994) (turquoise). Subantarctic taxa at MD06-2986 are still less than the western Tasman Sea.

Fig. 5.12A - (Left) Coiling ratio Nq. pachyderma-Nq. incompta of E3626. Depths converted to match Marine Isotope stages in Fig. 5.12B. Fig. 5.12B - Planktic foraminiferal province composition of planktic foraminifera in E36-26. Blue lines indicate max abundance of $N q$. pachyderma at E36-23, calculated from coiling ratio of Fig. $5.12 \mathrm{~A}$, and summarised in Table I (after Martinez, 1994).

Table 5.1 - (Below) Summary of maximum abundances of $N q$. pachyderma, comparing abundances between east and west Tasman Sea. 
Subantarctic taxa comparison, eastern vs western Tasman Sea

E36-23 (Martinez 1994) MD06-2986

Latitude

$43^{\circ} 53^{\prime} \mathrm{S}$

$43^{\circ} 26^{\prime} \mathrm{S}$

MIS 12 max abundance

MIS 10 max abundance

MIS 8 max abundance

MIS 6 max abundance

MIS 2 max abundance

$\begin{array}{cc}31 \% & 13 \% \\ 41 \% & 8 \% \\ 25 \% & 17 \% \\ 32 \% & 11 \% \\ 14 \% & 17 \%\end{array}$

abundance reported by Martinez (1994). Furthermore, including $N q$. incompta in with the subantarctic taxa demonstrates the temperate nature of this species, as the abundance of subantarctic taxa generally becomes higher in interglacials than in glacials. By selecting the maximum Nq. pachyderma (S) coiling ratio of Martinez (1994) for each glacial stage, and comparing this number to the corresponding subantarctic taxa abundance for E36-23, we were able to get a rough estimate of the maximum amount of $N q$. pachyderma that make up the subantarctic taxa in glacial periods, and then compare it to MD06-2986 (Fig 5.12A, B). The abundance of Nq. pachyderma for E36-23 was much higher than for MD06-2986 (Table 5.1) with max abundances of $\sim 14-41 \%$ compared to $\sim 8-17 \%$ (though maximum abundance (31\%) at MD06-2986 occurs at MIS 5d, an interval which is not discernable in the record of Martinez (1994) and not used in this comparison). Nevertheless, subantarctic taxa appear to have a higher abundance off eastern Tasmania than on the Challenger Plateau. This is not surprising, given the proximal location of E36-23 $\left(\sim 43^{\circ} \mathrm{S}\right)$ to the STF $\left(\sim 44-45^{\circ} \mathrm{S}\right)$, which is poorly constrained by the bathymetry and hence, prone to fluctuations and incursions of SAW (Sikes et al., 2009).

Comparing the abundance of subtropical taxa of Martinez (1994) is more difficult as there are no additional data, such as coiling ratios, to work with. Here, Gt. glutinata was combined with the subtropical taxa for MD06-2986 (Fig. 5.13) to see if abundances are similar to those of Martinez (1994). Given that present-day biogeographic data shows that abundances of Gt. glutinata are highest in subtropical waters, if the combined Gt. glutinata and subtropical taxa abundances are higher than the western Tasman Sea, Pelejero et al. 
(2006) may be correct in their suggestion that the eastern Tasman Sea is more susceptible to incursions of subtropical water from the Western Pacific Warm Pool. We added a line at 5\% abundance to determine higher or lower abundance than Martinez, (1994)

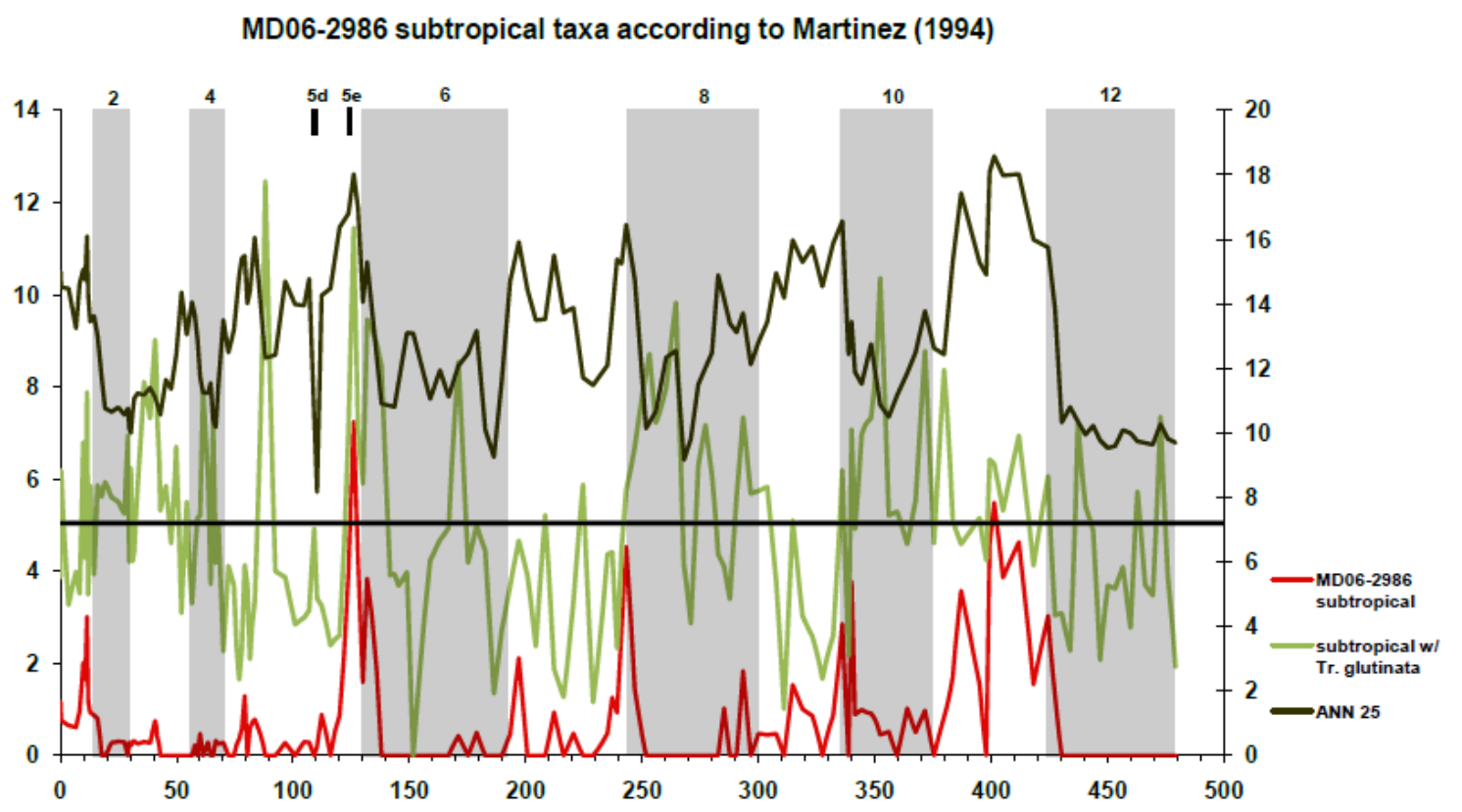

Fig 5.13 - Subtropical taxa from MD06-2986 (red) plotted against subtropical taxa grouping of Martinez (1994) (green). Subtropical taxa at MD06-2986 are still less than the western Tasman Sea.

(5\% was the minimum abundance throughout his record). While combining Gt. glutinata with the subtropical taxa does increase the overall abundance at MD06-2986, minimum abundance (0-1\%) is still well short of Martinez (1994). Furthermore, Gt. glutinata seems to increase in abundance more in the glacial periods, rather than the interglacials, and as a result, the subtropical abundance is now higher in some glacial periods than interglacial periods. This reinforces the idea that Gt. glutinata is more of a eutrophic species than a subtropical species (Boersma et al., 1998). Glacial periods tend to be more productive due to wind-induced upwelling (Shulmeister et al., 2004), and northward migrating nutrient-rich water masses (Weaver et al., 1998), so given that Gt. glutinata increases during glacial periods, this suggests that it is more of a nutrient-tracking species.

Regardless of how the data of Martinez (1994) and MD06-2986 are grouped, it is foraminiferal evidence that suggests that the western Tasman Sea received stronger STW and SAW inflow compared to the eastern Tasman Sea, which is not evident from alkenone SSTs alone (e.g. Pelejero et al., 2006). Contrary to Pelejero et al. (2006), it is suggested that 
the eastern Tasman Sea was not influenced by incursions of warm water from the Tasman Front. Instead, it appears that the eastern Tasman Sea, particularly the Challenger Plateau, was generally isolated from any major inflow of either high or low latitude source. SSTs from offshore western New Zealand were influenced mostly by climatic thermal changes as opposed to well-defined ocean inflows such as those offshore eastern New Zealand (Stanton et al., 1997; Chiswell and Roemmich, 1998; Sutton, 2003). This is evident from present ocean circulation charts (Carter et al., 1998), and also is supported from faunal data of MD06-2986, which indicate very little inflow during peak glacial and interglacial conditions. Proportions of subtropical taxa were low (average $\sim 0.6 \%$ ) throughout the record, and had only an elevated contribution ( 4-7\%) during SST maxima (Fig. 5.1). These abundances are well below those recorded from the western Tasman Sea (Martinez, 1994) and the Southwest Pacific off eastern New Zealand (Crundwell et al., 2008), two locations that receive direct STW inflow via the Subtropical Gyre (Tilburg et al., 2001; Ridgway and Dunn, 2007). Subantarctic taxa also had a low abundance (average $~ 5.1 \%$ ) which increased during glacial periods $(\sim 8-17 \%)$. While the subantarctic taxa do not make up a large proportion of assemblages, they make up a higher contribution than the subtropical taxa, implying that MD06-2986 was more influenced by northward migrations of the SAF (Howard and Prell, 1992) than southern incursions of STW via the Tasman Front (Martinez, 1994; Pelejero et al., 2006).

\subsubsection{MIS 11 vs Holocene}

MIS 11 is the longest and possibly warmest interglacial period in the last $500 \mathrm{ka}$ (Droxler, 2000, Howard, 1997). Important boundary conditions $\left(\mathrm{CO}_{2}\right.$, insolation) are similar to today (Loutre and Berger, 2003; Howard, 1997) which has led to suggestions that the evolution of global climate through MIS 11 can provide perspective as to how Earth's climate might evolve in the future - that is, MIS 11 may be a useful past analogue for future (natural) changes in climate (Loutre, 2003) and may provide a baseline against which we can assess the impact of greatly enhanced greenhouse gas emissions on the climate system. Hoddell et al. (2000) and Pelejero et al. (2006) provided evidence that surface water temperatures during MIS 11 in the South Atlantic sector of the Southern Ocean and Southwest Pacific Ocean respectively were not significantly warmer than other interglacial periods. This section compares the paleoceanography of MIS 11 and MIS 1 at MD06-2986 and provides a 
New Zealand perspective on (a) the relative local magnitude of SSTs between the two stages (b) the overall stability of temperature during the long MIS 11 interglacial and (c) changes in faunal assemblages between the two stages.

Here, MIS 11 is compared to the Holocene using SSTs and faunal responses from MD062986 (Figs. 5.14, 5.15A-D). It is important to acknowledge that the Holocene has a higher sample resolution than MIS 11 ( 750 years per sample vs. 1,650 years per sample, respectively). Very few data comparisons exist in the New Zealand region, as many records do not extend back as far as MIS 11. This study provides a unique opportunity to analyse the relationship between MIS 11 and the Holocene in the region.

Data from MIS 11 ranges from 430-400 ka, and is used to compare data from MIS 2 through to the present day (30-0 ka), to understand the relationship of the timing and magnitude of temperature increase and faunal response from a glacial period to an interglacial period. MIS 11 data from 400-370 $\mathrm{ka}$ is to be used as an analogue of future warming for the Holocene.

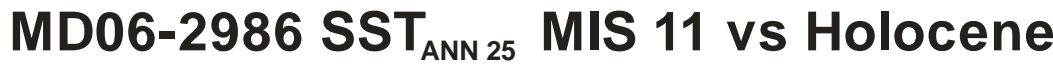

30 ka to present day plus 30 kyr future

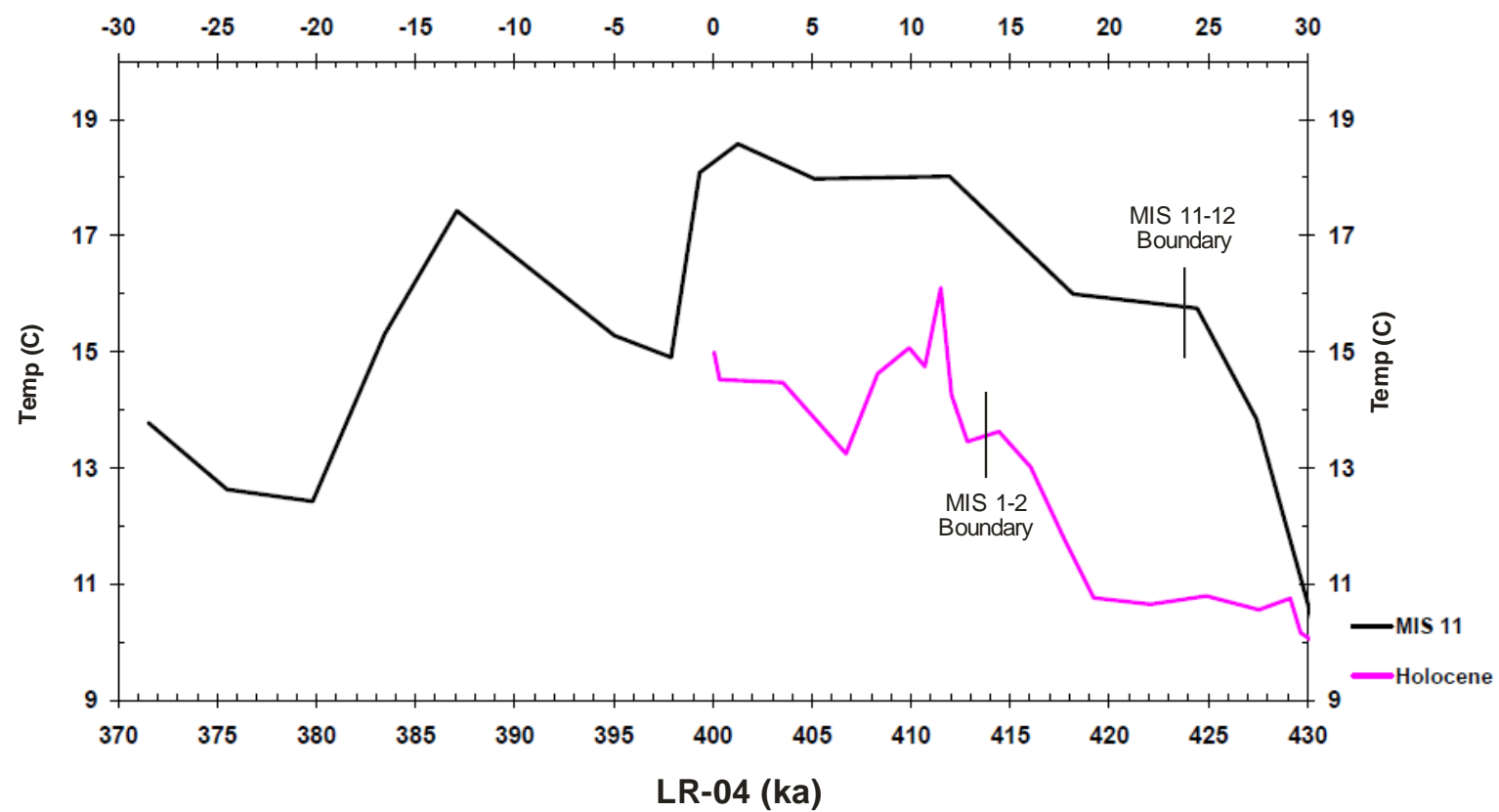

Fig. 5.14 - SSTs from MD06-2986 comparing MIS 11 (black, bottom X-axis) and the Holocene (pink, top X-axis). SSTs are plotted coincidentally so that after $400 \mathrm{ka}$ is analogue to future warming. SSTs overall are warmer during MIS 11. 
Comparison of SSTs (Fig. 5.14) shows that MIS 11 temperatures increased more rapidly at the end of MIS 12 than the temperatures did at the end of MIS 2. MIS 11 maintained overall higher temperatures $\left(\sim 2-4^{\circ} \mathrm{C}\right)$. Even during the Holocene Climatic Optimum, SSTs were $\sim 2^{\circ} \mathrm{C}$ higher in MIS 11 .

The response of foraminifera during these two intervals sheds light on why MIS 11 SST $_{\mathrm{ANN}}$ 25 was warmer than the Holocene (Figs. 5.15A-D). The comparison between the two faunal records is hampered slightly, because, as Crundwell et al. (2008) showed, taxonomic groups peak at different times during the glacial-deglacial phase. Thus, it is important, for instance, to compare the temperate abundance peak of MIS 11 with the temperate abundance peak of MIS 1, which may not occur at the same time period on the graph.

The glacial-deglacial response of temperate and subantarctic taxa was very similar in both MIS 11 and the Holocene. Temperate species appear to have risen rapidly before the G-IG transition, though the abundance of temperate taxa in MIS 11 continued to increase well after the transition (Fig 5.15 A). The abundance of Holocene subantarctic taxa (Fig. 5.15C) was similar to the trend of subantarctic taxa abundance from MIS 11, in that the abundance becomes insignificant to the present day (and MIS 11 analogue). There was a brief spike in late MIS $2(\sim 10 \%)$ that coincided with the LGM. 


\section{MD06-2986 Faunal data: MIS 11 vs Holocene}

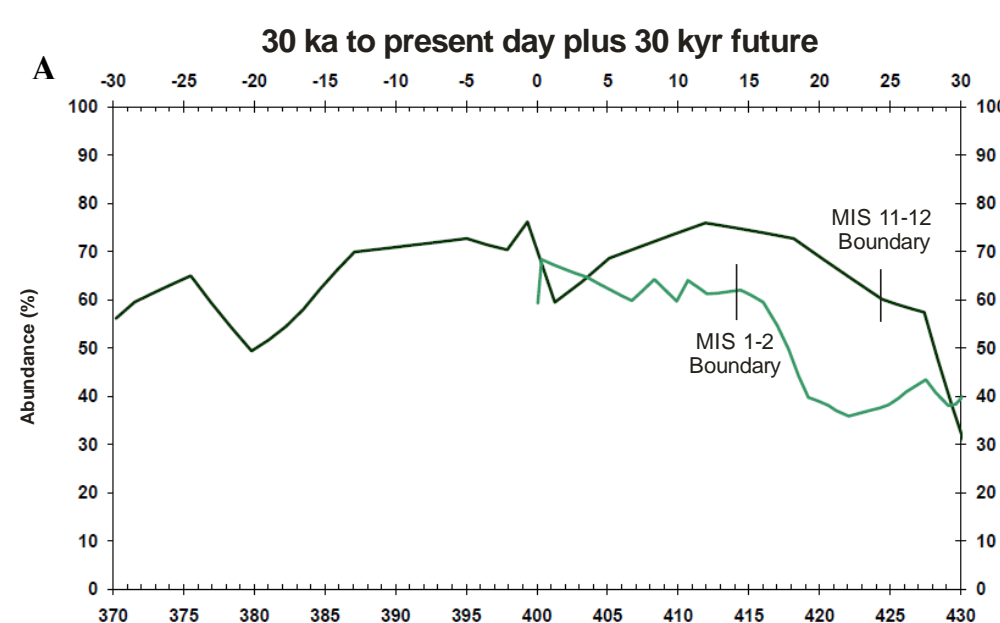

Temperate taxa: MIS 11 vs Holocene

Subantarctic taxa: MIS 11 vs Holocene

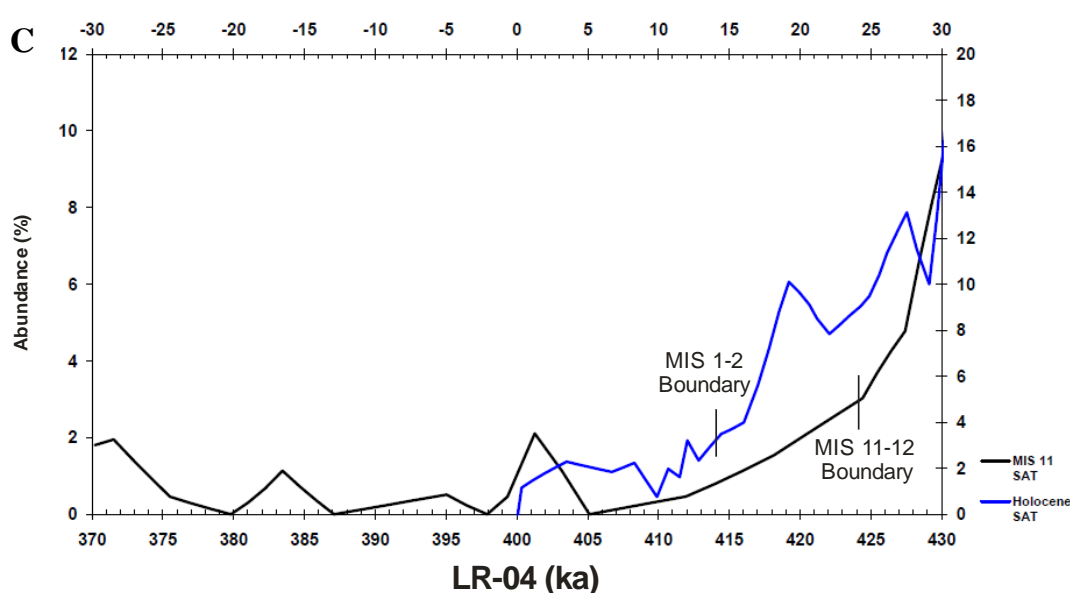

30 ka to present day plus 30 kyr future

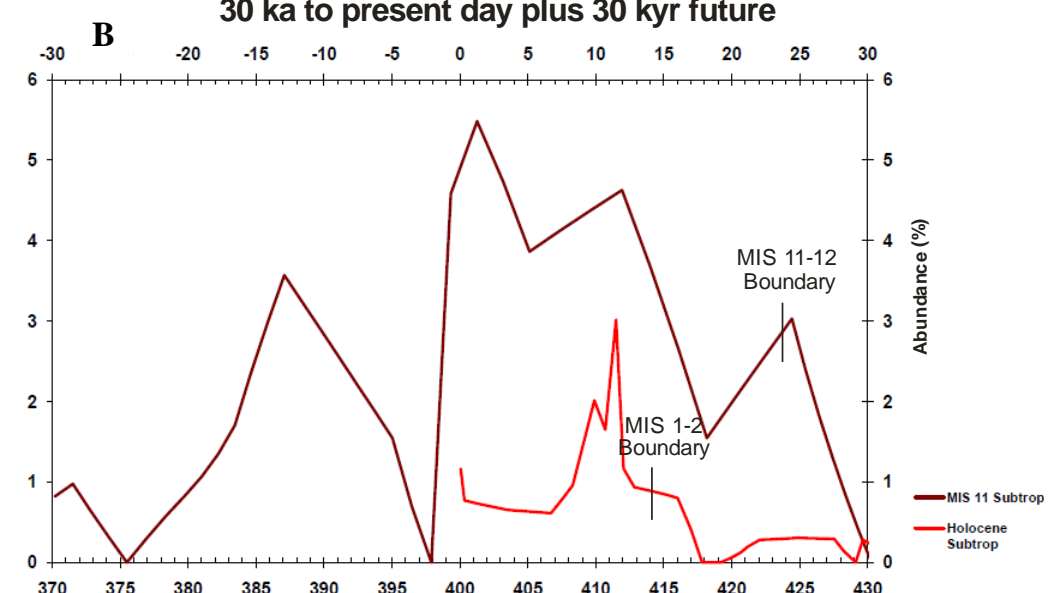

Subtropical taxa: MIS 11 vs Holocene

\section{Eutrophic taxa: MIS 11 vs Holocene}

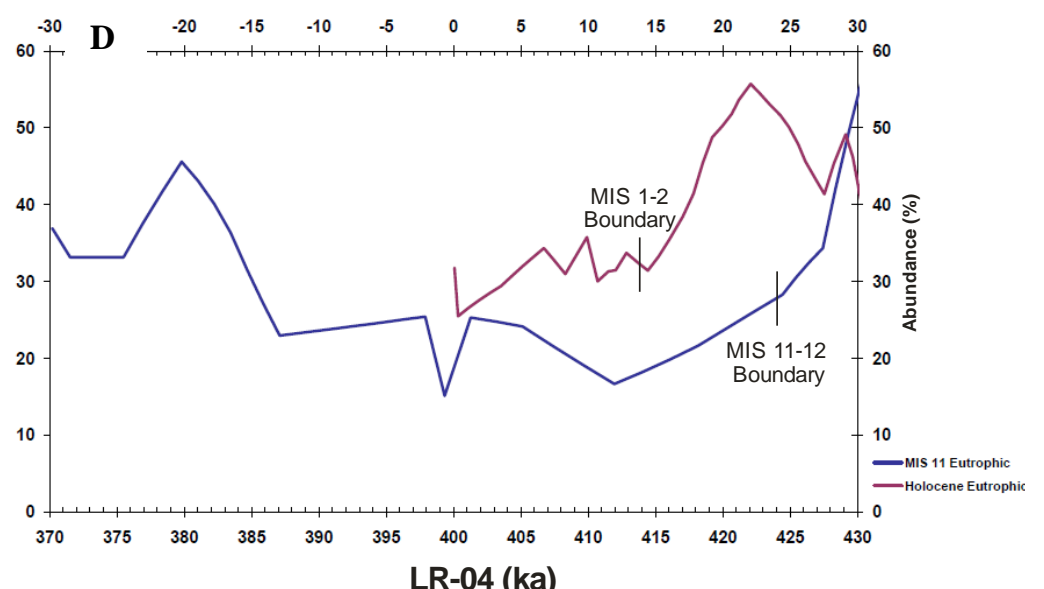

Fig 5.15 - Foraminiferal comparison of MIS 11 and the Holocene for MD06-.2986. A) Temperate taxa for MIS 11 (black, bottom axis) and Holocene (green, top axis). B) Subtropical taxa for MIS 11 (brown) and the Holocene (red). C) Subantarctic taxa for MIS 11 (black) and Holocene (blue). D) Eutrophic taxa for MIS 11 (blue) and the Holocene (purple). Dates for comparison between the two stages are from Loutre and Berger, (2004). 
The main faunal difference between MIS 11 and the Holocene is found in the abundance of subtropical and eutrophic taxa. The abundance of eutrophic taxa continued to decrease after the MIS 12-11 transition, whereas in the Holocene, the abundance of eutrophic taxa fluctuated, but remained roughly the same for about $\sim 10 \mathrm{kyr}$ after the transition. Subtropical taxa were higher in abundance ( 2\%) in MIS 11 than during the Holocene, and appears to have increased long after the MIS 12-11 transition, whereas in the Holocene, the abundance of the subtropical taxa appears to have already peaked, (though another future peak in abundance cannot be ruled out, especially given the state of the warming world). The combination of a higher abundance of eutrophic taxa and lower abundance of subtropical taxa in the Holocene suggests that the eastern Tasman Sea was cooler and more productive in the Holocene than during MIS 11, with well-mixed surface waters. While the overall abundance of subtropical taxa during MIS 11 is not spectacular relative to total faunal composition, it does suggest that warmer surface waters were present in the eastern Tasman Sea compared to the Holocene.

SST and faunal data from MD06-2986 show that MIS 11 was warmer than present day, which is consistent with results from the region (Hayward et al. 2008; Crundwell et al. 2009). The regional comparison illustrates that, despite having similar boundary conditions, MIS 11 was significantly warmer than the Holocene. This raises questions about the sensitivity of the climate to perturbations in the boundary conditions. For instance, could temperatures be expected to continue to climb even without influence from humans? Will human influence on climate push future temperatures higher than they were in MIS 11 ? Perhaps there are fundamental processes and mechanisms related to climate changes that we do not understand yet. These questions are outside of the scope of this thesis, however, more climate records from New Zealand and around the world are needed to increase our understanding of the oceanographic links between MIS 11 and the Holocene.

\subsection{Migration of the Subtropical Front, West of New Zealand}

The STF migrated north and south during glacial and interglacial periods respectively (Howard and Prell, 1992; Martinez, 1994; Nees, 1997, Sikes et al. 2009, Bard and Rickaby 2009), except where it has been constrained by bathymetry and associated current systems (Weaver et al., 1998, Hayward et al. 2008). This suggests that the lack of pronounced 
shallow bathymetry in the central and eastern Tasman Sea should give the STF freedom to shift northwards during glacial periods. Past research data have been insufficient to test this hypothesis, mostly owing to the scatter of SST records (e.g. DSDP 593 in Martinez, 1994; Pelejero et al., 2006; Barrows et al., 2007). In contrast, in the western Tasman Sea, there have been several studies done to resolve this. Passlow et al. (1997) suggested that the STF migrated north of $\sim 45^{\circ} \mathrm{S}$, while Martinez (1994) and Sikes et al. (2009) suggested that the STF migrated north to $\sim 43^{\circ} \mathrm{S}$ during glacial periods. Data presented from MD06-2986 suggest that the STF in the eastern Tasman Sea migrated northwards from its present location during glacials, coming close to MD06-2986 during MIS 12 and 5d. The supporting data are a combination of SSTs, faunal data, Nq. pachyderma/Nq. incompta ratios and productivity data. It is important to note that this study uses one core; therefore, it is impossible to constrain the exact paleo-movement of the STF. To overcome this, any suggested STF movements will be noted in terms of proximity to MD06-2986.

$\operatorname{SST}_{\mathrm{ANN} 25}$ shows that MIS 12 and 5d were markedly cold (Fig. 5.2). Temperatures at these stages were $\sim 8^{\circ} \mathrm{C}$, which is $\sim 2^{\circ} \mathrm{C}$ colder than present-day SAW mean annual SST (Uddstrom and Oien, 1999). However, temperature alone cannot indicate a northward shift of SAW as the SAW was undoubtedly colder than today during glacials. The faunal composition record of the subantarctic taxonomic group (SAT hereafter) provides additional information (Fig. 5.1). The most prolific SAT abundance occurred in MIS 5d ( 31\%), and the longest sustained period of elevated abundance was in MIS 12 (8.5-13.5\% for most of the interval). SAT abundance reached $15 \%$ at least once in MIS 8, 5d, 4, and the 3-2 boundary, and at least $10 \%$ for all other glacial periods. Such abundances are not high, especially when compared to the SAT group from eastern New Zealand (Weaver et al., 1998; Schaefer et al., 2005; Hayward et al., 2008), where abundances reach upwards of 90\% in glacial periods. The reason for this major difference in SAT composition is probably due to the fact that eastern New Zealand receives a direct inflow of SAW and Circumpolar Surface Water from the ACC and its offshoots, whereas the eastern Tasman Sea has no substantial subantarctic inflow. 


\section{Ratio N. pachyderma/N. incompta}

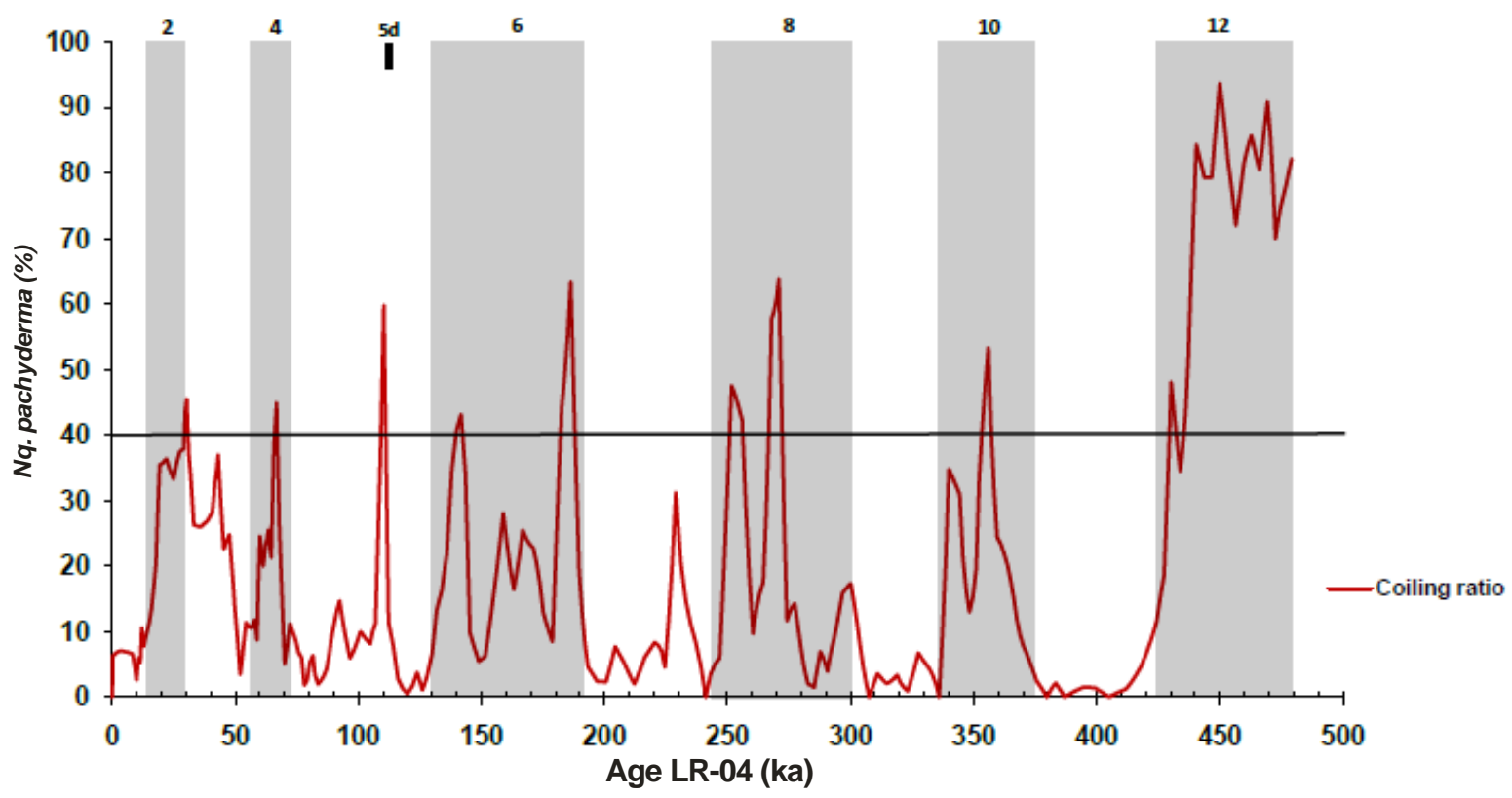

Fig. 5.16 - Ratio of Nq. pachyderma to Nq. incompta from MD06-2986 as a method of estimating STF movement. Black horizontal line indicates ratio needed to estimate whether STF reached the core, based on assumptions of Martinez, (1994).

Low SAT does not necessarily rule out a northward migrating STF. The ratio of $N q$. pachyderma/Nq. incompta ( $p / i$ here after) has been used as an indicator of STF movement, since more $N q$. pachyderma are mostly found south of the STF. We employ the methods and assumptions of Martinez (1994) and use a 40\% ratio as an approximation for the nearby presence of the STF (Fig. 5.16). Several features are revealed using this approach. First, the $40 \%$ ratio was exceeded several times, including at least once in every glacial period (except MIS 2, where it is found at the MIS 3-2 boundary) and MIS 5d. This may indicate STF movement toward MD06-2986 during these intervals. Second, the $p / i$ ratio in MIS 12 was markedly higher than other glacial periods, at 70-94\%. Third, the $p / i$ ratio was highest in the early or middle part of the glacial periods and decreased by the end. This indicates that glacial SSTs may have peaked in the middle of the glacial period, and then weakened towards the end of the period. 

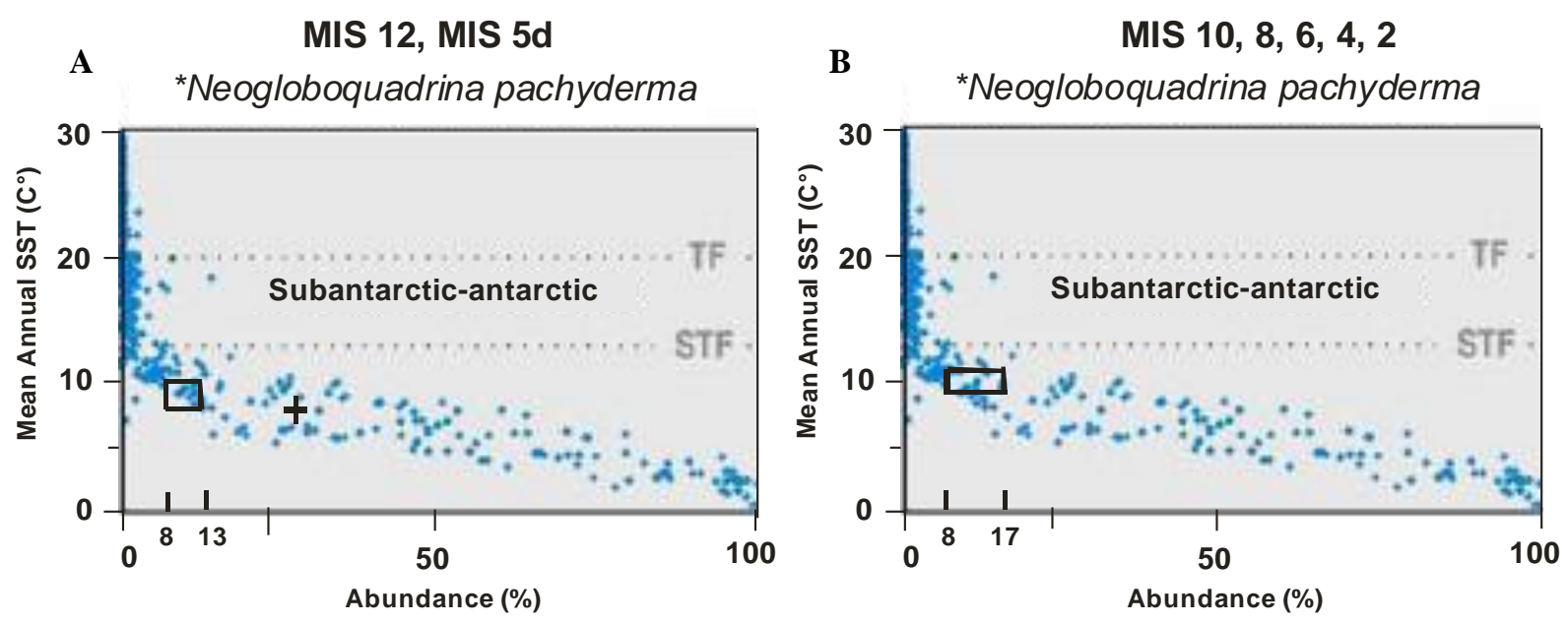

Fig. 5.17A - Present-day Southern Hemisphere biogeographic data of subantarctic taxa with the range of abundance plotted for MIS 12 (box) and MIS 5d (cross). 5.17B-Present-day Southern Hemisphere biogeographic data of subantarctic taxa with the range of abundance plotted for the rest of the glacials periods for MD06-2986. Modified from Crundwell et al. (2008).

Assemblage data of SAT species of MD06-2986 is compared to the assemblage data of the SH1204 coretop database to further elucidate STF movement. Figures 5.17A and 5.17B show the biogeography of the SAT of the SH1204 coretop database (Crundwell et al., 2008). Each coretop has a species abundance and associated present day SST. The figures show that the abundance of subantarctic species increases markedly south of the STF. For a data comparison to be useful, the estimated SST and abundance of the SAT of MD06-2986 must correlate with the temperature and abundances of the SH1204 database. Figure 5.17A has the abundance of SAT for MIS 12 and 5d plotted against the range of $\mathrm{SST}_{\mathrm{ANN}} 25$ from MD06-2986, and figure 5.17B plots the data ranges for the other glacials for when the $p / i$ ratio indicates STF movement. The assemblage data from MD06-2986 compares well with the SH1204 assemblage data, and based on the biogeography from the coretop database, it appears that the STF has migrated during the glacial periods, as indicated by the $p / i$ ratio. 


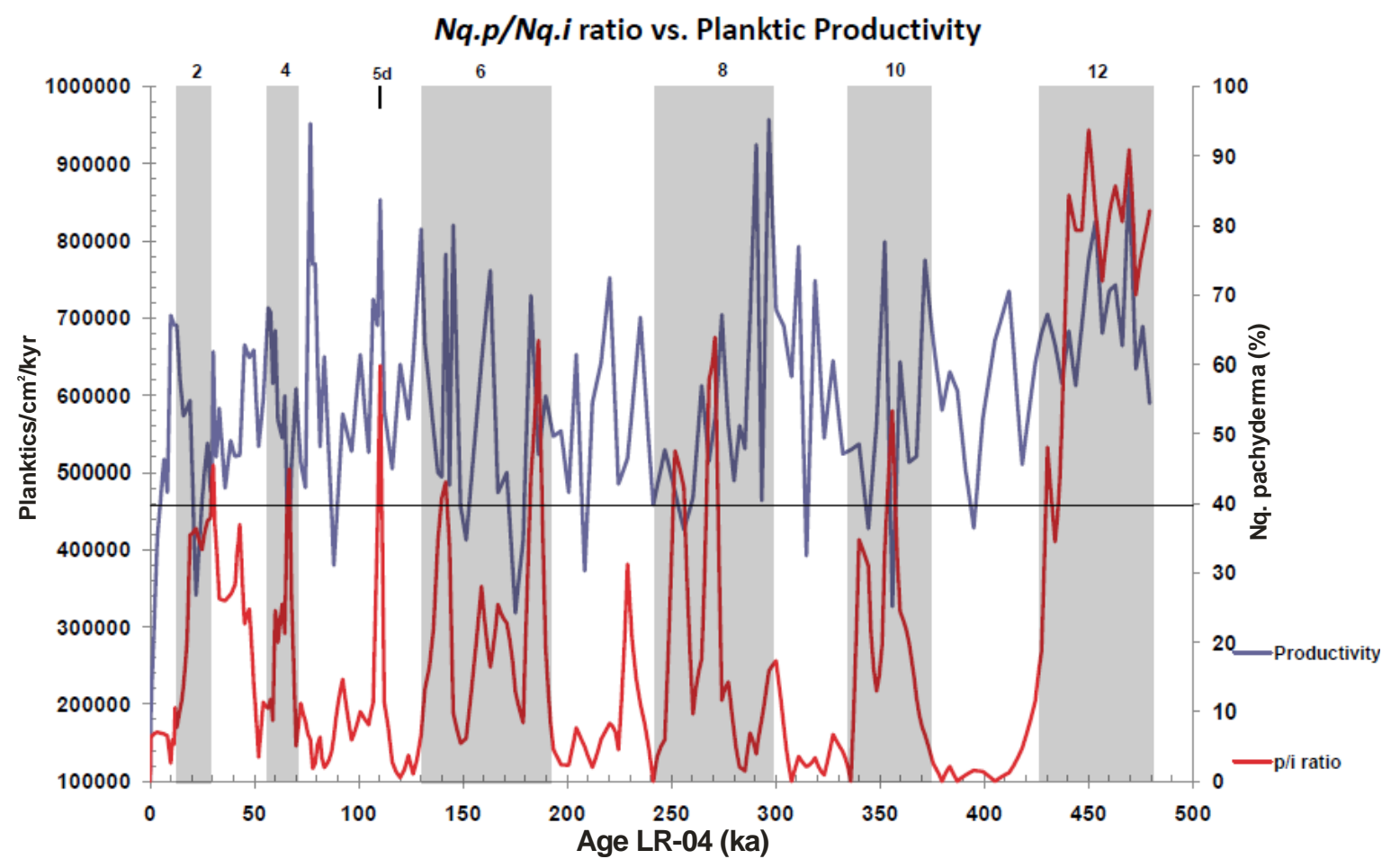

Fig 5.18 - Planktic productivity plotted against $N q . p / N q . i$ ratio as a method to separate apparent STF movement indicated by the ratio and periods of high productivity. Only during MIS 12 and MIS 5d does high productivity match with a $+\mathbf{4 0 \%}$ ratio.

If the STF did indeed migrate to MD06-2986 in all glacial periods as the assemblage and $p / i$ ratio suggest, then other proxies should show some response as well. Productivity has been used as an indicator of STF movement (e.g. Nees, 1997; 1999), and is higher at oceanic frontal boundaries (Yoder et al. 1994; Murphy et al. 2001). When planktic productivity is plotted against the $p / i$ ratio, the only time the highest productivity levels coincided with a $40 \% \mathrm{p} / \mathrm{i}$ ratio are in MIS $12\left(600 \mathrm{k}\right.$ and $800 \mathrm{k}$ planktics $\left./ \mathrm{cm}^{2} / \mathrm{ky}\right)$, and MIS 5d ( 950k $\mathrm{p} / \mathrm{cm}^{2} / \mathrm{kyr}$ ) (Fig. 5.18). In contrast, the other glacial periods where a $40 \% \mathrm{p} / \mathrm{i}$ was reached all coincide with low productivity, between $\sim 320 \mathrm{k}-520 \mathrm{k} \mathrm{n} / \mathrm{g}$. As described in the MIS 12 section, the productivity proxy is limited in that it may indicate other processes. High productivity could result from an increase in aeolian iron-rich dust, and upwelling as well. The presence of Tr. crassula in both MIS 12 and MIS 10 in the MD06-2986 record suggests upwelling could have been a factor. However, since productivity was much higher in MIS 12 than MIS 10, it cannot be upwelling alone, or else productivity levels should be similar to MIS 10. Since we can rule out aeolian dust influx as an influence on productivity levels in MIS 12 (Hesse, 1994), we suggest that a combination of upwelling from increased windiness (Shulmeister et al., 2004) plus a mixing of water masses from a northward 
migrating STF resulted in such high productivity levels. The combination of high $p / i$ ratio of this interval ( 70-94\%), high productivity and low, sustained SSTs, suggests that MIS 12 is the only glacial that the STF migrated very near to, or perhaps past MD06-2986.

MIS 5d is another period where a high $p / i$ ratio $(\sim 60 \%)$ and high productivity levels $(\sim 950 \mathrm{k}$ $\mathrm{p} / \mathrm{cm}^{2} / \mathrm{kyr}$ ) were attained. It appears as though that MIS $5 \mathrm{~d}$ is another interval where the STF could have migrated close to MD06-2986. Unlike MIS 12, we cannot rule out aeolian dust influx as a contributor to productivity (Hesse, 1994), so perhaps the elevated productivity levels of MIS 5d could be solely dust induced, a combination of aeolian dust influx and a northward migrating STF, or solely the mixing of water-masses along the migrating STF. Therefore, it is possible, but cannot be concluded with certainty, that the STF migrated as far north as MD06-2986.

The $p / i$ ratio, SST, faunal data and coretop biogeographic data suggest that the STF reached MD06-2986 at least once in MIS 10, 8, 6, 4 and at the 3-2 boundary. The only data demonstrating a difference between the STF occurrence in MIS 12 and 5d compared to other glacial periods is the productivity counts. This requires an explanation of why the $p / i$ ratio suggests that the STF may have reached MD06-2986 during MIS 10, 8, 6, 4 and the 32 boundary. One explanation could be that the STF migrated northwards during glacials towards the site, near enough that cold water eddies reached the Challenger Plateau, thereby increasing the abundance of $N q$. pachyderma. This could increase the $p / i$ ratio, perhaps to $40 \%$, without the STF actually reaching the site. Another explanation may be that the coiling ratio assumptions of Martinez (1994) are too simplistic. The Nq. pachyderma coiling ratio in E36-23 from the western Tasman Sea indicates that the STF did not reach the site at $\sim 43^{\circ} \mathrm{S}$ during the LGM, whereas Sikes et al. (2009) suggest it did, or came very near there. These contrasting conclusions may indicate some flaws in Martinez's assumptions. To get a complete understanding of data from $p / i$ ratios, it appears best to compare it with other proxies to properly interpret STF migrations. 


\subsection{Dissolution in the Tasman Sea}

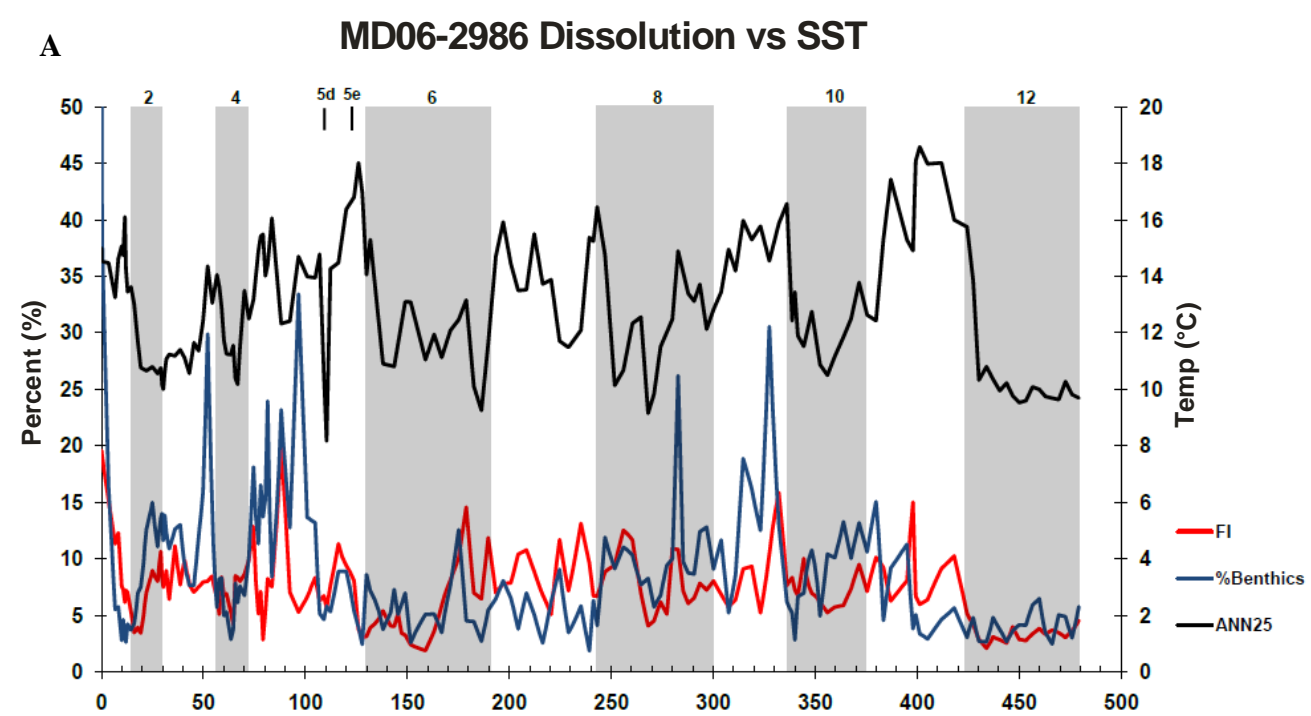

B MD06-2986 Dissolution vs Productivity

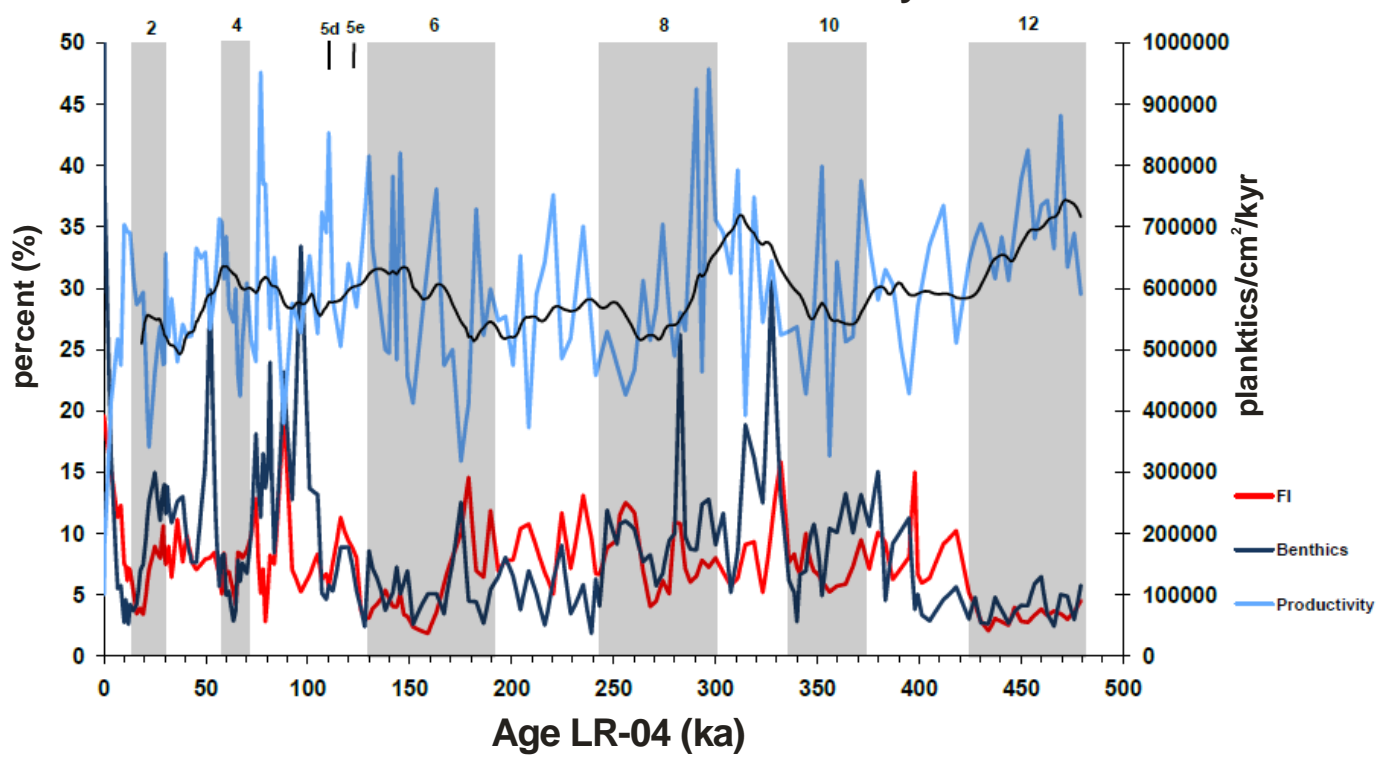

Fig. 5.19A - Measure of dissolution for MD06-2986 using the fragmentation index (Le and Shackleton, 1992) and \% benthics (Thunnel, 1976). Fig. 5.19B-MD06-2986 dissolution and productivity as a method to analyse marine productivity effects on foraminifera. Trendline is a 25-point moving average.

The Fragmentation Index (FI) (Le and Shackelton, 1992) and \% benthic foraminifers in the total foraminiferal assemblage (Thunnel, 1976) provide robust proxies of dissolution for paleoclimate studies. MD06-2986 lies at a depth of 1,477 m, and is well above the Tasman Sea lysocline of $3600 \mathrm{~m}$ (Martinez, 1994b). FI is low (average 7.4\%) at MD06-2986, and therefore, assemblages are not adversely affected (Fig. 5.19A). Elsewhere in the region, dissolution at MD06-2986 is comparable to DSDP Site 593 on the Challenger Plateau 
(Martinez, 1994b), and R657 (Weaver et al., 1998) and ODP Site 1125 (Schaefer et al., 2005), both north of Chatham Rise. Core E36-26 (western Tasman Sea, Martinez, 1994b) has higher fragmentation (11-50\%) than MD06-2986. However, its $2521 \mathrm{~m}$ water depth is closer to the lysocline, so more dissolution should be expected, especially during glacial periods when the lysocline becomes less deep.

The dissolution record of MD06-2986 is devoid of any G-IG cyclicity. In particular, the MD06-2986 assemblages are generally more fragmented in interglacial periods than in glacial periods. Weaver et al. (1998) and Hall et al. (2001) suggest that fragmentation increased during glacial periods in the Southwest Pacific ocean due to an invigoration of the DWBC and a shoaling of the lysocline. However, since MD06-2986 is not located near the DWBC and is far above the lysocline, then these mechanisms would not affect dissolution here.

The low dissolution at MD06-2986 is also suggesting that test preservation is little affected by detrital organic carbon in contrast to DSDP 594, which although at a similar water depth to MD06-2986 (1204 $\mathrm{m}$ ) has a high degree of dissolution ( $10-20 \% \mathrm{CaCO}_{3}$ in glacials) that the authors attribute to $\mathrm{pH}$ lowering under high organic input (Kowalski and Meyers, 1997). Comparing productivity (planktics/cm²/kyr) to dissolution at MD06-2986 suggests no real correlation between the two proxies (Fig. 5.19B). For instance, high periods of productivity, such as MIS 12, coincide with the some of the lowest FI and \% benthic numbers of the record ( 2-6\%). As FI and \% benthics increased into MIS 11, productivity decreased. In MIS 6, productivity increased, and dissolution decreased to MIS 12 levels.

Another mechanism for dissolution could be bottom water temperature. Colder water temperatures can keep more $\mathrm{CO}_{2}$ in solution, thereby increasing corrosion of $\mathrm{CaCO}_{3}$ (Stewart, 2008). However, the high relief $(<1400 \mathrm{~m})$ of the Challenger Plateau and core location above the lysocline suggests that cold water temperatures and high dissolution were not a factor.

Therefore, unlike DSDP 594 off eastern New Zealand (Kowalski and Meyers, 1997), dissolution at MD06-2986 was not caused by an abundance of marine production of organic material, temperature or circulation changes during G-IG periods. This supports the idea 
that the Challenger Plateau is a stable oceanographic system, without competing inflows that would drastically change temperature.

\subsection{Comparison to offshore eastern New Zealand}

\subsubsection{Faunal comparison-offshore eastern vs western New Zealand}

In this section, faunal composition data from MD06-2986 will be compared to four cores from offshore eastern New Zealand: ODP Sites 1123 and 1125 located north of the STF and ODP Site 1119 and DSDP Site 594 today located east and south of the STF respectively (Fig. 1.2). Figures 4.19-4.22 compare subantarctic, eutrophic, subtropical and temperate taxa from the four eastern sites to MD06-2986.

ODP Site 1123 is located northeast of Chatham Rise and receives direct flow of STW from the ECC (Stanton et al. 1997; Chiswell and Roemmich, 1998) and is $~ 2^{\circ}$ north of MD062986. Subantarctic taxa are more prominent at MD06-2986 compared with ODP 1123 (Fig. 5.20C). While abundances were fairly similar in interglacials (except for MIS 5 and 3) there was a discernable difference in glacial periods. MD06-2986 received more incursions of SAW for all glacials, except late MIS 6. MD06-2986 also had higher abundances of the eutrophic taxa, between $\sim 10-60 \%$ in glacials and $\sim 0-30 \%$ in glacials (Fig. 5.20D). One exception to this is late MIS 6-early MIS 5, where ODP 1123 eutrophic taxa was $~ 1-10 \%$ higher. The abundance of subtropical taxa was higher at ODP 1123 in both glacials ( 0$4 \%$ ) and interglacials ( 0-10\%), except at MIS 5 and 1 (Fig. 5.20B). Since ODP 1123 receives direct inflow of STW, this is to be expected. The abundance of temperate taxa was much higher in both glacials and interglacials at ODP 1123 as well (Fig. 5.20A). Given that ODP 1123 is further north and is lying in warmer water than MD06-2986, faunal data suggest that ODP 1123 was more influenced by warmer water conditions and offshore western New Zealand was substantially cooler, with more nutrient-mixing in surface waters. That the western site was always colder during every other glacial stage highlights how anomalously cold MIS 6 was at ODP 1123. It is important to note the reduction of subtropical taxa at ODP 1123, especially MIS 5 and 1 in relation to MD06-2986. This could indicate a weakening of the Tasman Front system off eastern New Zealand due to a 
strengthening of the East Australian Current down to Tasmania (Ridgway and Dunn, 2007; Hall et al. 2008).

ODP Site 1125 is located on the northern margin of Chatham rise at $\sim 42^{\circ} \mathrm{S}$, on the boundary between the ECC and the STF. It is important to note that the sample resolution is lower than 
A

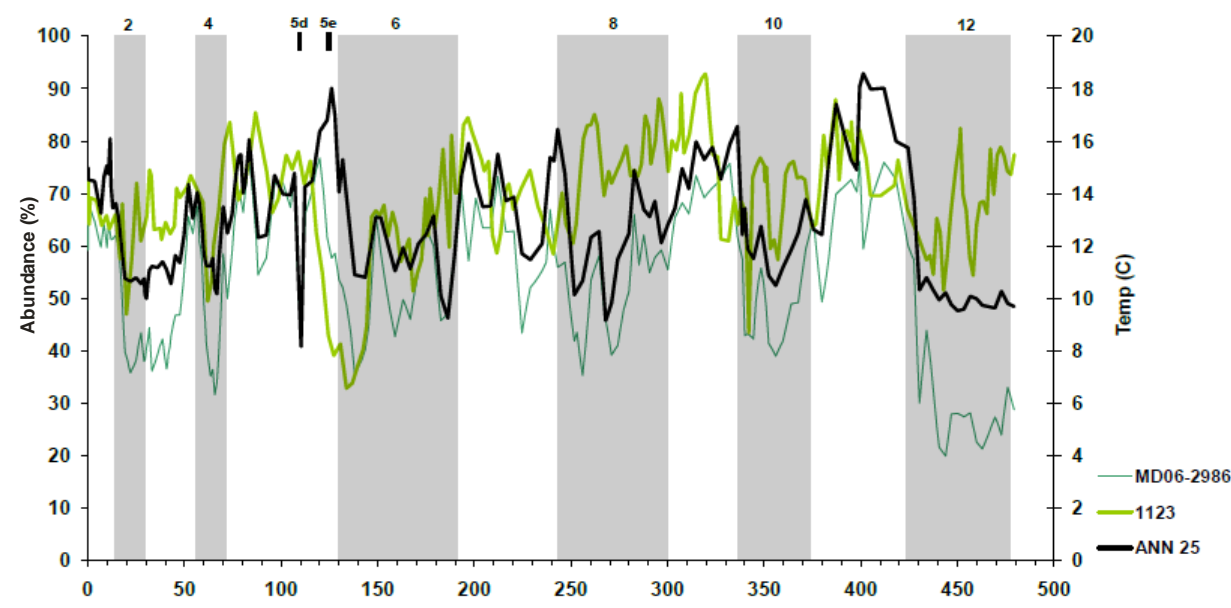

B
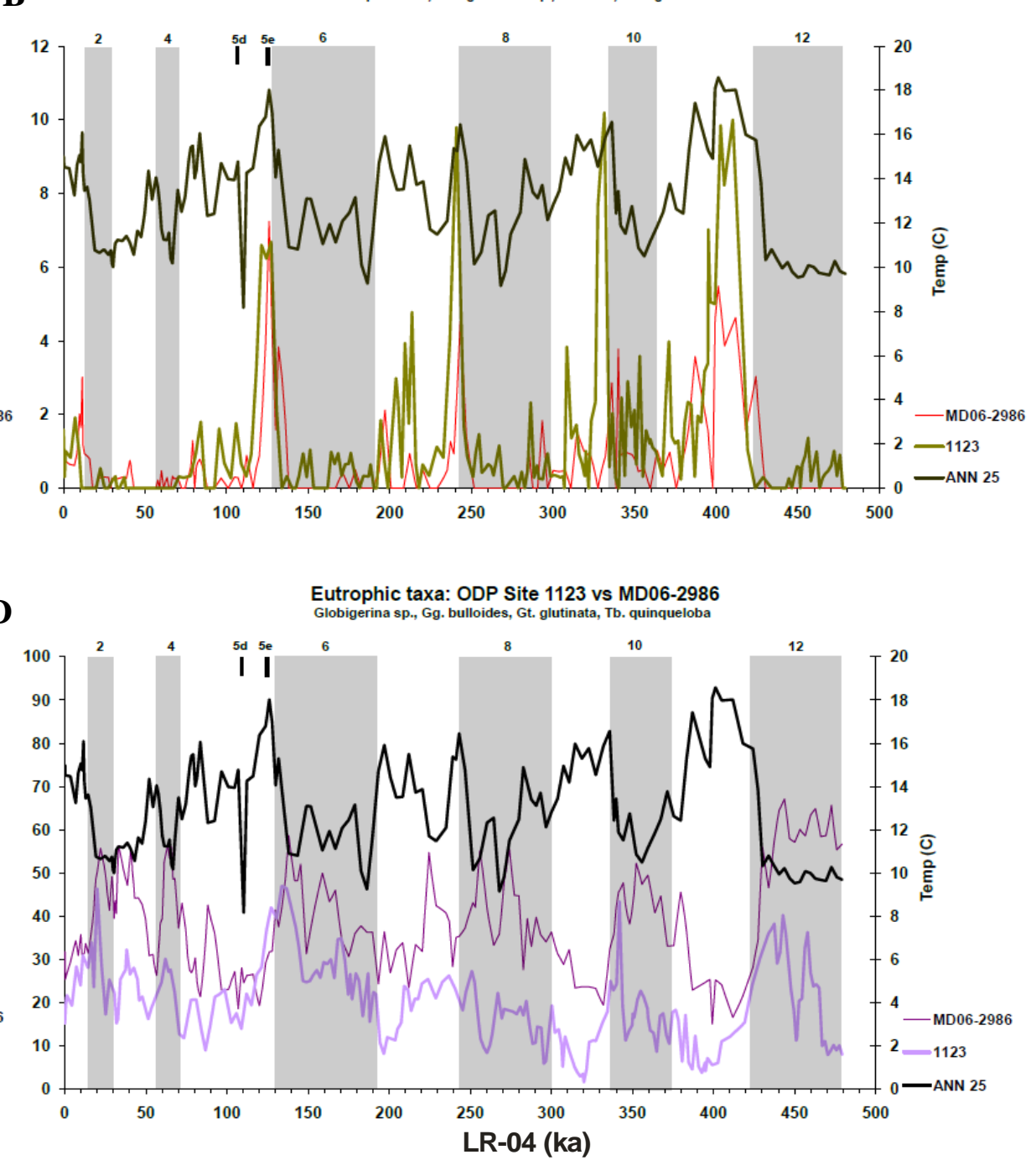

Subtropical taxa: ODP Site 1123 vs MD06-2986
D

C

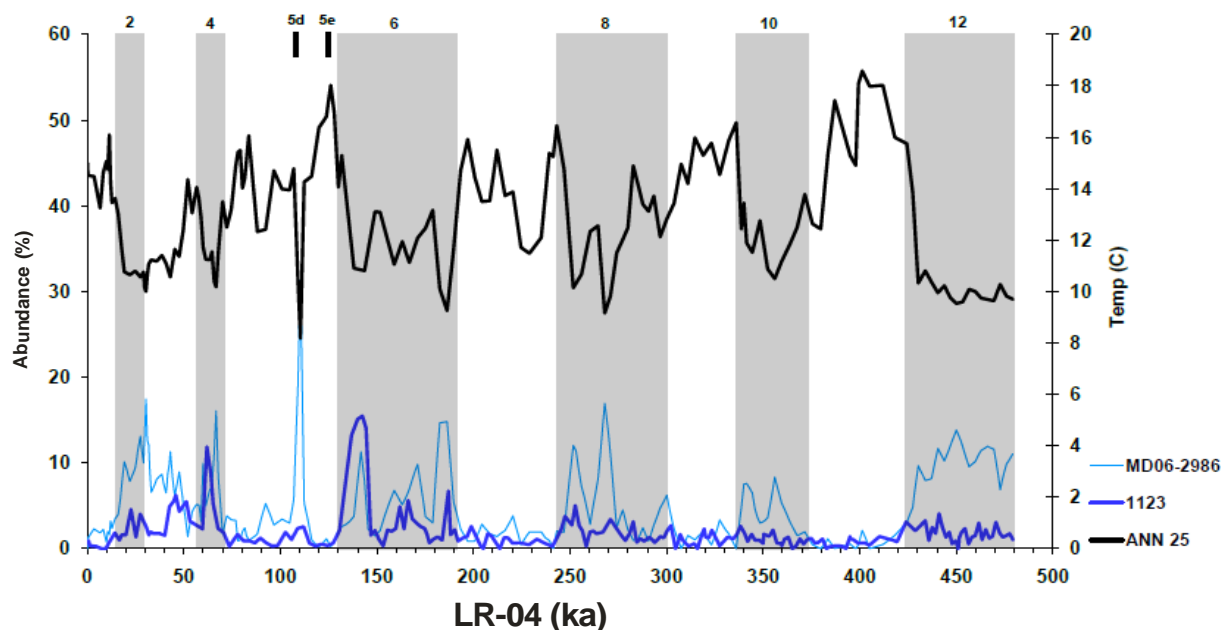

Fig. 5.20 - Comparison of faunal data between ODP Site 1123 (Crundwell et al., 2008) and MD06-2986. A) Comparison of temperate data for ODP 1123 (thick, light green) and MD06-2986 (thin, dark green). B) Comparison of subtropical taxa for ODP 1123 (thick, green) and MD06-2986 (thin, red). C) Comparison of subantarctic data for ODP 1123 10 (thick, dark blue) and MD06-2986 (thin, light blue). D) Comparison of eutrophic taxa for ODP 1123 (thick, light purple) and MD06-2986 (thin, dark purple). 

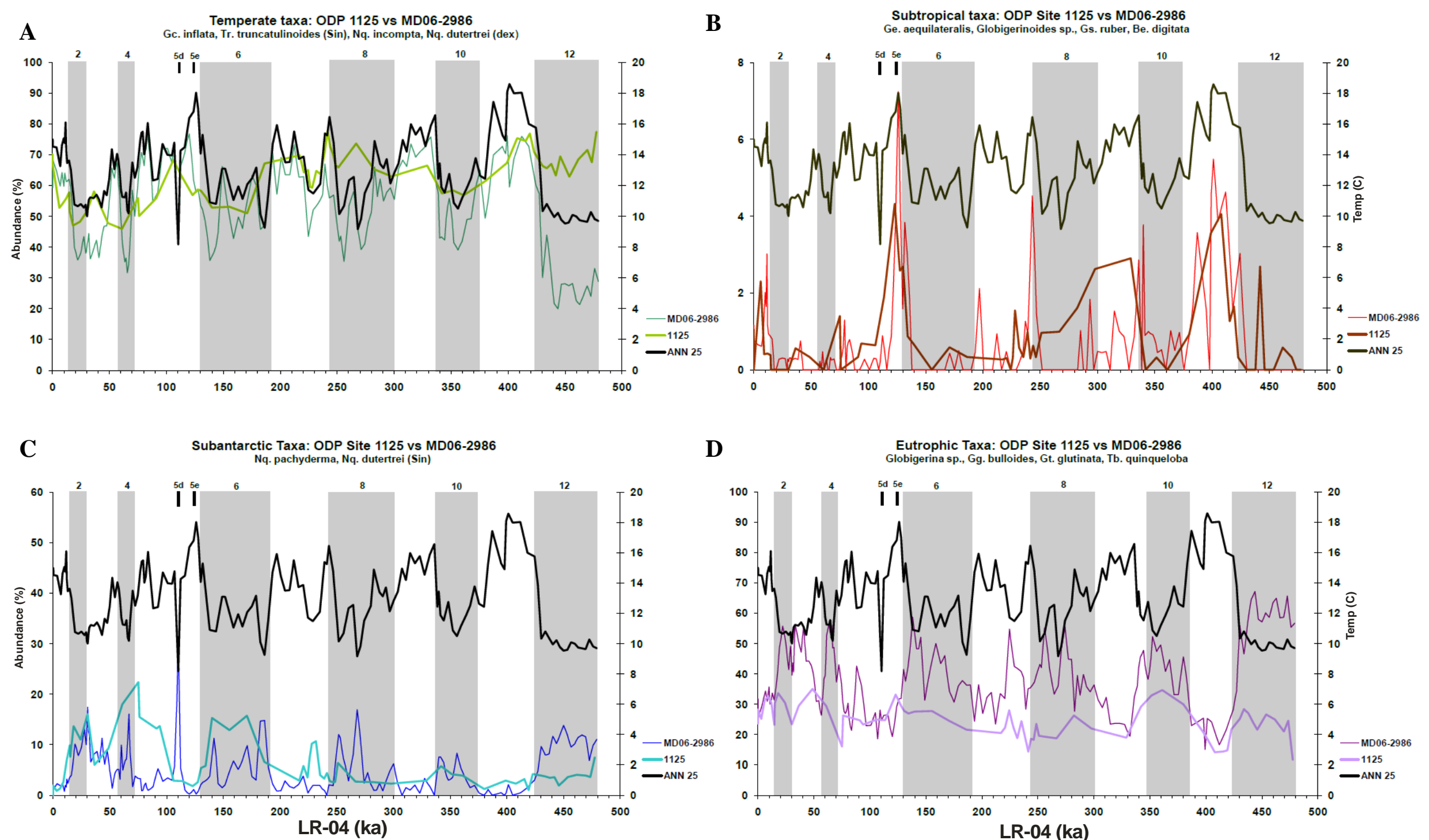

Fig. 5.21 - Comparison of faunal data between ODP Site 1125 (Schaefer et al, 2005) and MD06-2986. A) Comparison of temperate data for ODP 1125 (thick, light green) and MD06-2986 (thin, dark green). B) Comparison of subtropical taxa for ODP 1125 (thick, brown) and MD06-2986 (thin, red). C) Comparison of subantarctic data for ODP 1125 (thick, dark blue) and MD06-2986 (thin, light blue). D) Comparison of eutrophic taxa for ODP 1125 (thick, light purple) and MD06-2986 (thin, dark purple). 

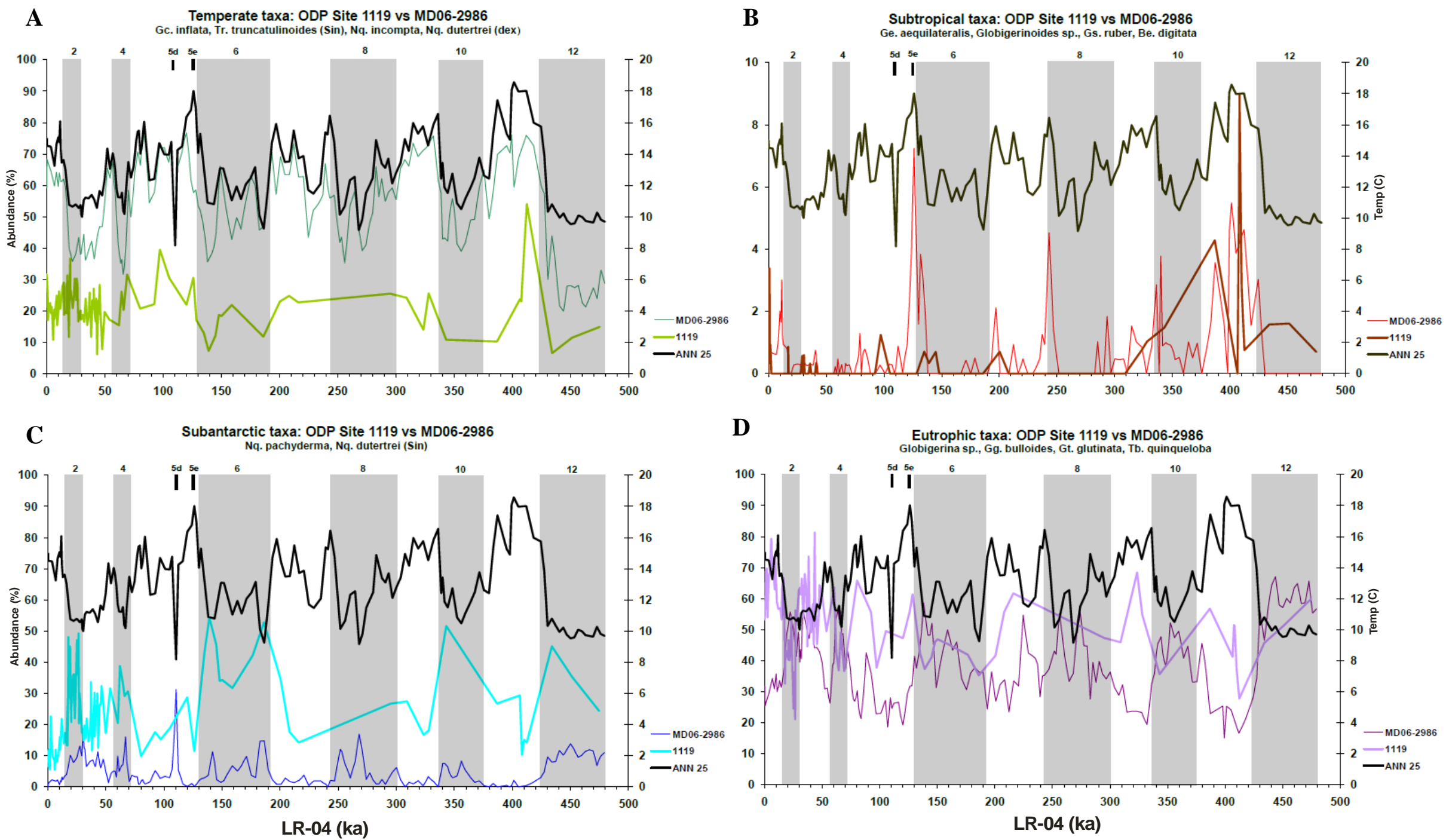

Fig. 5.22 - Comparison of faunal data between ODP Site 1119 (Wilson et al., 2005) and MD06-2986. A) Comparison of temperate data for ODP 1119 (thick, light green) and MD06-2986 (thin, dark green). B) Comparison of subtropical taxa for ODP 1119 (thick, brown) and MD06-2986 (thin, red). C) Comparison of subantarctic data for ODP 1119 (thick, dark blue) and MD06-2986 (thin, light blue). D) Comparison of eutrophic taxa for ODP 1119 (thick, light purple) and MD06-2986 (thin, dark purple). 


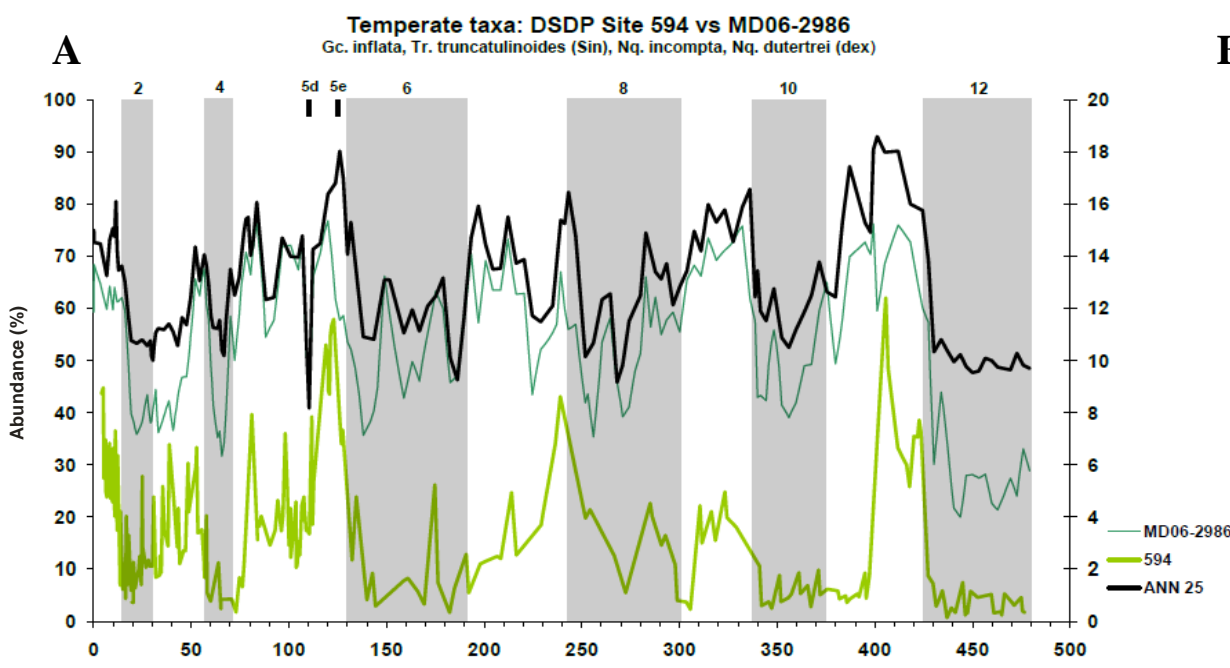

B

Subtropical taxa: DSDP Site 594 vs MD06-2986
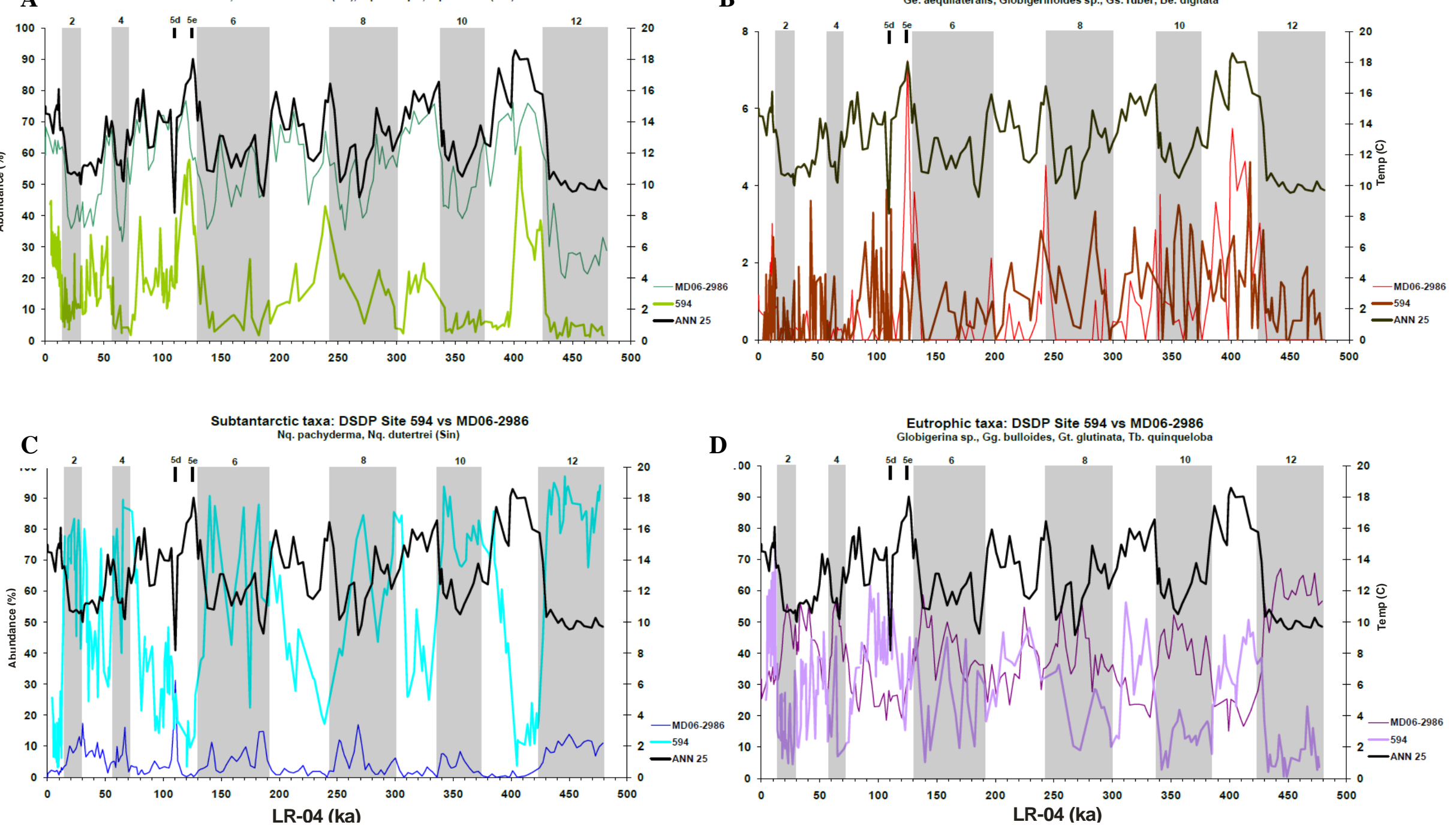

Fig. 5.23 - Comparison of faunal data between DSDP Site 594 (Wilson et al, 2005) and MD06-2986. A) Comparison of temperate data for DSDP 594 (thick, light green) and MD06-2986 (thin, dark green). B) Comparison of subtropical taxa for DSDP 594 (thick, green) and MD06-2986 (thin, red). C) Comparison of subantarctic data for DSDP 594 (thick, dark blue) and MD06-2986 (thin, light blue). D) Comparison of eutrophic taxa for DSDP 594 (thick, light purple) and MD06-2986 (thin, dark purple). 
MD06-2986 for ODP 1125, as MIS 10 and 2 are recognised in three data points, and MIS 4 is recognised by a single data point. Subantarctic taxa appear to have had a slightly higher abundance at MD06-2986 than at ODP 1125 during MIS 12-8 (Fig. 5.21C). After MIS 8, subantarctic taxa abundance was slightly higher at ODP 1125. Since the sampling resolution is not as good or consistent compared to MD06-2986, we would not rule out that ODP 1125 may have an equal or higher abundance of subantarctic taxa throughout the record. The abundance of eutrophic taxa was lower at ODP 1125 than MD06-2986, more so in glacials than in interglacials (Fig. 5.21D). This is somewhat surprising, given that ODP $1125\left(\sim 42^{\circ} \mathrm{S}\right)$ is located near the STF $\left(\sim 43^{\circ} \mathrm{S}\right)$. The abundance of subtropical taxa was not as high as MD062986 during peak interglacials, but it was higher during glacials (Fig 5.21C). Temperate taxa from ODP 1125 are comparable to MD06-2986, with the exception of MIS 12 (Fig. 5.21A).

ODP Site 1119 sits on the eastern continental shelf of the South Island at $\sim 44^{\circ} \mathrm{S}$, in SAW south of the STW today. The sample resolution for ODP 1119 is high during MIS 4-1, but significantly less for the rest of the record. Subantarctic taxa were significantly higher in abundance ( 30-40\%) in glacials at ODP 1119 than MD06-2986 (Fig 5.22C). Eutrophic taxa were generally more common at ODP 1119 during interglacials, but not glacials (Fig. 5.22D). Subtropical taxa were rare at ODP 1119; however, abundances exceeded those at MD06-2986 during MIS 11 ( 9\% vs 7\%) (Fig. 5.22B). Temperate taxa were significantly lower at ODP 1119 ( 5-50\% lower) and MD06-2986. Faunal data for ODP 1119 suggests that this site has been significantly colder throughout its history, with very little subtropical and temperate influence (Fig. 5.22A). This is unsurprising as ODP 1119 lay beneath subantarctic water in interglacials and cool STW or SAW in glacials (Wilson et al., 2005; Hayward et al., 2008), so colder faunas would be expected.

DSDP Site 594 is in the Bounty Trough at $\sim 45^{\circ} \mathrm{S}$ in SAW. Subantarctic taxa dominate the DSDP 594 record, with abundances between $\sim 25-95 \%$ in glacials and $\sim 5-85 \%$ in interglacials (Fig. 5.23C). The abundance of eutrophic taxa at DSDP 594 was lower than MD06-2986 in glacials $(\sim 0-45 \%)$ than in interglacials ( 8-68\%) (Fig. 5.23D). The abundance of subtropical taxa at DSDP 594 did not exceed that of MD06-2986 during interglacials, except for MIS 3; however, there was a stronger presence of subtropical taxa throughout the record, in particular 
during glacial periods (Fig. 5.23B). The abundance of temperate taxa was lower at DSDP 594 in both glacials ( 0-27\%) and interglacials ( 3-60\%) (Fig. 5.23A). Given the location of DSDP 594 in SAW, faunal composition should reflect cold water assemblages.

\subsubsection{SST comparison-offshore eastern vs western New Zealand}

In this section, SST data from MD06-2986 will be compared to the same four cores from offshore eastern New Zealand. Table 5.2 compares minimum glacial and maximum interglacial $\mathrm{SST}_{\mathrm{ANN}} 25$ data between each eastern site and MD06-2986. The latitude for each core is listed below each name, to compare latitudinal proximity to MD06-2986. Finally, the difference in SST for each MIS between each site is calculated. Positive values show that the eastern site is warmer than MD06-2986, while negative values show that the eastern site is cooler than MD06-2986.

Table 5.2

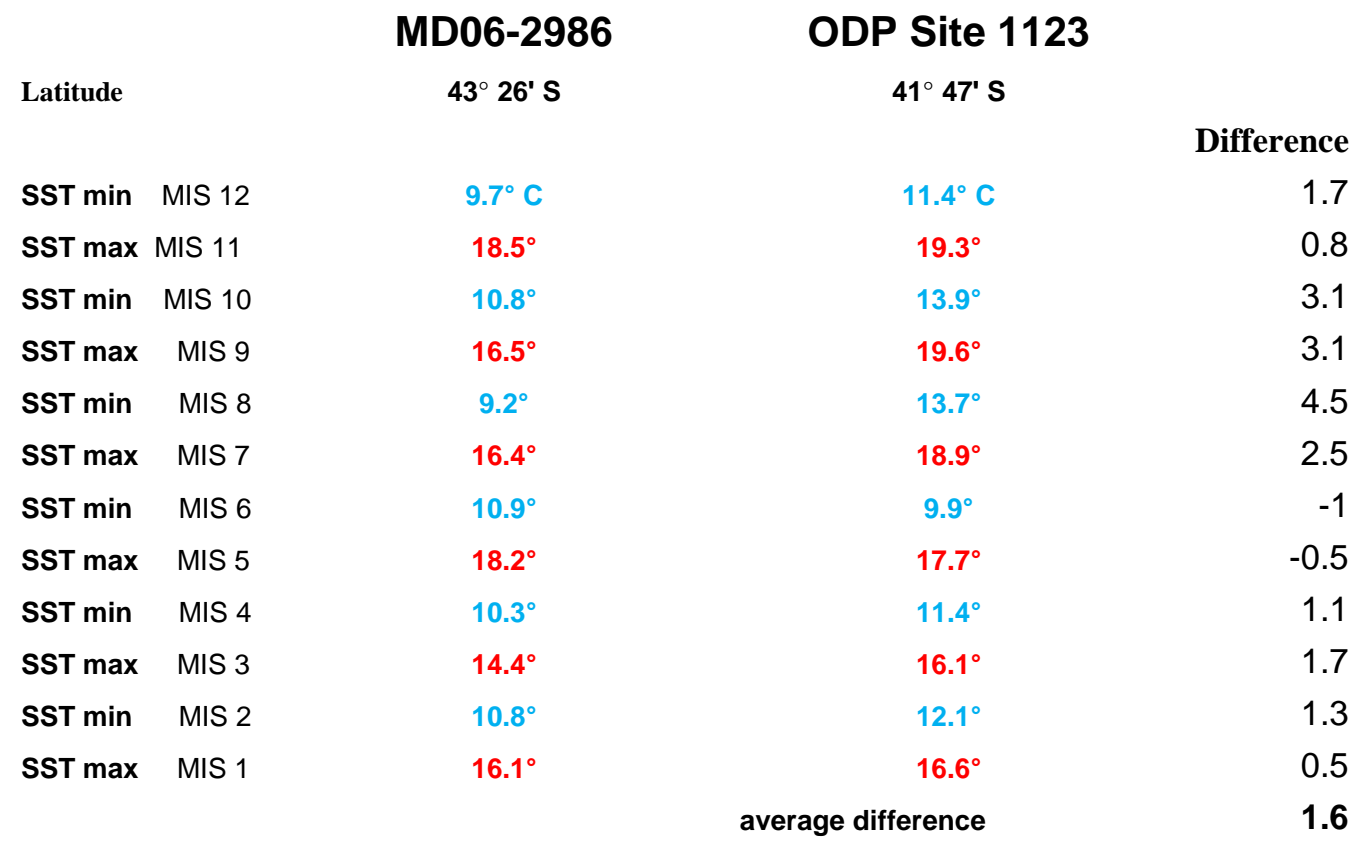

Table 5.2 - SST $_{\mathrm{ANN} 25}$ comparison between MD06-2986 and ODP Site 1123. Blue numbers represent glacial SST minima, and red numbers represent interglacial SST maxima. SST difference is calculated with respect to MD06-2986. A positive difference indicates that the eastern site is warmer, and a negative difference indicates that the eastern site is colder. SST data for eastern cores are from Hayward et al. (2009). 
SSTs were warmer at ODP Site 1123 than at MD06-2986 for most of the record. Only MIS 6 and MIS 5 were cooler than MD06-2986, but are within error. Crundwell et al. (2008) reported MIS 6 to be unusually cold at ODP Site 1123 , and the $\sim 7^{\circ} \mathrm{C}$ MIS 6-5 amplitude change is consistent with other SST records offshore eastern New Zealand (Pahnke and Sachs, 2006). The average difference of peak glacial and interglacial SSTs between east and western New Zealand is $1.6^{\circ} \mathrm{C}$. This difference is about the same between east and west present day mean annual SSTs for these sites $\left(\sim 15.5^{\circ}\right.$ vs $\left.\sim 14.0^{\circ} \mathrm{C}\right)$ (Uddstrom and Oien, 1999).

SSTs at ODP Site 1125 are the most similar to MD06-2986, with ODP 1125 being slightly warmer on average $\left(\sim 0.4^{\circ} \mathrm{C}\right)$ throughout the record (Table 5.3). This is consistent with the present-day temperature difference as well $\left(14.5^{\circ}\right.$ vs $\left.\sim 14.0^{\circ} \mathrm{C}\right)$. The temperature difference with respect to latitude is consistent as well. SST gradients for eastern and western New Zealand are $\sim 0.5^{\circ} \mathrm{C} / 100 \mathrm{~km}$ and $0.75^{\circ} \mathrm{C} / 100 \mathrm{~km}$, respectively. When SSTs of glacials and interglacials are compared, some interesting trends develop.

Table 5.3

\section{MD06-2986 ODP Site 1125}

Latitude

SST min MIS 12

SST max MIS 11

SST min MIS 10

SST max MIS 9

SST min MIS 8

SST max MIS 7

SST min MIS 6

SST max MIS 5

SST min MIS 4

SST max MIS 3

SST min MIS 2

SST max MIS 1 $43^{\circ} 26^{\prime} \mathrm{S}$

$9.7^{\circ} \mathrm{C}$
$18.5^{\circ}$
$10.8^{\circ}$
$16.5^{\circ}$
$9.2^{\circ}$
$16.4^{\circ}$
$10.9^{\circ}$
$18.2^{\circ}$
$10.3^{\circ}$
$14.4^{\circ}$
$10.8^{\circ}$
$16.1^{\circ}$

$42^{\circ} 33^{\prime} \mathrm{S}$

$\begin{array}{rr}12.4^{\circ} \mathrm{C} & 2.7 \\ 17.2^{\circ} & -1.3 \\ 12.5^{\circ} & 1.7 \\ 16.6^{\circ} & 0.1 \\ 14.2^{\circ} & 5 \\ 15.7^{\circ} & -0.7 \\ 11.3^{\circ} & 0.4 \\ 16.2^{\circ} & -2 \\ 10.8^{\circ} & 0.5 \\ 13.8^{\circ} & -0.6 \\ 11.1^{\circ} & 0.3 \\ 15.3^{\circ} & -0.8 \\ \text { ference } & 0.4\end{array}$

Table 5.3 - $\mathrm{SST}_{\mathrm{ANN} 25}$ comparison between MD06-2986 and ODP Site 1125. Blue numbers represent glacial SST minima, and red numbers represent interglacial SST maxima. SST difference is calculated with respect to MD06-2986. A positive difference indicates that the eastern site is warmer, and a negative difference indicates that the eastern site is colder. SST data for eastern cores are from Hayward et al. (2009). 
Glacial SSTs at ODP 1125 were warmer than at MD06-2986. This is because the Chatham Rise prevented northward overflow of SAW to ODP 1125 during glacial lowstands, so SSTs remained relatively warm, influenced more by STW (Hayward et al. 2008). During interglacials, MD06-2986 was warmer, most notably MIS $11\left(1.3^{\circ} \mathrm{C}\right)$ and MIS 5e $\left(2.0^{\circ} \mathrm{C}\right)$. This is harder to explain, since ODP 1125 receives direct inflow of STW via the ECC, whereas MD06-2986 does not.

\section{Table 5.4}

Latitude

SST min MIS 12

SST max MIS 11

SST min MIS 10

SST max MIS 9

SST min MIS 8

SST max MIS 7

SST min MIS 6

SST max MIS 5

SST min MIS 4

SST max MIS 3

SST min MIS 2

SST max MIS 1
MD06-2986

$43^{\circ} 26^{\prime} \mathrm{S}$

$9.7^{\circ} \mathrm{C}$
$18.5^{\circ}$
$10.8^{\circ}$
$16.5^{\circ}$
$9.2^{\circ}$
$16.4^{\circ}$
$10.9^{\circ}$
$18.2^{\circ}$
$10.3^{\circ}$
$14.4^{\circ}$
$10.8^{\circ}$
$16.1^{\circ}$

$11.7^{\circ}$

$6.2^{\circ}$

$9.7^{\circ}$

$9.6^{\circ}$

$6.1^{\circ}$

$10.9^{\circ}$

$8.0^{\circ}$

$10.1^{\circ}$

$6.1^{\circ}$

$11.2^{\circ}$

average difference

Difference

$-2.9$

$-6.8$

$-4.6$

$-6.8$

$-6.8$

$-4.8$

$-7.3$

$-2.3$

$-4.3$

$-4.7$

$-4.9$

$-5.1$

Table 5.4 - SST $_{\text {ANN } 25}$ comparison between MD06-2986 and ODP Site 1119. Blue numbers represent glacial SST minima, and red numbers represent interglacial SST maxima. SST difference is calculated with respect to MD06-2986. A positive difference indicates that the eastern site is warmer, and a negative difference indicates that the eastern site is colder. SST data for eastern cores are from Hayward et al. (2009).

Present day mean annual SST for ODP Site 1119 is $\sim 11^{\circ} \mathrm{C}$, indicating a $\sim 3^{\circ} \mathrm{C}$ difference between ODP 1119 and MD06-2986. Comparison of glacial and interglacial SSTs, however, shows that ODP 1119 was significantly cooler than MD06-2986 (Table 5.4). Similar to ODP 1125, sample spacing here is not great, with only one data point for MIS 10 and 6, and no data points for MIS 8. Interglacials were significantly cooler at ODP 1119 ( 4.3-7.3 C), particularly in MIS $12,10,8$, and $6\left(6.8-7.3^{\circ} \mathrm{C}\right)$. Glacials were cooler at ODP 1119 , though the SST difference was not as significant as interglacial SSTs $\left(\sim 2.9-4.8^{\circ} \mathrm{C}\right)$. These SST 
differences highlight several points. First, despite being one degree of latitude south of MD062986, ODP 1119 SSTs were significantly cooler (average difference $\sim 5.1^{\circ} \mathrm{C}$ ). This is due to ODP 1119 lying in SAW and receiving regular incursions of ACC coming into the region through the Pukaki Saddle and into the Bounty Gyre (Weaver et al. 1998; Schaefer et al. 2005; Hayward et al. 2008). Secondly, since the discrepancy is larger between interglacial SSTs than between glacial SSTs, this reinforces the idea that MD06-2986 is prone to incursions of cool SAW during glacial periods. The mechanism for this would be a northward migration of the STF at or proximal to MD06-2986, similar to the migrations suggested by Howard and Prell, (1992) and Sikes et al. (2009). Also, ODP 1119 was subject to cool STW flowing over the site during some glacials as a result of seaward (eastward) migration of the STF over the site (Wilson et al., 2005).

Table 5.5-SST ${ }_{\mathrm{ANN}}^{25}$ comparison between MD06-2986 and DSDP Site 594. Blue numbers represent glacial SST minima, and red numbers represent interglacial SST maxima. SST difference is calculated with respect to MD062986. A positive difference indicates that the eastern site is warmer, and a negative difference indicates that the eastern site is colder. SST data for eastern cores are from Hayward et al. (2009).

Table 5.5

Latitude

SST min MIS 12

SST max MIS 11

SST min MIS 10

SST max MIS 9

SST min MIS 8

SST max MIS 7

SST min MIS 6

SST max MIS 5

SST min MIS 4

SST max MIS 3

SST min MIS 2

SST max MIS 1
MD06-2986

$43^{\circ} 26^{\prime} \mathrm{S}$

$9.7^{\circ} \mathrm{C}$

$18.5^{\circ}$

$10.8^{\circ}$

$16.5^{\circ}$

$9.2^{\circ}$

$16.4^{\circ}$

$10.9^{\circ}$

$18.2^{\circ}$

$10.3^{\circ}$

$14.4^{\circ}$

$10.8^{\circ}$

$16.1^{\circ}$

\section{DSDP Site 594}

$45^{\circ} 31^{\prime} \mathrm{S}$

Difference

$2.6^{\circ} \mathrm{C}$

$-7.1$

$-4.3$

$-7.9$

$-6.9$

$-5.5$

$-4.5$

$-7.9$

$-2.7$

$-7.1$

$-5.5$

$-7.4$

$-4.6$ 
Present day mean annual SSTs for DSDP 594 are $11^{\circ} \mathrm{C}$, which is a $\sim 3^{\circ} \mathrm{C}$ difference between this site and MD06-2986 (Table 5.5). Both glacial and interglacial SSTs were significantly colder at DSDP 594 (average $\sim 6.0^{\circ} \mathrm{C}$ ). However, unlike ODP 1119, glacials at DSDP 594 were far colder $\left(\sim 5.5-7.9^{\circ} \mathrm{C}\right)$ than interglacials $\left(\sim 2.7-6.9^{\circ} \mathrm{C}\right)$ when compared to MD06-2986. SSTs from DSDP 594 highlight how this site was oceanographically different from ODP 1119 and MD06-2986. First, not only did DSDP 594 receive SAW from the SAF and ACC, it also received Circumpolar Surface Water during glacials (Schaefer et al., 2005), whereas ODP 1119 received only SAW or cool STW and MD06-2986 received SAW incursions only during glacial periods. Second, that the interglacials of DSDP 594 were warmer than ODP 1119 with respect to MD06-2986 reiterates conclusions that incursions of STW jet through the Mernoo Saddle to affect DSDP 594 (Hayward et al., 2008).

\subsubsection{Glacial-Deglacial Faunal Changes}

Crundwell et al. (2008) tracked peak abundances of taxonomic groups through glacialinterglacial periods and found a repetitive pattern that suggested changing inflows from cold subantarctic water from the south to warm subtropical water from the north. At ODP Site 1123, the faunal change from glacial to interglacial was subantarctic-eutrophic-subtropicaltemperate and it occurred over a 20 kyr period.

\section{Table 5.6 \\ Rate of Glacial-Interglacial Faunal Change} (kyr)

$\begin{array}{lrcc} & \text { MD06-2986 } & \text { ODP Site 1123 } \\ \text { MIS 12/11 } & 51 & 30 \\ \text { MIS } & \mathbf{1 0} / \mathbf{9} & 23 & 20 \\ \text { MIS } & \mathbf{8} / 7 & 38 & 15 \\ \text { MIS } & \mathbf{6 / 5} & 21 & 20 \\ \text { MIS } & \mathbf{2} / \mathbf{1} & 30 & 22\end{array}$

Table 5.6 - Comparison of the rate of glacial-deglacial faunal change between ODP Site 1123 and MD06-2986 for each major Termination. 
The faunal change of MD06-2986 is investigated here by examining peaks of taxonomic groups through glacial-deglacial periods (Table 5.6). Similar to ODP Site 1123, the same pattern of subantarctic-eutrophic-subtropical-temperate is detected. However, the main difference is that this transition took place generally over a longer time, between $\sim 20-50 \mathrm{kyr}$ offshore western New Zealand. The most notable transitions occurred in MIS 12-11 (50 kyr versus $30 \mathrm{kyr}$ at Site 1123), MIS 8-7 (38 kyr versus $15 \mathrm{kyr}$ ) and MIS 2-1 (30 kyr versus 22 kyr). This difference in the duration of the faunal change highlights the contrasting oceanographic regimes between offshore eastern and western New Zealand. The response of the changing global climate from glacial phase to deglacial phase would appear more instantaneous in the geological record off eastern New Zealand from the direct inflow of competing water masses via the ECC and ACC. In contrast, offshore western New Zealand is lacking that direct inflow of either warm water or cold water masses. Therefore, the response of the eastern Tasman Sea to a changing global climate would be either weak or slow compared to offshore eastern New Zealand.

\subsubsection{Oceanographic interpretation-eastern and western New Zealand}

Comparison of faunal and SST data between offshore eastern and western New Zealand suggests that MD06-2986 ( 43 $\mathrm{S})$ is most similar with the cores that are north of the STF on the eastern side of New Zealand. The core most similar in both temperature and faunal composition is ODP 1125, which is situated on the northern margin of the STF. That the subantarctic taxa abundance was very similar for both sites suggests that the STF very likely migrated northward to a location just south of MD06-2986. It is important to note, however, that the glacial subantarctic signal from ODP 1125 may be a result of SAW jetting through the Mernoo Saddle, as opposed to a northward migration of the STF (Hayward et al., 2008). The abundance of eutrophic taxa was significantly higher at MD06-2986 compared to the eastern cores north of the STF. This is surprising, as ODP 1123 and 1125 are located close to the bathymetrically-bound STF, and productivity from the nutrient-mixing water-mass boundary should be present year-round. Murphy et al. (2001) examined phytoplankton blooms from spring 1997 to late autumn 2000 and found that Chatham Rise has a steady concentration of phytoplankton blooms throughout the year, while the Tasman Sea had spring and autumn 
bloom cycles. Since productivity was highest in glacial periods at MD06-2986, the main sources of increased productivity could be from upwelling (Bradford, 1983; Bowman, 1983; Shirtcliffe et al. 1990), aeolian dust influx from Australia (Hesse, 1994) and nutrient mixing at water-mass boundaries from a migrating STF (Howard and Prell, 1992). Shulmeister et al (2004) shows upwelling occurs offshore eastern New Zealand, and Murphy et al. (2001) the STF along Chatham Rise is the highest source of productivity in the New Zealand region. Carter and Manighetti (2006) however, suggest that aeolian dust influx offshore eastern New Zealand is not particularly significant. Given that eastern and western New Zealand have upwelling systems and intersect a water mass boundary, perhaps it is possible that the additional influence of aeolian dust influx into the Tasman Sea is what made offshore western New Zealand more productive than offshore eastern New Zealand.

SSTs from eastern cores south of the STF were much cooler than MD06-2986. Subantarctic taxa were more abundant in ODP 1119 and DSDP 594 than MD06-2986, while eutrophic taxa were comparable. In the present interglacial, DSDP 594 receives a more constant flow of STW water via Mernoo Saddle (Greig and Gilmore, 1992) and through eddy exchange across the Chatham Rise (Williams, 2004). This highlights the major oceanographic difference between offshore eastern and western New Zealand: the oceanography east of New Zealand is dominated by competing flows of STW and SAW during glacials and interglacials (Weaver et al. 1998; Crundwell et al. 2008; Hayward et al. 2008) whereas the oceanography west of New Zealand is fairly isolated from warm STW, and slightly less isolated from SAW. MD06-2986 received significant $(\sim 4-7 \%)$ contributions of subtropical taxa only during peak interglacial warmth, and received low (8-17\%) contributions from subantarctic taxa during glacial periods. The comparison of glacial-deglacial faunal transitions between eastern and western New Zealand highlights how climate changes from high and low latitudes affect eastern New Zealand quicker than offshore western New Zealand. This also supports the idea that offshore western New Zealand is in fact, isolated from any major surface water inflow from high or low latitude sources. 


\subsection{Conclusions}

\subsection{Project Achievements}

This project examined Late Quaternary oceanographic changes in the Tasman Sea using planktic foraminiferal assemblages. Insights into water mass movement and SSTs through GIG periods were gained. In particular, this study:

- Produced the longest SST record yet for the Tasman Sea

- Gained an understanding of water mass variability in the eastern Tasman Sea through G-IG cycles by analysing planktic foraminiferal assemblage composition in term of biogeographic affinities of the constituent taxa.

- Identified northward migration of the STF off western New Zealand during glacial periods.

- Compared faunal and SST data with similar data from the western Tasman Sea for an overall understanding of how the Tasman Sea responded to large scale climate changes.

- Compared faunal and SST data to offshore eastern New Zealand to better understand the contrasting oceanographic regimes on either side of the New Zealand landmass.

\subsection{Oceanographic History of the Last $\sim 480,000$ Years}

\subsubsection{Eastern Tasman Sea}

Faunal data from MD06-2986 suggests that brief, small (4-7\%) incursions of subtropical taxa occurred during peak interglacials. A higher abundance of subantarctic taxa (8-17\%) that occurred during glacials suggests that MD06-2986 was more prone to receive incursions from a subantarctic source, rather than a subtropical source. This is mainly due to an unconstrained STF that migrated northwards towards the site during glacials and perhaps over the site during MIS 12 and perhaps MIS 5d, and migrated closer to the site than its present-day position in the other glacial periods. Given that the abundance of both subantarctic and subtropical taxa are fairly low compared to either offshore eastern New Zealand or offshore eastern Australia, we 
conclude that MD06-2986, offshore western New Zealand, has been fairly well isolated from any major inflow of currents from either high or low latitude source. Changes in temperature are influenced mostly by climatic thermal changes as opposed to well-defined ocean inflows. SSTs estimated from planktic assemblages at MD06-2986 suggest a sustained, cold MIS 12 $\left(\sim 10^{\circ} \mathrm{C}\right)$, a long warm MIS 11 (SST $\left.\max \sim 18^{\circ} \mathrm{C}\right)$, and moderate G-IG temperature fluctuations $\left(\sim 6.0-7.3^{\circ} \mathrm{C}\right)$ for the rest of the record. There is an unusual cold event in MIS 5d, which is corroborated by offshore pollen records. SST comparison of MIS 11 and MIS 1 suggests MIS 11 was much warmer $\left(\sim 1-2^{\circ} \mathrm{C}\right)$ than the Holocene.

\subsubsection{Comparison-Eastern Tasman Sea to western Tasman Sea}

Comparison of faunal and SST data between eastern and western Tasman Sea reveal that western Tasman Sea was more prone to competing inflows of STW and SAW. Faunal data shows western Tasmania received more subtropical and subantarctic taxa compared to the eastern Tasman Sea at the same degree of latitude. The subtropical taxa are carried south via expansions of the EAC as part of the oceanic supergyre, and the large subantarctic taxa signal comes via the close proximity of eastern Tasmania to the STF.

\subsubsection{Comparison-Offshore western New Zealand to offshore eastern New Zealand}

A latitudinal comparison of faunal and SST data between offshore western New Zealand and four cores offshore eastern New Zealand show that MD06-2986, located at $\sim 43^{\circ} \mathrm{S}$, is most similar to ODP Site $1125\left(\sim 42^{\circ} \mathrm{S}\right)$. Similar comparisons show that at ODP Site $1119\left(\sim 44^{\circ} \mathrm{S}\right)$, SSTs were much colder $\left(5^{\circ} \mathrm{C}\right)$ than MD06-2986. This comparison highlights the unique and complicated oceanography of eastern New Zealand, that within only a few degrees of latitude SSTs and surface water mass change drastically, whereas offshore western New Zealand, the oceanography is more stable, with temperate conditions persisting throughout most of the record, with minor incursions of SAW during glacials. 


\subsection{Future Work}

More research is certainly needed in the Tasman Sea. To start with:

- Faunal and SST records that date back to $1 \mathrm{Ma}$ would be useful so that an historical oceanographic comparison to eastern New Zealand can be completed. This in turn will also lead to an extension of the history of the STF movement in the Tasman Sea. Such a study is currently underway at Geomarine research, Auckland.

- A similar study to this thesis on a core located further south of site MD06-2986 would better constrain actual latitudinal migrations of the STF during the G-IG cycles.

- Further studies on G-IG changes in the dissolution proxies at different depths west of New Zealand might help explain the unusual greater dissolution during interglacials.

- Study of the aeolian iron composition in MD06-2986 through the G-IG cycles might better constrain the role of this nutrient source in influencing the abundance of eutrophic planktic foraminifera. Such a study is underway by Dr. Silke Steph (Germany). 


\section{References}

Andrews, J. C., Lawrence, M. W., \& Nilsson, C. S. (1980). Observations of the Tasman Front. Journal of physical oceanography, 10, 1854-1869.

Armstrong, H.A., \& Brasier, M.D. (2005). Foraminifera. In: H.A. Armstrong and M.D.

Brasier, (Editors), Microfossils (2nd ed.), Blackwell Publishing, Oxford (2005), pp. 142-187.

Bard, E., \& Rickaby, R. E. M. (2009). Migration of the Subtropical Front as a modulator of Glacial Climate. Nature, 460(7253), 380-383.

Barrows, T. T., \& Juggins, S. (2005). Sea-surface temperatures around the Australian margin and Indian Ocean during the Last Glacial Maximum. Quaternary Science Reviews, 24(7-9), 1017-1047.

Barrows, T. T., Juggins, S., De Deckker, P., Calvo, E., \& Pelejero, C. (2007). Long-term sea surface temperature and climate change in the Australian-New Zealand region.

Paleoceanography, 22(2), PA2215.

Barrows, T. T., Juggins, S., De Deckker, P., Thiede, J., \& Martinez, J. I. (2000). Sea-Surface Temperatures of the Southwest Pacific Ocean During the Last Glacial Maximum.

Paleoceanography, 15(1), 95-109.

Be, A. W. H., \& Hutson, W. H. (1977). Ecology of Planktonic Foraminifera and Biogeographic Patterns of Life and Fossil Assemblages in the Indian Ocean. Micropaleontology, 23(4), 369414.

Belkin, I.M., 1988. Main hydrological features of the Central-South Pacific. In: Vinogradov, M.E., Flint, M.V. (Eds.), Ecosystems of the Subantarctic Zone of the Pacific Ocean. Nauka, 
Moscow, pp. 21-28 [Translated as 'Pacific Subantarctic Ecosystems'”. New Zealand Translation Centre Ltd.,Wellington, 1996, pp. 12-17].

Belkin, I.M., (1993). Frontal structure of the South Atlantic. In: Voronina, N.M. (Ed.), Pelagic Ecosystems of the Southern Ocean. Nauka, Moscow, pp. 40-53.

Belkin, I. M., \& Gordon, A. L. (1996). Southern Ocean Fronts from the Greenwich meridian to Tasmania. Journal of Geophysical Research, 101(C2), 3675-3696.

Boersma, A., Silva, I.P., Hallock, P., (1998). Trophic models for the well-mixed and poorly mixed warm oceans across the Paleocene/Eocene epoch boundary. In: Aubry, M.-P., Lucas, S.G., Berggren, W.A. (Eds.), Late Paleocene-Early Eocene climatic and biotic events in the marine and terrestrial records. Columbia University Press, New York, N.Y., pp. 204-213.

Bostock, H. C., Opdyke, B. N., Gagan, M. K., Kiss, A. E., \& Fifield, L. K. (2006).

Glacial/interglacial changes in the East Australian current. Climate Dynamics, 26(6), 645-659.

Bowman, M. J.; Chiswell, S. M.; Lapennas, P. P.; Murtagh, R. A.; Foster, B. A.; Wilkinson, V. J.; Battaerd, W. R. 1983: Coastal upwelling, cyclogenesis and squid fishing near Cape Farewell, New Zealand. In : Coastal oceanography. Gade, H. ed. Plenum Press, New York. 279-310.

Boyd, P. W., G. McTainsh, Sherlock, V., Richardson, K., Nichol, S., Ellwood, M., and Frew, R. (2004). "Episodic enhancement of phytoplankton stocks in New Zealand subantarctic waters: Contribution of atmospheric and oceanic iron supply." Global Biogeochemical Cycles 18(1): GB1029

Bradford, J. M. (1983). Physical and chemical oceanographic observations off Westland, New Zealand, June 1979. New Zealand Journal of Marine and Freshwater Research 17: 71-81 
Brassell, S. C., Eglinton, G., Marlowe, I. T.P Flaumann, U., \& Sarnthein, M. (1986). Molecular stratigraphy: a new tool for climatic assessment. Nature, 320, 129-133.

Budillon. G \& Rintoul S.R. (2003). Fronts and upper ocean thermal variability south of New Zealand. Antarctic Science, 15(01), 141-152.

Carter, L.,Garlick, R., Sutton, P.,Chiswell, S.,Oien,N.A., Stanton,B.R., (1998). Ocean circulation New Zealand. NIWA Chart, Miscellaneous Series, 76. National Institute of Water and Atmosphere, Wellington, New Zealand.

Carter, L., Manighetti, B., Elliot, M., Trustrum, N., Gomez, B., (2002). Source, sea level and circulation effects on the sediment flux to the deep ocean over the past $15 \mathrm{ka}$ off eastern New Zealand. Global and Planetary Change 33, 339-355.

Carter, L., \& McCave, I. N. (1994). Development of sediment drifts approaching an active plate margin under the SW Pacific Deep Western Boundary Current. Paleoceanography, 9, 1061-1085.

Carter, L., \& McCave, I. N. (1997). The sedimentary regime beneath the Deep Western Boundary Current inflow to the Southwest Pacific Ocean. Journal of Sedimentary Research, 67(6), 1005-1017.

Carter, L., McCave, I. N., \& Williams, M. J. M. (2009). Circulation and Water Masses of the Southern Ocean: A Review. In F. Florindo \& M. Siegert (Eds.), Antarctic Climate Evolution: Elsevier.

Carter, L., Neil, H.L., and McCave, I.N., (2000). Glacial to interglacial changes in noncarbonate and carbonate accumulation in the SW Pacific Ocean New Zealand.

Palaeoclimatology, Palaeogeography, Palaeoecology 162: 333-356. 
Chang, F. H., Bradford-Grieve, J. M., Vincent, W. F., \& Woods, P. H. (1995). Nitrogen uptake by the summer size-fractionated phytoplankton assemblages in the Westland, New Zealand, upwelling system. New Zealand Journal of Marine and Freshwater Research, 29(2), 147 - 161.

Chiswell, S. M. (1994). Variability in sea surface temperature around New Zealand from AVHRR images. New Zealand Journal of Marine and Freshwater Research, 28, 179-192.

Chiswell, S. M. (2001). Eddy energetics in the Subtropical Front over the Chatham Rise, New Zealand. New Zealand Journal of Marine and Freshwater Research, 35, 1-15.

Chiswell, S. M., \& Roemmich, D. (1998). The East Cape Current and two eddies: a mechanism for larval retention? New Zealand Journal of Marine and Freshwater Research, 32, 385-397.

Chiswell, S. M. (1996). Variability in the Southland Current, New Zealand. New Zealand Journal of Marine and Freshwater Research, 30, 1-17.

Chen, M. T., Huang, C. C., Pflaumann, U., Waelbroeck, C., \& Kucera, M. (2005). Estimating glacial western Pacific sea-surface temperature: methodological overview and data compilation of surface sediment planktic foraminifer faunas. Quaternary Science Reviews, 24(7-9), 10491062.

Clarke and Wheeler, 1922 The inorganic constituents of marine invertebrates, United States Geological Survey Professional Paper 124 (1922), pp. 1-62.

Contribution of Working Group I to the Fourth Assessment Report of the Intergovernmental Panel on Climate Change (2007).

Crundwell, M., Scott, G., Naish, T., \& Carter, L. (2008). Glacial-interglacial ocean climate variability from planktonic foraminifera during the Mid-Pleistocene transition in the temperate Southwest Pacific, ODP Site 1123. Palaeogeography, Palaeoclimatology, Palaeoecology, 260(1-2), 202-229. 
Darling, K. F., Kucera, M., Kroon, D., \& Wade, C. M. (2006). A resolution for the coiling direction paradox in Neogloboquadrina pachyderma. Paleoceanography, 21(2), PA2011.

Darling, K. F., Kucera, M., Pudsey, C. J., and Wade, C. M. (2004). Molecular evidence links cryptic diversification in polar planktonic protists to Quaternary climate dynamics, Proceedings of the National Academy of Sciences, 101, 7657-7662,.

Denham, R. N., Bannister, R. W., Guthrie, K. M., \& Crook, F. G. (1984). Surveys of the East Auckland and East Cape Currents, New Zealand. New Zealand Journal of Marine and Freshwater Research, 35, 491-504.

Denham, R. N., \& Crook, F. G. (1976). The Tasman Front. New Zealand Journal of Marine and Freshwater Research, 10(1), 15-30.

Dudley, W. C., \& Nelson, C. S. (1989). Quaternary surface-water stable isotope signal from calcareous nannofossils at DSDP Site 593, southern Tasman Sea. Marine Micropaleontology, 13(4), 353-373.

Droxler, A. W. and J. W. Farrell (2000). "Marine Isotope Stage 11 (MIS 11): new insights for a warm future." Global and Planetary Change 24(1): 1-5.

Emiliani, C. (1954). Temperatures of Pacific Bottom Waters and Polar Superficial Waters during the Tertiary. Science, 119(3103), 853-855.

Fenner, J., Carter, L., \& Stewart, R. (1992). Late Quaternary paleoclimatic and paleoceanographic change over northern Chatham Rise, New Zealand. Marine Geology, 108(34), 383-404.

Gillett, N. P., Kell, T. D., \& Jones, P. D. (2006). Regional climate impacts of the Southern Annular Mode. Geophysical Research Letters, 33(23), L23704. 
Gordon, A. L. (1975). An Antarctic oceanographic section along $170^{\circ}$ E. Deep Sea Research and Oceanographic Abstracts, 22(6), 357-374, IN351, 375-377.

Greig, M. J. \& Gilmour, A. E. (1992). Flow through the Mernoo Saddle, New Zealand New Zealand Journal of Marine and Freshwater Research, 26, 155-165.

Hall, I. R., McCave, I. N., Shackleton, N. J., Weedon, G. P., \& Harris, S. E. (2001). Intensified deep Pacific inflow and ventilation in Pleistocene glacial times. Nature, 412(6849), 809-812.

Hamilton, L. J. (2006). Structure of the Subtropical Front in the Tasman Sea. Deep Sea Research Part I: Oceanographic Research Papers, 53(12), 1989-2009.

Haslett, S. K. (2002). Quaternary Environmental Micropalaeontology. London: Arnold, A member of the Hodder Headline Group, London

Harris, T. F. W. (1985). North Cape to East Cape: aspects of the physical oceanography. Unpublished Unpublished Report. Department of Physics and Marine Laboratory, University of Auckland, Leigh, University of Auckland Library,.

Hays, J. D., Imbrie, J., \& Shackleton, N. J. (1976). Variations in the Earth's Orbit: Pacemaker of the Ice Ages. Science, 194(4270), 1121-1132.

Hayward, B. W., Grenfell, H. R., Carter, R., \& Hayward, J. J. (2004). Benthic foraminiferal proxy evidence for the Neogene palaeoceanographic history of the Southwest Pacific, east of New Zealand. Marine Geology, 205(1-4), 147-184.

Hayward, B. W. Grenfell, H. R. Sabaa, A.T. Sikes, E. L. (2005). Deep-sea benthic foraminiferal record of the mid-Pleistocene transition in the South-west Pacific. In: M. J. Head and P. L. Gibbard (eds). Early-Middle Pleistocene transitions: the land-ocean evidence. Geological Society (London), Special Publication 247. pp. 85-115. 
Hayward, B. W., Grenfell, H. R., Sabaa, A. T., \& Neil, H. L. (2007). Factors influencing the distribution of Subantarctic deep-sea benthic foraminifera, Campbell and Bounty Plateaux, New Zealand. Marine Micropaleontology, 62(3), 141-166.

Hayward, B. W., Neil, H., Carter, R., Grenfell, H. R., \& Hayward, J. J. (2002). Factors influencing the distribution patterns of Recent deep-sea benthic foraminifera, east of New Zealand, Southwest Pacific Ocean. Marine Micropaleontology, 46(1-2), 139-176.

Hayward, B. W., Scott, G. H., Crundwell, M. P., Kennett, J. P., Carter, L., Neil, H. L., Sabaa, A. T., Wilson, K., Rodger, J. S., Schaefer, G., Grenfell, H. R., \& Li, Q. (2008). The effect of submerged plateaux on Pleistocene gyral circulation and sea-surface temperatures in the Southwest Pacific. Global and Planetary Change, 63(4), 309-316.

Hayward, B. W., Sabaa, A., \& Grenfell, H. R. (2004). Benthic foraminifera and the late Quaternary (last $150 \mathrm{ka}$ ) paleoceanographic and sedimentary history of the Bounty Trough, east of New Zealand. Palaeogeography, Palaeoclimatology, Palaeoecology, 211(1-2), 59-93.

Heath, R. A. (1972). The Southland Current. New Zealand Journal of Marine and Freshwater Research, 6(4), 497-533.

Heath, R. A. (1973). Direct Measurements of Coastal Currents Around Southern New Zealand. New Zealand Journal of Marine and Freshwater Research, 7(4), 331-367.

Heath, R. A. (1976). Circulation in Tasman Bay. New Zealand Journal of Marine and Freshwater Research, 10(3), 469-483.

Heath, R. A. (1978). Atmospherically induced water motions off the west coast of New Zealand. New Zealand Journal of Marine and Freshwater Research, 12(4), 381-390.

Heath, R. A. (1980). Eastwards oceanic flow past northern New Zealand. New Zealand Journal 128 
of Marine and Freshwater Research, 14(2), 169-182.

Heath, R. A. (1981). Oceanic fronts around southern New Zealand. Deep Sea Research Part A. Oceanographic Research Papers, 28(6), 547-560.

Heath, R. A. (1982). What drives the mean circulation on the New Zealand west coast continental shelf? New Zealand Journal of Marine and Freshwater Research, 16, 215-226.

Heath, R. A. (1985). A review of the physical oceanography of the seas around New Zealand 1982. New Zealand Journal of Marine and Freshwater Research, 19, 79-124.

Berger W.H., Herguera J.C. 1992. Reading the sedimentary record of the Ocean's productivity. In: "Primary Productivity and Biogeochemical Cycles in the Sea" (P.G. Falkowski, A.D. Woodhead, eds.), Plenum Press, N.Y., pp. 455-486. Hemleben, C., Spindler, M., Anderson, O.R., 1989. Modern planktonic foraminifera. Springer-Verlag, Massachusetts, U.S.A. 363 pp.

Hermelin, J. O. R., \& Shimmield, G. B. (1995). Impact of Productivity Events on the Benthic Foraminiferal Fauna in the Arabian Sea Over the Last 150,000 Years. Paleoceanography, $10(1), 85-116$.

Hesse, P. P. (1994). The record of continental dust from Australia in Tasman Sea Sediments. Quaternary Science Reviews, 13(3), 257-272.

Hesse, P. P., \& McTainsh, G. H. (1999). Last Glacial Maximum to Early Holocene Wind Strength in the Mid-latitudes of the Southern Hemisphere from Aeolian Dust in the Tasman Sea. Quaternary Research, 52(3), 343-349.

Hicks, D. M., \& Shankar, U. (2003). Sediment from New Zealand Rivers. National Institute of Water and Atmosphere Chart. Miscellaneous Series, 79.

Hill, K. L., Rintoul, S. R., Coleman, R., \& Ridgway, K. R. (2008). Wind forced low frequency variability of the East Australia Current. Geophysical Research Letters., 35(8), L08602. 
Hodell, D. A., C. D. Charles, et al. (2000). "Comparison of interglacial stages in the South Atlantic sector of the southern ocean for the past $450 \mathrm{kyr}$ : implifications for Marine Isotope Stage (MIS) 11." Global and Planetary Change 24(1): 7-26.

Howard, W. R. (1997). Palaeoclimatology: A warm future in the past. Nature, 388(6641), 418419.

Howard, W. R., \& Prell, W. L. (1992). Late Quaternary Surface Circulation of the Southern Indian Ocean and its Relationship to Orbital Variations. Paleoceanography, 7(1), 79-117.

Hutson, W. H. (1980). The Agulhas current during the late Pleistocene: analysis of modern faunal analogs. Science, 207, 64-66.

Ikehara, M., Kawamura, K., Ohkouchi, N., Kimoto, K., Murayama, M., Nakamura, T., Oba, T., \& Taira, A. (1997). Alkenone sea surface temperature in the Southern Ocean for the last two deglaciations. Geophys. Res. Lett., 24(6), 679-682.

Imbrie, J., Kipp, N.G., 1971. A new micropaleontological method for paleoclimatology: application to a Late Pleistocene Caribbean core. In: Turekian, K.K. (Ed.), The Late Cenozoic Glacial Ages. Yale University Press, New Haven, pp. 71-131.

Jeffrey, M. Z. (1986). Climatological features of the Subtropical Convergence in Australian and New Zealand waters Ocean Sciences Institute Report No. 17: University of Sydney.

Jorissen, F. J., Barmawidjaja, D. M., Puskaric, S., \& van der Zwaan, G. J. (1992). Vertical distribution of benthic foraminifera in the northern Adriatic Sea: The relation with the organic flux. Marine Micropaleontology, 19(1-2), 131-146.

Kennett, J. P. (1968). Latitudinal variation in Globigerina pachyderma (Ehrenberg) in surface sediments of the southwest Pacific Ocean. Micropaleontology, 14(3), 305-318. 
Kidson, J. W. (1988), Interannual variations in the Southern Hemisphere circulation, Journal of Climatology, 1, 1177-1198.

Kowalski, E. A., \& A. Meyers, P. (1997). Glacial-interglacial variations in Quaternary production of marine organic matter at DSDP Site 594, Chatham Rise, southeastern New Zealand margin. Marine Geology, 140(3-4), 249-263.

Le, J., \& Shackleton, N. J. (1992). Carbonate Dissolution Fluctuations in the Western Equatorial Pacific During the Late Quaternary. Paleoceanography, 7(1), 21-42.

Lisiecki, L. E., \& Raymo, M. E. (2005). A Pliocene-Pleistocene stack of 57 globally distributed benthic \& 948;180 records. Paleoceanography, 20(1), PA1003.

Loutre, M. F. (2003). "Clues from MIS 11 to predict the future climate - a modelling point of view." Earth and Planetary Science Letters 212(1-2): 213-224.

Loutre, M. F., \& Berger, A. (2003). Marine Isotope Stage 11 as an analogue for the present interglacial. Global and Planetary Change, 36(3), 209-217.

Malmgren, B., \& Kennett, J. P. (1972). Biometric analysis of phenotypic variation; globigerina pachyderma (Ehrenberg) in the South Pacific Ocean. Micropaleontology, 18(2), 241-248.

Malmgren, B. A., Kucera, M., Nyberg, J., \& Waelbroeck, C. (2001). Comparison of Statistical and Artificial Neural Network Techniques for Estimating Past Sea Surface Temperatures from Planktonic Foraminifer Census Data. Paleoceanography, 16(5), 520-530.

Malmgren, B. A., \& Nordlund, U. (1997). Application of artificial neural networks to paleoceanographic data. Palaeogeography, Palaeoclimatology, Palaeoecology, 136(1-4), 359373. 
Markgraf, V., Dodson, J. R., Kershaw, A. P., McGlone, M. S., \& Nicholls, N. (1992).

Evolution of late pleistocene and holocene climates in the circum-south pacific land areas.

Climate Dynamics, 6(3), 193-211.

Martínez, J. I. (1994). Late Pleistocene palaeocenography of the Tasman Sea: Implications for the dynamics of the warm pool in the western Pacific. Palaeogeography, Palaeoclimatology, Palaeoecology, 112(1-2), 19-62.

Martinez, J. I. (1994b). Late pleistocene carbonate dissolution patterns in the Tasman Sea. In K. M. S. Gerrit J van der Lingen, Roderick J. Muir (Ed.), Evolution of the Tasman Sea Basin (pp. 261). Rotterdam: A.A. Balkema/Rotterdam/Brookfield.

Martinson, D. G., Pisias, N. G., Hays, J. D., Imbrie, J., Moore, T. C., \& Shackleton, N. J. (1987). Age dating and the orbital theory of the ice ages: Development of a high-resolution 0 to 300,000-year chronostratigraphy. Quaternary Research, 27(1), 1-29.

McCartney, M. S., (1977). Subantarctic Mode Water. In: A Voyage of Discovery: George Deacon 70th Anniversary Volume, M. V. Angel, editor, Supplement to Deep-Sea Research, Pergamon Press, Oxford, pp. 103-119.

McCave, I. N., \& Carter, L. (1997). Recent sedimentation beneath the Deep Western Boundary Current off northern New Zealand. Deep Sea Research Part I: Oceanographic Research Papers, 44(7), 1203-1237.

McGlone, M. S. (1995). Late-glacial landscape and vegetation change and the younger dryas climatic oscillation in New Zealand. Quaternary Science Reviews, 14(9), 867-881.

Meinen, C. S., Luther, D. S., Watts, D. R., Chave, A. D., \& Tracey, K. L. (2003). Mean stream coordinates structure of the Subantarctic Front: Temperature, salinity, and absolute velocity. Journal of Geophysical Research, 108(C8), 3263. 
Menviel, L., Timmermann, A., Mouchet, A., \& Timm, O. (2008). Climate and marine carbon cycle response to changes in the strength of the Southern Hemispheric westerlies. Paleoceanography, 23(4), PA4201.

Milliman, J. D., \& Syvitski, J. P. M. (1992). Geomorphic tectonic control of sediment discharge to the ocean: the importance of small, mountainous rivers. Journal of Geology., 100, $525-544$.

Moore, J. K., Abbott, M. R., \& Richman, J. G. (1999). Location and dynamics of the Antarctic Polar Front from satellite sea surface temperature data. Journal of Geophysical Research, 104(C2), 3059-3073.

Moreno, P. I., Lowell T. V., Jacobson G. L. J. and G. M. Denton, (1999) Abrupt vegetation and climate changes during the Last Glacial Maximum and last termination in the Chilean Lake District: A case study from Canal de la Puntilla (41_s). Geografiska Annaler Series. A, $81,285-311$.

Morris, M., Stanton, B., \& Neil, H. (2001). Subantarctic oceanography around New Zealand: preliminary results from an ongoing survey. New Zealand Journal of Marine and Freshwater Research, 35, 499-519.

Mullan, A. B. (1995). On the linearity and stability of Southern Oscillation-climate relationships for New Zealand International Journal of Climatology, 15, 1365-1386.

Muller, P. J., Kirst, G., Ruhland, G., von Storch, I., \& Rosell-Mele, A. (1998). Calibration of the alkenone paleotemperature index $U^{K^{\prime} 37}$ based on core-tops from the eastern South Atlantic and the global ocean $(60 \square \mathrm{N}-60$ S $)$ Geochica et Cosmochimica Acta, 62, 1757-1772. 
Murphy, R. J., Pinkerton, M. H., RIchardson, K. M., Bradford-Grieve, J. M., \& Boyd, P. W. (2001). Phytoplankton distributions around New Zealand derived from SeaWiFS remotelysensed ocean colour data. New Zealand Journal of Marine and Freshwater Research, 35, 343362.

Nees, S. (1997). Late Quaternary palaeoceanography of the Tasman Sea: the benthic foraminiferal view. Palaeogeography, Palaeoclimatology, Palaeoecology, 131(3-4), 365-389.

Nees, S., Armand, L., De Deckker, P., Labracherie, M. and Passlow, V., (1999). A diatom and benthic foraminiferal record from the South Tasman Rise (Southeastern Indian Ocean): implications for paleoceanographic changes for the last 200,000 years. Marine Micropaleontology. 38, pp. 69-89.

Nelson, C. S., Cooke, P. J., Hendy, C. H., \& Cuthbertson, A. M. (1993). Oceanographic and Climatic Changes Over the Past 160,000 Years at Deep Sea Drilling Project Site 594 Off Southeastern New Zealand, Southwest Pacific Ocean. Paleoceanography, 8(4), 435-458.

Nelson, C. S., Hendy, I. L., Neil, H. L., Hendy, C. H., \& Weaver, P. P. E. (2000). Last glacial jetting of cold waters through the Subtropical Convergence zone in the Southwest Pacific off eastern New Zealand, and some geological implications. Palaeogeography, Palaeoclimatology, Palaeoecology, 156(1-2), 103-121.

Nürnberg, D., \& Groeneveld, J. (2006). Pleistocene variability of the Subtropical Convergence at East Tasman Plateau: Evidence from planktonic foraminiferal Mg/Ca (ODP Site 1172A). Geochemistry, Geophysics, Geosystems, 7(4), Q04P11.

Orsi, A. H., Whitworth, T., \& Nowlin, W. D. (1995). On the meridional extent and fronts of the Antarctic Circumpolar Current. Deep Sea Research Part I: Oceanographic Research Papers, 42(5), 641-673. 
Ortiz, J. D., \& Mix, A. C. (1997). Comparison of Imbrie-Kipp Transfer Function and Modern Analog Temperature Estimates Using Sediment Trap and Core Top Foraminiferal Faunas. Paleoceanography, 12(2), 175-190.

Pahnke, K., \& Sachs, J. P. (2006). Sea surface temperatures of southern mid-latitudes 0-160 kyr B.P. Paleoceanography, 21(2), PA2003.

Pahnke, K., \& Zahn, R. (2005). Southern Hemisphere Water Mass Conversion Linked with North Atlantic Climate Variability. Science, 307(5716), 1741-1746.

Passlow, V., Pinxian, W., \& Chivas, A. R. (1997). Late Quaternary palaeoceanography near Tasmania, southern Australia. Palaeogeography, Palaeoclimatology, Palaeoecology, 131(3-4), 433-463.

Pedersen, T. F., Pickering, M., Vogel, J. S., Southon, J. N., \& Nelson, D. E. (1988). The response of benthic foraminifera to productivity cycles in the eastern equatorial Pacific: faunal and geochemical constraints on glacial bottom water oxygen levels. Paleoceanography, 3(2), 157-168.

Pelejero, C., Calvo, E., Barrows, T. T., Logan, G. A., \& De Deckker, P. (2006). South Tasman Sea alkenone palaeothermometry over the last four glacial/interglacial cycles. Marine Geology, 230(1-2), 73-86.

Peterson, L. C., \& Prell, W. L. (1985). Carbonate dissolution in Recent sediments of the eastern equatorial Indian Ocean: Preservation patterns and carbonate loss above the lysocline. Marine Geology, 64(3-4), 259-290.

Piola, A. R., \& Georgi, D. T. (1982). Circumpolar properties of Antarctic intermediate water and Subantarctic Mode Water. Deep Sea Research Part A. Oceanographic Research Papers, 29(6), 687-711. 
Prahl, F., Herbert, T., Brassell, S. C., Ohkouchi, N., Pagani, M., Repeta, D., Rosell-Melé, A., \&

Sikes, E. (2000). Status of alkenone paleothermometer calibration: Report from Working

Group 3. Geochemistry, Geophysics, Geosystems, 1(11).

Prahl, F. G., \& Wakeham, S. G. (1987). Calibration of unsaturation patterns in long-chain ketone compositions for palaeotemperature assessment. Nature, 330, 367-369.

Prell, W. L. (1985). The stability of low-latitude sea-surface temperatures: an evaluation of the CLIMAP reconstruction with emphasis on the positive SST anomalies. Washington, DC: US Department of Energy.

Prell, W. L., \& Curry, W. B. (1980). Faunal and isotopic indices of monsoonal upwelling: Western Arabian Sea. Oceanologica Acta (in press).

Proust, J.-N., Lamarche, G., Migeon, S., \& Neil, H. (2006). MD152/Matacore: Tectonic and climatic controls on sediment budget on board Marion Dufresne: Institut Polaire Francais.

Ridgway, K. R., \& Dunn, J. R. (2003). Mesoscale structure of the mean East Australian Current System and its relationship with topography. Progress In Oceanography, 56(2), 189-222.

Ridgway, K. R., \& Dunn, J. R. (2007). Observational evidence for a Southern Hemisphere oceanic supergyre. Geophysical Research Letters., 34(13), L13612.

Ridgway, N. M. (1980). Hydrological conditions and circulation off the west coast of the North Island, New Zealand. New Zealand Journal of Marine and Freshwater Research, 14(2), 155167.

Rintoul, S. R., Hughes, C., \& Olbers, D. (2001). The Antarctic Circumpolar Current System. In G. Siedler, J. Church \& J. Gould (Eds.), Ocean Circulation and Climate, Volume 77:

Observing and Modelling the Global Ocean: Academic Press. 
Roemmich, D., \& Sutton, P. (1998). The mean and variability of ocean circulation past northern New Zealand: Determining the representativeness of hydrographic climatologies. Journal of Geophysical Research, 103(C6), 13041-13054.

Rojas, M., Moreno, P., Kageyama, M., Crucifix, M., Hewitt, C., Abe-Ouchi, A., Ohgaito, R., Brady, E., \& Hope, P. (2009). The Southern Westerlies during the last glacial maximum in PMIP2 simulations. Climate Dynamics, 32(4), 525-548.

Ryan, M. T. (2010). A Palynological Record of the Vegetations and Climate of Westland Since 210 Ka. MSc Thesis. Victoria University of Wellington

Salinger, M. J., Basher, R. E., Fitzharris, B. B., Hay, J. E., Jones, P. D., MacVeigh, J. P., \& Schmidely-Leleu, I. (1995). Climate trends in the Southwest Pacific. International Journal of Climatology, 15, 285-302.

Schaefer, G., Rodger, J. S., Hayward, B. W., Kennett, J. P., Sabaa, A. T., \& Scott, G. H. (2005). Planktic foraminiferal and sea surface temperature record during the last $1 \mathrm{Myr}$ across the Subtropical Front, Southwest Pacific. Marine Micropaleontology, 54(3-4), 191-212.

Schiebel, R., \& Hemleben, C. (2005). Modern planktic foraminifera. Paläontologische Zeitschrift, 79(1), 135-148.

Scott, G.H., Bishop, S., Burt, B.J., 1990. Guide to some Neogene globorotalids (Foraminiferida) from New Zealand. New Zealand Geological Survey Paleontological Bulletin 61

Shaw, A. G. P., \& Vennell, R. (2000). Variability of water masses through the Mernoo Saddle, South Island, New Zealand. New Zealand Journal of Marine and Freshwater Research, 34, 103-116. 
Shirtcliffe, T. G. L., Moore, M. I., Cole, A. G., Viner, A. B., Baldwin, R., \& Chapman, B. (1990). Dynamics of the Cape Farewell upwelling plume, New Zealand. New Zealand Journal of Marine and Freshwater Research, 24(4), 555-568.

Shulmeister, J., Goodwin, I., Renwick, J., Harle, K., Armand, L., McGlone, M. S., Cook, E., Dodson, J., Hesse, P. P., Mayewski, P., \& Curran, M. (2004). The Southern Hemisphere westerlies in the Australasian sector over the last glacial cycle: a synthesis. Quaternary International, 118-119, 23-53.

Sikes, E. L., Howard, W. R., Neil, H. L., \& Volkman, J. K. (2002). Glacial-interglacial sea surface temperature changes across the subtropical front east of New Zealand based on alkenone unsaturation ratios and foraminiferal assemblages. Paleoceanography, 17(2), 1012.

Sikes, E. L., Howard, W. R., Samson, C. R., Mahan, T. S., Robertson, L. G., \& Volkman, J. K. (2009). Southern Ocean seasonal temperature and Subtropical Front movement on the South Tasman Rise in the late Quaternary. Paleoceanography, 24(2), PA2201.

Sikes, E. L., O'Leary, T., Nodder, S. D., \& Volkman, J. K. (2005). Alkenone temperature records and biomarker flux at the subtropical front on the chatham rise, SW Pacific Ocean. Deep Sea Research Part I: Oceanographic Research Papers, 52(5), 721-748.

Sobarzo, M., Figueroa, M., \& Djurfeldt, L. (2001). Upwelling of subsurface water into the rim of the Biobío submarine canyon as a response to surface winds. Continental Shelf Research, 21(3), 279-299.

Stanley, S. M., (1990). The General Correlation between Rate of Speciation and Rate of Extinction: Fortuitous Casual Linkage. In: Ross, R. \& Allmon, W. D., Causes of Evolution: a paleontological perspective. University of Chicago Press, Chicago

Stanton, B. R. (1971) Hydrology of Karamea Bight, New Zealand. New Zealand Journal of Marine and Freshwater Research 5: 141-163. 
Stanton, B. R. (1973). Hydrolgical Investigations Around Northern New Zealand. New Zealand Journal of Marine and Freshwater Research, 7(1 \& 2), 85-110.

Stanton, B. R. (1976). Circulation and Hydrology off the West Coast of the South Island, New Zealand. New Zealand Journal of Marine and Freshwater Research, 10(3), 445-467.

Stanton, B. R., \& Ridgway, N. M. (1988). An oceanographic survey of the subtropical convergence zone in the Tasman Sea. New Zealand Journal of Marine and Freshwater Research, 22, 583-593.

Stanton, B. R., Sutton, P. J. H., \& Chiswell, S. M. (1997). The East Auckland Current, 199495. New Zealand Journal of Marine and Freshwater Research, 31, 537-549.

Stewart, R. B. (2008). Introduction to Physical Oceanography. Texas A \& M University, viewed March 26, 2010, http://oceanworld.tamu.edu/resources/ocng_textbook/PDF_files /book.pdf

Stewart, R. B., \& Neall, V. E. (1984). Chronology of palaeoclimatic change at the end of the last glaciation. Nature, 311(5981), 47-48.

Sturman, A. P., \& Tapper, N. J. (2006). The weather and climate of Australia and New Zealand (2nd Edition ed.). Melbourne, Vic.: Oxford University Press.

Sutton, P. J. H. (2003). The Southland Current: a subantarctic current. New Zealand Journal of Marine and Freshwater Research, 37, 645-652.

Sutton, P. J. H., Bowen, M., \& Roemmich, D. (2005). Decadal temperature changes in the Tasman Sea. New Zealand Journal of Marine and Freshwater Research, 39, 1321-1329.

Thiede, J. (1979). Wind regimes over the late Quaternary southwest Pacific Ocean. Geology, 7(5), 259-262. 
Thunell, R. C. (1976). Optimum indices of calcium carbonate dissolution, in deep-sea sediments. Geology, 4(9), 525-528.

Tilburg, C.E., Hurlburt, H.E., O’Brien, J.J., Shriver, J.F., (2001). The dynamics of the East Australian Current system: the Tasman Front, the East Auckland Current, and the East cape Current. Journal of Physical Oceanography. 31, 2917-2943.

Toggweiler, J. R., Russell, J. L., \& Carson, S. R. (2006). Midlatitude westerlies, atmospheric $\mathrm{CO} 2$, and climate change during the ice ages. Paleoceanography, 21(2), PA2005.

Tomczak Jr, M. (1981). Bass Strait Water Intrusions in the Tasman Sea and Mean Temperature-Salinity Curves. New Zealand Journal of Marine and Freshwater Research, 32, 699-708.

Uddstrom, M. J., \& Oien, N. A. (1999). On the use of high-resolution satellite data to describe the spatial and temporal variability of sea surface temperatures in the New Zealand region. Journal of Geophysical Research, 104(C9), 20729-20751.

Villanoy, C. L., \& Tomczak, M. (1991). Influence of Bass Strait Water on the Tasman Sea Thermocline. New Zealand Journal of Marine and Freshwater Research, 42, 451-464.

Vincent, E. and Berger, W.H., 1981. Planktonic foraminifera and their use in palaeoceanography. In: Emiliani, C., Editor, 1981. The Sea Vol. 7, Wiley-Interscience, New York, pp. 1025-1119.

Volkman, J. K., Eglinton, G., Corner, E. D. S., \& Sargent, J. R. (1980). Novel unsaturated straight-chain C37---C39 methyl and ethyl ketones in marine sediments and a coccolithophore Emiliania huxleyi. Physics and Chemistry of The Earth, 12, 219-227.

Warren, B. A. (1970) General circulation of the South Pacific. In Scientific exploration of the South Pacific, ed. W. S. Wooster, pp. 33-49. National Academy of Sciences, Washington, D.C. 
Warren BA. 1981. Deep circulation of the world ocean. In Evolution of Physical Oceanography. Scientific Surveys in Honor of Henry Stommel, ed. BA Warren, C Wunsch, pp. 6-41. Cambridge, MA: MIT Press

Weaver, P. P. E., Carter, L., \& Neil, H. L. (1998). Response of Surface Water Masses and Circulation to Late Quaternary Climate Change East of New Zealand. Paleoceanography, 13(1), 70-83.

Wefer, G., Berger, W. H., Bijma, J., \& Fischer, G. (1999). Clues to Ocean History: a Brief Overview of Proxies. In G. Fischer \& G. Wefer (Eds.), Use of Proxies in Paleoceanography: Examples from the South Atlantic (pp. 1-68). Berlin Heidelberg: Springer-Verlag.

Wells, P., \& Okada, H. (1997). Response of nannoplankton to major changes in sea-surface temperature at the South Chatham Rise, southeastern New Zealand: PANGAEA.

Wells, P. E., \& Connell, R. (1997). Movement of hydrological fronts and widespread erosional events in the southwestern Tasman Sea during the late Quaternary. Australian Journal of Earth Sciences, 44, 105-112.

Williams, M. J. M. (2004). Analysis of quasi-synoptic eddy observations in the New Zealand subantarctic. New Zealand Journal of Marine and Freshwater Research, 38, 183-194

Wilson, K., Hayward, B. W., Sabaa, A. T., Scott, G. H., \& Kennett, J. P. (2005). A one-millionyear history of a north-south segment of the Subtropical Front, east of New Zealand. Paleoceanography, 20(2), PA2004.

Yoder, J. A., Ackleson, S. G., Barber, R. T., Flament, P., \& Balch, W. M. (1994). A line in the sea. Nature, 371(6499), 689-692. 